\title{
Dietary polyphenols: modulators of energy and substrate metabolism in obese humans
}

Citation for published version (APA):

Most, J. (2016). Dietary polyphenols: modulators of energy and substrate metabolism in obese humans. [Doctoral Thesis, Maastricht University]. Maastricht University. https://doi.org/10.26481/dis.20160115jm

Document status and date:

Published: 01/01/2016

DOI:

10.26481/dis.20160115jm

Document Version:

Publisher's PDF, also known as Version of record

\section{Please check the document version of this publication:}

- A submitted manuscript is the version of the article upon submission and before peer-review. There can be important differences between the submitted version and the official published version of record.

People interested in the research are advised to contact the author for the final version of the publication, or visit the DOI to the publisher's website.

- The final author version and the galley proof are versions of the publication after peer review.

- The final published version features the final layout of the paper including the volume, issue and page numbers.

Link to publication

\footnotetext{
General rights rights.

- You may freely distribute the URL identifying the publication in the public portal. please follow below link for the End User Agreement:

www.umlib.nl/taverne-license

Take down policy

If you believe that this document breaches copyright please contact us at:

repository@maastrichtuniversity.nl

providing details and we will investigate your claim.
}

Copyright and moral rights for the publications made accessible in the public portal are retained by the authors and/or other copyright owners and it is a condition of accessing publications that users recognise and abide by the legal requirements associated with these

- Users may download and print one copy of any publication from the public portal for the purpose of private study or research.

- You may not further distribute the material or use it for any profit-making activity or commercial gain

If the publication is distributed under the terms of Article $25 \mathrm{fa}$ of the Dutch Copyright Act, indicated by the "Taverne" license above, 


\section{DIETARY POLYPHENOLS}

\section{Modulators of energy and substrate}

metabolism in obese humans 
The studies presented in this thesis were performed within NUTRIM School of Nutrition and Translational Research in Metabolism, which participates in the Graduate School VLAG (Food Technology, Agrobiotechnology, Nutrition and Health Sciences), accredited by the Royal Netherlands Academy of Arts and Sciences.
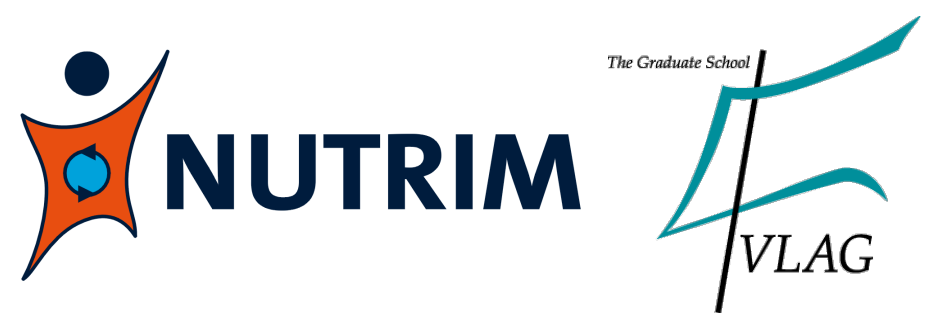

The research described in this thesis was supported by a grant from the Alpro Foundation.

\section{alpro Foundation Knowledge in plant-based nutrition}

Financial support by the Netherlands Association for the Study of Obesity (NASO) for the publication of this thesis is gratefully acknowledged

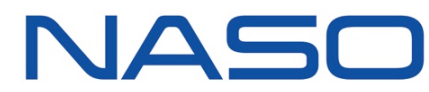

(C) Jasper Most, Maastricht 2015

Cover design: Jack Reijnders

Layout: Jasper Most

Printed by: Proefschriftmaken.nl I Uitgeverij BOXpress 


\title{
DIETARY POLYPHENOLS
}

\section{Modulators of energy and substrate metabolism in obese humans}

\author{
PROEFSCHRIFT \\ ter verkrijging van de graad van doctor aan de Universiteit Maastricht, \\ op gezag van de Rector Magnificus, Prof. dr. L.L.G Soete \\ volgens het besluit van het College van Decanen, \\ in het openbaar te verdedigen \\ op vrijdag 15 januari 2016 om 10.00 uur \\ door
}

Jasper Most

Geboren te Flensburg, Duitsland, op 28 september 1986 


\section{Promotor}

Prof. dr. E.E. Blaak

\section{Copromotor}

Dr. G.H. Goossens

\section{Beoordelingscommissie}

Prof. dr. A. Bast (voorzitter)

Dr. J. Hager, Nestlé Institute of Health Sciences SA, Switzerland Prof. dr. M.K.C. Hesselink

Prof. dr. M. Laville, Hospices Civils de Lyon/Lyon 1-University, France Dr. K. Venema 


\section{Content}

$\begin{array}{lll}\text { Chapter } 1 \text { General introduction } & 7\end{array}$

Chapter 2 A 3-day EGCG-supplementation reduces interstitial 55 lactate concentration in skeletal muscle of overweight subjects

Chapter 3 Short-term supplementation with a specific combination of dietary polyphenols increases energy expenditure and alters substrate metabolism in overweight subjects

Chapter 4 Combined epigallocatechin-3-gallate and resveratrol supplementation for 12 weeks increases mitochondrial capacity and fat oxidation, but not insulin sensitivity in obese humans: a randomized controlled trial

Chapter 5 The effects of polyphenol supplementation on adipose tissue morphology and gene expression in overweight and obese humans

Chapter 6 Gut microbiota composition strongly correlates to peripheral insulin sensitivity in obese men but not in women

Chapter 7 Gut microbiota composition in relation to the metabolic response to 12 weeks combined polyphenol supplementation in overweight men and women

Chapter 8 General discussion

Appendices Summary

Samenvatting

Zusammenfassung

Valorization

Acknowledgements, Dankwoord, Danksagungen

Publications

Curriculum vitae 



\section{CHAPTER 1}

General introduction 

In 2010 almost $50 \%$ of the European women and nearly $60 \%$ of the European men had overweight $\left(\mathrm{BMI}>25 \mathrm{~kg} / \mathrm{m}^{2}\right)$ or obesity $\left(\mathrm{BMI}>30 \mathrm{~kg} / \mathrm{m}^{2}\right)$ based on the classification of the World Health Organization ${ }^{1}$. Worldwide, this prevalence reached $40 \%$ in $2013(\sim 2.5$ billion people) ${ }^{2,3}$. The increasing obesity prevalence is one of the major health concerns of our society, since overweight and obesity increase the risk for developing type 2 diabetes mellitus (T2DM) ${ }^{4}$ and cardiovascular diseases (CVD) ${ }^{5}$. Additionally, obesity is associated with a variety of cancers ${ }^{6,7}$, mental diseases ${ }^{8}$, a reduced functional mobility and lower quality of life ${ }^{9}$. According to the traditional concept, obesity is the consequence of a dysbalance in energy intake, energy expenditure and energy excretion. Excessive fat accumulation in adipose tissue ${ }^{10}$, the liver ${ }^{11}$ and skeletal muscle ${ }^{12}$ associates with insulin resistance and inflammation, which are central elements in the development of T2DM and CVD $^{13,14}$.

To prevent the development of obesity and associated cardiometabolic and inflammatory diseases, lifestyle interventions are the preferred treatment to achieve (negative) energy balance and prevent metabolic complications, but are not effective in all participants ${ }^{15,16}$. Moreover, long-term weight maintenance requires sustained macronutrient balance ${ }^{17}$. For this reason, nutrient and substrate interactions are pertinent issues to be considered in body weight regulation. Importantly, protein and carbohydrate balance are regulated more closely than fat balance ${ }^{17}$. Thus, the regulation of fat metabolism and balance is an important determinant for both body weight control and metabolic health ${ }^{18}$.

A possible strategy to affect lipid catabolism may be supplementation with dietary polyphenols. Polyphenols are natural components of plants that have been first identified as antioxidants, but more recently, supplementation studies with polyphenols have shown promising effects on lipid catabolism, including lipolysis and fat oxidation, thereby reducing ectopic fat accumulation and improving insulin sensitivity in rodents. Moreover, consumption of polyphenol-rich products such as green tea, red wine and soy has been associated with a reduced risk for developing obesity and related cardiometabolic diseases in humans. In intervention studies, effects of single polyphenol supplementation are not yet convincing.

In this introduction, first the organ crosstalk in substrate and energy metabolism will be discussed (Figure 1.1), with focus on the adipose tissue, the liver, skeletal muscle and gut microbiota in the development of obesity-related metabolic impairments and insulin 


\section{Chapter 1}

resistance. In the second part, the potential benefits of polyphenol supplementation on substrate metabolism, in particular fatty acid metabolism, and insulin sensitivity will be addressed.

\section{Inter-organ crosstalk in substrate metabolism}

All organs have distinct functions and, therefore, distinct requirements to their source of energy. Whereas the brain and red blood cells, amongst others, consume only glucose ${ }^{19}$, skeletal muscle, the liver and adipose tissue switch between glucose and fat oxidation, dependent on substrate availability. The provision and utilization of energy-rich substrates, mainly carbohydrates and fats, is coordinated within the body through an inter-organ crosstalk that is tightly regulated and capable of adapting to varying conditions.

Chronic energy oversupply overwhelms the capacity of adipose tissue to store energy as fat and causes tissue dysfunction, which is characterized by a reduced lipid buffering capacity ${ }^{20}$. Consequently, lipid clearance and postprandial suppression of lipolysis are impaired and lipids spillover in the circulation and accumulate in the liver and skeletal muscle. In the liver, increased lipid uptake of plasma free fatty acids (FFA) and chylomicron-remnants may cause lipid accumulation, which is associated with increased glucose and very lowdensity lipoprotein (VLDL) -triacylglycerol (TAG) output ${ }^{21}$. Skeletal muscle is one of the most important organs with respect to whole-body glucose homeostasis, since it is responsible for about $80 \%$ of insulin-stimulated glucose disposal ${ }^{22}$. Randle et al. ${ }^{23}$ proposed that increased plasma FFA concentrations induce disruptions in skeletal muscle glucose metabolism, which may lead to impaired glucose tolerance and insulin resistance. Although this model needs to be adjusted by factors such as mitochondrial function and inflammation, the postulated concept of substrate competition and lipotoxicity causing insulin resistance still holds true. Paradoxically, this model does not apply to conditions of insulin resistance, in which despite high lipid availability, muscle glucose oxidation is increased during fasting conditions, highlighting the importance of the interaction between substrates, since glucose availability may be also increased ${ }^{24-27}$. An increased uptake of systemic lipids as well as an impaired capacity to adjust fat oxidation to fatty acid supply (metabolic inflexibility) may contribute to accumulation of detrimental lipid intermediates, thereby inducing lipotoxicity and insulin resistance ${ }^{28}$. In insulin resistant conditions, processes such as intracellular lipid turnover ${ }^{29-33}$, adipogenesis ${ }^{34}$ and protein anabolism ${ }^{35}$ 
are impaired. Hyperglycemia and hyperlipidemia may cause glucotoxicity and lipotoxicity also in pancreatic beta-cells ${ }^{36,37}$ and the nervous system ${ }^{38,39}$.

Over the past decade, the gut microbiota has been recognized as a metabolic organ with significant impact on host energy metabolism and insulin sensitivity ${ }^{40,41}$. The gut microbiota produces short-chain fatty acids, is involved in bile acid metabolism and induces hormonal secretion into the circulation, all of which may have a significant impact on energy and substrate regulation ${ }^{42}$.

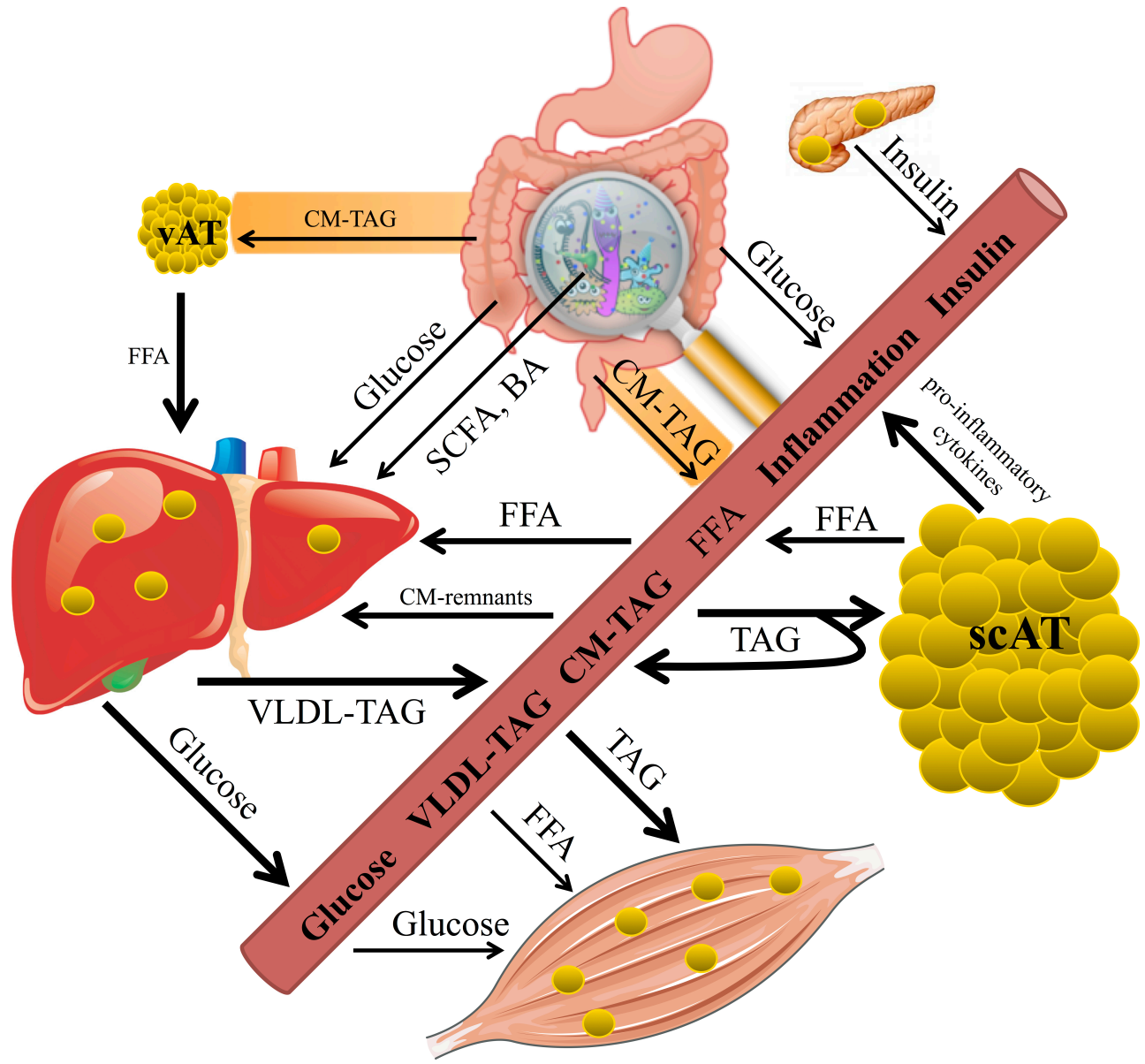

Figure 1.1. Inter-organ crosstalk

Substrate fluxes between different organs. Bold font and arrows indicate increased plasma concentrations and substrate fluxes in obese, insulin resistant humans. BA, bile acids; CM, chylomicron; FFA, free fatty acids; TAG, triacylglycerol; VLDL, very low density lipoprotein; SCFA, short-chain fatty acids; scAT subcutaneous adipose tissue; vAT, visceral adipose tissue. 


\section{Pathophysiology of major metabolic organs in relation to insulin resistance}

\section{Adipose tissue}

Within the last decade the adipose tissue gained importance in our view on human (patho)physiology, which goes beyond its capacity to store excessive energy intake in the form of fat ${ }^{30,43,44}$. In most cases, obesity development has already occurred in childhood ( $<20$ years): $\sim 75 \%$ of obese children (mean age 10) remained obese in adulthood (mean age 27$)^{45}$ and $\sim 80 \%$ of obese adults were obese during childhood ${ }^{46}$. Disturbances in adipose tissue function in overweight, obese and insulin resistant subjects are characterized by an altered adipose tissue morphology, possibly caused by impaired adipogenesis, and an impaired lipid buffering capacity, which is regulated by lipid uptake, storage and release (lipolysis). Lastly, adipose tissue secretion of endocrine signals may be altered in dysfunctional adipose tissue and contribute to systemic low-grade inflammation.

\section{Adipose tissue morphology}

Whereas the generation rate of adipocytes differs between lean and obese children ${ }^{47,48}$, adipocyte number remains stable during adulthood, independent of obesity ${ }^{49}$. A constant number of fat cells have been reported in intervention studies of weight loss and weight (re)gain in adults, whereas fat cell volume significantly changed due to intervention ${ }^{50,51}$, underscoring the tight regulation between adipogenesis and apoptosis/autophagy, which together define the turnover of adipose tissue, in which about $10 \%$ of adipocytes are renewed every year ${ }^{49}$. However, these measurements were performed within 2 years and might therefore not relate to cases, in which obesity is acquired over longer periods of time during adulthood. Interestingly, obese subjects had a lower adipocyte TAG turnover as compared to lean subjects ${ }^{52,53}$. A low adipocyte and lipid turnover might reflect a reduced capacity to adapt to chronic environment changes (such as development of obesity) and was associated with obesity ${ }^{52}$, familial combined hyperlipidemia ${ }^{53}$ and hypertrophic, dysfunctional adipose tissue ${ }^{54}$.

When the energy intake exceeds expenditure in the long term, the excess energy is primarily stored in the adipose tissue. Expanding adipose tissue initially grows hypertrophic 
55 . Subsequent induction of adipogenic pathways triggers hyperplasia, thus creating more storage capacity ${ }^{56}$. The limitation of hyperplasic growth determines adipose tissue morphology, adipose tissue function and its impact on other tissues ${ }^{54,57-59}$. Indeed, the adipogenic potential predicted adipose tissue morphology in rodents, where a low adipogenic potential contributed to a reduced adipose tissue lipid buffering capacity and ectopic fat storage and insulin resistance ${ }^{60}$. By stimulation of adipogenesis, the average adipocyte size remains constant, indicative for preserved metabolic function, despite the increase in adipose tissue mass ${ }^{54,60}$. Moreover, increasing adipose tissue mass and therefore increasing buffering capacity by transplantation may ameliorate metabolic derangements ${ }^{61}$. Contrary, a limited adipogenic potential has been found higher in obese diabetic patients as compared to obese subjects without metabolic complications ${ }^{62-65}$. The process of adipogenesis is determined by intrinsic factors such as mitochondrial function ${ }^{66}$, adipogenic progenitors ${ }^{67,68}$, expression of transcription factors ${ }^{69,70}$ and extrinsic factors such as the extracellular matrix and angiogenesis ${ }^{71,72}$.

\section{Adipose tissue lipolysis}

Lipolysis describes the process of the hydrolysation of TAG into glycerol and FFA by adipose tissue TAG lipase (ATGL), hormone-sensitive lipase (HSL) and monoacylglyceride lipase (MGL). It has been suggested in $1963^{73}$, that plasma FFA concentrations increase with accumulating fat mass, indicating an increased adipose tissue lipolysis in obese people, since approximately $90 \%$ of plasma FFA are derived from adipose tissue ${ }^{74}$.

However, more recent studies questioned whether an overload of FFA exists in obesity ${ }^{75}$. In fact, the rate of appearance of FFA during basal conditions in obese subjects was even reduced as compared to lean individuals, when expressed per $\mathrm{kg}$ fat mass ${ }^{76,77}$. In line, a reduced catecholamine-stimulated lipolytic response has been shown for obese compared to lean men ${ }^{77,78}$. It is yet unclear, whether defects in lipolysis are a primary cause or a secondary effect in the etiology of obesity and related diseases ${ }^{31,74}$. On the one hand, catecholamine-resistance may be primary in the etiology of obesity causing an impaired release of lipids from adipose tissue ${ }^{31}$. This has been observed in childhood onset obesity ${ }^{79,80}$, and in first-degree relatives of obese subjects ${ }^{81}$. On the other hand, a reduced lipolytic 


\section{Chapter 1}

activity has been suggested to be secondary to the development of obesity ${ }^{52}$, and might be caused by systemic hyperinsulinemia that is frequently observed in obesity ${ }^{82}$.

In the postprandial state, lipolytic activity is inhibited by insulin. Although a lower antilipolytic activity of insulin in obese as compared to lean subjects has been reported ${ }^{82-84}$, McQuaid et al. ${ }^{20}$ showed that systemic FFA concentrations over a 24 h-period are comparable between lean and abdominally obese men. This indicates that total FFA flux towards ectopic tissues may not be or is only slightly elevated.

\section{Adipose tissue lipid uptake and storage}

The adipose tissue stores lipoprotein-derived TAG by hydrolyzing FFA from TAG through the action of lipoprotein lipase (LPL) at the endothelial membrane ${ }^{85}$. Hydrolyzed fatty acids are taken up by mammalian cells via passive diffusion or active transporters and are subsequently re-esterified into $\mathrm{TAG}^{86}$. High insulin levels favor this lipid uptake and storage by inducing LPL ${ }^{87}$, fatty acid transporters ${ }^{88,89}$ and fatty acid synthase (FAS) ${ }^{90}$. In slightly overweight $\left(\mathrm{BMI}=26 \mathrm{~kg} / \mathrm{m}^{2}\right)$, yet insulin sensitive $(\mathrm{HOMA}-\mathrm{IR}=1.34)$ subjects, storage of dietary lipids in the postprandial state was increased ${ }^{91}$, whereas in obese subjects, lipid buffering was impaired resulting in increased plasma concentrations of TAG 20,92. This impaired clearance of dietary fat and subsequent release of FFA or TAG has been described as AT lipid spillover ${ }^{93}$.

Since dietary lipids are transported in the adipose tissue via capillaries, the delivery of lipoproteins and TAG to adipocytes is dependent on adipose tissue blood flow (ATBF) ${ }^{94}$. The adipose tissue of obese is characterized by a reduced ATBF ${ }^{95-101}$, which in turn may contribute to the reduced postprandial clearance of lipids, and a subsequent overflow of adipose tissue derived FFA and chylomicron- and VLDL-bound TAG to ectopic tissues ${ }^{30}$.

\section{Endocrine role of adipose tissue}

Besides its buffering function in lipid metabolism, adipose tissue seems to exert an important role in peripheral metabolism and low-grade inflammation through the secretion of various endocrine peptides, cytokines and/or hormones (adipokines) with distinct and synergistic actions ${ }^{30,44,102}$.

The most prominent adipokines that have been discovered yet, are adiponectin and leptin 103,104. Adiponectin is secreted by adipocytes and has insulin-sensitizing effects on muscle and liver cells 103,105 . Adiponectin has stimulated insulin sensitivity, fat oxidation and 
mitochondrial capacity in liver and skeletal muscle of healthy subjects, possibly mediated by AMPK and PPAR- $\alpha^{106-108}$. Furthermore, adiponectin concentrations were associated with low adipose tissue mass in lean and obese humans ${ }^{109-111}$ and low ectopic fat accumulation in obese women ${ }^{112}$. In high-fat fed adiponectin-knock-out mice, adiponectin replacement prevented insulin resistance by reducing autophagy and oxidative stress ${ }^{113}$. Contrary to adiponectin, leptin levels are positively associated with fat mass ${ }^{104}$, more specific with hypertrophic adipose tissue ${ }^{114,115}$. Leptin is mainly secreted by subcutaneous adipocytes and exerts its function in the hypothalamus as a non-acute satiety signal and stimulator of energy expenditure ${ }^{116,117}$, thereby counteracting weight gain and subsequent metabolic disturbances as reviewed earlier ${ }^{118}$. In more detail, leptin administration induced heat production, mitochondrial function and glucose tolerance in skeletal muscle of dietinduced obese mice and ewes ${ }^{119,120}$. These properties are best documented in (relative) leptin deficiency such as lipodystrophy ${ }^{121-123}$. Human obesity is characterized by both elevated leptin concentrations as well as by a reduced action of the hormone both centrally and in the periphery (leptin resistance) ${ }^{124}$.

Hotamisligil and colleagues ${ }^{125}$ first reported that TNF- $\alpha$ gene and protein expression were increased in adipose tissue of obese compared with lean subjects, indicating adipose tissue inflammation. Moreover, other adipose tissue-derived cytokines are altered in obese subjects, such as macrophage attracting protein 1 (MCP-1) and interleukin 6 (IL-6) ${ }^{44,102,126}$. In hypertrophic adipocytes, the homeostatic capacity of various organelles is overwhelmed by a mechanical limitation and lipid overload ${ }^{127}$. Consequently, newly synthesized unfolded proteins accumulate in the endoplasmic reticulum (ER) lumen and lead to the ER stress ${ }^{128,129}$. In consequence, the unfolded protein response (UPR) is activated to support the ER in function ${ }^{130}$. This activation is pivotal in order to maintain responsiveness to nutritional needs in adipose tissue ${ }^{131}$, but coincides with an inflammatory response through the induction of oxidative, mitochondrial and ER stress ${ }^{132,133}$. Additionally, the lipid-rich environment (FFA) may further stimulate inflammatory pathways through the activation of toll-like receptors and ceramide synthesis ${ }^{134}$.

Through the expression of MCP-1, macrophages are attracted to obese adipose tissue ${ }^{135}$, in which the cell proportion of macrophages can increase from $10 \%$ in non-obese up to $50 \%$ in obese subjects ${ }^{136}$. The primary purposes of macrophage infiltration are removal of cell debris, tissue remodeling and additional lipid buffer in order to reduce the lipid overload 


\section{Chapter 1}

137 . However, in rodents, chronic lipid overload may induce macrophage polarization from M2 to M1 ${ }^{126,138}$, which themselves produce inflammatory cytokines to attract more macrophages and induce a vicious inflammatory cycle ${ }^{139}$. In humans, macrophage phenotypes distinction may be more complex ${ }^{44,140}$ and may be determined by other pathways than its classical activation ${ }^{141}$.

The local inflammatory milieu has a profound impact on adipose tissue metabolism. Via direct and indirect pathways, insulin signaling, lipid buffering and adipokine secretion are disturbed ${ }^{142}$. The activation of c-Jun NH2-terminal kinase (JNK) and inhibitor of nuclear transcription factor $\kappa \mathrm{B}$ kinase (IKK- $\beta$ ) are suggested as intracellular mediators of inflammatory signals, that impair insulin signaling by Ser-phosphorylation of insulinreceptor substrate (IRS) and increase inflammatory response through the inflammasome and nuclear transcription factor $\kappa \mathrm{B}(\mathrm{NF} \kappa \mathrm{B}){ }^{132}$. Moreover, inflammatory signals may increase rates of lipolysis and inhibit lipid storage, as indicated by animal studies ${ }^{143}$. In conditions of lipid overload, this may indicate an adaptive mechanism to reduce lipid accumulation and ER stress, which was indeed shown to be reversible ${ }^{144}$.

This initially local inflammatory milieu is likely to spill over as long as it is not counteracted, thereby contributing to systemic low-grade inflammation, insulin resistance and lipotoxicity in several other tissues like skeletal muscle and the liver ${ }^{30,44,142}$.

\section{Adipose tissue depot-differences}

Various studies show depot-differences for the impact on metabolic health in humans ${ }^{145,146}$. With respect to upper-body fat, visceral adipose tissue (vAT) is more closely associated with the metabolic syndrome and cardiovascular risk factors than subcutaneous adipose tissue (scAT) ${ }^{147-150}$. Interestingly, insulin resistance of scAT was associated with vAT mass ${ }^{151}$, suggesting that dysfunctional scAT may contribute to vAT accumulation. As discussed, insulin resistant ScAT is characterized by increased FFA release and a reduced postprandial uptake of lipids. Storage of VLDL-TAG, formed from plasma FFA in the liver, was found comparable between adipose tissue sites in lean and obese women ${ }^{152}$. Therefore, dysfunctional scAT may rather contribute to vAT accumulation through a compensatory buffering of dietary lipids in vAT ${ }^{153,154}$.

The proportion of FFA release from vAT to systemic concentrations during fasting conditions is relatively small as compared to $\operatorname{scAT}(\sim 10 \%)$, although this increases up to 
$40 \%$ during insulin-mediated suppression of lipolysis ${ }^{155}$. This indicates a more pronounced insulin resistance of vAT as compared to scAT. As vAT is localized between the gut and the liver, lipolytic FFA from vAT drain first into the liver and may contribute to hepatic lipid accumulation and insulin resistance ${ }^{156}$. Indeed, vAT, not scAT, has been related to hepatic lipid accumulation in overweight and obese women ${ }^{157}$. As discussed in more detail later in this introduction, FFA delivery to the liver as well as hepatic lipid accumulation stimulate VLDL-TAG output ${ }^{158}$, and may therefore significantly contribute to postprandial lipid overflow to skeletal muscle ${ }^{156}$.

Lastly, there is accumulating evidence that macrophage infiltration in vAT of patients with obesity, metabolic syndrome or coronary artery disease indicates a more proinflammatory profile, that might also affect systemic inflammation ${ }^{159}$. Regional differences in preadipocyte replication, differentiation, susceptibility to apoptosis or senescence, and gene expression may contribute to regional variation in adipose tissue function ${ }^{67,160}$. Thus, scAT dysfunction may promote vAT lipid accumulation, as in other ectopic tissues. Increased vAT mass may cause hepatic insulin resistance and lipid overflow to other ectopic tissues.

\section{Liver}

The liver accounts for approximately $20 \%$ of resting energy expenditure, and has a profound role in substrate metabolism ${ }^{161}$. The liver takes up FFA linearly to their plasma concentration and by active facilitated transport by fatty acid transporters. Hepatic lipase and LPL-mediated hydrolysis of TAG may contribute to lipid influx into hepatocytes. In the cell, fatty acids are either stored into TAG, oxidized to provide energy and acetyl-CoA for gluconeogenesis, or secreted as esterified TAG within LDL/VLDL-particles.

Whereas insulin leads to a reduction of plasma FFA and hepatic uptake, and may therefore reduce VLDL output ${ }^{162}$, dietary lipids increase VLDL secretion ${ }^{163,164}$. Although dietary TAGs, packed in chylomicrons, are first bypassing the liver via the lymphatic system, the impaired postprandial clearance of dietary lipids in obese adipose tissue results in higher TAG concentrations in the circulation and increased hepatic and muscle uptake ${ }^{20,165}$. Additionally, the anti-lipolytic action of insulin is impaired in dysfunctional adipose tissue and may contribute substantially to increase plasma fatty acid concentrations and consequently fatty acid uptake in the liver, mainly in the postprandial phase ${ }^{166}$. Although 


\section{Chapter 1}

whole-body fat oxidation seems increased over 24 hours in conditions of high lipid availability ${ }^{167}$, this adaptive mechanism may not completely prevent hepatic lipid accumulation in obesity, as indicated by the strong correlation between obesity and liver fat ${ }^{168-170}$. As a consequence of hepatic lipid accumulation, and the production and secretion of lipid-rich lipoproteins (VLDL-TAG) are increased ${ }^{20,158,165}$, which in turn contributes to increase cardiovascular disease risk ${ }^{171,172}$. Within the liver, the accumulation of lipids and lipid metabolites, such as diacylglycerol ${ }^{173}$ and ceramides ${ }^{174}$, interferes with the insulin signaling pathway. Also, lipid accumulation may increase reactive oxygen species (ROS) that are generated as consequence of impaired or overloaded mitochondria ${ }^{175}$. Due to the consequent induction of ER stress ${ }^{176}$, inflammation ${ }^{177}$ and insulin resistance, insulin fails to reduce hepatic glucose production, which may contribute to hyperglycemia ${ }^{11}$. Hyperglycemia, in turn, has been shown to reduce hepatic fat oxidation in men and may consequently contribute to increase plasma TAG concentrations ${ }^{178}$.

\section{Skeletal Muscle}

Skeletal muscle is the predominant tissue regarding whole-body insulin sensitivity, since it is responsible for $80 \%$ of insulin-mediated glucose disposal ${ }^{22}$. Furthermore, skeletal muscle accounts for $80 \%$ of $24-\mathrm{h}$ energy expenditure ${ }^{179}$, which establishes it as a main target to tackle obesity. Disturbances in skeletal muscle fatty acid metabolism have been linked to the development of obesity and type 2 diabetes ${ }^{12,13,32,33,180}$. Like in the adipose tissue and liver, a mismatch between lipid uptake and oxidation, as well as an impaired lipid turnover within skeletal muscle, contribute to muscle lipid accumulation and, consequently, metabolic dysfunction of skeletal muscle.

\section{Lipid uptake}

Lipid uptake was shown increased in insulin resistant subjects; most likely due to increased plasma TAG concentrations and the subsequent extraction in skeletal muscle ${ }^{181}$. This may be, at least in part, be attributed to higher CD36-transporters within skeletal muscle, which facilitate lipid uptake ${ }^{182}$. Besides an impaired TAG clearance in adipose tissue resulting in systemic lipid overflow, a reduced insulin-induced inhibition of skeletal muscle LPL activity may contribute to the higher muscle lipid uptake ${ }^{183}$. Although chylomicron-TAGs 
are the preferential substrate as compared to VLDL and plasma FFA under normal conditions ${ }^{184}$, uptake of VLDL-TAG is increased in insulin resistant subjects ${ }^{185}$. However, because both VLDL and chylomicrons share a common saturable binding mechanism ${ }^{186}$, the net amount of TAG delivered to skeletal muscle may be more important than its fractions. Due to the impaired clearance in AT, plasma TAG remain elevated for a longer time and may further increase with the next meal ${ }^{20}$.

\section{Skeletal muscle lipolysis}

As in adipose tissue, skeletal muscle lipolysis is also mainly determined by the actions of ATGL and HSL, of which the latter is inducible by $\beta$-adrenergic stimulation or by an increased activity of AMPK ${ }^{31}$. In obese subjects, $\beta$-adrenergic stimulation of lipolytic activity in skeletal muscle is blunted ${ }^{187,188}$. Recently, it has been proposed that the majority of lipids are first stored before they are hydrolyzed, dependent on the activity of lipolytic enzymes, highlighting the importance of lipolysis for oxidative metabolism and TAG accumulation ${ }^{189,190}$. A reduced activation of PPARs by lipolytic products might contribute to a reduced mitochondrial capacity and may thereby impair fat oxidation ${ }^{189,190}$. Recent data from our lab has shown that an impaired insulin-mediated suppression of muscle lipolysis in T2DM compared with age and BMI-matched normal glucose tolerant subjects was associated with the accumulation of membrane-saturated DAG and protein kinase C (PKC) activation, which was associated with insulin resistance ${ }^{191}$.

\section{Lipid accumulation in skeletal muscle}

An oversupply of lipids that is not compensated by oxidation is stored into lipid droplets as TAG or lipid intermediates such as DAG, fatty acyl-CoA and ceramides. TAG storage might be a protection mechanism against the accumulation of detrimental lipidintermediates ${ }^{192}$, and is per se not necessarily deleterious to insulin sensitivity of myocytes, which is indicated as the 'athlete paradox' ${ }^{193}$. However, preferential storage of lipids in skeletal muscle may promote lipid accumulation and insulin resistance in the long term ${ }^{194-}$ 196. There are indications that lipogenesis is upregulated in skeletal muscle of extreme obese humans, resulting in an increased lipid accumulation and reduced fat oxidation 194 . However, TAG synthesis has been shown be reduced in obesity and insulin resistance 196,197, which leads to accumulation of DAG and ceramides. The accumulation of these lipid-intermediates has been related to inhibition of insulin signaling and a reduced 


\section{Chapter 1}

mitochondrial function ${ }^{12,174}$. Noteworthy, muscle lipid turnover depends on the saturation of fatty acids, of which saturated fatty acids had the least favorable effect on lipid uptake, glucose tolerance and gene expression of oxidative pathways ${ }^{198}$. More recently, it has been discovered that the location and saturation of bioactive lipid fractions as well as their turnover might be more important in relation to insulin signaling than the amount per se 191,199,200.

\section{Substrate partitioning and substrate competition within the skeletal muscle}

To meet the complexity of changes in fuel oxidation, the concept of metabolic flexibility has been introduced, defined as the capacity to increase fat oxidation upon increased fatty acid availability and to switch between fat and glucose as the primary fuel source after a meal ${ }^{29,201}$. According to the concept of metabolic flexibility, an increased availability of fat would enhance fat oxidation in order to prevent lipid accumulation ${ }^{201}$. The compensatory increase was impaired in obese insulin resistant subjects, and may contribute to increased lipid storage and the accumulation of lipid intermediates 18,197,202-209. Moreover, an increased availability and uptake of extracellular lipids has been shown to reduce the oxidation of intracellular lipids and may thereby attribute to lipid accumulation ${ }^{210}$. To which extent humans can adapt fat oxidation to an increased availability may at least partly be intrinsically determined ${ }^{211,212}$.

Under insulin-stimulated conditions the concept of metabolic flexibility describes the shift from fat oxidation to carbohydrate oxidation in the presence of insulin, reflected by an increased respiratory quotient (RQ) in the muscle ${ }^{29}$. Both characteristics of metabolic flexibility, the capacity to dynamically stimulate and suppress fat oxidation, were positively related to insulin sensitivity ${ }^{201,213}$. Already in 1991, Boden ${ }^{214}$ demonstrated that increased plasma lipids are taken up in skeletal muscle cells and exert direct acute inhibitory effect on glucose metabolism in human muscles in hyperinsulinemic conditions.

On the other hand, in human muscle a combination of hyperinsulinemia and hyperglycemia increases malonyl-CoA concentrations, inhibits functional carnitine-palmitoyl-transferase 1 (CPT1) activity and consequently reduces mitochondrial lipid uptake and oxidation ${ }^{204}$. Hyperglycemia, hyperinsulinemia and a reduced lipid oxidation have been shown in combination with an increased skeletal muscle content of malonyl-CoA, an allosteric inhibitor of mitochondrial FA transport, in rodent models of obesity and insulin resistance 
215. Also, the chronic inhibition of insulin signaling by postprandial hyperlipidemia and lipid accumulation may contribute to an impaired postprandial metabolic flexibility in subjects with impaired glucose metabolism ${ }^{213,216}$. Thus, nutrient overload and increased substrate competition result in mitochondrial indecision, impaired fuel switching and energy dysregulation ${ }^{180}$. Moreover, metabolic inflexibility has been associated with mitochondrial dysfunction, insulin resistance and weight gain ${ }^{18,217}$. Although intrinsic disturbances may predispose to metabolic inflexibility ${ }^{18,218}$, lifestyle interventions or weight loss studies indicate that metabolic inflexibility (partly) improves after weight loss $213,219,220$

\section{Fat oxidation and mitochondrial capacity}

A higher fasting muscle RQ may reflect metabolic inflexibility. Some studies found a negative relationship between whole body fasting RQ and in vivo mitochondrial function (Phospho-Creatine recovery) and skeletal muscle mitochondrial content in humans ${ }^{26,217}$. An impaired mitochondrial respiration may be compensated by glycolytic ATP production, which would lead to a higher RQ. An increased fasting RQ was reported in insulin resistant ${ }^{24}$, insulin resistant offspring of T2DM patients ${ }^{25}$ or diabetic subjects ${ }^{26,27}$ as compared to healthy controls. Also, skeletal muscle oxidative capacity was reduced in diabetic and obese as compared to healthy (trained) subjects ${ }^{221-223}$, which may contribute to reduce fat oxidation during moderate intensity exercise ${ }^{224}$. Moreover, a parallel increase of fat oxidation and mitochondrial capacity that was observed after 9 months exercise training indicates that mitochondrial capacity may determine fat oxidation ${ }^{225}$. Mitochondrial respiration is determined by energy demand (low ATP/ADP ratio) and to a lesser extent by substrate supply, as discussed by Muoio and Neufer ${ }^{226}$. This is substantiated by respiration measurements before and after ADP supply in isolated skeletal muscle fibers ${ }^{227}$. Physical activity increases energy demand, which leads to an increased ROS-induced stimulation of $\mathrm{Ca}^{2+} /$ calmodulin-dependent protein kinase (CAMKII). CAMKII activates mitochondrial biogenesis and fat oxidation in healthy, obese, diabetic and aging subjects ${ }^{220,228-232}$. In line with an increased mitochondrial capacity, exercise training increased submaximal ADP sensitivity of mitochondria ${ }^{233}$. An increased ADP sensitivity implies that lower ADP concentrations induce the same extent of ATP generation through mitochondrial respiration with less activation of glycolytic enzymes (glycogen phosphorylase and pyruvate 


\section{Chapter 1}

dehydrogenase) fluxes, thereby maintaining fat oxidation. Interestingly, in diabetic rats a reduced ADP sensitivity was found ${ }^{234}$. Noteworthy, in humans the relationship between fat oxidation and obesity ${ }^{235}$ and insulin resistance ${ }^{213}$ were studied on a whole-body level or in skeletal muscle (or corrected for muscle mass) ${ }^{213,235}$. Other organs may have contributed to lower fasting fat oxidation as well, but this has not yet been investigated in such detail.

\section{Mitochondrial dysfunction and insulin sensitivity}

There is evidence that an impaired mitochondrial fat oxidation (capacity) contributes to the development of insulin resistance ${ }^{236}$. However, to date no conclusive causal relationship between mitochondrial oxidative capacity and insulin sensitivity has been established in humans ${ }^{237,238}$. Whereas insulin resistant subjects are mostly characterized by a low skeletal muscle oxidative capacity ${ }^{223,239-242}$, others have found no relation between mitochondrial capacity and insulin action ${ }^{243,244}$. Interestingly, not only mitochondrial function, but also mitochondrial size was found to be positively correlated to insulin sensitivity ${ }^{245}$. As reviewed by Liesa and Shirihai ${ }^{246}$, through fragmentation (fission) and elongation (fusion) mitochondria can modulate energy efficiency and prevent ROS emission despite high substrate availability. During increased energy demand, mitochondria increase in size and integrity to facilitate efficient energy production. In conditions of decreased substrate supply, transient fragmentation of mitochondria generates a network of smaller mitochondria with a low integrity. The low membrane potential leads to less energy wasting and may prevent ROS emission ${ }^{247}$. However, during sustained nutrient excess, an increased proton motive force across the mitochondrial membrane increased ROS production, which induced inflammatory pathways, and may therefore contribute to mitochondrial dysfunction and insulin resistance ${ }^{248,249}$. Additionally, autophagic recycling of mitochondria with low membrane potential is impaired by nutrient excess, which can contribute to accumulation of dysfunctional mitochondria ${ }^{246,250}$.

In conclusion, skeletal muscle fat oxidation is reduced in the obese insulin-resistant state. This impaired fat oxidation may contribute to the accumulation of lipid metabolites and may be driven by lipid supply from either extracellular or intracellular sources as well as intrinsic impairments in mitochondrial capacity. However, whether reduced mitochondrial function is causally related to insulin resistance or rather a consequence of the sedentary lifestyle needs to be investigated in more detail in future research. 


\section{Gut microbiota}

The gut microbiota, which consists of $\sim 10^{14}$ bacteria, has gained increased attention in metabolic research over the last decade. The microbiota composition may be influenced by age ${ }^{251}$, genetic predisposition ${ }^{252}$, early life acquisition ${ }^{253}$, dietary compounds (sweeteners ${ }^{254}$, pre- and probiotics 255 and macronutrient composition ${ }^{256,257}$ ) and lifestyle (local environment ${ }^{258}$, eating and defecation pattern ${ }^{259}$ ). The gut and its resident microbiota may contribute to the development of obesity through their capacity to harvest energy by fermenting non-digestible fibers, which has been demonstrated in rodents ${ }^{260,261}$. Also in humans, a significant association between bacterial composition and obesity has been reported by Ley et al. ${ }^{262}$. More recently, various studies in humans have demonstrated that the gut microbiota composition ${ }^{263,264}$, diversity ${ }^{265,266}$ and richness ${ }^{267}$ are associated with its host phenotype related to obesity, insulin resistance, T2DM, the immune system and nervous system, which has been reviewed more extensively elsewhere ${ }^{268-273}$.

Interestingly, it has been shown that manipulation of the gut microbiota by means of fecal transplantation ${ }^{274}$ and antibiotics treatment ${ }^{275}$ modulates peripheral insulin sensitivity in humans, however conflicting data exists ${ }^{276}$. Although the impact of the microbiota has been reported in several studies, the understanding of possible mechanisms, by which the microbiota or specific species affect human metabolism, is yet evolving. The capacity of bacteria to ferment non-digestible food ingredients such as dietary fiber may contribute to energy harvesting, and thus an positive energy balance ${ }^{277}$. While human data is still scarce 276,278,279, evidence, based on rodent studies, suggests that short-chain fatty acid ${ }^{42}$, bile acid 280 and other metabolite ${ }^{281}$ concentrations may modulate the metabolic effects that are induced by the microbiota composition. Besides their function as energy substrate, shortchain fatty acids (SCFA) may modulate human substrate and energy metabolism through stimulation of hormonal release of GLP-1 and PYY ${ }^{278,279}$, and additionally through direct peripheral effects on adipogenesis, lipolysis and lipid uptake ${ }^{42}$.

Moreover, the gut microbiota is involved in bile acid metabolism and bile acids in turn may affect microbiota composition ${ }^{282}$. Because of their metabolic impact ${ }^{280}$, modulation of bile acid profile may have an impact on host physiology, as has been shown in rodents ${ }^{283}$. Bile acid modification has been shown to improve lipid profile und glucose homeostasis in humans ${ }^{280}$, however the potential role of the gut microbiota needs to be elucidated. 


\section{Chapter 1}

Lastly, gut bacteria may modulate immunity and inflammation, and alterations in gut microbiota composition have been linked with metabolic endotoxemia ${ }^{271}$. Through interactions with immune cells and the inflammasome within the intestinal mucosa, bacteria exert a profound regulatory role in the immune system ${ }^{284-286}$.

\section{Prevention strategies}

Prevention and treatment strategies for obesity and related insulin resistance preferably include lifestyle intervention, focused on caloric restriction, a change in diet composition and an increased physical activity. Lifestyle interventions, according to general guidelines for diet and physical activity, have been shown to be effective in the prevention of obesityrelated diseases such as type 2 diabetes ${ }^{15,16}$. Unfortunately, however, about $30 \%$ of subjects do not respond and/or adhere to lifestyle interventions, which indicates the demand for new additional approaches to complement the success of lifestyle interventions.

One approach to induce health benefits by means of dietary interventions is the supplementation of natural food ingredients, including polyphenols. Polyphenols are plant antioxidants that are synthesized as intrinsic defense mechanisms upon stress exposure and may exert protective effects against oxidative stress in consumers of these plants as well, which is described in the xenohormesis hypothesis ${ }^{287,288}$. Among the most abundant and bioactive polyphenols in the human diet are epigallocatechin-3-gallate, resveratrol and soy isoflavones, which have been found in green tea ${ }^{289}$, red wine and grapes ${ }^{290}$, and soy ${ }^{291}$, respectively. Originally, these have attracted attention for their anti-oxidant and anticarcinogenic effects ${ }^{292-294}$. However, their application might go beyond these effects. Polyphenols may affect pathways of fatty acid catabolism, fat oxidation and insulin sensitivity.

Green tea first gained attention because its consumption was shown negatively associated with cardiovascular diseases in humans ${ }^{295,296}$. Later, the most abundant catechin in green tea, epigallocatechin-3-gallate, was implicated in the benefits of green tea on body weight control ${ }^{297}$, possibly by stimulating $24-\mathrm{h}$ energy expenditure and fat oxidation ${ }^{298}$. Importantly, effects of epigallocatechin-3-gallate supplementation may be modulated by obesity $^{299}$, gender ${ }^{300}$, and genetic predisposition ${ }^{301}$. 
By introduction of the 'French paradox' ${ }^{302,303}$, resveratrol has attracted attention because a low risk for coronary heart diseases in the French population was associated with red wine consumption despite high fat intake ${ }^{302}$ and because of its potential to inhibit oxidation of human LDL in vitro ${ }^{303}$. Interestingly, resveratrol was found to improve markers of metabolic health in various model organisms ${ }^{304-306}$, including obese humans ${ }^{307}$. The benefits of resveratrol supplementation may depend on the dosage 308,309 and type of subjects ${ }^{310}$.

Although the beneficial effect of soy was first ascribed to its protein and fiber content ${ }^{311}$, soy isoflavones have been attributed with a variety of health benefits related to osteoporosis, reproduction and infant growth ${ }^{312-317}$. More recently, the phytoestrogenic activity of isoflavones has been implicated in the prevention of cardiometabolic diseases as well ${ }^{318-320}$. Beneficial effects on insulin sensitivity have been found in postmenopausal women ${ }^{321}$, but not in premenopausal women or men yet.

In conclusion, dietary polyphenols are associated with a reduced risk for cardiometabolic diseases. However, literature on the impact of polyphenols on energy and substrate metabolism in humans is not consistent. In the next section, the effects of supplementation of specific polyphenols, namely epigallocatechin-3-gallate, resveratrol and soy isoflavones, in Caucasian subjects will be discussed in more detail.

\section{Epigallocatechin-3-gallate (EGCG)}

\section{Body weight control and energy expenditure}

In Caucasian overweight and obese subjects, EGCG supplementation reduced body weight, fat mass or fat percentage in most ${ }^{322-325}$, but not all studies ${ }^{326,327}$. The potential of EGCG to modulate body weight control has further been shown in combination with exercise ${ }^{325}$ and during weight maintenance after weight loss ${ }^{328}$, although data are not consistent ${ }^{329-332}$.

The benefit of EGCG supplementation on body weight control has been shown in rodents receiving obesogenic diets ${ }^{333-339}$. Lipid accumulation in adipose tissue and the liver was decreased by EGCG supplementation in these animals by decreasing energy uptake 334,335 and by increasing adipose tissue lipolysis, adipose tissue and skeletal muscle uncoupling and skeletal muscle fat oxidation ${ }^{335-338}$. Direct effects of EGCG on adipocyte gene 


\section{Chapter 1}

expression related to lipolysis, fat oxidation and uncoupling have been confirmed in vitro 340-342

In humans, green tea extract (GTE) supplementation for 12 weeks indeed reduced lipid absorption, although no effect on body weight was found ${ }^{343}$. No human in vivo data is available regarding the effect of EGCG supplementation on lipolysis. With respect to energy expenditure (EE), Dulloo and colleagues ${ }^{298}$ could show that supplementing GTE (270 mg EGCG, $150 \mathrm{mg}$ caffeine) increased $24 \mathrm{~h}$-EE in 10 healthy men versus caffeine alone $(150 \mathrm{mg})$. Surprisingly, an earlier reported acute effect of caffeine on metabolic rate was not found in this study ${ }^{344}$. In contrast, Berube-Parent et al. ${ }^{345}$ showed that EGCG had no additional benefit to caffeine supplementation on EE. Hursel et al. ${ }^{346}$ reported a thermogenic effect of decaffeinated green tea supplements on resting EE (250 mg EGCG), whereas no effect was observed on postprandial EE ${ }^{299,346}$. These differences may be explained by a variation in fat mass, since responders to EGCG supplementation (on resting and postprandial EE) had higher fat mass than subjects that did not respond ${ }^{299}$, or the activity of catechol-O-methyl-transferase (COMT) ${ }^{301}$, which is EGCG's suggested target enzyme ${ }^{347}$. Finally, Boschmann and Thielecke ${ }^{348,349}$ did not observe significant increases in EE in overweight subjects following 2 days of EGCG supplementation (300 mg/d).

To conclude, short-term studies showed possible benefits of EGCG on EE in lean, but not in overweight subjects. To induce changes in body mass, EE must be stimulated over a longer period of time. To our knowledge, three studies have addressed the more long-term effects of EGCG on EE. While in two studies with lean subjects, no effect was observed 325,350, EGCG supplementation increased EE in female multiple sclerosis patients as compared to placebo, but not in male patients (women: $25.9 \mathrm{~kg} / \mathrm{m}^{2}$; men: $24.2 \mathrm{~kg} / \mathrm{m}^{2}$, $\mathrm{P}=$ N.S. $)^{300}$. Subjects were limited in their caffeine consumption $(<300 \mathrm{mg} / \mathrm{d})$ and groups showed no differences in norepinephrine concentrations, but a differential effect on the autonomic and endocrine nervous system was suggested to account for the different effect of EGCG-supplementation between gender, but no data was provided to support this hypothesis.

\section{Fat oxidation and insulin sensitivity}

Interestingly, short-term EGCG supplementation stimulated fat oxidation during fasting/nocturnal ${ }^{298,301}$ and postprandial/diurnal conditions (meal contained $35-40 \%$ of 
energy intake (energy\%)) ${ }^{298,348,349}$ but studies are not consistent ${ }^{299,345,351,352}$. Also, after 4 weeks supplementation with decaffeinated GTE (dGTE) in lean subjects ${ }^{325}$ and after 12 weeks with EGCG in female, not in male, multiple sclerosis patients ${ }^{300}$, fat oxidation was increased during fasting and postprandial conditions (35 energy $\%$ fat). The stimulation of lipid oxidation by EGCG and GTE may have contributed to an improved lipoprotein status and fasting and postprandial plasma TAG concentrations in humans ${ }^{300,323,326}$, since plasma lipids are preferentially oxidized, as discussed ${ }^{210}$. In rodents, EGCG supplementation indeed reduced adipose tissue inflammation and hepatic lipid accumulation and increased insulin sensitivity ${ }^{337-339,353,354}$. The evidence for an insulin sensitizing effect of EGCG in humans is, however, scarce. Improved insulin sensitivity (reduction in HOMA-IR) after 12 weeks GTE supplementation has been shown in one study ${ }^{326}$, whereas the majority of studies found no effect on insulin sensitivity in overweight and obese subjects ${ }^{300,322,323,327}$. Still, recent studies in rodents support the potential of EGCG in the prevention of insulin resistance ${ }^{355}$.

\section{Resveratrol}

\section{Mitochondrial capacity and substrate oxidation}

Rodent studies have shown that resveratrol may stimulate mitochondrial biogenesis ${ }^{304,356}$. Indeed, resveratrol has been shown to activate NAD-dependent deacetylase sirtuin-1 (SIRT1) ${ }^{357}$ and $5^{\prime}$ adenosine monophosphate-activated protein kinase (AMPK) ${ }^{358}$ and inhibit phosphodiesterase (PDE) ${ }^{359}$, which led to an increased peroxisome proliferatoractivated receptor gamma coactivator $1-\alpha(\mathrm{PGC} 1-\alpha)$ activity ${ }^{357-359}$, the master regulator of mitochondrial biogenesis and function ${ }^{360,361}$.

In humans, the potential of resveratrol to improve substrate metabolism is less consistent. While no effects on body weight or fat mass have been reported in humans yet ${ }^{307,309,310,362-}$ ${ }^{364}$, Resveratrol supplementation appears to have pronounced effects on substrate metabolism. In obese men supplementation of $150 \mathrm{mg}$ resveratrol (resVida ${ }^{\circledR}$ ) for 30 days significantly increased ex vivo mitochondrial oxidative capacity as compared to placebo ${ }^{307}$. Furthermore, $2 \mathrm{~g}$ of grape polyphenols ( $\sim 1 \mathrm{mg}$ resveratrol) prevented a fructose-induced decrease of mitochondrial and oxidative gene expression in skeletal muscle ${ }^{365}$. 


\section{Chapter 1}

Nevertheless, others have not found these beneficial effects of resveratrol supplementation for reasons that remain unclear (Yoshino et al. ${ }^{310}: 75 \mathrm{mg} / \mathrm{d}$ (Temmer Werke), 12 weeks, 30 lean women; Poulsen et al. ${ }^{309}: 1500$ mg/d (Fluxome), 4 weeks, 24 obese men; Olesen et al. ${ }^{362}: 250 \mathrm{mg} / \mathrm{d}$ (Fluxome), 8 weeks, 16 overweight men; van der Made et al. ${ }^{366}: 150 \mathrm{mg} / \mathrm{d}$ $\left(\right.$ resVida $\left.^{\circledR}\right), 4$ weeks, 45 men and women $(25 \mathrm{M}, 20 \mathrm{~F})$; Chachay et al. ${ }^{308}: 3000 \mathrm{mg} / \mathrm{d}$ (Biotivia), 8 weeks, 20 men).

In skeletal muscle, the increased capacity to oxidize fat after resveratrol supplementation in humans ${ }^{307}$ may contribute to improve metabolic flexibility and insulin sensitivity, as discussed earlier. Indeed, resveratrol supplementation increased the respiratory quotient (RQ) during daytime on an isocaloric diet (33 energy\% fat) as compared to placebo, indicative for an increased insulin-stimulated carbohydrate oxidation, whereas nocturnal RQ was not affected ${ }^{307}$.

\section{Adipose tissue morphology}

Interestingly, resveratrol supplementation has also been shown to alter adipose tissue morphology, with a reduction in mean adipocyte size ${ }^{370}$. As mentioned earlier, a decrease in adipocyte size is associated with an improved metabolic and endocrine function ${ }^{30}$. In that respect, the observed inhibition of postprandial lipolysis after resveratrol supplementation may indicate increased adipose tissue insulin sensitivity, and the reduction in plasma TNF- $\alpha$ concentrations may also reflect improvement of the endocrine function of adipose tissue $^{307}$.

\section{Insulin sensitivity}

Decreased glucose, insulin and HOMA-IR values after resveratrol supplementation suggest improved insulin sensitivity in sedentary ${ }^{367}$, obese ${ }^{307}$, and diabetic subjects ${ }^{353,368}$. It is tempting to speculate that reduction of liver fat after resveratrol supplementation may have contributed to these beneficial effects ${ }^{307}$, as has been shown in rodents ${ }^{369}$. Importantly, studies that have used the gold standard hyperinsulinemic-euglycemic clamp to assess insulin sensitivity have so far not found improved insulin sensitivity after resveratrol supplementation in humans ${ }^{308-310}$. In contrast to Timmers et al. ${ }^{307}$, resveratrol was not effective to alter substrate metabolism on any parameter of energy or substrate metabolism (body weight and fat mass, insulin sensitivity and substrate oxidation, inflammatory markers) in these studies ${ }^{308-310}$. Therefore, although rodent studies have consistently 
demonstrated improvement of skeletal muscle and hepatic insulin sensitivity ${ }^{356,369,371-373}$, it remains to be investigated whether resveratrol supplementation also increases insulin sensitivity in humans ${ }^{366}$.

\section{Soy isoflavones}

\section{Plasma metabolic profile}

Soy isoflavones (SI) have been characterized as potential phytoestrogens ${ }^{374}$ and have been suggested to improve body weight control and substrate metabolism in postmenopausal women ${ }^{375}$. However, in men and premenopausal women, no isoflavone-induced reduction in body mass or fat mass was observed after $6(165 \mathrm{mg} / \mathrm{d})$ or 12 weeks $(130 \mathrm{mg} / \mathrm{d}){ }^{376,377}$. Nevertheless, SI have been found to prevent LDL-oxidation and other markers of oxidative stress in humans ${ }^{378,379}$. Moreover, SI supplementation significantly improved plasma lipid and lipoprotein profile in men and premenopausal women ${ }^{376-378}$. In rodents, an improved plasma profile (higher HDL- and lower LDL-cholesterol and FFA ${ }^{380}$, TAG ${ }^{380,381}$, total cholesterol $^{380-382}$ and lower insulin ${ }^{382,383}$ ) was associated with increased hepatic lipid catabolism ${ }^{380-383}$. Furthermore, SI have been found to prevent hepatic lipid accumulation through increased peroxisomal and mitochondrial oxidation ${ }^{381,382,384}$, and improved hepatic insulin sensitivity ${ }^{382,383}$. Comparable findings have been reported for skeletal muscle $382,383,385,386$. To date, only one study found that SI supplementation increased insulin sensitivity, assessed by means of an oral glucose tolerance-test (OGTT), in postmenopausal women $^{321}$.

\section{Adipose tissue metabolism}

It remains to be established whether effects on adipose tissue metabolism may contribute to the metabolic effects of SI supplementation. Penza et al. ${ }^{387}$ found that nutritional doses (5 $\mathrm{mg} / \mathrm{kg} / \mathrm{d}$ ) of SI for 15 days increased epididymal and renal fat mass and epididymal adipocyte volume in male mice, which was accompanied by a slight reduction in insulin sensitivity, assessed by an insulin tolerance-test. An increased pancreatic insulin secretion by isoflavones ${ }^{388,389}$ may compensate and maintain glucose homeostasis during an OGTT 387. In visceral adipose tissue, genistein supplementation suppressed the high-fat dietinduced hypertrophy of adipocytes via the upregulation of genes involved in fatty acid $\beta$ - 


\section{Chapter 1}

oxidation, as well as through the downregulation of genes associated with adipogenesis or lipogenesis ${ }^{380}$. The improvement in plasma lipid profile, as well as increased adiponectin and decreased TNF- $\alpha$ concentrations, may contribute to the potential improved hepatic and peripheral insulin sensitivity after long-term isoflavone supplementation, as discussed earlier ${ }^{103,390,391}$.

\section{Outline of the thesis}

This thesis focuses on the effects of combined polyphenol supplementation on substrate and energy metabolism, with specific emphasis on fatty acid metabolism and insulin sensitivity in overweight and obese men and women.

Dietary polyphenols may affect pathways of lipid catabolism that are impaired in obese, insulin resistant subjects. An increased availability of lipids through induction of lipolysis as well as stimulation of oxidative pathways may facilitate fat oxidation, thereby reducing ectopic fat accumulation and improving insulin sensitivity. Chapter $\mathbf{2}$ describes a study, which was designed to investigate the effects of 3-day epigallocatechin-3-gallate on fasting and postprandial fat oxidation (meal: 35 energy $\%$ fat) in overweight men and women. Here, we combined indirect calorimetry measurements, blood sampling and microdialysis in skeletal muscle (m. gastrocnemius) to assess fasting and postprandial whole-body substrate metabolism as well as local lipolysis and blood flow. To increase the benefit of polyphenol supplementation, we postulated that combining specific polyphenols with common and distinct mechanisms of action might achieve additive and synergistic effects on systemic lipolysis and fat oxidation. Therefore, in Chapter 3, we describe a study, similarly designed as the study in Chapter 2, to examine the effects of combined epigallocatechin-3gallate and resveratrol supplementation $(E+R)$, and $E+R$ plus soy isoflavones $(E+R+S)$ on fat oxidation before and after a high-fat mixed meal (61 energy\% fat) in 18 overweight subjects ( 9 men, 9 women). In Chapter 4, we questioned whether short-term effects of the most promising combination of polyphenols examined in Chapter 3 would translate into longer-term benefits on tissue-specific insulin sensitivity. Therefore, we performed a 12 week randomized, placebo-controlled double-blind trial to investigate the effects of longterm combined $\mathrm{E}+\mathrm{R}$ supplementation on lipid metabolism, metabolic profile, peripheral, hepatic and adipose tissue insulin sensitivity in overweight and obese, non-diabetic 
subjects. We performed a hyperinsulinemic-euglycemic clamp with a primed $\left[6,6-{ }^{2} \mathrm{H}_{2}\right]-$ glucose infusion before and after 12 weeks combined polyphenol or placebo supplementation. Additionally, fasting and postprandial lipid metabolism was measured during a high-fat mixed meal-test by means of indirect calorimetry, blood sampling and microdialysis in adipose tissue and skeletal muscle. In skeletal muscle, we also determined gene expression profiles using microarray technology and assessed mitochondrial oxidative capacity. Next, the effects of this long-term intervention on adipose tissue morphology and gene expression are described in Chapter 5.

The gut microbiota has been described to differ between lean and obese subjects and to correlate with the metabolic phenotype of its host. In Chapter 6, the results of a crosssectional study that we performed to assess the relationship between the gut microbiota composition, peripheral and hepatic insulin sensitivity in overweight and obese men and women are described. Microbiota composition may affect and be affected by dietary polyphenols and, therefore, may be involved in the effects of polyphenol supplementation on substrate metabolism. In Chapter 7, we describe the effects of combined E+R supplementation on gut microbiota composition in overweight and obese men and women. We measured fecal abundances of bacterial taxa before and after a 12-week supplementation period with either $\mathrm{E}+\mathrm{R}$ or placebo. Furthermore, we performed regression analysis to investigate the impact of alterations in gut microbiota composition on $\mathrm{E}+\mathrm{R}$ supplementation-induced effects on lipid metabolism. Finally, the main findings are discussed in a broader perspective and implications for future research are described in

\section{Chapter 8.}




\section{References}

1. IASO. Overweight \& Obesity in the EU27. 2008.

2. $\mathrm{Ng} \mathrm{M}$, Fleming $\mathrm{T}$, Robinson $\mathrm{M}$, et al. Global, regional, and national prevalence of overweight and obesity in children and adults during 1980-2013: a systematic analysis for the Global Burden of Disease Study 2013. Lancet 2014;384:766-81.

3. Obesity and overweight - Fact sheet $N^{\circ} 311$. 2015. (Accessed August, 5th, 2015, at http://www.who.int/mediacentre/factsheets/fs311/en/.)

4. Kahn SE, Hull RL, Utzschneider KM. Mechanisms linking obesity to insulin resistance and type 2 diabetes. Nature 2006;444:840-6.

5. Emerging Risk Factors C, Wormser D, Kaptoge S, et al. Separate and combined associations of body-mass index and abdominal adiposity with cardiovascular disease: collaborative analysis of 58 prospective studies. Lancet 2011;377:1085-95.

6. Bhaskaran K, Douglas I, Forbes H, dos-Santos-Silva I, Leon DA, Smeeth L. Bodymass index and risk of 22 specific cancers: a population-based cohort study of 5.24 million UK adults. Lancet 2014;384:755-65.

7. Renehan AG, Zwahlen M, Egger M. Adiposity and cancer risk: new mechanistic insights from epidemiology. Nat Rev Cancer 2015;15:484-98.

8. Preiss K, Brennan L, Clarke D. A systematic review of variables associated with the relationship between obesity and depression. Obesity reviews : an official journal of the International Association for the Study of Obesity 2013;14:906-18.

9. Forhan M, Gill SV. Obesity, functional mobility and quality of life. Best practice \& research Clinical endocrinology \& metabolism 2013;27:129-37.

10. Guilherme A, Virbasius JV, Puri V, Czech MP. Adipocyte dysfunctions linking obesity to insulin resistance and type 2 diabetes. Nature reviews Molecular cell biology 2008;9:367-77.

11. Perry RJ, Samuel VT, Petersen KF, Shulman GI. The role of hepatic lipids in hepatic insulin resistance and type 2 diabetes. Nature 2014;510:84-91.

12. Shulman GI. Ectopic fat in insulin resistance, dyslipidemia, and cardiometabolic disease. The New England journal of medicine 2014;371:2237-8.

13. Samuel VT, Petersen KF, Shulman GI. Lipid-induced insulin resistance: unravelling the mechanism. Lancet 2010;375:2267-77.

14. Olefsky JM, Glass CK. Macrophages, inflammation, and insulin resistance. Annual review of physiology 2010;72:219-46.

15. Roumen C, Corpeleijn E, Feskens EJ, Mensink M, Saris WH, Blaak EE. Impact of 3year lifestyle intervention on postprandial glucose metabolism: the SLIM study. Diabet Med 2008;25:597-605.

16. Tuomilehto J, Lindstrom J, Eriksson JG, et al. Prevention of type 2 diabetes mellitus by changes in lifestyle among subjects with impaired glucose tolerance. The New England journal of medicine 2001;344:1343-50.

17. Martinez JA, Navas-Carretero S, Saris WH, Astrup A. Personalized weight loss strategies-the role of macronutrient distribution. Nature reviews Endocrinology 2014;10:749-60.

18. Astrup A. The relevance of increased fat oxidation for body-weight management: metabolic inflexibility in the predisposition to weight gain. Obesity reviews : an 
official journal of the International Association for the Study of Obesity 2011;12:85965 .

19. Schonfeld P, Reiser G. Why does brain metabolism not favor burning of fatty acids to provide energy? Reflections on disadvantages of the use of free fatty acids as fuel for brain. Journal of cerebral blood flow and metabolism : official journal of the International Society of Cerebral Blood Flow and Metabolism 2013;33:1493-9.

20. McQuaid SE, Hodson L, Neville MJ, et al. Downregulation of adipose tissue fatty acid trafficking in obesity: a driver for ectopic fat deposition? Diabetes 2011;60:4755.

21. Yki-Jarvinen H. Non-alcoholic fatty liver disease as a cause and a consequence of metabolic syndrome. The lancet Diabetes \& endocrinology 2014;2:901-10.

22. Thiebaud D, Jacot E, DeFronzo RA, Maeder E, Jequier E, Felber JP. The effect of graded doses of insulin on total glucose uptake, glucose oxidation, and glucose storage in man. Diabetes 1982;31:957-63.

23. Randle PJ, Garland PB, Hales CN, Newsholme EA. The glucose fatty-acid cycle. Its role in insulin sensitivity and the metabolic disturbances of diabetes mellitus. Lancet 1963;1:785-9.

24. Carstens MT, Goedecke JH, Dugas L, et al. Fasting substrate oxidation in relation to habitual dietary fat intake and insulin resistance in non-diabetic women: a case for metabolic flexibility? Nutrition \& metabolism 2013;10:8.

25. Lattuada G, Costantino F, Caumo A, et al. Reduced whole-body lipid oxidation is associated with insulin resistance, but not with intramyocellular lipid content in offspring of type 2 diabetic patients. Diabetologia 2005;48:741-7.

26. van de Weijer T, Sparks LM, Phielix E, et al. Relationships between mitochondrial function and metabolic flexibility in type 2 diabetes mellitus. PloS one 2013;8:e51648.

27. Kelley DE, Simoneau JA. Impaired free fatty acid utilization by skeletal muscle in non-insulin-dependent diabetes mellitus. The Journal of clinical investigation 1994;94:2349-56.

28. Schrauwen P, Schrauwen-Hinderling V, Hoeks J, Hesselink MK. Mitochondrial dysfunction and lipotoxicity. Biochim Biophys Acta 2010;1801:266-71.

29. Corpeleijn E, Saris WH, Blaak EE. Metabolic flexibility in the development of insulin resistance and type 2 diabetes: effects of lifestyle. Obesity reviews : an official journal of the International Association for the Study of Obesity 2009;10:178-93.

30. Goossens GH. The role of adipose tissue dysfunction in the pathogenesis of obesityrelated insulin resistance. Physiology \& behavior 2008;94:206-18.

31. Jocken JW, Blaak EE. Catecholamine-induced lipolysis in adipose tissue and skeletal muscle in obesity. Physiology \& behavior 2008;94:219-30.

32. Szendroedi J, Phielix E, Roden M. The role of mitochondria in insulin resistance and type 2 diabetes mellitus. Nature reviews Endocrinology 2012;8:92-103.

33. Stinkens R, Goossens GH, Jocken JW, Blaak EE. Targeting fatty acid metabolism to improve glucose metabolism. Obesity reviews : an official journal of the International Association for the Study of Obesity 2015.

34. Yang X, Jansson PA, Nagaev I, et al. Evidence of impaired adipogenesis in insulin resistance. Biochem Biophys Res Commun 2004;317:1045-51.

35. Stephens FB, Chee C, Wall BT, et al. Lipid-induced insulin resistance is associated with an impaired skeletal muscle protein synthetic response to amino acid ingestion in healthy young men. Diabetes 2015;64:1615-20. 
36. Poitout V, Amyot J, Semache M, Zarrouki B, Hagman D, Fontes G. Glucolipotoxicity of the pancreatic beta cell. Biochim Biophys Acta 2010;1801:289-98.

37. Giacca A, Xiao C, Oprescu AI, Carpentier AC, Lewis GF. Lipid-induced pancreatic beta-cell dysfunction: focus on in vivo studies. American journal of physiology Endocrinology and metabolism 2011;300:E255-62.

38. Tomlinson DR, Gardiner NJ. Glucose neurotoxicity. Nat Rev Neurosci 2008;9:36-45.

39. Martinez de Morentin PB, Varela L, Ferno J, Nogueiras R, Dieguez C, Lopez M. Hypothalamic lipotoxicity and the metabolic syndrome. Biochim Biophys Acta 2010;1801:350-61.

40. Diamant M, Blaak EE, de Vos WM. Do nutrient-gut-microbiota interactions play a role in human obesity, insulin resistance and type 2 diabetes? Obesity reviews : an official journal of the International Association for the Study of Obesity 2011;12:27281 .

41. Tilg H, Kaser A. Gut microbiome, obesity, and metabolic dysfunction. The Journal of clinical investigation 2011;121:2126-32.

42. Canfora EE, Jocken JW, Blaak EE. Short-chain fatty acids in control of body weight and insulin sensitivity. Nature reviews Endocrinology 2015.

43. Frayn KN. Adipose tissue as a buffer for daily lipid flux. Diabetologia 2002;45:120110.

44. Rosen ED, Spiegelman BM. What we talk about when we talk about fat. Cell 2014;156:20-44.

45. Freedman DS, Khan LK, Dietz WH, Srinivasan SR, Berenson GS. Relationship of childhood obesity to coronary heart disease risk factors in adulthood: the Bogalusa Heart Study. Pediatrics 2001;108:712-8.

46. Freedman DS, Khan LK, Mei Z, Dietz WH, Srinivasan SR, Berenson GS. Relation of childhood height to obesity among adults: the Bogalusa Heart Study. Pediatrics 2002;109:E23.

47. Prins JB, O'Rahilly S. Regulation of adipose cell number in man. Clin Sci (Lond) 1997;92:3-11.

48. Knittle JL, Timmers K, Ginsberg-Fellner F, Brown RE, Katz DP. The growth of adipose tissue in children and adolescents. Cross-sectional and longitudinal studies of adipose cell number and size. The Journal of clinical investigation 1979;63:239-46.

49. Spalding KL, Arner E, Westermark PO, et al. Dynamics of fat cell turnover in humans. Nature 2008;453:783-7.

50. Sims EA, Goldman RF, Gluck CM, Horton ES, Kelleher PC, Rowe DW. Experimental obesity in man. Transactions of the Association of American Physicians 1968;81:153-70.

51. Bjorntorp P, Carlgren G, Isaksson B, Krotkiewski M, Larsson B, Sjostrom L. Effect of an energy-reduced dietary regimen in relation to adipose tissue cellularity in obese women. The American journal of clinical nutrition 1975;28:445-52.

52. Ryden M, Andersson DP, Bernard S, Spalding K, Arner P. Adipocyte triglyceride turnover and lipolysis in lean and overweight subjects. Journal of lipid research 2013;54:2909-13.

53. Arner P, Bernard S, Salehpour M, et al. Dynamics of human adipose lipid turnover in health and metabolic disease. Nature 2011;478:110-3.

54. Arner E, Westermark PO, Spalding KL, et al. Adipocyte turnover: relevance to human adipose tissue morphology. Diabetes 2010;59:105-9. 
55. Krotkiewski M, Bjorntorp P, Sjostrom L, Smith U. Impact of obesity on metabolism in men and women. Importance of regional adipose tissue distribution. The Journal of clinical investigation 1983;72:1150-62.

56. Faust IM, Johnson PR, Stern JS, Hirsch J. Diet-induced adipocyte number increase in adult rats: a new model of obesity. Am J Physiol 1978;235:E279-86.

57. Srdic B, Stokic E, Korac A, Ukropina M, Velickovic K, Breberina M. Morphological characteristics of abdominal adipose tissue in normal-weight and obese women of different metabolic profiles. Exp Clin Endocrinol Diabetes 2010;118:713-8.

58. Lonn M, Mehlig K, Bengtsson C, Lissner L. Adipocyte size predicts incidence of type 2 diabetes in women. FASEB J 2010;24:326-31.

59. Drolet R, Richard C, Sniderman AD, et al. Hypertrophy and hyperplasia of abdominal adipose tissues in women. Int J Obes (Lond) 2008;32:283-91.

60. Kim SM, Lun M, Wang M, et al. Loss of white adipose hyperplastic potential is associated with enhanced susceptibility to insulin resistance. Cell metabolism 2014;20:1049-58.

61. Tran TT, Kahn CR. Transplantation of adipose tissue and stem cells: role in metabolism and disease. Nature reviews Endocrinology 2010;6:195-213.

62. Dubois SG, Heilbronn LK, Smith SR, et al. Decreased expression of adipogenic genes in obese subjects with type 2 diabetes. Obesity 2006;14:1543-52.

63. Lundgren M, Svensson M, Lindmark S, Renstrom F, Ruge T, Eriksson JW. Fat cell enlargement is an independent marker of insulin resistance and 'hyperleptinaemia'. Diabetologia 2007;50:625-33.

64. Pasarica M, Xie H, Hymel D, et al. Lower total adipocyte number but no evidence for small adipocyte depletion in patients with type 2 diabetes. Diabetes care 2009;32:9002 .

65. van Tienen FH, van der Kallen CJ, Lindsey PJ, Wanders RJ, van Greevenbroek MM, Smeets HJ. Preadipocytes of type 2 diabetes subjects display an intrinsic gene expression profile of decreased differentiation capacity. Int $J$ Obes (Lond) 2011;35:1154-64.

66. De Pauw A, Tejerina S, Raes M, Keijer J, Arnould T. Mitochondrial (dys)function in adipocyte (de)differentiation and systemic metabolic alterations. Am J Pathol 2009;175:927-39.

67. Joe AW, Yi L, Even Y, Vogl AW, Rossi FM. Depot-specific differences in adipogenic progenitor abundance and proliferative response to high-fat diet. Stem cells 2009;27:2563-70.

68. San Martin N, Galvez BG. A new paradigm for the understanding of obesity: the role of stem cells. Arch Physiol Biochem 2011;117:188-94.

69. Ros Perez M, Medina-Gomez G. [Obesity, adipogenesis and insulin resistance]. Endocrinol Nutr 2011;58:360-9.

70. Cristancho AG, Lazar MA. Forming functional fat: a growing understanding of adipocyte differentiation. Nature reviews Molecular cell biology 2011;12:722-34.

71. Mariman EC, Wang P. Adipocyte extracellular matrix composition, dynamics and role in obesity. Cell Mol Life Sci 2011;67:1277-92.

72. Brakenhielm E, Cao R, Gao B, et al. Angiogenesis inhibitor, TNP-470, prevents dietinduced and genetic obesity in mice. Circ Res 2004;94:1579-88.

73. Opie LH, Walfish PG. Plasma free fatty acid concentrations in obesity. The New England journal of medicine 1963;268:757-60. 
74. Lafontan M, Langin D. Lipolysis and lipid mobilization in human adipose tissue. Progress in lipid research 2009;48:275-97.

75. Karpe F, Dickmann JR, Frayn KN. Fatty acids, obesity, and insulin resistance: time for a reevaluation. Diabetes 2011;60:2441-9.

76. Mittendorfer B, Magkos F, Fabbrini E, Mohammed BS, Klein S. Relationship between body fat mass and free fatty acid kinetics in men and women. Obesity 2009;17:1872-7.

77. Jocken JW, Goossens GH, van Hees AM, et al. Effect of beta-adrenergic stimulation on whole-body and abdominal subcutaneous adipose tissue lipolysis in lean and obese men. Diabetologia 2008;51:320-7.

78. Reynisdottir S, Eriksson M, Angelin B, Arner P. Impaired activation of adipocyte lipolysis in familial combined hyperlipidemia. The Journal of clinical investigation 1995;95:2161-9.

79. Bougneres P, Stunff CL, Pecqueur C, Pinglier E, Adnot P, Ricquier D. In vivo resistance of lipolysis to epinephrine. A new feature of childhood onset obesity. The Journal of clinical investigation 1997;99:2568-73.

80. Enoksson S, Talbot M, Rife F, Tamborlane WV, Sherwin RS, Caprio S. Impaired in vivo stimulation of lipolysis in adipose tissue by selective beta2-adrenergic agonist in obese adolescent girls. Diabetes 2000;49:2149-53.

81. Hellstrom L, Langin D, Reynisdottir S, Dauzats M, Arner P. Adipocyte lipolysis in normal weight subjects with obesity among first-degree relatives. Diabetologia 1996;39:921-8.

82. Campbell PJ, Carlson MG, Nurjhan N. Fat metabolism in human obesity. Am J Physiol 1994;266:E600-5.

83. Nellemann B, Gormsen LC, Sorensen LP, Christiansen JS, Nielsen S. Impaired insulin-mediated antilipolysis and lactate release in adipose tissue of upper-body obese women. Obesity 2012;20:57-64.

84. Roust LR, Jensen MD. Postprandial free fatty acid kinetics are abnormal in upper body obesity. Diabetes 1993;42:1567-73.

85. Kersten S. Physiological regulation of lipoprotein lipase. Biochim Biophys Acta 2014;1841:919-33.

86. Abumrad N, Coburn C, Ibrahimi A. Membrane proteins implicated in long-chain fatty acid uptake by mammalian cells: CD36, FATP and FABPm. Biochim Biophys Acta 1999;1441:4-13.

87. Goldberg IJ, Eckel RH, Abumrad NA. Regulation of fatty acid uptake into tissues: lipoprotein lipase- and CD36-mediated pathways. Journal of lipid research 2009;50 Suppl:S86-90.

88. Wang Y, Van Oort MM, Yao M, Van der Horst DJ, Rodenburg KW. Insulin and chromium picolinate induce translocation of CD36 to the plasma membrane through different signaling pathways in 3T3-L1 adipocytes, and with a differential functionality of the CD36. Biol Trace Elem Res 2011;142:735-47.

89. Stahl A, Evans JG, Pattel S, Hirsch D, Lodish HF. Insulin causes fatty acid transport protein translocation and enhanced fatty acid uptake in adipocytes. Dev Cell 2002;2:477-88.

90. Claycombe KJ, Jones BH, Standridge MK, et al. Insulin increases fatty acid synthase gene transcription in human adipocytes. Am J Physiol 1998;274:R1253-9. 
91. Puga GM, Meyer C, Mandarino LJ, Katsanos CS. Postprandial spillover of dietary lipid into plasma is increased with moderate amounts of ingested fat and is inversely related to adiposity in healthy older men. The Journal of nutrition 2012;142:1806-11.

92. Potts JL, Coppack SW, Fisher RM, Humphreys SM, Gibbons GF, Frayn KN. Impaired postprandial clearance of triacylglycerol-rich lipoproteins in adipose tissue in obese subjects. Am J Physiol 1995;268:E588-94.

93. Fielding B. Tracing the fate of dietary fatty acids: metabolic studies of postprandial lipaemia in human subjects. The Proceedings of the Nutrition Society 2011;70:34250 .

94. Sotornik R, Brassard P, Martin E, Yale P, Carpentier AC, Ardilouze JL. Update on adipose tissue blood flow regulation. American journal of physiology Endocrinology and metabolism 2012;302:E1157-70.

95. Andersson J, Karpe F, Sjostrom LG, Riklund K, Soderberg S, Olsson T. Association of adipose tissue blood flow with fat depot sizes and adipokines in women. Int J Obes (Lond) 2011.

96. Rutkowski JM, Davis KE, Scherer PE. Mechanisms of obesity and related pathologies: the macro- and microcirculation of adipose tissue. FEBS J 2009;276:5738-46.

97. Blaak EE, van Baak MA, Kemerink GJ, Pakbiers MT, Heidendal GA, Saris WH. Beta-adrenergic stimulation and abdominal subcutaneous fat blood flow in lean, obese, and reduced-obese subjects. Metabolism 1995;44:183-7.

98. Goossens GH, Jocken JW, Blaak EE, Schiffers PM, Saris WH, van Baak MA. Endocrine role of the renin-angiotensin system in human adipose tissue and muscle: effect of beta-adrenergic stimulation. Hypertension 2007;49:542-7.

99. Jansson PA, Larsson A, Lonnroth PN. Relationship between blood pressure, metabolic variables and blood flow in obese subjects with or without non-insulindependent diabetes mellitus. Eur J Clin Invest 1998;28:813-8.

100. Summers LK, Samra JS, Humphreys SM, Morris RJ, Frayn KN. Subcutaneous abdominal adipose tissue blood flow: variation within and between subjects and relationship to obesity. Clin Sci (Lond) 1996;91:679-83.

101. Virtanen KA, Lonnroth P, Parkkola R, et al. Glucose uptake and perfusion in subcutaneous and visceral adipose tissue during insulin stimulation in nonobese and obese humans. J Clin Endocrinol Metab 2002;87:3902-10.

102. Ouchi N, Parker JL, Lugus JJ, Walsh K. Adipokines in inflammation and metabolic disease. Nature reviews Immunology 2011;11:85-97.

103. Yamauchi T, Kamon J, Waki H, et al. The fat-derived hormone adiponectin reverses insulin resistance associated with both lipoatrophy and obesity. Nature medicine 2001;7:941-6.

104. Considine RV, Sinha MK, Heiman ML, et al. Serum immunoreactive-leptin concentrations in normal-weight and obese humans. The New England journal of medicine 1996;334:292-5.

105. Berg AH, Combs TP, Du X, Brownlee M, Scherer PE. The adipocyte-secreted protein Acrp30 enhances hepatic insulin action. Nature medicine 2001;7:947-53.

106. Yoon MJ, Lee GY, Chung JJ, Ahn YH, Hong SH, Kim JB. Adiponectin increases fatty acid oxidation in skeletal muscle cells by sequential activation of AMP-activated protein kinase, p38 mitogen-activated protein kinase, and peroxisome proliferatoractivated receptor alpha. Diabetes 2006;55:2562-70. 
107. Iwabu M, Yamauchi T, Okada-Iwabu M, et al. Adiponectin and AdipoR1 regulate PGC-1alpha and mitochondria by $\mathrm{Ca}(2+)$ and AMPK/SIRT1. Nature 2010;464:13139.

108. Yamauchi T, Kamon J, Minokoshi Y, et al. Adiponectin stimulates glucose utilization and fatty-acid oxidation by activating AMP-activated protein kinase. Nature medicine 2002;8:1288-95.

109. Turer AT, Khera A, Ayers CR, et al. Adipose tissue mass and location affect circulating adiponectin levels. Diabetologia 2011;54:2515-24.

110. Cnop M, Havel PJ, Utzschneider KM, et al. Relationship of adiponectin to body fat distribution, insulin sensitivity and plasma lipoproteins: evidence for independent roles of age and sex. Diabetologia 2003;46:459-69.

111. Adamska A, Nikolajuk A, Karczewska-Kupczewska M, et al. Relationships between serum adiponectin and soluble TNF-alpha receptors and glucose and lipid oxidation in lean and obese subjects. Acta Diabetol 2011;49:17-24.

112. Bredella MA, Torriani M, Ghomi RH, et al. Adiponectin is inversely associated with intramyocellular and intrahepatic lipids in obese premenopausal women. Obesity 2011;19:911-6.

113. Liu Y, Palanivel R, Rai E, et al. Adiponectin stimulates autophagy and reduces oxidative stress to enhance insulin sensitivity during high-fat diet feeding in mice. Diabetes 2015;64:36-48.

114. Couillard C, Mauriege $P$, Imbeault $P$, et al. Hyperleptinemia is more closely associated with adipose cell hypertrophy than with adipose tissue hyperplasia. International journal of obesity and related metabolic disorders : journal of the International Association for the Study of Obesity 2000;24:782-8.

115. Lofgren P, Andersson I, Adolfsson B, et al. Long-term prospective and controlled studies demonstrate adipose tissue hypercellularity and relative leptin deficiency in the postobese state. J Clin Endocrinol Metab 2005;90:6207-13.

116. Perry RJ, Zhang XM, Zhang D, et al. Leptin reverses diabetes by suppression of the hypothalamic-pituitary-adrenal axis. Nature medicine 2014;20:759-63.

117. Gao S, Kinzig KP, Aja S, et al. Leptin activates hypothalamic acetyl-CoA carboxylase to inhibit food intake. Proceedings of the National Academy of Sciences of the United States of America 2007;104:17358-63.

118. Gautron L, Elmquist JK. Sixteen years and counting: an update on leptin in energy balance. The Journal of clinical investigation 2011;121:2087-93.

119. Keung W, Palaniyappan A, Lopaschuk GD. Chronic central leptin decreases food intake and improves glucose tolerance in diet-induced obese mice independent of hypothalamic malonyl CoA levels and skeletal muscle insulin sensitivity. Endocrinology 2011;152:4127-37.

120. Henry BA, Andrews ZB, Rao A, Clarke IJ. Central leptin activates mitochondrial function and increases heat production in skeletal muscle. Endocrinology 2011;152:2609-18.

121. Rosenbaum M, Murphy EM, Heymsfield SB, Matthews DE, Leibel RL. Low dose leptin administration reverses effects of sustained weight-reduction on energy expenditure and circulating concentrations of thyroid hormones. J Clin Endocrinol Metab 2002;87:2391-4.

122. Shimomura I, Hammer RE, Ikemoto S, Brown MS, Goldstein JL. Leptin reverses insulin resistance and diabetes mellitus in mice with congenital lipodystrophy. Nature 1999;401:73-6. 
123. Oral EA, Simha V, Ruiz E, et al. Leptin-replacement therapy for lipodystrophy. The New England journal of medicine 2002;346:570-8.

124. Myers MG, Jr., Heymsfield SB, Haft C, et al. Challenges and opportunities of defining clinical leptin resistance. Cell metabolism 2012;15:150-6.

125. Hotamisligil GS, Shargill NS, Spiegelman BM. Adipose expression of tumor necrosis factor-alpha: direct role in obesity-linked insulin resistance. Science 1993;259:87-91.

126. Brestoff JR, Artis D. Immune regulation of metabolic homeostasis in health and disease. Cell 2015;161:146-60.

127. Ozcan U, Cao Q, Yilmaz E, et al. Endoplasmic reticulum stress links obesity, insulin action, and type 2 diabetes. Science 2004;306:457-61.

128. Sharma NK, Das SK, Mondal AK, et al. Endoplasmic reticulum stress markers are associated with obesity in nondiabetic subjects. J Clin Endocrinol Metab 2008;93:4532-41.

129. Boden G, Duan X, Homko C, et al. Increase in endoplasmic reticulum stress-related proteins and genes in adipose tissue of obese, insulin-resistant individuals. Diabetes 2008;57:2438-44.

130. Walter P, Ron D. The unfolded protein response: from stress pathway to homeostatic regulation. Science 2011;334:1081-6.

131. Hotamisligil GS, Erbay E. Nutrient sensing and inflammation in metabolic diseases. Nature reviews Immunology 2008;8:923-34.

132. Odegaard JI, Chawla A. Pleiotropic actions of insulin resistance and inflammation in metabolic homeostasis. Science 2013;339:172-7.

133. Calay ES, Hotamisligil GS. Turning off the inflammatory, but not the metabolic, flames. Nature medicine 2013;19:265-7.

134. Glass CK, Olefsky JM. Inflammation and lipid signaling in the etiology of insulin resistance. Cell metabolism 2012;15:635-45.

135. Bai Y, Sun Q. Macrophage recruitment in obese adipose tissue. Obesity reviews : an official journal of the International Association for the Study of Obesity 2015;16:12736.

136. Weisberg SP, McCann D, Desai M, Rosenbaum M, Leibel RL, Ferrante AW, Jr. Obesity is associated with macrophage accumulation in adipose tissue. The Journal of clinical investigation 2003;112:1796-808.

137. Kosteli A, Sugaru E, Haemmerle G, et al. Weight loss and lipolysis promote a dynamic immune response in murine adipose tissue. The Journal of clinical investigation 2010;120:3466-79.

138. Lumeng CN, Bodzin JL, Saltiel AR. Obesity induces a phenotypic switch in adipose tissue macrophage polarization. The Journal of clinical investigation 2007;117:17584.

139. Chawla A, Nguyen KD, Goh YP. Macrophage-mediated inflammation in metabolic disease. Nature reviews Immunology 2011;11:738-49.

140. Sica A, Mantovani A. Macrophage plasticity and polarization: in vivo veritas. The Journal of clinical investigation 2012;122:787-95.

141. Kratz M, Coats BR, Hisert KB, et al. Metabolic dysfunction drives a mechanistically distinct proinflammatory phenotype in adipose tissue macrophages. Cell metabolism 2014;20:614-25.

142. Lumeng CN, Saltiel AR. Inflammatory links between obesity and metabolic disease. The Journal of clinical investigation 2011;121:2111-7. 
143. Cawthorn WP, Sethi JK. TNF-alpha and adipocyte biology. FEBS Lett 2008;582:11731 .

144. Gregor MF, Yang L, Fabbrini E, et al. Endoplasmic reticulum stress is reduced in tissues of obese subjects after weight loss. Diabetes 2009;58:693-700.

145. Karpe F, Pinnick KE. Biology of upper-body and lower-body adipose tissue--link to whole-body phenotypes. Nature reviews Endocrinology 2015;11:90-100.

146. Tchkonia $\mathrm{T}$, Thomou $\mathrm{T}$, Zhu Y, et al. Mechanisms and metabolic implications of regional differences among fat depots. Cell metabolism 2013;17:644-56.

147. Ibrahim MM. Subcutaneous and visceral adipose tissue: structural and functional differences. Obesity reviews : an official journal of the International Association for the Study of Obesity 2010;11:11-8.

148. Fox CS, Massaro JM, Hoffmann U, et al. Abdominal visceral and subcutaneous adipose tissue compartments: association with metabolic risk factors in the Framingham Heart Study. Circulation 2007;116:39-48.

149. Mundi MS, Karpyak MV, Koutsari C, Votruba SB, O'Brien PC, Jensen MD. Body fat distribution, adipocyte size, and metabolic characteristics of nondiabetic adults. J Clin Endocrinol Metab 2010;95:67-73.

150. Marinou K, Hodson L, Vasan SK, et al. Structural and functional properties of deep abdominal subcutaneous adipose tissue explain its association with insulin resistance and cardiovascular risk in men. Diabetes care 2014;37:821-9.

151. Casey BA, Kohrt WM, Schwartz RS, Van Pelt RE. Subcutaneous adipose tissue insulin resistance is associated with visceral adiposity in postmenopausal women. Obesity 2014;22:1458-63.

152. Sondergaard E, Nellemann B, Sorensen LP, et al. Similar VLDL-TG storage in visceral and subcutaneous fat in obese and lean women. Diabetes 2011;60:2787-91.

153. Jensen MD, Sarr MG, Dumesic DA, Southorn PA, Levine JA. Regional uptake of meal fatty acids in humans. American journal of physiology Endocrinology and metabolism 2003;285:E1282-8.

154. Votruba SB, Mattison RS, Dumesic DA, Koutsari C, Jensen MD. Meal fatty acid uptake in visceral fat in women. Diabetes 2007;56:2589-97.

155. Jensen MD. Gender differences in regional fatty acid metabolism before and after meal ingestion. The Journal of clinical investigation 1995;96:2297-303.

156. Jensen MD. Is visceral fat involved in the pathogenesis of the metabolic syndrome? Human model. Obesity 2006;14 Suppl 1:20S-4S.

157. Rocha PM, Barata JT, Minderico CS, Silva AM, Teixeira PJ, Sardinha LB. Visceral abdominal and subfascial femoral adipose tissue have opposite associations with liver fat in overweight and obese premenopausal caucasian women. $J$ Lipids 2011;2011:154672.

158. Nielsen S, Karpe F. Determinants of VLDL-triglycerides production. Current opinion in lipidology 2012;23:321-6.

159. Alexopoulos N, Katritsis D, Raggi P. Visceral adipose tissue as a source of inflammation and promoter of atherosclerosis. Atherosclerosis 2014;233:104-12.

160. Tchkonia T, Morbeck DE, Von Zglinicki T, et al. Fat tissue, aging, and cellular senescence. Aging cell 2010;9:667-84.

161. Kummitha CM, Kalhan SC, Saidel GM, Lai N. Relating tissue/organ energy expenditure to metabolic fluxes in mouse and human: experimental data integrated with mathematical modeling. Physiological reports 2014;2. 
162. Adiels M, Westerbacka J, Soro-Paavonen A, et al. Acute suppression of VLDL1 secretion rate by insulin is associated with hepatic fat content and insulin resistance. Diabetologia 2007;50:2356-65.

163. Shojaee-Moradie F, Ma Y, Lou S, Hovorka R, Umpleby AM. Prandial hypertriglyceridemia in metabolic syndrome is due to an overproduction of both chylomicron and VLDL triacylglycerol. Diabetes 2013;62:4063-9.

164. Barrows BR, Timlin MT, Parks EJ. Spillover of dietary fatty acids and use of serum nonesterified fatty acids for the synthesis of VLDL-triacylglycerol under two different feeding regimens. Diabetes 2005;54:2668-73.

165. Bissonnette S, Salem H, Wassef H, et al. Low density lipoprotein delays clearance of triglyceride-rich lipoprotein by human subcutaneous adipose tissue. Journal of lipid research 2013;54:1466-76.

166. Donnelly KL, Smith CI, Schwarzenberg SJ, Jessurun J, Boldt MD, Parks EJ. Sources of fatty acids stored in liver and secreted via lipoproteins in patients with nonalcoholic fatty liver disease. The Journal of clinical investigation 2005;115:1343-51.

167. Hodson L, McQuaid SE, Humphreys SM, et al. Greater dietary fat oxidation in obese compared with lean men: an adaptive mechanism to prevent liver fat accumulation? American journal of physiology Endocrinology and metabolism 2010;299:E584-92.

168. Ratziu V, Giral P, Charlotte F, et al. Liver fibrosis in overweight patients. Gastroenterology 2000;118:1117-23.

169. Bellentani S, Saccoccio G, Masutti F, et al. Prevalence of and risk factors for hepatic steatosis in Northern Italy. Ann Intern Med 2000;132:112-7.

170. Fabbrini E, Sullivan S, Klein S. Obesity and nonalcoholic fatty liver disease: biochemical, metabolic, and clinical implications. Hepatology 2010;51:679-89.

171. Meshkani R, Adeli K. Hepatic insulin resistance, metabolic syndrome and cardiovascular disease. Clin Biochem 2009;42:1331-46.

172. Kim JY, Park JH, Jeong SW, et al. High levels of remnant lipoprotein cholesterol is a risk factor for large artery atherosclerotic stroke. J Clin Neurol 2011;7:203-9.

173. Jornayvaz FR, Shulman GI. Diacylglycerol activation of protein kinase Cepsilon and hepatic insulin resistance. Cell metabolism 2012;15:574-84.

174. Bikman BT, Summers SA. Ceramides as modulators of cellular and whole-body metabolism. The Journal of clinical investigation 2011;121:4222-30.

175. Bashan N, Kovsan J, Kachko I, Ovadia H, Rudich A. Positive and negative regulation of insulin signaling by reactive oxygen and nitrogen species. Physiological reviews 2009;89:27-71.

176. Fu S, Watkins SM, Hotamisligil GS. The role of endoplasmic reticulum in hepatic lipid homeostasis and stress signaling. Cell metabolism 2012;15:623-34.

177. Park EJ, Lee JH, Yu GY, et al. Dietary and genetic obesity promote liver inflammation and tumorigenesis by enhancing IL-6 and TNF expression. Cell 2010;140:197-208.

178. Sidossis LS, Mittendorfer B, Walser E, Chinkes D, Wolfe RR. Hyperglycemiainduced inhibition of splanchnic fatty acid oxidation increases hepatic triacylglycerol secretion. Am J Physiol 1998;275:E798-805.

179. Ravussin E, Lillioja S, Anderson TE, Christin L, Bogardus C. Determinants of 24hour energy expenditure in man. Methods and results using a respiratory chamber. The Journal of clinical investigation 1986;78:1568-78.

180. Muoio DM. Metabolic inflexibility: when mitochondrial indecision leads to metabolic gridlock. Cell 2014;159:1253-62. 
181. Moors CC, van der Zij1 NJ, Diamant M, Blaak EE, Goossens GH. Impaired insulin sensitivity is accompanied by disturbances in skeletal muscle fatty acid handling in subjects with impaired glucose metabolism. Int J Obes (Lond) 2012;36:709-17.

182. Bonen A, Parolin ML, Steinberg GR, et al. Triacylglycerol accumulation in human obesity and type 2 diabetes is associated with increased rates of skeletal muscle fatty acid transport and increased sarcolemmal FAT/CD36. FASEB J 2004;18:1144-6.

183. Farese RV, Jr., Yost TJ, Eckel RH. Tissue-specific regulation of lipoprotein lipase activity by insulin/glucose in normal-weight humans. Metabolism 1991;40:214-6.

184. Bickerton AS, Roberts R, Fielding BA, et al. Preferential uptake of dietary Fatty acids in adipose tissue and muscle in the postprandial period. Diabetes 2007;56:168-76.

185. van Hees AM, Jans A, Hul GB, Roche HM, Saris WH, Blaak EE. Skeletal muscle fatty acid handling in insulin resistant men. Obesity 2011;19:1350-9.

186. Brunzell JD, Hazzard WR, Porte D, Jr., Bierman EL. Evidence for a common, saturable, triglyceride removal mechanism for chylomicrons and very low density lipoproteins in man. The Journal of clinical investigation 1973;52:1578-85.

187. Blaak EE, Schiffelers SL, Saris WH, Mensink M, Kooi ME. Impaired betaadrenergically mediated lipolysis in skeletal muscle of obese subjects. Diabetologia 2004;47:1462-8.

188. Jocken JW, Roepstorff C, Goossens GH, et al. Hormone-sensitive lipase serine phosphorylation and glycerol exchange across skeletal muscle in lean and obese subjects: effect of beta-adrenergic stimulation. Diabetes 2008;57:1834-41.

189. Haemmerle G, Moustafa T, Woelkart G, et al. ATGL-mediated fat catabolism regulates cardiac mitochondrial function via PPAR-alpha and PGC-1. Nature medicine 2011;17:1076-85.

190. Meex RC, Hoy AJ, Mason RM, et al. ATGL-mediated triglyceride turnover and the regulation of mitochondrial capacity in skeletal muscle. American journal of physiology Endocrinology and metabolism 2015;308:E960-70.

191. Jocken JW, Goossens GH, Boon H, et al. Insulin-mediated suppression of lipolysis in adipose tissue and skeletal muscle of obese type 2 diabetic men and men with normal glucose tolerance. Diabetologia 2013;56:2255-65.

192. Kim JK, Fillmore JJ, Chen Y, et al. Tissue-specific overexpression of lipoprotein lipase causes tissue-specific insulin resistance. Proceedings of the National Academy of Sciences of the United States of America 2001;98:7522-7.

193. Goodpaster BH, He J, Watkins S, Kelley DE. Skeletal muscle lipid content and insulin resistance: evidence for a paradox in endurance-trained athletes. J Clin Endocrinol Metab 2001;86:5755-61.

194. Hulver MW, Berggren JR, Carper MJ, et al. Elevated stearoyl-CoA desaturase-1 expression in skeletal muscle contributes to abnormal fatty acid partitioning in obese humans. Cell metabolism 2005;2:251-61.

195. Bergman BC, Perreault L, Hunerdosse DM, Koehler MC, Samek AM, Eckel RH. Intramuscular lipid metabolism in the insulin resistance of smoking. Diabetes 2009;58:2220-7.

196. Perreault L, Bergman BC, Hunerdosse DM, Playdon MC, Eckel RH. Inflexibility in intramuscular triglyceride fractional synthesis distinguishes prediabetes from obesity in humans. Obesity 2010;18:1524-31.

197. Sparks LM, Bosma M, Brouwers B, et al. Reduced incorporation of fatty acids into triacylglycerol in myotubes from obese individuals with type 2 diabetes. Diabetes 2014;63:1583-93. 
198. Jans A, Konings E, Goossens GH, et al. PUFAs acutely affect triacylglycerol-derived skeletal muscle fatty acid uptake and increase postprandial insulin sensitivity. The American journal of clinical nutrition 2012;95:825-36.

199. Bergman BC, Hunerdosse DM, Kerege A, Playdon MC, Perreault L. Localisation and composition of skeletal muscle diacylglycerol predicts insulin resistance in humans. Diabetologia 2012;55:1140-50.

200. Timmers S, de Vogel-van den Bosch J, Hesselink MK, et al. Paradoxical increase in TAG and DAG content parallel the insulin sensitizing effect of unilateral DGAT1 overexpression in rat skeletal muscle. PloS one 2011;6:e14503.

201. Ukropcova B, McNeil M, Sereda O, et al. Dynamic changes in fat oxidation in human primary myocytes mirror metabolic characteristics of the donor. The Journal of clinical investigation 2005;115:1934-41.

202. Bell JA, Reed MA, Consitt LA, et al. Lipid partitioning, incomplete fatty acid oxidation, and insulin signal transduction in primary human muscle cells: effects of severe obesity, fatty acid incubation, and fatty acid translocase/CD36 overexpression. J Clin Endocrinol Metab 2010;95:3400-10.

203. Dube JJ, Coen PM, DiStefano G, et al. Effects of acute lipid overload on skeletal muscle insulin resistance, metabolic flexibility, and mitochondrial performance. American journal of physiology Endocrinology and metabolism 2014;307:E1117-24.

204. Bandyopadhyay GK, Yu JG, Ofrecio J, Olefsky JM. Increased malonyl-CoA levels in muscle from obese and type 2 diabetic subjects lead to decreased fatty acid oxidation and increased lipogenesis; thiazolidinedione treatment reverses these defects. Diabetes 2006;55:2277-85.

205. Simoneau JA, Veerkamp JH, Turcotte LP, Kelley DE. Markers of capacity to utilize fatty acids in human skeletal muscle: relation to insulin resistance and obesity and effects of weight loss. FASEB J 1999;13:2051-60.

206. Boyle KE, Canham JP, Consitt LA, et al. A high-fat diet elicits differential responses in genes coordinating oxidative metabolism in skeletal muscle of lean and obese individuals. J Clin Endocrinol Metab 2011;96:775-81.

207. Kim JY, Hickner RC, Cortright RL, Dohm GL, Houmard JA. Lipid oxidation is reduced in obese human skeletal muscle. American journal of physiology Endocrinology and metabolism 2000;279:E1039-44.

208. Hulver MW, Berggren JR, Cortright RN, et al. Skeletal muscle lipid metabolism with obesity. American journal of physiology Endocrinology and metabolism 2003;284:E741-7.

209. Kitzmann M, Lantier L, Hebrard S, Mercier J, Foretz M, Aguer C. Abnormal metabolism flexibility in response to high palmitate concentrations in myotubes derived from obese type 2 diabetic patients. Biochim Biophys Acta 2011;1812:42330 .

210. Corpeleijn E, Hessvik NP, Bakke SS, et al. Oxidation of intramyocellular lipids is dependent on mitochondrial function and the availability of extracellular fatty acids. American journal of physiology Endocrinology and metabolism 2010;299:E14-22.

211. Schmidt SL, Kealey EH, Horton TJ, VonKaenel S, Bessesen DH. The effects of shortterm overfeeding on energy expenditure and nutrient oxidation in obesity-prone and obesity-resistant individuals. Int J Obes (Lond) 2013;37:1192-7.

212. Astrup A, Buemann B, Christensen NJ, Toubro S. Failure to increase lipid oxidation in response to increasing dietary fat content in formerly obese women. Am J Physiol 1994;266:E592-9. 
213. Corpeleijn E, Mensink M, Kooi ME, Roekaerts PM, Saris WH, Blaak EE. Impaired skeletal muscle substrate oxidation in glucose-intolerant men improves after weight loss. Obesity 2008;16:1025-32.

214. Boden G, Jadali F, White J, et al. Effects of fat on insulin-stimulated carbohydrate metabolism in normal men. The Journal of clinical investigation 1991;88:960-6.

215. Ruderman NB, Saha AK, Vavvas D, Witters LA. Malonyl-CoA, fuel sensing, and insulin resistance. Am J Physiol 1999;276:E1-E18.

216. Faerch K, Vaag A. Metabolic inflexibility is a common feature of impaired fasting glycaemia and impaired glucose tolerance. Acta Diabetol 2011;48:349-53.

217. Chomentowski P, Coen PM, Radikova Z, Goodpaster BH, Toledo FG. Skeletal muscle mitochondria in insulin resistance: differences in intermyofibrillar versus subsarcolemmal subpopulations and relationship to metabolic flexibility. J Clin Endocrinol Metab 2011;96:494-503.

218. Ukropcova B, Sereda O, de Jonge L, et al. Family history of diabetes links impaired substrate switching and reduced mitochondrial content in skeletal muscle. Diabetes 2007;56:720-7.

219. Amati F, Dube JJ, Shay C, Goodpaster BH. Separate and combined effects of exercise training and weight loss on exercise efficiency and substrate oxidation. J Appl Physiol 2008;105:825-31.

220. Meex RC, Schrauwen-Hinderling VB, Moonen-Kornips E, et al. Restoration of muscle mitochondrial function and metabolic flexibility in type 2 diabetes by exercise training is paralleled by increased myocellular fat storage and improved insulin sensitivity. Diabetes 2010;59:572-9.

221. Bakkman L, Fernstrom M, Loogna P, Rooyackers O, Brandt L, Lagerros YT. Reduced respiratory capacity in muscle mitochondria of obese subjects. Obesity facts 2010;3:371-5.

222. Phielix E, Meex R, Ouwens DM, et al. High oxidative capacity due to chronic exercise training attenuates lipid-induced insulin resistance. Diabetes 2012;61:2472-8.

223. Phielix E, Schrauwen-Hinderling VB, Mensink M, et al. Lower intrinsic ADPstimulated mitochondrial respiration underlies in vivo mitochondrial dysfunction in muscle of male type 2 diabetic patients. Diabetes 2008;57:2943-9.

224. Blaak EE, van Aggel-Leijssen DP, Wagenmakers AJ, Saris WH, van Baak MA. Impaired oxidation of plasma-derived fatty acids in type 2 diabetic subjects during moderate-intensity exercise. Diabetes 2000;49:2102-7.

225. Sparks LM, Johannsen NM, Church TS, et al. Nine months of combined training improves ex vivo skeletal muscle metabolism in individuals with type 2 diabetes. $\mathrm{J}$ Clin Endocrinol Metab 2013;98:1694-702.

226. Muoio DM, Neufer PD. Lipid-induced mitochondrial stress and insulin action in muscle. Cell metabolism 2012;15:595-605.

227. Chance B, Williams GR. Respiratory enzymes in oxidative phosphorylation. I. Kinetics of oxygen utilization. The Journal of biological chemistry 1955;217:383-93.

228. Irving BA, Short KR, Nair KS, Stump CS. Nine days of intensive exercise training improves mitochondrial function but not insulin action in adult offspring of mothers with type 2 diabetes. J Clin Endocrinol Metab 2011;96:E1137-41.

229. Toledo FG, Menshikova EV, Ritov VB, et al. Effects of physical activity and weight loss on skeletal muscle mitochondria and relationship with glucose control in type 2 diabetes. Diabetes 2007;56:2142-7. 
230. Toledo FG, Watkins S, Kelley DE. Changes induced by physical activity and weight loss in the morphology of intermyofibrillar mitochondria in obese men and women. $\mathrm{J}$ Clin Endocrinol Metab 2006;91:3224-7.

231. Barbieri E, Agostini D, Polidori E, et al. The pleiotropic effect of physical exercise on mitochondrial dynamics in aging skeletal muscle. Oxidative medicine and cellular longevity 2015;2015:917085.

232. Schrauwen P, van Aggel-Leijssen DP, Hul G, et al. The effect of a 3-month lowintensity endurance training program on fat oxidation and acetyl-CoA carboxylase-2 expression. Diabetes 2002;51:2220-6.

233. Holloszy JO, Coyle EF. Adaptations of skeletal muscle to endurance exercise and their metabolic consequences. Journal of applied physiology: respiratory, environmental and exercise physiology 1984;56:831-8.

234. Smith BK, Perry CG, Herbst EA, et al. Submaximal ADP-stimulated respiration is impaired in ZDF rats and recovered by resveratrol. The Journal of physiology 2013;591:6089-101.

235. Blaak EE, Hul G, Verdich C, et al. Fat oxidation before and after a high fat load in the obese insulin-resistant state. J Clin Endocrinol Metab 2006;91:1462-9.

236. Koves TR, Ussher JR, Noland RC, et al. Mitochondrial overload and incomplete fatty acid oxidation contribute to skeletal muscle insulin resistance. Cell metabolism 2008;7:45-56.

237. Goodpaster BH. Mitochondrial deficiency is associated with insulin resistance. Diabetes 2013;62:1032-5.

238. Holloszy JO. "Deficiency" of mitochondria in muscle does not cause insulin resistance. Diabetes 2013;62:1036-40.

239. Schrauwen-Hinderling VB, Kooi ME, Hesselink MK, et al. Impaired in vivo mitochondrial function but similar intramyocellular lipid content in patients with type 2 diabetes mellitus and BMI-matched control subjects. Diabetologia 2007;50:113-20.

240. Mootha VK, Lindgren CM, Eriksson KF, et al. PGC-1alpha-responsive genes involved in oxidative phosphorylation are coordinately downregulated in human diabetes. Nature genetics 2003;34:267-73.

241. Patti ME, Butte AJ, Crunkhorn S, et al. Coordinated reduction of genes of oxidative metabolism in humans with insulin resistance and diabetes: Potential role of PGC1 and NRF1. Proceedings of the National Academy of Sciences of the United States of America 2003;100:8466-71.

242. Lowell BB, Shulman GI. Mitochondrial dysfunction and type 2 diabetes. Science 2005;307:384-7.

243. Bajpeyi S, Pasarica M, Moro C, et al. Skeletal muscle mitochondrial capacity and insulin resistance in type 2 diabetes. J Clin Endocrinol Metab 2011;96:1160-8.

244. Boushel R, Gnaiger E, Schjerling P, Skovbro M, Kraunsoe R, Dela F. Patients with type 2 diabetes have normal mitochondrial function in skeletal muscle. Diabetologia 2007;50:790-6.

245. Kelley DE, He J, Menshikova EV, Ritov VB. Dysfunction of mitochondria in human skeletal muscle in type 2 diabetes. Diabetes 2002;51:2944-50.

246. Liesa M, Shirihai OS. Mitochondrial dynamics in the regulation of nutrient utilization and energy expenditure. Cell metabolism 2013;17:491-506.

247. Schonfeld P, Wojtczak L. Fatty acids as modulators of the cellular production of reactive oxygen species. Free radical biology \& medicine 2008;45:231-41. 
248. Anderson EJ, Lustig ME, Boyle KE, et al. Mitochondrial H2O2 emission and cellular redox state link excess fat intake to insulin resistance in both rodents and humans. The Journal of clinical investigation 2009;119:573-81.

249. Bonnard C, Durand A, Peyrol S, et al. Mitochondrial dysfunction results from oxidative stress in the skeletal muscle of diet-induced insulin-resistant mice. The Journal of clinical investigation 2008;118:789-800.

250. Kim KH, Lee MS. Autophagy--a key player in cellular and body metabolism. Nature reviews Endocrinology 2014;10:322-37.

251. Yatsunenko T, Rey FE, Manary MJ, et al. Human gut microbiome viewed across age and geography. Nature 2012;486:222-7.

252. Goodrich JK, Waters JL, Poole AC, et al. Human genetics shape the gut microbiome. Cell 2014;159:789-99.

253. Cho I, Blaser MJ. The human microbiome: at the interface of health and disease. Nature reviews Genetics 2012;13:260-70.

254. Suez J, Korem T, Zeevi D, et al. Artificial sweeteners induce glucose intolerance by altering the gut microbiota. Nature 2014;514:181-6.

255. Delzenne NM, Neyrinck AM, Backhed F, Cani PD. Targeting gut microbiota in obesity: effects of prebiotics and probiotics. Nature reviews Endocrinology 2011;7:639-46.

256. David LA, Maurice CF, Carmody RN, et al. Diet rapidly and reproducibly alters the human gut microbiome. Nature 2014;505:559-63.

257. Wu GD, Chen J, Hoffmann $\mathrm{C}$, et al. Linking long-term dietary patterns with gut microbial enterotypes. Science 2011;334:105-8.

258. Tyakht AV, Kostryukova ES, Popenko AS, et al. Human gut microbiota community structures in urban and rural populations in Russia. Nature communications 2013;4:2469.

259. Zarrinpar A, Chaix A, Yooseph S, Panda S. Diet and feeding pattern affect the diurnal dynamics of the gut microbiome. Cell metabolism 2014;20:1006-17.

260. Backhed F, Ding H, Wang T, et al. The gut microbiota as an environmental factor that regulates fat storage. Proceedings of the National Academy of Sciences of the United States of America 2004;101:15718-23.

261. Turnbaugh PJ, Ley RE, Mahowald MA, Magrini V, Mardis ER, Gordon JI. An obesity-associated gut microbiome with increased capacity for energy harvest. Nature 2006;444:1027-31.

262. Ley RE, Turnbaugh PJ, Klein S, Gordon JI. Microbial ecology: human gut microbes associated with obesity. Nature 2006;444:1022-3.

263. Karlsson FH, Tremaroli V, Nookaew I, et al. Gut metagenome in European women with normal, impaired and diabetic glucose control. Nature 2013;498:99-103.

264. Arumugam M, Raes J, Pelletier E, et al. Enterotypes of the human gut microbiome. Nature 2011;473:174-80.

265. Eckburg PB, Bik EM, Bernstein CN, et al. Diversity of the human intestinal microbial flora. Science 2005;308:1635-8.

266. Human Microbiome Project C. Structure, function and diversity of the healthy human microbiome. Nature 2012;486:207-14.

267. Le Chatelier E, Nielsen T, Qin J, et al. Richness of human gut microbiome correlates with metabolic markers. Nature 2013;500:541-6.

268. Khan MT, Nieuwdorp M, Backhed F. Microbial modulation of insulin sensitivity. Cell metabolism 2014;20:753-60. 
269. Tilg H, Moschen AR. Microbiota and diabetes: an evolving relationship. Gut 2014;63:1513-21.

270. Nieuwdorp M, Gilijamse PW, Pai N, Kaplan LM. Role of the microbiome in energy regulation and metabolism. Gastroenterology 2014;146:1525-33.

271. Belkaid Y, Hand TW. Role of the microbiota in immunity and inflammation. Cell 2014;157:121-41.

272. Garrett WS. Cancer and the microbiota. Science 2015;348:80-6.

273. Ridaura V, Belkaid Y. Gut microbiota: the link to your second brain. Cell 2015;161:193-4.

274. Vrieze A, Van Nood E, Holleman F, et al. Transfer of intestinal microbiota from lean donors increases insulin sensitivity in individuals with metabolic syndrome. Gastroenterology 2012;143:913-6 e7.

275. Vrieze A, Out C, Fuentes S, et al. Impact of oral vancomycin on gut microbiota, bile acid metabolism, and insulin sensitivity. Journal of hepatology 2014;60:824-31.

276. Reijnders D, Goossens GH, Neis EP, et al. Effects of gut microbiota manipulation by antibiotics on host metabolism in obese humans. Obesity facts $2015 ; 8$.

277. Fernandes J, Su W, Rahat-Rozenbloom S, Wolever TM, Comelli EM. Adiposity, gut microbiota and faecal short chain fatty acids are linked in adult humans. Nutrition \& diabetes 2014;4:e121.

278. Canfora EE, van der Beek CM, Goossens GH, et al. Colonic short-chain fatty acids infusions promote fat oxidation and improve metabolic parameters in overweight males. Obesity facts 2015;8.

279. Canfora EE, van der Beek CM, Lenaerts K, et al. Colonic Acetate Infusions Promote Fat Oxidation and Improve Metabolic Parameters in Overweight Males. Diabetes 2014;63.

280. Kuipers F, Bloks VW, Groen AK. Beyond intestinal soap--bile acids in metabolic control. Nature reviews Endocrinology 2014;10:488-98.

281. Sharon G, Garg N, Debelius J, Knight R, Dorrestein PC, Mazmanian SK. Specialized metabolites from the microbiome in health and disease. Cell metabolism 2014;20:71930 .

282. Cremers CM, Knoefler D, Vitvitsky V, Banerjee R, Jakob U. Bile salts act as effective protein-unfolding agents and instigators of disulfide stress in vivo. Proceedings of the National Academy of Sciences of the United States of America 2014;111:E1610-9.

283. Sayin SI, Wahlstrom A, Felin J, et al. Gut microbiota regulates bile acid metabolism by reducing the levels of tauro-beta-muricholic acid, a naturally occurring FXR antagonist. Cell metabolism 2013;17:225-35.

284. Erny D, Hrabe de Angelis AL, Jaitin D, et al. Host microbiota constantly control maturation and function of microglia in the CNS. Nature neuroscience 2015;18:96577.

285. Garidou L, Pomie C, Klopp P, et al. The Gut Microbiota Regulates Intestinal CD4 T Cells Expressing RORgammat and Controls Metabolic Disease. Cell metabolism 2015;22:100-12.

286. Markle JG, Frank DN, Mortin-Toth S, et al. Sex differences in the gut microbiome drive hormone-dependent regulation of autoimmunity. Science 2013;339:1084-8.

287. Howitz KT, Sinclair DA. Xenohormesis: sensing the chemical cues of other species. Cell 2008;133:387-91.

288. Surh YJ. Xenohormesis mechanisms underlying chemopreventive effects of some dietary phytochemicals. Ann N Y Acad Sci 2011;1229:1-6. 
289. Kao YH, Hiipakka RA, Liao S. Modulation of endocrine systems and food intake by green tea epigallocatechin gallate. Endocrinology 2000;141:980-7.

290. Burns J, Yokota T, Ashihara H, Lean ME, Crozier A. Plant foods and herbal sources of resveratrol. Journal of agricultural and food chemistry 2002;50:3337-40.

291. Kitada Y, Ueda Y, Yamamoto M, Ishikawa M, Nakazawa H, Fujita M. Determination of isoflavones in soy bean by high-performance liquid chromatography with amperometric detection. Journal of chromatography 1986;366:403-6.

292. Fujita Y, Yamane T, Tanaka M, et al. Inhibitory effect of (-)-epigallocatechin gallate on carcinogenesis with N-ethyl-N'-nitro-N-nitrosoguanidine in mouse duodenum. Japanese journal of cancer research : Gann 1989;80:503-5.

293. Jang M, Cai L, Udeani GO, et al. Cancer chemopreventive activity of resveratrol, a natural product derived from grapes. Science 1997;275:218-20.

294. Messina M, Barnes S. The role of soy products in reducing risk of cancer. Journal of the National Cancer Institute 1991;83:541-6.

295. Sasazuki S, Kodama H, Yoshimasu K, et al. Relation between green tea consumption and the severity of coronary atherosclerosis among Japanese men and women. Annals of Epidemiology 2000;10:401-8.

296. Imai K, Nakachi K. Cross sectional study of effects of drinking green tea on cardiovascular and liver diseases. BMJ 1995;310:693-6.

297. Wolfram S, Wang Y, Thielecke F. Anti-obesity effects of green tea: from bedside to bench. Mol Nutr Food Res 2006;50:176-87.

298. Dulloo AG, Duret C, Rohrer D, et al. Efficacy of a green tea extract rich in catechin polyphenols and caffeine in increasing 24-h energy expenditure and fat oxidation in humans. The American journal of clinical nutrition 1999;70:1040-5.

299. Lonac MC, Richards JC, Schweder MM, Johnson TK, Bell C. Influence of short-term consumption of the caffeine-free, epigallocatechin-3-gallate supplement, Teavigo, on resting metabolism and the thermic effect of feeding. Obesity 2011;19:298-304.

300. Mahler A, Steiniger J, Bock M, et al. Metabolic response to epigallocatechin-3-gallate in relapsing-remitting multiple sclerosis: a randomized clinical trial. The American journal of clinical nutrition 2015;101:487-95.

301. Hursel R, Janssens PL, Bouwman FG, Mariman EC, Westerterp-Plantenga MS. The role of catechol-O-methyl transferase Val(108/158)Met polymorphism (rs4680) in the effect of green tea on resting energy expenditure and fat oxidation: a pilot study. PloS one 2014;9:e106220.

302. Renaud S, de Lorgeril M. Wine, alcohol, platelets, and the French paradox for coronary heart disease. Lancet 1992;339:1523-6.

303. Frankel EN, Waterhouse AL, Kinsella JE. Inhibition of human LDL oxidation by resveratrol. Lancet 1993;341:1103-4.

304. Baur JA, Pearson KJ, Price NL, et al. Resveratrol improves health and survival of mice on a high-calorie diet. Nature 2006;444:337-42.

305. Howitz KT, Bitterman KJ, Cohen HY, et al. Small molecule activators of sirtuins extend Saccharomyces cerevisiae lifespan. Nature 2003;425:191-6.

306. Wood JG, Rogina B, Lavu S, et al. Sirtuin activators mimic caloric restriction and delay ageing in metazoans. Nature 2004;430:686-9.

307. Timmers S, Konings E, Bilet L, et al. Calorie restriction-like effects of 30 days of resveratrol supplementation on energy metabolism and metabolic profile in obese humans. Cell metabolism 2011;14:612-22. 
308. Chachay VS, Macdonald GA, Martin JH, et al. Resveratrol does not benefit patients with nonalcoholic fatty liver disease. Clinical gastroenterology and hepatology : the official clinical practice journal of the American Gastroenterological Association 2014;12:2092-103 e1-6.

309. Poulsen MM, Vestergaard PF, Clasen BF, et al. High-dose resveratrol supplementation in obese men: an investigator-initiated, randomized, placebocontrolled clinical trial of substrate metabolism, insulin sensitivity, and body composition. Diabetes 2013;62:1186-95.

310. Yoshino J, Conte C, Fontana L, et al. Resveratrol supplementation does not improve metabolic function in nonobese women with normal glucose tolerance. Cell metabolism 2012;16:658-64.

311. Erdman JW, Jr., Fordyce EJ. Soy products and the human diet. The American journal of clinical nutrition 1989;49:725-37.

312. Cederroth CR, Zimmermann C, Nef S. Soy, phytoestrogens and their impact on reproductive health. Molecular and cellular endocrinology 2011;355:192-200.

313. Mendez MA, Anthony MS, Arab L. Soy-based formulae and infant growth and development: a review. The Journal of nutrition 2002;132:2127-30.

314. Wei P, Liu M, Chen Y, Chen DC. Systematic review of soy isoflavone supplements on osteoporosis in women. Asian Pac J Trop Med 2012;5:243-8.

315. Dijsselbloem N, Vanden Berghe W, De Naeyer A, Haegeman G. Soy isoflavone phyto-pharmaceuticals in interleukin- 6 affections. Multi-purpose nutraceuticals at the crossroad of hormone replacement, anti-cancer and anti-inflammatory therapy. Biochem Pharmacol 2004;68:1171-85.

316. Dinsdale EC, Ward WE. Early exposure to soy isoflavones and effects on reproductive health: a review of human and animal studies. Nutrients 2010;2:1156-87.

317. Setchell KD, Zimmer-Nechemias L, Cai J, Heubi JE. Isoflavone content of infant formulas and the metabolic fate of these phytoestrogens in early life. The American journal of clinical nutrition 1998;68:1453S-61S.

318. Liu XX, Li SH, Chen JZ, et al. Effect of soy isoflavones on blood pressure: a metaanalysis of randomized controlled trials. Nutr Metab Cardiovasc Dis 2012;22:463-70.

319. Orgaard A, Jensen L. The effects of soy isoflavones on obesity. Experimental biology and medicine 2008;233:1066-80.

320. Rimbach G, Boesch-Saadatmandi C, Frank J, et al. Dietary isoflavones in the prevention of cardiovascular disease--a molecular perspective. Food Chem Toxicol 2008;46:1308-19.

321. Villa P, Costantini B, Suriano R, et al. The differential effect of the phytoestrogen genistein on cardiovascular risk factors in postmenopausal women: relationship with the metabolic status. J Clin Endocrinol Metab 2009;94:552-8.

322. Basu A, Sanchez K, Leyva MJ, et al. Green tea supplementation affects body weight, lipids, and lipid peroxidation in obese subjects with metabolic syndrome. J Am Coll Nutr 2010;29:31-40.

323. Brown AL, Lane J, Holyoak C, Nicol B, Mayes AE, Dadd T. Health effects of green tea catechins in overweight and obese men: a randomised controlled cross-over trial. Br J Nutr 2011;106:1880-9.

324. Suliburska J, Bogdanski P, Szulinska M, Stepien M, Pupek-Musialik D, Jablecka A. Effects of green tea supplementation on elements, total antioxidants, lipids, and glucose values in the serum of obese patients. Biol Trace Elem Res 2012;149:315-22. 
325. Roberts JD, Roberts MG, Tarpey MD, Weekes JC, Thomas CH. The effect of a decaffeinated green tea extract formula on fat oxidation, body composition and exercise performance. Journal of the International Society of Sports Nutrition 2015;12:1.

326. Bogdanski P, Suliburska J, Szulinska M, Stepien M, Pupek-Musialik D, Jablecka A. Green tea extract reduces blood pressure, inflammatory biomarkers, and oxidative stress and improves parameters associated with insulin resistance in obese, hypertensive patients. Nutrition research 2012;32:421-7.

327. Brown AL, Lane J, Coverly J, et al. Effects of dietary supplementation with the green tea polyphenol epigallocatechin-3-gallate on insulin resistance and associated metabolic risk factors: randomized controlled trial. Br J Nutr 2009;101:886-94.

328. Westerterp-Plantenga MS, Lejeune MP, Kovacs EM. Body weight loss and weight maintenance in relation to habitual caffeine intake and green tea supplementation. Obes Res 2005;13:1195-204.

329. Cardoso GA, Salgado JM, Cesar Mde C, Donado-Pestana CM. The effects of green tea consumption and resistance training on body composition and resting metabolic rate in overweight or obese women. Journal of medicinal food 2013;16:120-7.

330. Diepvens K, Kovacs EM, Vogels N, Westerterp-Plantenga MS. Metabolic effects of green tea and of phases of weight loss. Physiology \& behavior 2006;87:185-91.

331. Mielgo-Ayuso J, Barrenechea L, Alcorta P, Larrarte E, Margareto J, Labayen I. Effects of dietary supplementation with epigallocatechin-3-gallate on weight loss, energy homeostasis, cardiometabolic risk factors and liver function in obese women: randomised, double-blind, placebo-controlled clinical trial. Br J Nutr 2014;111:126371.

332. Hill AM, Coates AM, Buckley JD, Ross R, Thielecke F, Howe PRC. Can EGCG reduce abdominal fat in obese subjects? Journal of the American College of Nutrition 2007;26:396S-402S.

333. Wolfram S, Raederstorff D, Wang Y, Teixeira SR, Elste V, Weber P. TEAVIGO (epigallocatechin gallate) supplementation prevents obesity in rodents by reducing adipose tissue mass. Ann Nutr Metab 2005;49:54-63.

334. Chen YK, Cheung C, Reuhl KR, et al. Effects of green tea polyphenol (-)epigallocatechin-3-gallate on newly developed high-fat/Western-style diet-induced obesity and metabolic syndrome in mice. Journal of agricultural and food chemistry 2011;59:11862-71.

335. Klaus S, Pultz S, Thone-Reineke C, Wolfram S. Epigallocatechin gallate attenuates diet-induced obesity in mice by decreasing energy absorption and increasing fat oxidation. Int J Obes (Lond) 2005;29:615-23.

336. Sae-Tan S, Grove KA, Kennett MJ, Lambert JD. (-)-Epigallocatechin-3-gallate increases the expression of genes related to fat oxidation in the skeletal muscle of high fat-fed mice. Food Funct 2011;2:111-6.

337. Lee MS, Kim CT, Kim Y. Green tea (-)-epigallocatechin-3-gallate reduces body weight with regulation of multiple genes expression in adipose tissue of diet-induced obese mice. Ann Nutr Metab 2009;54:151-7.

338. Chen N, Bezzina R, Hinch E, et al. Green tea, black tea, and epigallocatechin modify body composition, improve glucose tolerance, and differentially alter metabolic gene expression in rats fed a high-fat diet. Nutrition research 2009;29:784-93. 
339. Moreno MF, De Laquila R, Okuda $\mathrm{MH}$, et al. Metabolic profile response to administration of epigallocatechin-3-gallate in high-fat-fed mice. Diabetology \& metabolic syndrome 2014;6:84.

340. Chen S, Osaki N, Shimotoyodome A. Green tea catechins enhance norepinephrineinduced lipolysis via a protein kinase A-dependent pathway in adipocytes. Biochem Biophys Res Commun 2015;461:1-7.

341. Lee MS, Kim Y. (-)-Epigallocatechin-3-gallate enhances uncoupling protein 2 gene expression in 3T3-L1 adipocytes. Biosci Biotechnol Biochem 2009;73:434-6.

342. Sakurai N, Mochizuki K, Kameji H, Shimada M, Goda T. (-)-Epigallocatechin gallate enhances the expression of genes related to insulin sensitivity and adipocyte differentiation in 3T3-L1 adipocytes at an early stage of differentiation. Nutrition 2009;25:1047-56.

343. Lisowska A, Stawinska-Witoszynska B, Bajerska J, Krzyzanowska P, Walkowiak J. Green tea influences intestinal assimilation of lipids in humans: a pilot study. European review for medical and pharmacological sciences 2015;19:209-14.

344. Acheson KJ, Zahorska-Markiewicz B, Pittet P, Anantharaman K, Jequier E. Caffeine and coffee: their influence on metabolic rate and substrate utilization in normal weight and obese individuals. The American journal of clinical nutrition 1980;33:989-97.

345. Berube-Parent S, Pelletier C, Dore J, Tremblay A. Effects of encapsulated green tea and Guarana extracts containing a mixture of epigallocatechin-3-gallate and caffeine on $24 \mathrm{~h}$ energy expenditure and fat oxidation in men. Br J Nutr 2005;94:432-6.

346. Hursel R, Westerterp-Plantenga MS. Consumption of milk-protein combined with green tea modulates diet-induced thermogenesis. Nutrients 2011;3:725-33.

347. Lu H, Meng X, Yang CS. Enzymology of methylation of tea catechins and inhibition of catechol-O-methyltransferase by (-)-epigallocatechin gallate. Drug metabolism and disposition: the biological fate of chemicals 2003;31:572-9.

348. Thielecke F, Rahn G, Bohnke J, et al. Epigallocatechin-3-gallate and postprandial fat oxidation in overweight/obese male volunteers: a pilot study. European journal of clinical nutrition 2010;64:704-13.

349. Boschmann M, Thielecke F. The effects of epigallocatechin-3-gallate on thermogenesis and fat oxidation in obese men: a pilot study. J Am Coll Nutr 2007;26:389S-95S.

350. Janssens PL, Hursel R, Westerterp-Plantenga MS. Long-term green tea extract supplementation does not affect fat absorption, resting energy expenditure, and body composition in adults. The Journal of nutrition 2015;145:864-70.

351. Gosselin C, Haman F. Effects of green tea extracts on non-shivering thermogenesis during mild cold exposure in young men. Br J Nutr 2013;110:282-8.

352. Gregersen NT, Bitz C, Krog-Mikkelsen I, et al. Effect of moderate intakes of different tea catechins and caffeine on acute measures of energy metabolism under sedentary conditions. Br J Nutr 2009;102:1187-94.

353. Bao S, Cao Y, Fan C, et al. Epigallocatechin gallate improves insulin signaling by decreasing toll-like receptor 4 (TLR4) activity in adipose tissues of high-fat diet rats. Mol Nutr Food Res 2014;58:677-86.

354. Kuzu N, Bahcecioglu IH, Dagli AF, Ozercan IH, Ustundag B, Sahin K. Epigallocatechin gallate attenuates experimental non-alcoholic steatohepatitis induced by high fat diet. J Gastroenterol Hepatol 2008;23:e465-70.

355. Liu HW, Chan YC, Wang MF, Wei CC, Chang SJ. Dietary (-)-epigallocatechin-3gallate supplementation counteracts aging-associated skeletal muscle insulin 
resistance and fatty liver in senescence-accelerated mouse. Journal of agricultural and food chemistry 2015.

356. Lagouge M, Argmann C, Gerhart-Hines Z, et al. Resveratrol improves mitochondrial function and protects against metabolic disease by activating SIRT1 and PGC-1alpha. Cell 2006;127:1109-22.

357. Price NL, Gomes AP, Ling AJ, et al. SIRT1 is required for AMPK activation and the beneficial effects of resveratrol on mitochondrial function. Cell metabolism 2012;15:675-90.

358. Um JH, Park SJ, Kang H, et al. AMP-activated protein kinase-deficient mice are resistant to the metabolic effects of resveratrol. Diabetes 2010;59:554-63.

359. Park SJ, Ahmad F, Philp A, et al. Resveratrol ameliorates aging-related metabolic phenotypes by inhibiting cAMP phosphodiesterases. Cell 2012;148:421-33.

360. Wu Z, Puigserver P, Andersson U, et al. Mechanisms controlling mitochondrial biogenesis and respiration through the thermogenic coactivator PGC-1. Cell 1999;98:115-24.

361. Leone TC, Lehman JJ, Finck BN, et al. PGC-1alpha deficiency causes multi-system energy metabolic derangements: muscle dysfunction, abnormal weight control and hepatic steatosis. PLoS biology 2005;3:e101.

362. Olesen J, Gliemann L, Bienso R, Schmidt J, Hellsten Y, Pilegaard H. Exercise training, but not resveratrol, improves metabolic and inflammatory status in skeletal muscle of aged men. The Journal of physiology 2014;592:1873-86.

363. Brasnyo P, Molnar GA, Mohas M, et al. Resveratrol improves insulin sensitivity, reduces oxidative stress and activates the Akt pathway in type 2 diabetic patients. Br $\mathrm{J}$ Nutr 2011;106:383-9.

364. Crandall JP, Oram V, Trandafirescu G, et al. Pilot study of resveratrol in older adults with impaired glucose tolerance. The journals of gerontology Series A, Biological sciences and medical sciences 2012;67:1307-12.

365. Hokayem M, Blond E, Vidal H, et al. Grape polyphenols prevent fructose-induced oxidative stress and insulin resistance in first-degree relatives of type 2 diabetic patients. Diabetes care 2013;36:1454-61.

366. van der Made SM, Plat J, Mensink RP. Resveratrol does not influence metabolic risk markers related to cardiovascular health in overweight and slightly obese subjects: a randomized, placebo-controlled crossover trial. PloS one 2015;10:e0118393.

367. Voduc N, la Porte C, Tessier C, Mallick R, Cameron DW. Effect of resveratrol on exercise capacity: a randomized placebo-controlled crossover pilot study. Applied physiology, nutrition, and metabolism = Physiologie appliquee, nutrition et metabolisme 2014;39:1183-7.

368. Movahed A, Nabipour I, Lieben Louis X, et al. Antihyperglycemic effects of short term resveratrol supplementation in type 2 diabetic patients. Evidence-based complementary and alternative medicine : eCAM 2013;2013:851267.

369. Cote CD, Rasmussen BA, Duca FA, et al. Resveratrol activates duodenal Sirt1 to reverse insulin resistance in rats through a neuronal network. Nature medicine 2015;21:498-505.

370. Konings E, Timmers S, Boekschoten MV, et al. The effects of 30 days resveratrol supplementation on adipose tissue morphology and gene expression patterns in obese men. Int J Obes (Lond) 2014;38:470-3. 
371. Chen LL, Zhang HH, Zheng J, et al. Resveratrol attenuates high-fat diet-induced insulin resistance by influencing skeletal muscle lipid transport and subsarcolemmal mitochondrial beta-oxidation. Metabolism 2011;60:1598-609.

372. Deng JY, Hsieh PS, Huang JP, Lu LS, Hung LM. Activation of estrogen receptor is crucial for resveratrol-stimulating muscular glucose uptake via both insulin-dependent and -independent pathways. Diabetes 2008;57:1814-23.

373. Zheng J, Chen LL, Zhang HH, Hu X, Kong W, Hu D. Resveratrol improves insulin resistance of catch-up growth by increasing mitochondrial complexes and antioxidant function in skeletal muscle. Metabolism 2012;61:954-65.

374. Kuiper GG, Lemmen JG, Carlsson B, et al. Interaction of estrogenic chemicals and phytoestrogens with estrogen receptor beta. Endocrinology 1998;139:4252-63.

375. Goodman-Gruen D, Kritz-Silverstein D. Usual dietary isoflavone intake is associated with cardiovascular disease risk factors in postmenopausal women. The Journal of nutrition 2001;131:1202-6.

376. Hermansen K, Sondergaard M, Hoie L, Carstensen M, Brock B. Beneficial effects of a soy-based dietary supplement on lipid levels and cardiovascular risk markers in type 2 diabetic subjects. Diabetes care 2001;24:228-33.

377. Merz-Demlow BE, Duncan AM, Wangen KE, et al. Soy isoflavones improve plasma lipids in normocholesterolemic, premenopausal women. The American journal of clinical nutrition 2000;71:1462-9.

378. Wiseman H, O'Reilly JD, Adlercreutz H, et al. Isoflavone phytoestrogens consumed in soy decrease $\mathrm{F}(2)$-isoprostane concentrations and increase resistance of low-density lipoprotein to oxidation in humans. The American journal of clinical nutrition 2000;72:395-400.

379. Xu X, Duncan AM, Merz BE, Kurzer MS. Effects of soy isoflavones on estrogen and phytoestrogen metabolism in premenopausal women. Cancer epidemiology, biomarkers \& prevention : a publication of the American Association for Cancer Research, cosponsored by the American Society of Preventive Oncology 1998;7:1101-8.

380. Kim MH, Kang KS, Lee YS. The inhibitory effect of genistein on hepatic steatosis is linked to visceral adipocyte metabolism in mice with diet-induced non-alcoholic fatty liver disease. Br J Nutr 2010;104:1333-42.

381. Lee YM, Choi JS, Kim MH, Jung MH, Lee YS, Song J. Effects of dietary genistein on hepatic lipid metabolism and mitochondrial function in mice fed high-fat diets. Nutrition 2006;22:956-64.

382. Ronis MJ, Chen Y, Badeaux J, Badger TM. Dietary soy protein isolate attenuates metabolic syndrome in rats via effects on PPAR, LXR, and SREBP signaling. The Journal of nutrition 2009;139:1431-8.

383. Weigt C, Hertrampf T, Kluxen FM, et al. Molecular effects of ER alpha- and betaselective agonists on regulation of energy homeostasis in obese female Wistar rats. Molecular and cellular endocrinology 2013;377:147-58.

384. Mezei O, Li Y, Mullen E, Ross-Viola JS, Shay NF. Dietary isoflavone supplementation modulates lipid metabolism via PPARalpha-dependent and independent mechanisms. Physiol Genomics 2006;26:8-14.

385. Arunkumar E, Anuradha CV. Genistein promotes insulin action through adenosine monophosphate-activated protein kinase activation and p70 ribosomal protein S6 kinase 1 inhibition in the skeletal muscle of mice fed a high energy diet. Nutrition research 2012;32:617-25. 
386. Cheong SH, Furuhashi K, Ito K, et al. Daidzein promotes glucose uptake through glucose transporter 4 translocation to plasma membrane in L6 myocytes and improves glucose homeostasis in Type 2 diabetic model mice. The Journal of nutritional biochemistry 2014;25:136-43.

387. Penza M, Montani C, Romani A, et al. Genistein affects adipose tissue deposition in a dose-dependent and gender-specific manner. Endocrinology 2006;147:5740-51.

388. Jonas JC, Plant TD, Gilon P, Detimary P, Nenquin M, Henquin JC. Multiple effects and stimulation of insulin secretion by the tyrosine kinase inhibitor genistein in normal mouse islets. Br J Pharmacol 1995;114:872-80.

389. Sorenson RL, Brelje TC, Roth C. Effect of tyrosine kinase inhibitors on islets of Langerhans: evidence for tyrosine kinases in the regulation of insulin secretion. Endocrinology 1994;134:1975-8.

390. Awazawa M, Ueki K, Inabe K, et al. Adiponectin enhances insulin sensitivity by increasing hepatic IRS-2 expression via a macrophage-derived IL-6-dependent pathway. Cell metabolism 2011;13:401-12.

391. Burska AN, Sakthiswary R, Sattar N. Effects of Tumour Necrosis Factor Antagonists on Insulin Sensitivity/Resistance in Rheumatoid Arthritis: A Systematic Review and Meta-Analysis. PloS one 2015;10:e0128889. 


\title{
CHAPTER 2
}

\author{
A 3-day EGCG-supplementation reduces \\ interstitial lactate concentration in skeletal \\ muscle of overweight subjects
}

Jasper Most, Judith GP van Can, Jan-Willem van Dijk, Gijs H Goossens, Johan WE Jocken, Jeannette J Hospers, Igor Bendik, Ellen E Blaak Published in Scientific Reports 2015: 5, Article number: 17896. 


\section{Abstract}

Background: Green tea, particularly epigallocatechin-3-gallate (EGCG), may affect body weight and composition, possibly by enhancing fat oxidation.

Objective and Methods: The aim of this double-blind, randomized placebo-controlled cross-over study was to investigate whether 3-day supplementation with EGCG (282 $\mathrm{mg}$ /day) stimulates fat oxidation and lipolysis in 24 overweight subjects (age $=30 \pm 2$ yrs, $\mathrm{BMI}=27.7 \pm 0.3 \mathrm{~kg} / \mathrm{m} 2$ ). Energy expenditure, substrate metabolism and circulating metabolites were determined during fasting and postprandial conditions. After $6 \mathrm{~h}$, a fat biopsy was collected to examine gene expression. In 12 subjects, skeletal muscle glycerol, glucose and lactate concentrations were determined using microdialysis.

Results: EGCG-supplementation did not alter energy expenditure and substrate oxidation compared to placebo. Although EGCG reduced postprandial circulating glycerol concentrations $(\mathrm{P}=0.015)$, no difference in skeletal muscle lipolysis was observed. Fasting $(\mathrm{P}=0.001)$ and postprandial $(\mathrm{P}=0.003)$ skeletal muscle lactate concentrations were reduced after EGCG-supplementation compared to placebo, despite similar tissue blood flow. Adipose tissue leptin $(\mathrm{P}=0.05)$ and FAT/CD36 expression $(\mathrm{P}=0.08)$ were increased after EGCG compared to placebo.

Conclusion: In conclusion, 3-day EGCG-supplementation decreased postprandial plasma glycerol concentrations, but had no significant effects on skeletal muscle lipolysis and whole-body fat oxidation in overweight individuals. Furthermore, EGCG decreased skeletal muscle lactate concentrations, which suggest a shift towards a more oxidative muscle phenotype. 


\section{Introduction}

The prevalence of obesity has become an epidemic problem during the last few decades ${ }^{1,2}$. Being overweight or obese is considered to be the most important risk factor for the onset of type 2 diabetes mellitus ${ }^{3}$.

In recent years there has been an increased interest in the health benefits of polyphenols in the prevention of obesity and type 2 diabetes mellitus. Green tea is rich in polyphenols, especially catechins. These catechins are comprised primarily of epigallocatechin-3-gallate (EGCG), epigallocatechin (EGC), and epicatechin (EC) ${ }^{4}$. Many of the beneficial health effects of green tea have been attributed to the most abundant catechin EGCG and were initially mainly related to their anti-oxidant activity ${ }^{5-8}$. More recently, interest has increased in the anti-obesity effect of green tea ${ }^{9}$. Consumption of green tea extracts $(270$ mg EGCG) in combination with caffeine supplementation (150 mg caffeine) has been shown to increase fat oxidation ${ }^{10,11}$ and energy expenditure ${ }^{10}$ in an acute manner in lean subjects, and to reduce body weight in overweight subjects ${ }^{12,13}$. However, studies are not consistent yet, which may be related to different doses of EGCG and caffeine, subjects' BMI and genetic predisposition ${ }^{11,14-17}$. Preliminary data suggest that short-term EGCG supplementation may stimulate fat oxidation during postprandial conditions in overweight subjects ${ }^{18}$. Moreover, we recently showed that EGCG, in combination with resveratrol, increased fasting and postprandial energy expenditure, associated with an increased metabolic flexibility ${ }^{19}$, which may be associated with an increased insulin sensitivity ${ }^{20}$. Although supplementation of a green tea supplement for 24 hours in healthy men increased the Matsuda index ${ }^{21}$, reflecting a higher insulin sensitivity based on glucose and insulin concentrations after an oral glucose tolerance test ${ }^{22}$, most studies found no short-term effect on glucose homeostasis in humans ${ }^{16,23,24}$.

The underlying mechanisms behind the possible effect of green tea components on energy expenditure and lipid metabolism are not well studied in humans. One of the putative mechanisms is that EGCG may modulate energy expenditure by inhibiting catechol-omethyltransferase (COMT) ${ }^{10,11}$, an enzyme involved in the degradation of norepinephrine 25. As a consequence there is a prolonged stimulation of the adrenergic receptors, thereby increasing lipolysis and fat oxidation. Another mechanism may involve activation of 
sirtuins, especially sirtuin1 (SIRT1) and its transcriptional co-factor PPAR- $\gamma$ coactivator 1 alpha (PGC-1 $\alpha$ ), although few data of human studies are available ${ }^{26}$.

Watanabe et al. ${ }^{27}$ have shown that EGCG inhibited acetyl CoA-carboxylase (ACC) in 3T3L1 cells, suggesting that EGCG could alter the partitioning of lipids from storage towards oxidation. In addition, chronic feeding of green tea extract to mice has been shown to elevate skeletal muscle gene expression of factors involved in lipid transport and oxidation, such as FAT/CD36, medium-chain acyl-CoA dehydrogenase (MCAD) and uncoupling protein 3 (UCP3) ${ }^{28,29}$. Moreover, green tea extract reduced malonyl-CoA in skeletal muscle, which is an inhibitor of carnitine palmitoyl transferase (CPT), an enzyme involved in fatty acid transportation into the mitochondria ${ }^{30}$. The latter studies in mice, as well as our recent human study showing that combined EGCG and resveratrol supplementation affects flexibility of postprandial substrate oxidation without changes in systemic lipolysis ${ }^{19}$ may suggest that skeletal muscle is a major target tissue for the EGCG-induced metabolic effects. Nevertheless, whether the effects of EGCG and/or green tea extract in humans are mediated through direct effects on muscle metabolism, or secondary to a transient increase in free fatty acids (FFA) related to changes in adipose tissue metabolism or a regulatory action on gene expression remains to be established.

Therefore, we aimed to investigate whether a 3-day supplementation of $282 \mathrm{mg} /$ day EGCG would increase fasting and postprandial fat oxidation, lipolysis (as indicated by circulating FFA and glycerol) and alter adipose tissue gene expression. Furthermore, in a subset of subjects $(\mathrm{n}=12)$, local skeletal muscle metabolism was also assessed using microdialysis.

\section{Methods}

\section{Ethics Statement}

The study was reviewed and approved by the Medical Ethical Committee of the Maastricht University Medical Centre $^{+}$and all subjects gave written informed consent before participation. All procedures were carried out in accordance with the approved guidelines.

\section{Subjects}

Twenty-four overweight men $(n=9)$ and women $(n=15)$ with a low habitual caffeine intake $(<300 \mathrm{mg} /$ day $)$ were recruited for this study. Sample size was calculated to detect a 
physiological relevant change in fat oxidation of $20 \%$ with a power of $90 \%$, assuming a significance level of $\alpha=0.05$ and a drop-out of $20 \%$, based on pilot data by Boschmann et al. ${ }^{18}$. Subjects' characteristics are presented in Table 2.1. Subjects with type 2 diabetes and/or overt cardiovascular complications, and those using medication for digestive disorders were excluded from the participation. All subjects tolerated the EGCG capsules well and no adverse effects were observed on liver enzymes ALAT and ASAT.

Table 2.1. Subjects' characteristics

$\mathrm{n}=24,9 \mathrm{M} / 15 \mathrm{~F}$

\begin{tabular}{lc} 
Age, years & $30 \pm 2$ \\
Body-mass-index, $\mathrm{kg} / \mathrm{m}^{2}$ & $27.7 \pm 0.3$ \\
Waist circumference, cm & $89.0 \pm 1.7$ \\
Hip circumference, cm & $99.0 \pm 1.1$ \\
Waist-hip-ratio & $0.90 \pm 0.01$ \\
Fat mass, \% & $28.8 \pm 1.9$ \\
Fat free mass, \% & $71.2 \pm 1.9$ \\
Glucose, $\mathrm{mmol} / \mathrm{L}$ & $5.20 \pm 0.06$ \\
Insulin, $\mu \mathrm{U} / \mathrm{mL}$ & $12.5 \pm 0.7$ \\
HOMA-IR & $2.9 \pm 0.2$ \\
Systolic blood pressure, $\mathrm{mmHg}$ & $114 \pm 2$ \\
Diastolic blood pressure, $\mathrm{mmHg}$ & $75 \pm 1$ \\
\hline
\end{tabular}

Values are presented as mean \pm SEM. HOMA-IR, Homeostatic assessment model for insulin resistance.

\section{Study design}

The effects of EGCG and placebo on postprandial fat oxidation were studied in a double blind, randomized cross-over design, with a washout-period of at least 7 days between both treatments. Subjects consumed the capsules during 2 days with breakfast and dinner (at both occasions 1 capsule of $141 \mathrm{mg}$ ). At day 3, subjects came to the university (Maastricht University Medical Centre+) for a test (test day). At this day the 2 capsules were ingested simultaneously, $1 \mathrm{~h}$ before the ingestion of a liquid mixed meal.

\section{Test product}

The test product EGCG (Teavigo TG Lot: UT05080001) was provided by DSM Nutritional Products Ltd to Temmler Werke GmbH (Munchen, Germany). All capsules supplied by Temmler Werke $\mathrm{GmbH}$ were manufactured, tested and released according to Good Manufacturing Practice (GMP) guidelines. Teavigo TG ${ }^{\mathrm{TM}}$ contains $>90 \%$ EGCG on a dry 
weight basis. The placebo capsules were filled with partially hydrolyzed cellulose. The capsules were of identical appearance containing either $141 \mathrm{mg}$ EGCG or placebo. $300 \mathrm{mg}$ EGCG per day has been shown to be safe and well tolerated in single doses as well as repeated dosing ${ }^{31}$.

\section{Protocol Test day}

All subjects were asked to refrain from drinking alcohol, smoking and doing strenuous exercise for a period of $24 \mathrm{~h}$ before the test day. Subjects came to the laboratory by car or bus in the morning after an overnight fast. At the beginning of the test day (day 3), a cannula was inserted into an antecubital vein for blood sampling. The EGCG or placebo capsules were consumed $1 \mathrm{~h}$ before metabolic testing and a fasting blood sample was drawn to determine baseline values of EGCG ( $\mathrm{t}=-60 \mathrm{~min})$. A liquid test meal was consumed 60 min after ingestion of EGCG/placebo capsules. Primary outcomes, energy expenditure and substrate utilization, were measured before and for $6 \mathrm{~h}$ after ingestion of the liquid test meal, using a ventilated hood system (Omnical, Maastricht University, The Netherlands) ${ }^{32}$. Gas analyses, which occurred every minute, are performed by dual paramagnetic $\mathrm{O}_{2}$ analysers and dual infrared $\mathrm{CO}_{2}$ analysers (type 1156, 1507, 1520; Servomex, Cowborough, Sussex, UK), similar to the analysis system described by Schoffelen et al. ${ }^{33}$. Blood samples were taken before ingestion of the liquid meal $(\mathrm{t}=0 \mathrm{~min})$ and for $6 \mathrm{~h}$ after meal ingestion at $\mathrm{t}=30,60,90,120,180,240,300$ and $360 \mathrm{~min}$ after EGCG/placebo ingestion to determine circulating metabolites and hormone concentrations.

The liquid meal had a total energy content equivalent of $40 \%$ of calculated $24 \mathrm{~h}$ resting energy expenditure based upon the formula of Harris and Benedict ${ }^{34}$. The energy content of the test meal was accounted for 49 energy\% CHO, 35 energy\% FAT and 16 eneryg\% protein and was consumed within 20 minutes. A fat biopsy was taken at the end of the $6 \mathrm{~h}$ postprandial period in each condition $(\mathrm{t}=360 \mathrm{~min})$. Blood samples and fat biopsy were snap frozen in liquid nitrogen and stored at $-80{ }^{\circ} \mathrm{C}$ until analysis.

\section{Fat biopsy}

A small amount (about $1 \mathrm{~g}$ ) of abdominal subcutaneous adipose tissue was collected under local anesthesia using a needle biopsy technique and snap frozen in liquid nitrogen. Total RNA was isolated, using the total RNA stabilization and purification kit for human samples Qiagen (Qiagen, Hombrechtikon, Switzerland). Gene expression of hormone-sensitive 
lipase (HSL), adipose triglyceride lipase (ATGL), CPT-1, ACC-1, FAT/CD36 and leptin was measured by the Taqman multiplex method using the ABI 7900 quantitative real-time RT-PCR instrument (Applied Biosystems, Rotkreuz, Switzerland) as described by Heim ${ }^{35}$. All probe and primer sets were designed with the Primer Express program version 1.0 (Applied Biosystems) and initially tested to have comparable ( $>90 \%)$ efficiency in multiplex assays using $18 \mathrm{~S}$ rRNA as an internal control. An overview of the primers and probes is listed in Table 2.2.

Table 2.2. Overview of primers and probes for RT-PCR of adipose tissue biopsies.

\begin{tabular}{|c|c|c|}
\hline & Primer & Probes \\
\hline $18 \mathrm{~S}$ & $\begin{array}{l}\text { f: CGGCTACCACATCCAAGGAA } \\
\text { r: GCTGGAATTACCGCGGCT }\end{array}$ & $\begin{array}{l}\text { 5'-VIC-TGCTGGCACC } \\
\text { AGACTTGCCCTC-TAMRA-3 }\end{array}$ \\
\hline HSL & $\begin{array}{l}\text { f: CTGCATAAGGGATGCTTCTATGG } \\
\text { r: CCTGTCTCGTTGCGTTTGTAGT }\end{array}$ & $\begin{array}{l}\text { 5'-FAM- CTGCCTGGGC } \\
\text { TTCCAGTTCACGC-TAMRA-3 }\end{array}$ \\
\hline ATGL & $\begin{array}{l}\text { f: TAGAGTGGCAGGTTGTCTGAAATG } \\
\text { r: CCCGTGTACTGTGGGCTCAT }\end{array}$ & $\begin{array}{l}\text { 5'-FAM- CACCATCCACG } \\
\text { TAGCGCACCCC -TAMRA-3 }\end{array}$ \\
\hline CPT-1 & $\begin{array}{l}\text { f: CCATGTTGTACAGCTTCCAGACA } \\
\text { r: CACCGACTGTAGATACCTGTTCACA }\end{array}$ & $\begin{array}{l}\text { 5'-FAM- CTGCCTCGCC } \\
\text { TGCCGGTCC-TAMRA-3 }\end{array}$ \\
\hline ACC-1 & $\begin{array}{l}\text { f: CAGCAGGCTGAACTTCACACA } \\
\text { r: CTGGAAGGCAGTATCCATTCATT }\end{array}$ & $\begin{array}{l}\text { 5'-FAM- CACGGATCCA } \\
\text { GAGCACGGCACTC-TAMRA-3 }\end{array}$ \\
\hline Leptin & $\begin{array}{l}\text { CCAAAACCCTCATCAAGACAATT } \\
\text { r: GAATGAAGTCCAAACCGGTGA }\end{array}$ & $\begin{array}{l}\text { 5'-FAM- CACGCAGTCAGTCTC } \\
\text { CTCCAAACAGAAA-TAMRA-3 }\end{array}$ \\
\hline
\end{tabular}

F, forward; r, reverse; HSL, hormone-sensitive lipase; ATGL, adipose triglyceride lipase; CPT-1, carnitine-palmitoyl-transferase-1; ACC-1, acetyl-Coenzyme-A-carboxylase.

\section{Microdialysis}

In a subset of 12 subjects ( 6 men, 6 women, representative for the whole-study group with respect to subjects characteristics), the lipolytic effects of EGCG in skeletal muscle were determined by the microdialysis technique. On arrival, two microdialysis probes (CMA 60, CMA microdialysis AB, Stockholm, Sweden) were inserted in the medial portion of the $m$. gastrocnemius of both legs after anesthesia (xylocaine $2 \%$ without adrenalin, Astra Zeneca). Thereafter, $90 \mathrm{~min}$ was allowed for recovery of muscle from insertion trauma.

One probe was perfused with Ringer's solution (147 mM sodium, $4 \mathrm{mM}$ potassium, 2.25 $\mathrm{mM}$ calcium and $156 \mathrm{mM}$ chloride, Baxter BV, Utrecht, The Netherlands) at a rate of 0.3 $\mu \mathrm{l} / \mathrm{min}$ to obtain a near $100 \%$ recovery. Microdialysate was collected from these probes in 30 min fractions during the baseline period and during the early postprandial period (0-120 $\mathrm{min})$ and at $60 \mathrm{~min}$ fractions during the last $4 \mathrm{~h}$ postprandially (120-360 $\mathrm{min})$, to determine glycerol, glucose and lactate concentrations. Baseline concentrations of glycerol, lactate 
and glucose were determined by the average of three baseline samples. The second microdialysis probe was used for determining tissue blood flow using the ethanol dilution technique ${ }^{36,37}$. For this, the probes were perfused with Ringer's solution supplemented with $50 \mathrm{mM}$ ethanol, at a flow rate of $5 \mu \mathrm{L} / \mathrm{min}$ (Harvard microinfusion pump, Plato BV, Diemen, The Netherlands).

Ethanol concentrations were determined both in the ingoing and outgoing perfusion solvent to assess the ethanol inflow/outflow ratio as an indicator for local nutritive blood flow. Ethanol concentrations were determined at the same day, whereas microdialysate samples for measurement of glycerol, glucose and lactate concentrations were immediately frozen and stored at $-80^{\circ} \mathrm{C}$ until analysis.

\section{Biochemical analyses}

At all time points, $8 \mathrm{ml}$ blood was collected in pre-chilled tubes with $200 \mu \mathrm{L}$ of $0.2 \mathrm{M}$ EDTA (Sigma, Dorset, UK). After collection, blood samples were centrifuged immediately at $4{ }^{\circ} \mathrm{C}$ for $10 \mathrm{~min}$ at $1000 \mathrm{~g}$ and frozen at $-80^{\circ} \mathrm{C}$ until analysis. Additionally, $500 \mu \mathrm{L}$ of the cell free plasma supernatant was combined with exactly $500 \mu \mathrm{L}$ stabilization buffer at ambient temperature for the determination of EGCG concentration by HPLC. Plasma glucose (Uni Kit III, Roche, Basel, Switzerland), lactate, FFA (NEFA-C, Wako Chemicals, Neuss, Germany), triacylglycerol (TAG) and free glycerol (148270, Roche Diagnostics, Indianapolis, IN, USA) concentrations were analyzed with a COBAS FARA semiautomatic analyzer (Roche). Insulin was analyzed by radioimmunoassay (Human Insulin RIA Kit, LINCO Research Inc, St. Charles, MO).

Glycerol, glucose and lactate concentrations from the microdialysates were measured by bioluminescence, lactate after enzymatic oxidation of L-Lactate ${ }^{38}$. Ethanol concentrations were measured spectrophotometrically using a standard enzymatic technique (R-Biopharm AG, Darmstadt, Germany).

\section{Calculations}

Substrate oxidation was calculated from $\mathrm{VO}_{2}(\mathrm{~L} / \mathrm{min})$ and $\mathrm{VCO}_{2}(\mathrm{~L} / \mathrm{min})$ according to the equations of Frayn ${ }^{39}$. Nitrogen excretion was calculated based on the assumption that protein oxidation represents $\sim 15 \%$ of total energy expenditure. Energy expenditure was calculated using the formula of Weir ${ }^{40}$. For each time point, the average of 20 min was used for calculation. 
Carbohydrate oxidation $(\mathrm{CHO})(\mathrm{g} / \mathrm{min})=\left(4.55 * \mathrm{VCO}_{2}\right)-\left(3.21 * \mathrm{VO}_{2}\right)-(2.87 * \mathrm{~N})$

FAT oxidation $(\mathrm{g} / \mathrm{min})=\left(1.67 * \mathrm{VO}_{2}\right)-\left(1.67 * \mathrm{VCO}_{2}\right)-(1.92 * \mathrm{~N})$

$\mathrm{N}(\mathrm{g} / \mathrm{min})=((0.15 * \mathrm{EE}) / 17) / 6.25$

\section{Statistics}

All data are expressed as means \pm SEM. The total response of parameters after ingestion EGCG or placebo was expressed as the total area under the curve (AUC) and calculated by the trapezoid method. Differences between placebo and EGCG were analyzed by means of student's paired t-test. Normal distribution was tested by the Kolmogorov-Smirnov test. If parameters were not normally distributed they were ln transformed. Plasma lactate, TAG, glycerol and the genes CPT-1, ACC-1, HSL and leptin data were ln transformed. SPSS 15 for Windows was used to perform all calculation. The level of statistical significance was set at $\mathrm{P} \leq 0.05$.

\section{Results}

\section{Bioavailability}

Plasma EGCG reached maximum concentration $(394 \pm 73 \mathrm{ng} / \mathrm{mL}(0.86 \pm 0.16 \mu \mathrm{mol} / \mathrm{L}))$ one hour after intake of EGCG ( $\mathrm{t}=0 \mathrm{~min})$ and gradually declined below the detection limit (20 $\mathrm{ng} / \mathrm{mL}$ ) at the end of the meal-test $(\mathrm{t}=360 \mathrm{~min}$, Figure 2.1A). Relative bioavailability $\left(\mathrm{AUC}_{\text {plasma }} /\right.$ dose) was $19 \pm 2 \%$.

\section{Energy expenditure and substrate oxidation}

Supplementation of EGCG did not change fasting or postprandial fat and carbohydrate oxidation (Figure 2.1B-C). Similarly, there were no differences in energy expenditure between conditions (Figure 2.1D). 

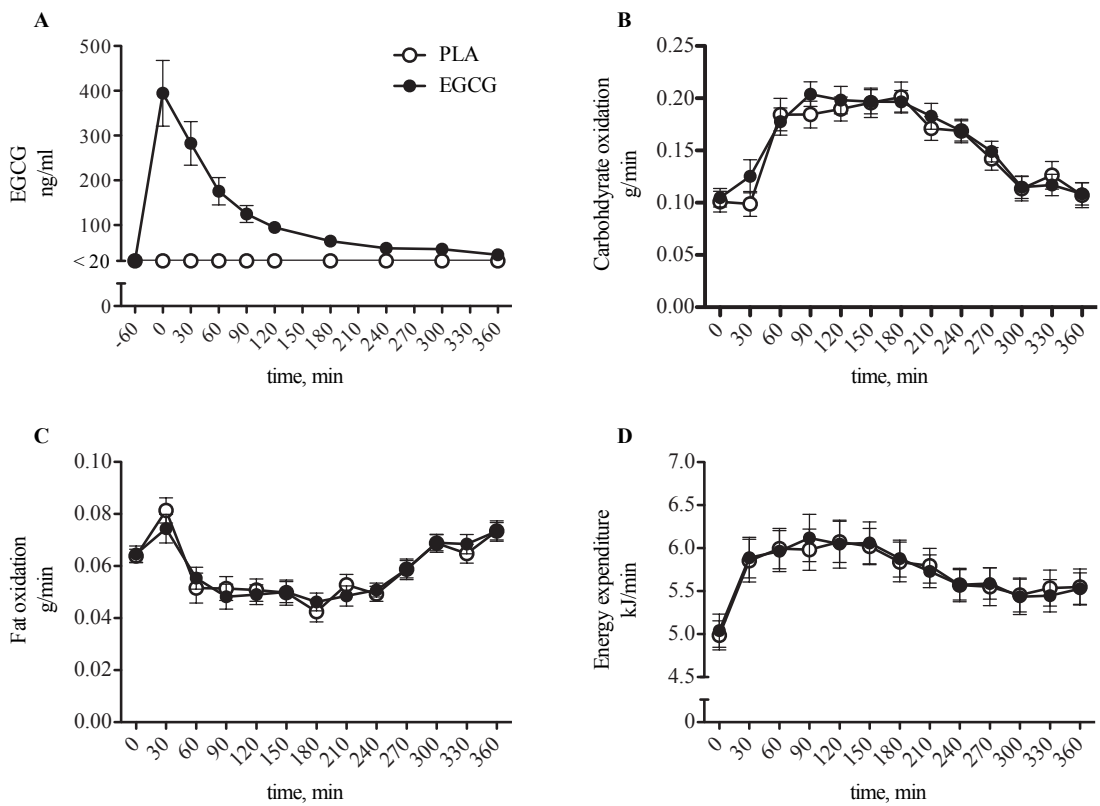

Figure 2.1. Time-course of plasma epigallocatechin-3-gallate, substrate oxidation and energy expenditure after oral intake of $282 \mathrm{mg} /$ day or placebo

Results represent mean \pm SEM; $n=24$. Plasma EGCG concentrations (A), carbohydrate oxidation (B), fat oxidation (C) and energy expenditure (D) before and after a mixed meal

\section{Circulating metabolites}

EGCG supplementation showed no differences in plasma glucose, insulin and lactate concentration compared to placebo (Figure 2.2A-C). Plasma free fatty acids (FFA) concentrations tended to be reduced after EGCG supplementation (AUC, $\mathrm{P}=0.07$, Figure 2.2D). Furthermore, plasma glycerol concentrations were significantly reduced after EGCG supplementation as compared with placebo (AUC, $\mathrm{P}=0.02$, Figure $2.2 \mathrm{E}$ ), which was most pronounced in the late postprandial period (240-360 $\mathrm{min}$ ). Plasma concentration responses to the meal, expressed as incremental area under the curve, were not affected by EGCG ( $\mathrm{p}=$ N.S.). EGCG supplementation did not induce differences in plasma TAG concentrations, although fasting TAG concentrations tended to be reduced after EGCG $(\mathrm{P}=0.07$, Figure $2.2 \mathrm{~F})$. 
$\mathbf{A}$

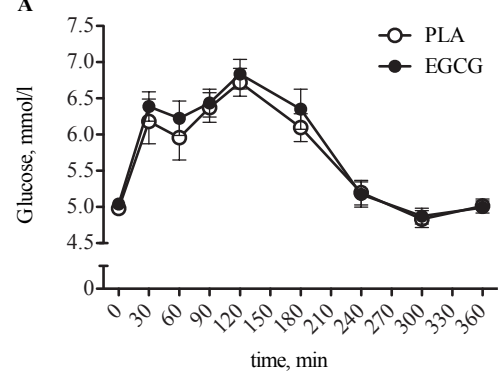

C

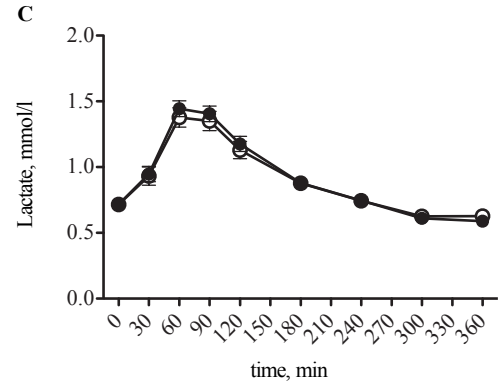

$\mathbf{E}$

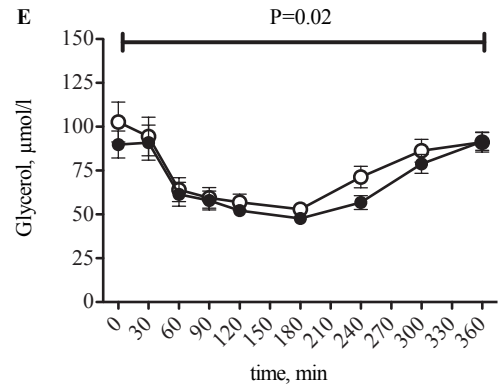

B
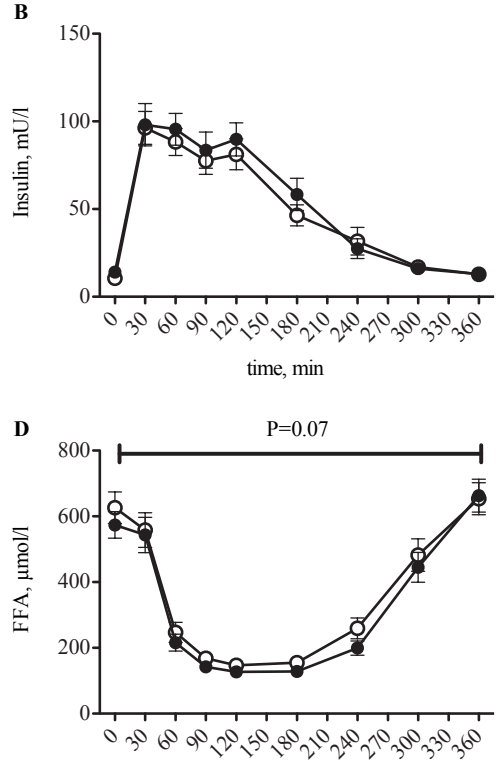

time, min

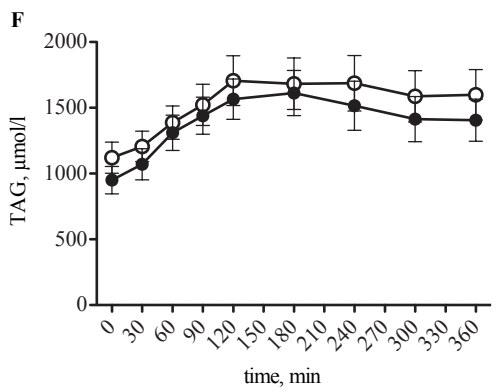

Figure 2.2. Time-course of systemic metabolite and hormone concentrations response after intake of $282 \mathrm{mg} /$ day EGCG or placebo.

Results represent mean \pm SEM; $n=24$. Plasma glucose (A), insulin (B), lactate (C), FFA (D), glycerol (E) and TAG (F) concentrations before and after a mixed meal. P: paired Student's t-test for AUCvalues.

\section{Skeletal muscle lipolysis}

Skeletal muscle interstitial glycerol, glucose concentrations, as well as ethanol in-out ratio were not different between EGCG supplementation and placebo (Figure 2.3A and C, 


\section{Chapter 2}

glucose data not shown). However, interstitial lactate was reduced with EGCG both for baseline levels $(\mathrm{P}<0.001)$ as well during the postprandial period $(\mathrm{P}=0.003$, Figure 2.3B). Moreover, the postprandial increase of interstitial lactate concentrations tended to be attenuated by EGCG (iAUC, PLA: 15.2 $\pm 2.1 \mathrm{mmol} /(\mathrm{L} * 360 \mathrm{~min})$, EGCG: $9.8 \pm 1.5$ $\mathrm{mmol} /(\mathrm{L} * 360 \mathrm{~min}), \mathrm{P}=0.06)$.
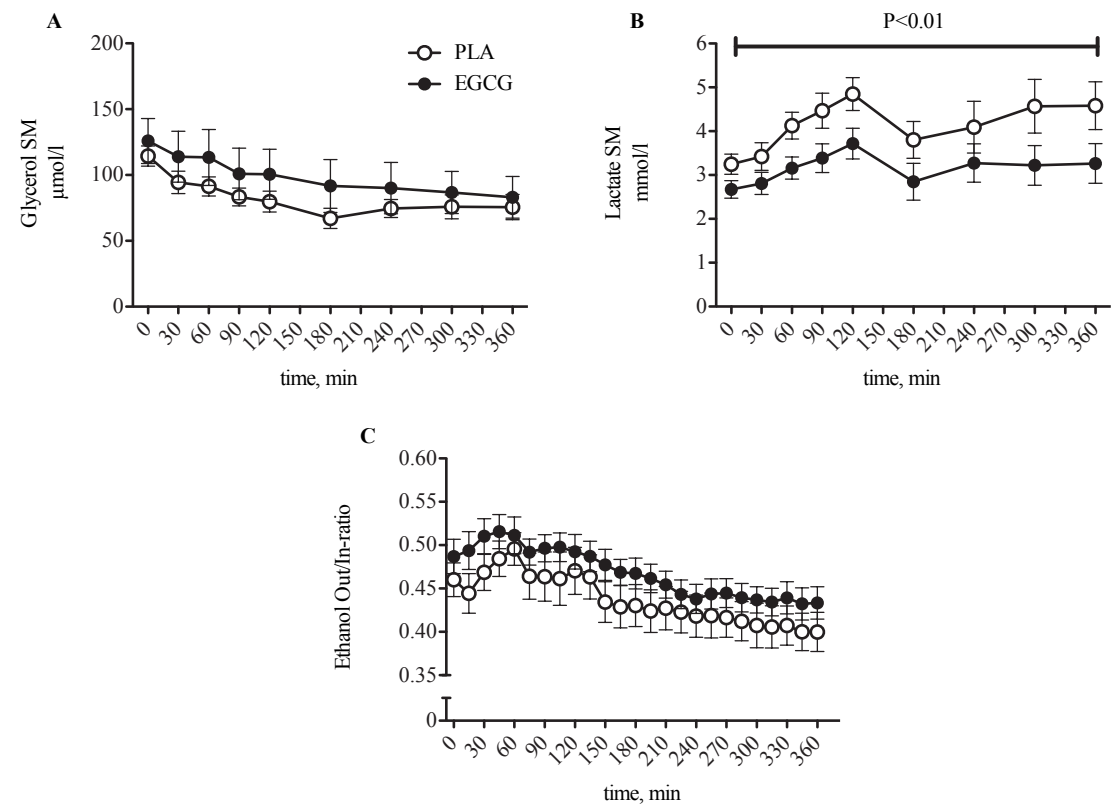

Figure 2.3. Time-course of interstitial metabolite concentrations in skeletal muscle after intake of $282 \mathrm{mg} /$ day EGCG or placebo.

Results represent mean \pm SEM; $n=12$. Skeletal muscle interstitial glycerol (A) and lactate (B) concentrations and ethanol Out/In-ratio $(\mathrm{C})$ before and after a mixed meal. P: paired Student's t-test for AUC-values.

\section{Adipose tissue gene and protein expression}

The mRNA expression of CPT-1, ACC-1, ATGL and HSL were similar after supplementation with EGCG or placebo capsules. EGCG increased leptin $(\mathrm{P}=0.05)$ and tended to increase FAT/CD36 $(\mathrm{P}=0.08)$ mRNA expression compared to placebo (Table 2.3). 
Table 2.3. Normalized mRNA expression in adipose tissue after EGCG or placebo.

\begin{tabular}{lccr}
\hline & EGCG & Placebo & P \\
\hline CPT-1 & $1.06 \cdot 10^{-5} \pm 1.0 \cdot 10^{-6}$ & $9.30 \cdot 10^{-6} \pm 7.4 \cdot 10^{-7}$ & 0.31 \\
ATGL & $3.51 \cdot 10^{-4} \pm 3.7 \cdot 10^{-5}$ & $3.70 \cdot 10^{-4} \pm 3.0 \cdot 10^{-5}$ & 0.12 \\
HSL & $5.38 \cdot 10^{-4} \pm 4.7 \cdot 10^{-5}$ & $5.19 \cdot 10^{-4} \pm 4.1 \cdot 10^{-5}$ & 0.73 \\
FAT/CD36 & $1.73 \cdot 10^{-3} \pm 1.2 \cdot 10^{-4}$ & $1.52 \cdot 10^{-3} \pm 9.1 \cdot 10^{-5}$ & 0.08 \\
ACC-1 & $2.16 \cdot 10^{-4} \pm 2.1 \cdot 10^{-5}$ & $2.18 \cdot 10^{-4} \pm 2.6 \cdot 10^{-5}$ & 0.81 \\
Leptin & $5.20 \cdot 10^{-4} \pm 5.9 \cdot 10^{-5}$ & $4.30 \cdot 10^{-4} \pm 5.9 \cdot 10^{-5}$ & 0.05 \\
\hline \hline
\end{tabular}

CPT-1, Carnitine-Palmitoyl-transferase-1; ATGL, Adipose triglyceride lipase; HSL, Hormonesensitive lipase; FAT/CD36, Fatty acid-translocase/cluster of differentiation; ACC-1, AcetylCoenzyme-A-Carboxylase. P, P-value for statistical difference between EGCG and placebo.

\section{Discussion}

This study was designed to study the acute effects of EGCG supplementation ( $282 \mathrm{mg} /$ day), the main catechin of green tea, on whole-body and skeletal muscle lipolysis and wholebody fat oxidation in overweight subjects. Supplementation of $282 \mathrm{mg} /$ day EGCG for 3 days decreased circulating glycerol and tended to reduce FFA concentrations but did not alter local muscle lipolysis, substrate oxidation and energy expenditure compared to placebo. Skeletal muscle lactate concentrations were significantly reduced by EGCG compared to placebo, whilst skeletal muscle glucose concentrations were comparable, suggesting an ECCG-induced shift towards a more oxidative skeletal muscle phenotype. Bioavailability was in line with previously published data ${ }^{41}$.

It has been suggested that EGCG stimulates fat oxidation by augmenting sympathic nervous stimulation ${ }^{10,42}$, however human studies have shown conflicting results ${ }^{19,43}$. In the present study, no significant effect on postprandial fat oxidation and energy expenditure was found, which is consistent with findings of Lonac et al. ${ }^{16}$ (945 mg EGCG in $48 \mathrm{~h}$ ) and Gregersen et al. ${ }^{17}$ (494-684 mg/day catechins and $150 \mathrm{mg}$ caffeine) after 2 days EGCG, respectively acute EGCG-enriched catechin supplementation, in healthy adults. In contrast to our results, Thielecke et al. ${ }^{24}$ observed an increased fat oxidation in the first $2 \mathrm{~h}$ of the postprandial period following 3-day supplementation of EGCG. This may be explained by an extra dose of $150 \mathrm{mg}$ EGCG that was ingested $1 \mathrm{~h}$ before meal intake, additional to the daily dose ingested in the morning. In addition, Dulloo et al. ${ }^{10}$ showed an increase in fat oxidation and energy expenditure following a single dose of catechins (375 mg catechins, 
$270 \mathrm{mg}$ EGCG) + $150 \mathrm{mg}$ caffeine in healthy young men. Since caffeine has been shown to independently stimulate energy expenditure in a dose-dependent manner, with doses as low as $100 \mathrm{mg}$ showing effects ${ }^{44}$, synergistic effects of EGCG and caffeine could possibly explain the discrepancy between the study of Dulloo et al. ${ }^{10}$ and our present findings. Of note, in the study of Gregersen et al. ${ }^{17}$, lower doses of combined EGCG and caffeine (600 $\mathrm{mg}$, respectively $150 \mathrm{mg}, 6 \mathrm{small}$ doses over $11 \mathrm{~h}$ ) did not induce significant increases in fat oxidation and energy expenditure. The synergistic action of different supplements may explain the increased energy expenditure that we reported in overweight men and women after combined EGCG and resveratrol supplementation ${ }^{19}$.

Although there were no significant effects on postprandial fat oxidation in the present study, skeletal muscle lactate concentrations were reduced after EGCG supplementation both in the fasted state as well as during the postprandial period. These data might indicate a shift towards a less glycolytic and/or more oxidative muscle phenotype after EGCG. It is increasingly recognized that skeletal muscle lipolysis may play an important role in the regulation of mitochondrial function in skeletal muscle by activation of PPARs ${ }^{45,46}$. Since we found no significant differences in muscle lipolysis, this has not driven the shift in oxidative potential in muscle after EGCG supplementation. Also, we found no differences in adipose tissue lipase expression, and even reduced systemic FFA concentrations, indicating that the shift towards a more oxidative phenotype in skeletal muscle was not related to differences in the supply of exogenous fatty acids, but may possibly be due to a direct effect on mitochondrial function which has been reported earlier ${ }^{26,47}$. However, the reduction of interstitial lactate, indicative for a more oxidative phenotype, does not translate into significant alterations in substrate oxidation or glucose disposal. Still, even though the acute effects of EGCG on fat oxidation were not significantly different from placebo treatment, this does not rule out the possibility that green tea can have beneficial effects on fat oxidation ${ }^{48,49}$, body composition ${ }^{12,13,48,50}$ and insulin sensitivity ${ }^{51}$ over longer time periods. Therefore, the duration of supplementation, addition of caffeine or other polyphenols and combination with exercise are factors that have to be taken into account for future studies.

Systemic glycerol concentrations even significantly reduced in the postprandial period with EGCG, but not during fasting conditions. This decrease may indicate a slightly improved insulin-mediated suppression of adipose tissue lipolysis after EGCG treatment. Further 
studies are necessary to examine this mechanism or possible others, including glycerol clearance. Additionally, EGCG supplementation resulted in an upregulation of leptin mRNA expression in adipose tissue, whilst mRNA expression of the fatty acid transporter FAT/CD36 tended to be higher after EGCG supplementation compared to placebo. Similarly, we have previously found increased fasting concentrations of the adipose tissue derived satiety hormone leptin after short-term supplementation with EGCG and resveratrol ${ }^{19}$. In line, Josic et al. ${ }^{52}$ suggested that green tea might increase satiety although the data should be confirmed in a large clinical trial with overweight and obese subjects. Altogether, these data indicate slight effects on adipose tissue metabolism and function; more pronounced effects might require a longer period of supplementation and/or higher dosage of EGCG.

Lastly, the interaction between polyphenols and the gut microbiota may modulate the effect of EGCG supplementation ${ }^{53}$. Previous research suggests pre- and anti-biotic properties of EGCG, which may influence peripheral metabolism through changes in microbiota composition and microbial products like short-chain fatty acid ${ }^{54}$. Moreover, it should be considered that microbial polyphenolic metabolites may have distinct effects on host metabolism ${ }^{55}$.

In conclusion, EGCG supplementation for 3 days decreased postprandial plasma glycerol concentrations, but had no significant effects on skeletal muscle lipolysis and whole-body fat oxidation in overweight individuals. Interestingly, EGCG decreased skeletal muscle lactate concentrations, suggesting a shift towards a more oxidative muscle phenotype. It can be speculated that the shift towards a more oxidative phenotype may be beneficial over a longer period in the prevention of obesity and related 


\section{References}

1. Overweight \& Obesity in the EU27. International Association for the Study of Obesity, 2008. (Accessed 28.09, 2015, at http://www.worldobesity.org/site_media/uploads/v2PDFforwebsiteEU27.pdf.)

2. Obesity and overweight - Fact sheet $\mathrm{N}^{\circ} 311$. 2015. (Accessed 28.09, 2015, at http://www.who.int/mediacentre/factsheets/fs311/en/.)

3. Kahn SE, Hull RL, Utzschneider KM. Mechanisms linking obesity to insulin resistance and type 2 diabetes. Nature 2006;444:840-6.

4. Sano M, Tabata M, Suzuki M, Degawa M, Miyase T, Maeda-Yamamoto M. Simultaneous determination of twelve tea catechins by high-performance liquid chromatography with electrochemical detection. Analyst 2001;126:816-20.

5. Jung YD, Ellis LM. Inhibition of tumour invasion and angiogenesis by epigallocatechin gallate (EGCG), a major component of green tea. Int J Exp Pathol 2001;82:309-16.

6. Sartippour MR, Shao ZM, Heber D, et al. Green tea inhibits vascular endothelial growth factor (VEGF) induction in human breast cancer cells. J Nutr 2002;132:230711 .

7. Kavanagh KT, Hafer LJ, Kim DW, et al. Green tea extracts decrease carcinogeninduced mammary tumor burden in rats and rate of breast cancer cell proliferation in culture. J Cell Biochem 2001;82:387-98.

8. Osada K, Takahashi M, Hoshina S, Nakamura M, Nakamura S, Sugano M. Tea catechins inhibit cholesterol oxidation accompanying oxidation of low density lipoprotein in vitro. Comp Biochem Physiol C Toxicol Pharmacol 2001;128:153-64.

9. Diepvens K, Westerterp KR, Westerterp-Plantenga MS. Obesity and thermogenesis related to the consumption of caffeine, ephedrine, capsaicin, and green tea. Am $\mathrm{J}$ Physiol Regul Integr Comp Physiol 2007;292:R77-85.

10. Dulloo AG, Duret C, Rohrer D, et al. Efficacy of a green tea extract rich in catechin polyphenols and caffeine in increasing 24-h energy expenditure and fat oxidation in humans. The American journal of clinical nutrition 1999;70:1040-5.

11. Hursel R, Janssens PL, Bouwman FG, Mariman EC, Westerterp-Plantenga MS. The role of catechol-O-methyl transferase Val(108/158)Met polymorphism (rs4680) in the effect of green tea on resting energy expenditure and fat oxidation: a pilot study. PloS one 2014;9:e106220.

12. Basu A, Sanchez K, Leyva MJ, et al. Green tea supplementation affects body weight, lipids, and lipid peroxidation in obese subjects with metabolic syndrome. J Am Coll Nutr 2010;29:31-40.

13. Brown AL, Lane J, Holyoak C, Nicol B, Mayes AE, Dadd T. Health effects of green tea catechins in overweight and obese men: a randomised controlled cross-over trial. Br J Nutr 2011;106:1880-9.

14. Berube-Parent S, Pelletier C, Dore J, Tremblay A. Effects of encapsulated green tea and Guarana extracts containing a mixture of epigallocatechin-3-gallate and caffeine on $24 \mathrm{~h}$ energy expenditure and fat oxidation in men. Br J Nutr 2005;94:432-6.

15. Gosselin C, Haman F. Effects of green tea extracts on non-shivering thermogenesis during mild cold exposure in young men. Br J Nutr 2013;110:282-8. 
16. Lonac MC, Richards JC, Schweder MM, Johnson TK, Bell C. Influence of short-term consumption of the caffeine-free, epigallocatechin-3-gallate supplement, Teavigo, on resting metabolism and the thermic effect of feeding. Obesity 2011;19:298-304.

17. Gregersen NT, Bitz C, Krog-Mikkelsen I, et al. Effect of moderate intakes of different tea catechins and caffeine on acute measures of energy metabolism under sedentary conditions. Br J Nutr 2009;102:1187-94.

18. Boschmann M, Thielecke F. The effects of epigallocatechin-3-gallate on thermogenesis and fat oxidation in obese men: a pilot study. J Am Coll Nutr 2007;26:389S-95S.

19. Most J, Goossens GH, Jocken JW, Blaak EE. Short-term supplementation with a specific combination of dietary polyphenols increases energy expenditure and alters substrate metabolism in overweight subjects. International journal of obesity 2014;38:698-706.

20. Corpeleijn E, Saris WH, Blaak EE. Metabolic flexibility in the development of insulin resistance and type 2 diabetes: effects of lifestyle. Obesity reviews : an official journal of the International Association for the Study of Obesity 2009;10:178-93.

21. Venables MC, Hulston CJ, Cox HR, Jeukendrup AE. Green tea extract ingestion, fat oxidation, and glucose tolerance in healthy humans. The American journal of clinical nutrition 2008;87:778-84.

22. Matsuda M, DeFronzo RA. Insulin sensitivity indices obtained from oral glucose tolerance testing: comparison with the euglycemic insulin clamp. Diabetes Care 1999;22:1462-70.

23. Stote KS, Clevidence BA, Novotny JA, Henderson T, Radecki SV, Baer DJ. Effect of cocoa and green tea on biomarkers of glucose regulation, oxidative stress, inflammation and hemostasis in obese adults at risk for insulin resistance. Eur J Clin Nutr 2012;66:1153-9.

24. Thielecke F, Rahn G, Bohnke J, et al. Epigallocatechin-3-gallate and postprandial fat oxidation in overweight/obese male volunteers: a pilot study. Eur J Clin Nutr 2010;64:704-13.

25. Borchardt RT, Huber JA. Catechol O-methyltransferase. 5. Structure-activity relationships for inhibition by flavonoids. J Med Chem 1975;18:120-2.

26. Valenti D, De Rasmo D, Signorile A, et al. Epigallocatechin-3-gallate prevents oxidative phosphorylation deficit and promotes mitochondrial biogenesis in human cells from subjects with Down's syndrome. Biochim Biophys Acta 2013;1832:542-52.

27. Watanabe J, Kawabata J, Niki R. Isolation and identification of acetyl-CoA carboxylase inhibitors from green tea (Camellia sinensis). Biosci Biotechnol Biochem 1998;62:532-4.

28. Murase T, Haramizu S, Shimotoyodome A, Nagasawa A, Tokimitsu I. Green tea extract improves endurance capacity and increases muscle lipid oxidation in mice. Am J Physiol Regul Integr Comp Physiol 2005;288:R708-15.

29. Sae-Tan S, Grove KA, Kennett MJ, Lambert JD. (-)-Epigallocatechin-3-gallate increases the expression of genes related to fat oxidation in the skeletal muscle of high fat-fed mice. Food \& function 2011;2:111-6.

30. Murase T, Haramizu S, Shimotoyodome A, Tokimitsu I, Hase T. Green tea extract improves running endurance in mice by stimulating lipid utilization during exercise. Am J Physiol Regul Integr Comp Physiol 2006;290:R1550-6.

31. Ullmann U, Haller J, Decourt JD, Girault J, Spitzer V, Weber P. Plasma-kinetic characteristics of purified and isolated green tea catechin epigallocatechin gallate 
(EGCG) after 10 days repeated dosing in healthy volunteers. Int J Vitam Nutr Res 2004;74:269-78.

32. Adriaens MP, Schoffelen PF, Westerterp KR. Intra-individual variation of basal metabolic rate and the influence of daily habitual physical activity before testing. Br $\mathrm{J}$ Nutr 2003;90:419-23.

33. Schoffelen PF, Westerterp KR, Saris WH, Ten Hoor F. A dual-respiration chamber system with automated calibration. J Appl Physiol 1997;83:2064-72.

34. Harris JA, Benedict FG. A Biometric Study of Human Basal Metabolism. Proc Natl Acad Sci U S A 1918;4:370-3.

35. Heim M, Frank O, Kampmann G, et al. The phytoestrogen genistein enhances osteogenesis and represses adipogenic differentiation of human primary bone marrow stromal cells. Endocrinology 2004;145:848-59.

36. Arner P, Bulow J. Assessment of adipose tissue metabolism in man: comparison of Fick and microdialysis techniques. Clin Sci (Lond) 1993;85:247-56.

37. Hickner RC, Rosdahl H, Borg I, Ungerstedt U, Jorfeldt L, Henriksson J. Ethanol may be used with the microdialysis technique to monitor blood flow changes in skeletal muscle: dialysate glucose concentration is blood-flow-dependent. Acta Physiol Scand 1991;143:355-6.

38. Arner P. Techniques for the measurement of white adipose tissue metabolism: a practical guide. Int J Obes Relat Metab Disord 1995;19:435-42.

39. Frayn KN. Calculation of substrate oxidation rates in vivo from gaseous exchange. J Appl Physiol 1983;55:628-34.

40. Weir JB. New methods for calculating metabolic rate with special reference to protein metabolism. The Journal of physiology 1949;109:1-9.

41. Henning SM, Niu Y, Liu Y, et al. Bioavailability and antioxidant effect of epigallocatechin gallate administered in purified form versus as green tea extract in healthy individuals. J Nutr Biochem 2005;16:610-6.

42. Klaus S, Pultz S, Thone-Reineke C, Wolfram S. Epigallocatechin gallate attenuates diet-induced obesity in mice by decreasing energy absorption and increasing fat oxidation. International journal of obesity 2005;29:615-23.

43. Lorenz M, Paul F, Moobed M, et al. The activity of catechol-O-methyltransferase (COMT) is not impaired by high doses of epigallocatechin-3-gallate (EGCG) in vivo. European journal of pharmacology 2014;740:645-51.

44. Astrup A, Toubro S, Cannon S, Hein P, Breum L, Madsen J. Caffeine: a double-blind, placebo-controlled study of its thermogenic, metabolic, and cardiovascular effects in healthy volunteers. The American journal of clinical nutrition 1990;51:759-67.

45. Haemmerle G, Moustafa T, Woelkart G, et al. ATGL-mediated fat catabolism regulates cardiac mitochondrial function via PPAR-alpha and PGC-1. Nature medicine 2011;17:1076-85.

46. Meex RC, Hoy AJ, Mason RM, et al. ATGL-mediated triglyceride turnover and the regulation of mitochondrial capacity in skeletal muscle. American journal of physiology Endocrinology and metabolism 2015;308:E960-70.

47. Liu J, Tang Y, Feng Z, Liu J, Liu J, Long J. (-)-Epigallocatechin-3-gallate attenuated myocardial mitochondrial dysfunction and autophagy in diabetic Goto-Kakizaki rats. Free radical research 2014;48:898-906.

48. Roberts JD, Roberts MG, Tarpey MD, Weekes JC, Thomas CH. The effect of a decaffeinated green tea extract formula on fat oxidation, body composition and exercise performance. J Int Soc Sports Nutr 2015;12:1. 
49. Mahler A, Steiniger J, Bock M, et al. Metabolic response to epigallocatechin-3-gallate in relapsing-remitting multiple sclerosis: a randomized clinical trial. The American journal of clinical nutrition 2015;101:487-95.

50. Suliburska J, Bogdanski P, Szulinska M, Stepien M, Pupek-Musialik D, Jablecka A. Effects of green tea supplementation on elements, total antioxidants, lipids, and glucose values in the serum of obese patients. Biological trace element research 2012;149:315-22.

51. Bogdanski P, Suliburska J, Szulinska M, Stepien M, Pupek-Musialik D, Jablecka A. Green tea extract reduces blood pressure, inflammatory biomarkers, and oxidative stress and improves parameters associated with insulin resistance in obese, hypertensive patients. Nutrition research 2012;32:421-7.

52. Josic J, Olsson AT, Wickeberg J, Lindstedt S, Hlebowicz J. Does green tea affect postprandial glucose, insulin and satiety in healthy subjects: a randomized controlled trial. Nutr J 2010;9:63.

53. Marin L, Miguelez EM, Villar CJ, Lombo F. Bioavailability of dietary polyphenols and gut microbiota metabolism: antimicrobial properties. Biomed Res Int 2015;2015:905215.

54. Canfora EE, Jocken JW, Blaak EE. Short-chain fatty acids in control of body weight and insulin sensitivity. Nature reviews Endocrinology 2015.

55. Lambert JD, Sang S, Yang CS. Biotransformation of green tea polyphenols and the biological activities of those metabolites. Mol Pharm 2007;4:819-25. 



\title{
CHAPTER 3
}

\author{
Short-term supplementation with a specific \\ combination of dietary polyphenols increases \\ energy expenditure and alters substrate \\ metabolism in overweight subjects
}




\section{Abstract}

Background and Objectives: Impaired regulation of lipid oxidation (metabolic inflexibility) is associated with obesity and type 2 diabetes mellitus. Recent evidence has indicated that dietary polyphenols may modulate mitochondrial function, substrate metabolism and energy expenditure (EE) in humans. The present study investigated the effects of short-term supplementation of two combinations of polyphenols on energy expenditure (EE) and substrate metabolism in overweight subjects.

Subjects and Methods: 18 healthy overweight volunteers (9 women, 9 men; age $35 \pm 2.5$ yrs; BMI $28.9 \pm 0.4 \mathrm{~kg} / \mathrm{m}^{2}$ ) participated in a randomized, double-blind cross-over trial. Combinations of epigallocatechin-3-gallate (E, $282 \mathrm{mg} / \mathrm{d})+\operatorname{resveratrol}(\mathrm{R}, 200 \mathrm{mg} / \mathrm{d})$, and $\mathrm{E}+\mathrm{R}+80 \mathrm{mg} / \mathrm{d}$ soy isoflavones (S), or placebo capsules (PLA) were supplemented twice daily for a period of 3 days. On day 3, circulating metabolite concentrations, EE and substrate oxidation (using indirect calorimetry) were measured during fasting and postprandial conditions for 6 hours (high-fat-mixed meal (2.6 MJ, 61.2 energy\% fat)).

Results: Short-term supplementation of $\mathrm{E}+\mathrm{R}$ increased resting $\mathrm{EE}$ ( $\mathrm{E}+\mathrm{R}$ vs. PLA: $5.45 \pm 0.24$ vs. $5.23 \pm 0.25 \mathrm{~kJ} / \mathrm{min}, \mathrm{P}=0.039)$, whereas both $\mathrm{E}+\mathrm{R}(699 \pm 18 \mathrm{~kJ} / 120 \mathrm{~min}$ vs. $676 \pm 20 \mathrm{~kJ} / 120 \mathrm{~min}, \mathrm{P}=0.028)$ and $\mathrm{E}+\mathrm{R}+\mathrm{S}(704 \pm 18 \mathrm{~kJ} / 120 \mathrm{~min} v s .676 \pm 20 \mathrm{~kJ} / 120 \mathrm{~min}$, $\mathrm{P}=0.014)$ increased 2-4 h-postprandial EE compared with PLA. Metabolic flexibility, calculated as the postprandial increase to highest respiratory quotient achieved, tended to be improved by $\mathrm{E}+\mathrm{R}$ compared with PLA and $\mathrm{E}+\mathrm{R}+\mathrm{S}$ only in men $(\mathrm{E}+\mathrm{R}$ vs. PLA: $0.11 \pm 0.02$ vs. $0.06 \pm 0.02, \mathrm{P}=0.059 ; \mathrm{E}+\mathrm{R}+\mathrm{S}: 0.03 \pm 0.02, \mathrm{P}=0.009) . \mathrm{E}+\mathrm{R}+\mathrm{S}$ increased fasting plasma free fatty acid $(\mathrm{P}=0.064)$ and glycerol $(\mathrm{P}=0.021)$ concentrations compared with PLA.

Conclusions: We demonstrated for the first time that combined $\mathrm{E}+\mathrm{R}$ supplementation for 3 days significantly increased fasting and postprandial EE, which was accompanied by improved metabolic flexibility in men but not women. Addition of soy isoflavones partially reversed these effects possibly due to their higher lipolytic potential. The present findings may imply that long-term supplementation of these dosages of epigallocatechin-3-gallate combined with resveratrol may improve metabolic health and body weight regulation. 


\section{Introduction}

Disturbances in lipid metabolism play a key role in the development of obesity, type 2 diabetes mellitus and cardiovascular disease. A mismatch between energy supply and expenditure as well as intrinsic disturbances in the capacity to adapt fuel oxidation to fuel availability (defined as metabolic inflexibility) in adipose tissue and skeletal muscle are major causes of obesity-related complications ${ }^{1}$.

Impairments in the lipid buffering capacity of adipose tissue may lead to lipid accumulation in non-adipose tissues (ectopic fat deposition) in conditions where oxidative capacity is insufficient ${ }^{2}$. It is well-established that lipid accumulation in the liver and skeletal muscle is strongly associated with insulin resistance ${ }^{3}$. Indeed, decreased fasting lipid oxidation and impaired switching between lipid and carbohydrate fuels in response to insulin, dietary stimuli or exercise has been observed in conditions of insulin resistance ${ }^{1,4,5}$. Underlying mechanisms for metabolic inflexibility may be a reduced mitochondrial function or capacity ${ }^{6}$, although recent studies indicate that glucose disposal rather than mitochondrial dysfunction is a determinant of substrate utilization during insulin stimulation ${ }^{7}$.

Lifestyle interventions, aiming at reducing (saturated) fat intake and increasing physical activity have been demonstrated to efficiently counteract disturbances in lipid metabolism, and seem to improve metabolic flexibility ${ }^{8,9}$. However, lifestyle interventions have been shown to be ineffective in about $30 \%$ of the subjects, indicating the need for additional preventive strategies.

Reversal of metabolic impairments by means of dietary supplementation may be a good strategy to increase the success of lifestyle interventions. Dietary polyphenols are natural components of fruits and vegetables that have recently been shown to alter substrate and energy metabolism.

Resveratrol (R), an activator of silent mating type information regulation 2 homolog 1 (SIRT1, a member of the NAD+ dependent deacetylases family of sirtuins) and peroxisome proliferator-activated receptor gamma co-activator 1 alpha (PGC-1 $\alpha$ ), that is abundantly present in grape skin, has been shown to exert significant effects on whole-body energetics, mitochondrial function and insulin sensitivity in animal models ${ }^{10,11}$. We have recently demonstrated for the first time in humans that 30 days $R$ supplementation $(150 \mathrm{mg} / \mathrm{d})$ 
improved metabolic profile, metabolic flexibility and skeletal muscle mitochondrial function, and evoked a reduction in energy expenditure (EE) ${ }^{12}$.

In addition to $\mathrm{R}$, it has been shown that the most potent polyphenol from green tea, epigallocatechin-3-gallate (E), may increase fat oxidation ${ }^{13-15}$ and EE ${ }^{14,16}$ in humans, although data are certainly not consistent ${ }^{13-18}$. Furthermore, human intervention studies have demonstrated that moderate dosing of green tea extract, containing $900 \mathrm{mg}$ polyphenols $+366 \mathrm{mg}$ E, may improve glucose tolerance ${ }^{19}$ and induce a shift in substrate oxidation towards a more oxidative phenotype in human skeletal muscle ${ }^{20}$.

Finally, soy isoflavones, in particular genistein, may beneficially affect lipid and glucose metabolism by reducing lipid accumulation in the liver ${ }^{21}$ and adipose tissue ${ }^{22}$. Improvements in homeostatic model assessment of insulin resistance (HOMA-IR), fasting glucose and area under the curve (AUC) during an oral glucose tolerance test were attributed to soy isoflavone supplementation in postmenopausal women ${ }^{23}$. In line with these findings, insulin-sensitizing effects have been demonstrated in rodents ${ }^{24}$. Short-term supplementation studies investigating the effects of soy isoflavones on lipid metabolism are completely lacking.

Altogether, there are strong indications that polyphenols may be attractive candidates in the prevention of chronic metabolic diseases through modulation of pathways of fatty acid metabolism and mitochondrial function. Importantly, however, rather than increasing the dosages of single supplements, which appeared to deteriorate possible supplementation effects ${ }^{16,25}$, it might be more efficient to combine lower dosages of multiple supplements to achieve metabolic and beneficial health effects. These potential synergies of polyphenols have already been indicated for lipolysis ${ }^{26}$ and $\mathrm{EE}^{14,16}$.

So far, the additive or possibly synergistic effects of combinations of specific polyphenols on fat oxidation and metabolic profile in humans have not been addressed. The aim of the present study was to examine the effects of short-term supplementation of a combination of specific polyphenols, with partly distinct mechanisms of action, on EE and substrate metabolism in overweight humans. 


\section{Subjects and Methods}

\section{Subjects}

Eighteen healthy, weight-stable overweight (BMI, 25-30 kg/m²) Caucasian subjects (age, $20-50 \mathrm{yrs})$ with a normal fasting glucose $(<6.1 \mathrm{mmol} / \mathrm{l})$ and normal blood pressure (systolic blood pressure, $100-140 \mathrm{mmHg}$; diastolic blood pressure, $60-90 \mathrm{mmHg}$ ) participated in this study. Subjects were assigned to order of treatments according to a computer-generated, randomization plan (block size, $n=6$ ). An independent researcher generated the randomization and provided the blinded supplements. Exclusion criteria were (a history of) diabetes, coagulation disorders, pulmonary, cardiovascular, hepatic, renal or gastrointestinal diseases, liver or thyroid disorders. Furthermore, subjects were excluded when using dietary supplements, amongst others vitamins, electrolytes or antioxidants, or having a high habitual intake of caffeine ( $>300 \mathrm{mg} /$ day), green tea $(>1 \mathrm{cup} / \mathrm{d})$ or alcohol $(>20 \mathrm{~g} / \mathrm{d})$. Finally, subjects were excluded from participation if they were on a special diet, donated blood, took antibiotics, followed intense fitness training, were smokers, pregnant or lactating, or were using drugs or medication interfering with the outcomes of the present study, over the 3 months prior to the start of the study. All procedures were according to the Declaration of Helsinki, all subjects gave written informed consent for the study, which was reviewed and approved by the local Medical Ethical Committee of the Maastricht University Medical Center ${ }^{+}$.

\section{Study design}

In this double-blind randomized placebo-controlled cross-over trial, subjects received two combinations of polyphenol supplements and placebo in randomized order: [1] epigallocatechin-3-gallate (E: $282 \mathrm{mg} / \mathrm{d})+$ resveratrol (RSV: $200 \mathrm{mg} / \mathrm{d}) ;[2] \mathrm{E}+\mathrm{R}+$ soy isoflavones (S: $80 \mathrm{mg} / \mathrm{d}$ ) and [3] placebo (PLA), containing partly hydrolyzed microcrystalline cellulose. Subjects consumed supplements orally for 2 days (twice daily at breakfast and dinner) and during the clinical investigation day (day 3) supplements were taken at arrival and simultaneously with the high-fat mixed meal. There was a wash-out period of at least 7 days between supplementation periods. 
Chapter 3

\section{Clinical investigation day}

Subjects were asked to maintain their habitual eating and physical activity pattern throughout the study. To standardize their eating pattern throughout the supplementation days, subjects were asked to keep a 3-day dietary record during the first supplementation period. Based on these first period records food intake was standardized during the second and third supplementation period. Furthermore, subjects were asked to refrain from drinking alcohol and intensive exercise $48 \mathrm{~h}$ prior to the study day, and to consume a lowfat, carbohydrate-rich meal at the evening prior to the study day. After an overnight fast of at least $12 \mathrm{~h}$, subjects arrived at the laboratory (Maastricht University Medical Center ${ }^{+}$) by car or bus. After ingestion of half of the daily amount of supplements, a cannula was inserted into an antecubital vein for blood sampling. Blood was sampled under fasting conditions ( $\mathrm{t}=0 \mathrm{~min})$ and for $6 \mathrm{~h}$ after the intake of a liquid high-fat mixed meal (consumed within 5 min at $\mathrm{t}=0 \mathrm{~min}$ ) at $\mathrm{t}=30,60,90,120,180,240,300$ and $360 \mathrm{~min}$. The liquid highfat mixed meal had an energy content of $2.6 \mathrm{MJ}$ (61 energy\% fat, 33 energy\% carbohydrate, 6 energy\% protein). Samples were immediately centrifuged $\left(3000 \mathrm{rpm}, 4{ }^{\circ} \mathrm{C}\right.$, $10 \mathrm{~min}$ ) and plasma aliquots were immediately snap-frozen in liquid nitrogen before storage at $-80^{\circ} \mathrm{C}$ until further analysis. Fasting and postprandial energy expenditure and substrate oxidation were measured by indirect calorimetry, using an open-circuit ventilated hood system (Omnical, Maastricht University, The Netherlands) ${ }^{27}$.

\section{Supplements}

The test products were commercial available via Pure Encapsulations Inc. (Massachusetts, USA) and were encapsulated for blinding by Wellspring Clinical Services (Placebo Lot 15897, Teavigo Lot 15898, Resveratrol Extra Lot: 15899, Soy Isoflavone 40 Lot: 15900). All capsules were manufactured, tested and checked in accordance to standards of EU GMP requirements.

Teavigo capsules contained 94 \% E (141 mg/capsule), Resveratrol extra contained $20 \% \mathrm{R}$ (100 mg trans-resveratrol/capsule, combined with $46 \mathrm{mg}$ grape seed polyphenols and 12,5 $\mathrm{mg}$ red wine polyphenols), and Soy Isoflavone 40 contained $40 \%$ isoflavones (40 $\mathrm{mg}$ soy isoflavones/capsule (100 mg)). Placebo capsules were filled with microcrystalline cellulose and encapsulated equally as the active supplements. Daily supplemented polyphenol 
amounts (E, $300 \mathrm{mg} / \mathrm{d} ; \mathrm{R}, 150 \mathrm{mg} / \mathrm{d} ; \mathrm{S}, 150 \mathrm{mg} / \mathrm{d}$ ) have been shown to be safe and welltolerated in humans ${ }^{12,28,29}$.

\section{Blood analyses}

Blood was sampled into pre-chilled EDTA tubes (0.2 M EDTA (Sigma, Dorset, UK)). Plasma FFA, triglycerides (TAG) and glucose were measured with enzymatic assays on an automated spectrophotometer (ABX Pentra 400 autoanalyzer, Horiba ABX, Montpellier, France). Plasma free glycerol was measured with an enzymatic assay (Enzytec ${ }^{\mathrm{TM}}$ Glycerol, Roche Biopharm, Switzerland) automated on a Cobas Fara spectrophotometric autoanalyzer (Roche Diagnostics, Basel, Switzerland). Circulating plasma insulin, adiponectin and leptin concentrations were determined using commercially available radioimmunoassay (RIA) kits (Human Insulin specific RIA, Human Adiponectin RIA, Human Leptin RIA, Millipore Corporation, MA, USA). Catecholamin analysis was performed using high performance liquid chromatography with electrochemical detection (ClinRep ${ }^{\circledR}$ Complete Kit for Catecholamines in Plasma, RECIPE chemicals \& Instruments $\mathrm{GmbH}$, Munich, Germany). Plasma concentrations of inflammatory markers (Interleukin-6 (IL6), Interleukin-8 (IL8) and tumor necrosis factor $\alpha(\mathrm{TNF} \alpha)$ ) were determined using a multiplex enzyme-linked immuno-sorbent assay (ELISA) (Human ProInflammatory II 4Plex Ultra-Sensitive Kit, Meso Scale Diagnositics, MD, USA).

\section{Calculations}

The equations of Weir ${ }^{30}$ and Frayn ${ }^{31}$ were used to calculate energy expenditure and the total rate of fat and carbohydrate oxidation, assuming that protein oxidation accounts for 15 $\%$ of total energy expenditure. Calculations are based on measurements of $\mathrm{VO}_{2}$ consumption and $\mathrm{VCO}_{2}$ production $(1 / \mathrm{min})$, averaged over 20 minutes for each time point.

Energy Expenditure $(\mathrm{EE})(\mathrm{kJ} / \mathrm{min})=\left(3.9 * \mathrm{VO}_{2}\right)+\left(1.1 * \mathrm{VCO}_{2}\right)$

Carbohydrate oxidation $(\mathrm{CHO})(\mathrm{g} / \mathrm{min})=\left(4.55 * \mathrm{VCO}_{2}\right)-\left(3.21 * \mathrm{VO}_{2}\right)-(2.87 * \mathrm{~N})$

Fat oxidation $(\mathrm{FAT})(\mathrm{g} / \mathrm{min})=\left(1.67 * \mathrm{VO}_{2}\right)-\left(1.67 * \mathrm{VCO}_{2}\right)-(1.92 * \mathrm{~N})$

$\mathrm{N}(\mathrm{g} / \mathrm{min})=((0.15 * \mathrm{EE}) / 17) / 6.25$

Macronutrient oxidation as percentages of energy expenditure:

$\mathrm{CHO} / \mathrm{EE}(\%)=(\mathrm{CHO} *(17 \mathrm{~kJ} / \mathrm{g})) / \mathrm{EE}$

$\mathrm{FAT} / \mathrm{EE}(\%)=\left(\mathrm{FAT}^{*}(39 \mathrm{~kJ} / \mathrm{g})\right) / \mathrm{EE}$

Metabolic Flexibility $=$ Postprandial $\mathrm{RQ}_{\text {Max }}-\mathrm{RQ}_{\text {Fasting }}$ 


\section{Statistics}

All data are given as means \pm standard error of means (SEM). The postprandial response is expressed as AUC and incremental AUC (iAUC), which is calculated by the trapezoid method. iAUC values are used, when differences in resting values are different. AUC and iAUC values are given as total (0-6 h), or divided in periods of 2 hours $(0-2 \mathrm{~h}, 2-4 \mathrm{~h}, 4-6 \mathrm{~h})$. Differences in fasting and postprandial AUC values between treatments were analyzed using analysis of variance (ANOVA), with gender as covariate. Only in case of a trend or a significance of a treatment (treat) effect or treatment-gender (treat*gender) interaction, post-hoc analyses with LSD correction were performed. Trends and significant outcomes of ANOVA and post-hoc tests are summarized in Table 3.2. Statistics was done using SPSS 19.0 for Macintosh. $\mathrm{P}<0.05$ was considered statistically significant.

\section{Results}

\section{Subjects' characteristics at baseline}

Eighteen healthy, overweight men and women volunteered to participate in this study. Subjects' characteristics are presented in Table 3.1. No major differences in macronutrient composition of the diet and energy intake could be identified between subjects $(3500 \mathrm{kcal} / 2$ d (14.8 MJ/2 d), 47.9 energy\% CHO, 36.5 energy\% FAT, 14.7 energy\% PRO).

Table 3.1. Subjects' characteristics.

\begin{tabular}{lccc}
\hline & Total, $\mathrm{n}=18$ & Men, $\mathrm{n}=9$ & Women, $\mathrm{n}=9$ \\
& & & \\
\hline Age, years & $34.0 \pm 2.6$ & $35.0 \pm 2.5$ & $33.0 \pm 2.8$ \\
Weight, kg & $86.6 \pm 2.9$ & $91.5 \pm 3.3$ & $81.6 \pm 1.9$ \\
Length, $\mathrm{m} *$ & $1.73 \pm 0.02$ & $1.76 \pm 0.02$ & $1.70 \pm 0.02$ \\
Body-mass-index, kg/m ${ }^{2}$ & $28.9 \pm 0.4$ & $29.5 \pm 0.4$ & $28.4 \pm 0.4$ \\
Fat mass, \% * & $27.3 \pm 1.9$ & $21.6 \pm 1.1$ & $33.0 \pm 1.5$ \\
Fat mass, kg * & $23.3 \pm 1.5$ & $19.7 \pm 1.2$ & $26.8 \pm 1.2$ \\
Waist-to-hip ratio * & $0.83 \pm 0.03$ & $0.92 \pm 0.01$ & $0.76 \pm 0.02$ \\
Systolic blood pressure, $\mathrm{mmHg} *$ & $121 \pm 2$ & $126 \pm 1$ & $116 \pm 3$ \\
Diastolic blood pressure, $\mathrm{mmHg}$ & $81 \pm 2$ & $84 \pm 2$ & $78 \pm 1$ \\
Fasting glucose, mmol/1 & $5.00 \pm 0.09$ & $5.07 \pm 0.09$ & $4.93 \pm 0.09$ \\
Fasting insulin, mU/1 * & $15.4 \pm 1.4$ & $18.6 \pm 1.3$ & $12.1 \pm 1.1$ \\
HOMA-IR * & $3.45 \pm 0.33$ & $4.21 \pm 0.31$ & $2.69 \pm 0.25$ \\
\hline \hline
\end{tabular}

Values are given as means \pm SEM. HOMA-IR: homeostatic model assessment of insulin resistance; Statistical significant difference between gender indicated as *, when $\mathrm{P}<0.05$. 


\section{Energy expenditure and substrate oxidation}

Resting EE after an overnight fast was significantly higher during E+R compared to PLA supplementation $(5.45 \pm 0.24$ vs. $5.23 \pm 0.25 \mathrm{~kJ} / \mathrm{min}, 7843 \pm 250 v s .7528 \pm 254 \mathrm{~kJ} / \mathrm{d}(1.30 \pm 0.04$ vs. $1.25 \pm 0.04 \mathrm{kcal} / \mathrm{min}, 1873 \pm 60$ vs. $1798 \pm 61 \mathrm{kcal} / \mathrm{d}, \mathrm{P}=0.039$ ) (Figure $3.1 \mathrm{~A}$ ).

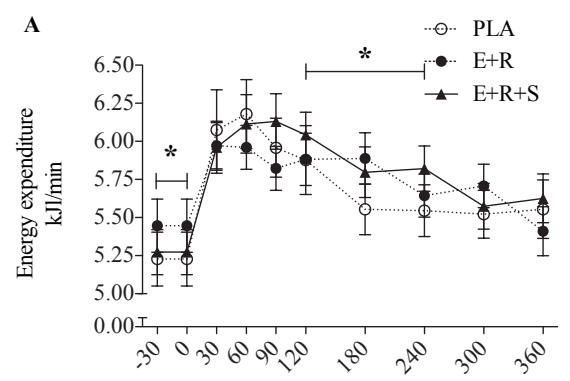

C

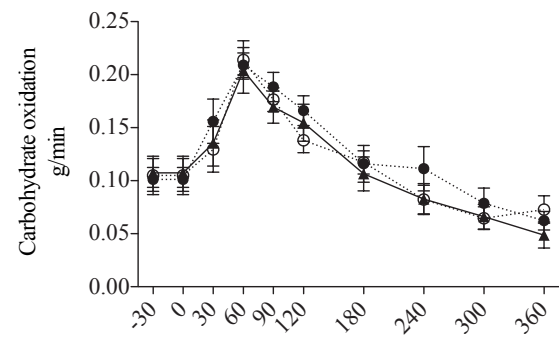

$\mathbf{E}$

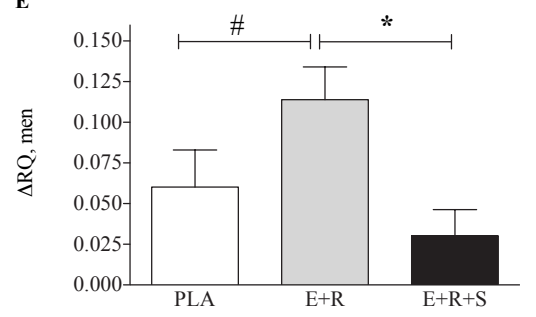

B

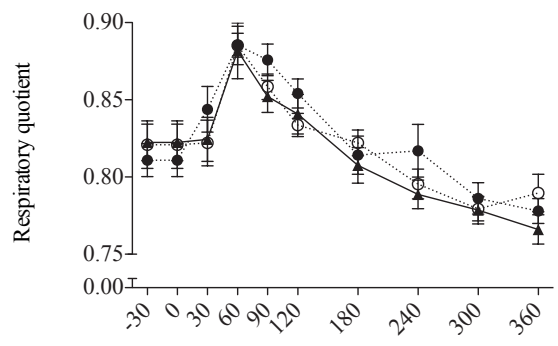

D

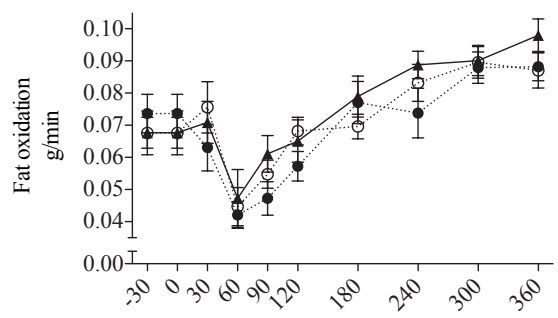

$\mathbf{F}$

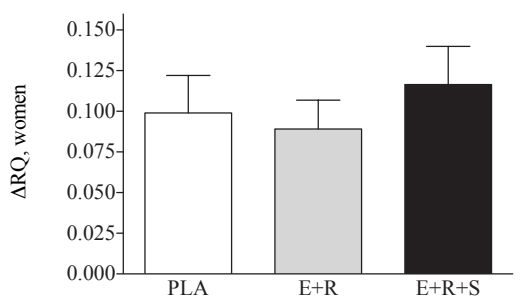

Figure 3.1. Substrate oxidation and energy expenditure before and after a high-fat mixed meal after 3 day polyphenol supplementation $(t=0)$.

Values are given as means \pm SEM (A-D: $n=18, E-F: n=9)$. A-D: Dashed line, circles: PLA, Solid line, solid circles: $\mathrm{E}+\mathrm{R}$, solid line, triangle: $\mathrm{E}+\mathrm{R}+\mathrm{S}$; E-F: white: PLA, grey: $\mathrm{E}+\mathrm{R}$, black: $\mathrm{E}+\mathrm{R}+\mathrm{S}$. Statistical significance indicated as *, when post-hoc testing $\mathrm{P}<0.05$. 
Postprandial EE remained elevated during $\mathrm{E}+\mathrm{R}$ as well as $\mathrm{E}+\mathrm{R}+\mathrm{S}$ during the midpostprandial period compared with PLA $\left(\mathrm{AUC}_{2-4 \mathrm{~h}}\right.$ : PLA, $675 \pm 20 \mathrm{~kJ} / 2 \mathrm{~h}(161 \pm 5 \mathrm{kcal} / 2 \mathrm{~h})$ vs. $\mathrm{E}+\mathrm{R}, 699 \pm 18(167 \pm 4 \mathrm{kcal} / 2 \mathrm{~h}), P=0.03$; PLA $v s . \mathrm{E}+\mathrm{R}+\mathrm{S}, 703 \pm 18 \mathrm{~kJ} / 2 \mathrm{~h}(168 \pm 4 \mathrm{kcal} / 2$ h), $P=0.02$ ) (Figure 3.1A). No significant effects were observed for respiratory quotient (RQ) (Figure 3.1B), carbohydrate (Figure 3.1C) and fat oxidation (Figure 3.1D) in the fasting and postprandial period. In men, metabolic flexibility (calculated as the difference between fasting and highest postprandial RQ) was increased during $E+R$ treatment as compared to PLA ( $\mathrm{E}+\mathrm{R} v$ s. $\mathrm{PLA}, \mathrm{P}=0.059)$ and as compared to $\mathrm{E}+\mathrm{R}+\mathrm{S}$ supplementation $(\mathrm{E}+\mathrm{R} v s . \mathrm{E}+\mathrm{R}+\mathrm{S}, \mathrm{P}=0.009)$ for men (Figure 3.1E), but not for women (Figure 3.1F). No differences were observed for the time point, at which the highest RQ was reached (PLA: $\mathrm{t}=81.7 ; \mathrm{E}+\mathrm{R}: \mathrm{t}=85.0 ; \mathrm{E}+\mathrm{R}+\mathrm{S}: \mathrm{t}=81.7 \mathrm{~min})$.

\section{Circulating metabolite concentrations}

Fasting and postprandial plasma glucose (Figure 3.2A) and insulin concentrations (Figure 3.2B) were not significantly affected by supplementation of combinations of polyphenols. Fasting lactate concentrations were not different between treatments, but overall lactate response was lower during $\mathrm{E}+\mathrm{R}+\mathrm{S}$ compared with PLA $\left(\mathrm{AUC}_{0-6 \mathrm{~h}}: 346.0 \pm 17.3\right.$ vs. $374.7 \pm 18.8 \mathrm{mmol} /(1 * 6 \mathrm{~h}), P=0.024$ ) (Figure $3.2 \mathrm{C}$ ). No significant treatment effects were observed for plasma TAG concentrations (Figure 3.2D), whereas fasting FFA concentrations tended to be increased by $\mathrm{E}+\mathrm{R}+\mathrm{S}$ compared with PLA (508 \pm 51 vs. $401 \pm 28$ $\mu \mathrm{mol} / 1, P=0.06$, Figure 3.2E). In line, FFA concentrations were higher in the postprandial phase during $\mathrm{E}+\mathrm{R}+\mathrm{S}$ compared with PLA as well as with $\mathrm{E}+\mathrm{R}\left(\mathrm{AUC}_{0-360}\right.$ : PLA: $146 \pm 7$, $\mathrm{E}+\mathrm{R}: 148 \pm 8, \mathrm{E}+\mathrm{R}+\mathrm{S}: 163 \pm 10 \mathrm{mmol} /(1 * 6 \mathrm{~h}), P=0.06 ; \mathrm{E}+\mathrm{R}+\mathrm{S} v s . \mathrm{E}+\mathrm{R}, P=0.02) . \mathrm{E}+\mathrm{R}$ had no significant effects on plasma FFA concentrations compared with PLA (Figure 3.2E). Finally, fasting glycerol concentrations were elevated by $\mathrm{E}+\mathrm{R}+\mathrm{S}$ compared with PLA $(\mathrm{E}+\mathrm{R}+\mathrm{S} v s$. PLA, $\mathrm{P}=0.02$ ), with no differences in postprandial conditions (Figure 3.2F).

\section{Circulating adipokine and norepinephrine concentrations}

Fasting leptin concentrations were elevated after E+R compared with PLA and E+R+S supplementation in women, but not in men (women, PLA: $13.6 \pm 1.9$ ( $v s . \mathrm{E}+\mathrm{R}, \mathrm{p}<0.01$ ), $\mathrm{E}+\mathrm{R}: 15.6 \pm 1.4, \mathrm{E}+\mathrm{R}+\mathrm{S}: 13.5 \pm 1.7 \mu \mathrm{g} / \mathrm{l}(v s . \mathrm{E}+\mathrm{R}, \mathrm{p}<0.01)$, Figure 3.3A-C). There were no significant differences in adiponectin (Figure 3.3D) and norepinephrine (Figure 3.3E) 
concentrations between treatments. Plasma concentrations of IL-6, IL-8 and TNF- $\alpha$ were not changed after polyphenol supplementation compared with PLA (Figures 3.3F-H).
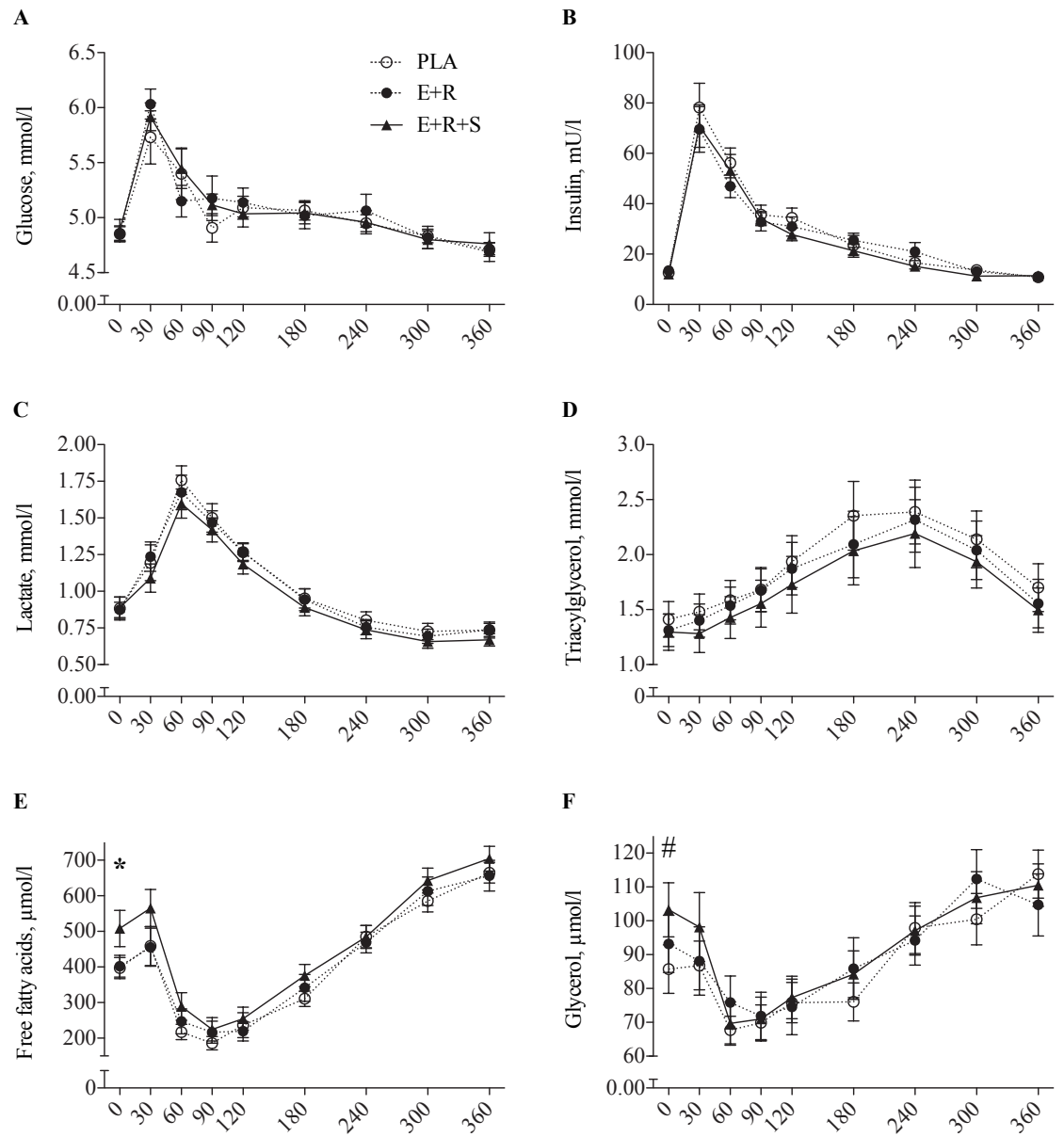

Figure 3.2. Plasma metabolite concentrations after 3 day supplementation before and after a high-fat mixed meal $(t=0)$.

Values are given as means \pm SEM $(n=18)$. Dashed line, circles: PLA, Solid line, solid circles: $E+R$, solid line, triangle: $\mathrm{E}+\mathrm{R}+\mathrm{S}$. Statistical significance for ANOVA indicated as *, when $\mathrm{P}<0.05$; trends indicated as \#, when $\mathrm{P}<0.10$. 
Chapter 3

A

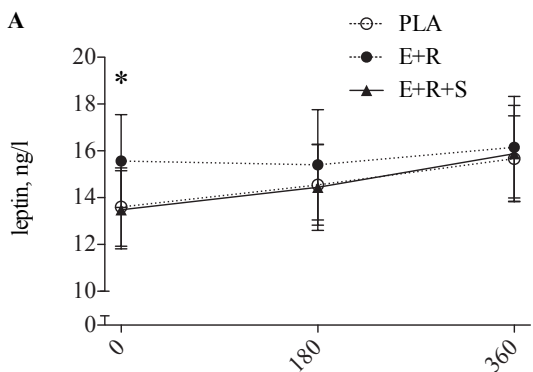

C

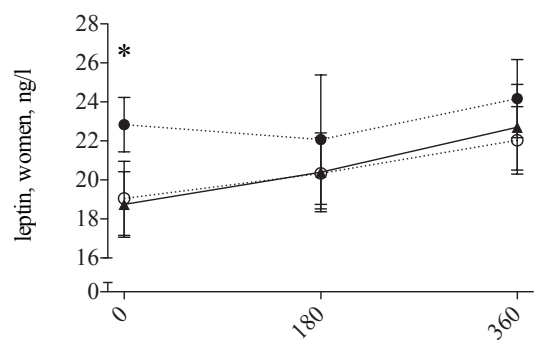

E

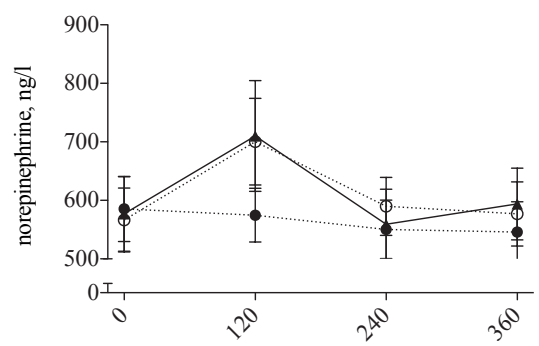

G

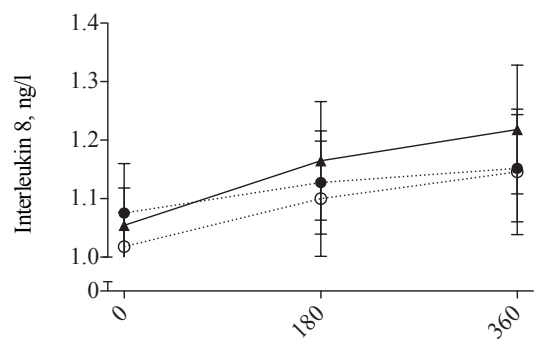

B

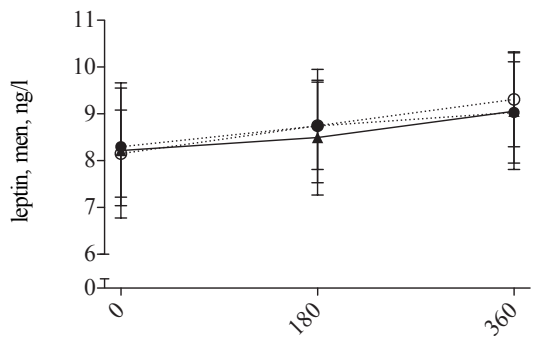

D

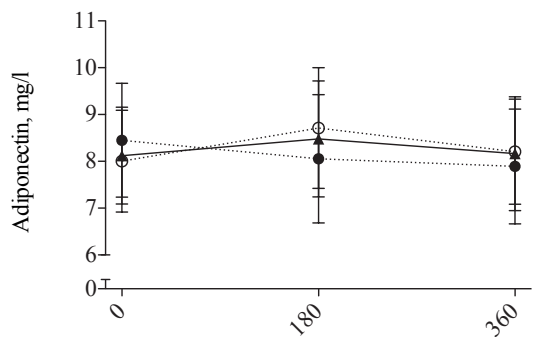

F

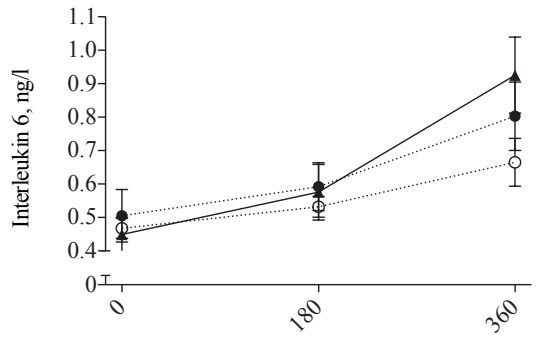

H

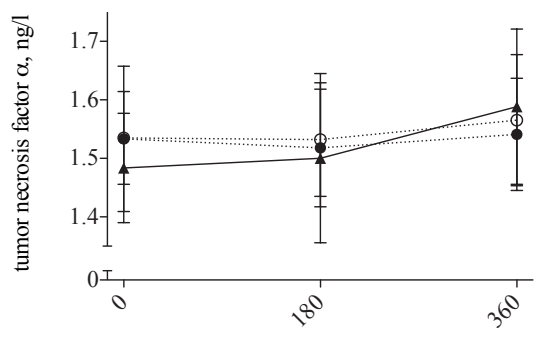

Figure 3.3. Plasma adipokine, norepinephrine \& cytokine concentrations after 3 day supplementation before and after a high-fat mixed meal $(t=0)$.

Values are given as means \pm SEM $(n=18)$. Dashed line, circles: PLA, Solid line, solid circles: $E+R$, solid line, triangle: $\mathrm{E}+\mathrm{R}+\mathrm{S}$. Statistical significance indicated as *, if $\mathrm{P}<0.05$. 
Table 3.2. ANOVA outcome of selected variables

\begin{tabular}{|c|c|c|c|c|c|c|c|c|c|}
\hline & Period & & $\mathrm{P}_{\text {treat }}$ & $P_{\text {treat*sex }}$ & group & PLA & $E+R$ & $\mathrm{E}+\mathrm{R}+\mathrm{S}$ & $\mathrm{P}$ \\
\hline \multirow[t]{8}{*}{$\overline{E E}$} & $\mathrm{t}=0$ & $\mathrm{~kJ} / \mathrm{min}$ & 0.12 & 0.59 & total & 5.23 & $5.45^{1)}$ & 5.27 & ${ }^{1)} 0.04$ \\
\hline & $\mathrm{AUC}_{0-2 \mathrm{~h}}$ & $\mathrm{~kJ} / 2 \mathrm{~h}$ & 0.51 & 0.19 & total & 705 & 699 & 712 & \\
\hline & $\mathrm{AUC}_{2-4 \mathrm{~h}}$ & $\mathrm{~kJ} / 2 \mathrm{~h}$ & 0.01 & 0.68 & total & 676 & $699^{1 \mathrm{a})}$ & $704^{1 b)}$ & $\begin{array}{l}\text { 1a) } 0.03 \\
{ }^{\text {lb) }} 0.01\end{array}$ \\
\hline & $\mathrm{AUC}_{4-6 \mathrm{~h}}$ & $\mathrm{~kJ} / 2 \mathrm{~h}$ & 0.33 & 0.68 & total & 664 & 674 & 678 & \\
\hline & iAUC $_{0-2 h}$ & $\mathrm{~kJ} / 2 \mathrm{~h}$ & 0.04 & 0.29 & total & 78 & $46^{1), 2)}$ & 79 & ${ }^{1)} 0.04$ \\
\hline & & & & & & & & & ${ }^{2)} 0.02$ \\
\hline & iAUC $_{2-4 h}$ & $\mathrm{~kJ} / 2 \mathrm{~h}$ & 0.23 & 0.61 & total & 49 & 45 & 71 & \\
\hline & $\mathrm{iAUC}_{4-6 \mathrm{~h}}$ & $\mathrm{~kJ} / 2 \mathrm{~h}$ & 0.23 & 0.38 & total & 37 & 20 & 45 & \\
\hline \multirow[t]{2}{*}{$\Delta \mathrm{RQ}$} & & & 0.31 & 0.03 & total & 0.08 & 0.1 & 0.07 & \\
\hline & & & & & men & 0.06 & $0.11^{1), 2)}$ & 0.03 & $\begin{array}{l}{ }^{1)} 0.06 \\
{ }^{2)} 0.01\end{array}$ \\
\hline \multicolumn{10}{|c|}{ Lactate } \\
\hline & $\mathrm{t}=0$ & $\mathrm{mmol} / 1$ & 0.95 & 0.41 & total & 0.9 & 0.9 & 0.9 & \\
\hline & $\mathrm{AUC}_{0-6 \mathrm{~h}}$ & $\mathrm{mmol} /(1 * 6 \mathrm{~h})$ & 0.04 & 0.31 & total & 382 & 367 & $337^{1)}$ & ${ }^{1)} 0.02$ \\
\hline & iAUC $_{0-6 \mathrm{~h}}$ & $\mathrm{mmol} /(1 * 6 \mathrm{~h})$ & 0.11 & 0.94 & total & 58 & 50 & 22 & \\
\hline \multicolumn{10}{|l|}{ FFA } \\
\hline & $\mathrm{t}=0$ & $\mu \mathrm{mol} / 1$ & 0.04 & 0.98 & total & 401 & 402 & $508^{1), 2)}$ & $\begin{array}{l}{ }^{1)} 0.06 \\
{ }^{2)} 0.06\end{array}$ \\
\hline & $\mathrm{AUC}_{0-6 \mathrm{~h}}$ & $\mathrm{mmol} /(1 * 6 \mathrm{~h})$ & 0.08 & 0.56 & total & 146 & 148 & $163^{1), 2)}$ & $\begin{array}{l}{ }^{1)} 0.09 \\
{ }^{2)} 0.04\end{array}$ \\
\hline & $\mathrm{AUC}_{0-2 \mathrm{~h}}$ & $\mathrm{mmol} /(1 * 2 \mathrm{~h})$ & 0.01 & 0.35 & total & 35 & 37 & $44^{1), 2)}$ & $\begin{array}{l}{ }^{1)} 0.02 \\
{ }^{2)} 0.01\end{array}$ \\
\hline & $\mathrm{AUC}_{2-4 \mathrm{~h}}$ & $\mathrm{mmol} /\left(\mathrm{l}^{* 2} \mathrm{~h}\right)$ & 0.40 & 0.54 & total & 41 & 40 & 45 & \\
\hline & $\mathrm{AUC}_{4-6 \mathrm{~h}}$ & $\mathrm{mmol} /(1 * 2 \mathrm{~h})$ & 0.38 & 0.91 & total & 70 & 71 & 74 & \\
\hline & iAUC $_{0-6 \mathrm{~h}}$ & $\mathrm{mmol} /(1 * 6 \mathrm{~h})$ & 0.32 & 0.95 & total & 0.9 & 2.2 & -20.2 & \\
\hline \multicolumn{10}{|c|}{ Glycerol } \\
\hline & $\mathrm{t}=0$ & $\mu \mathrm{mol} / 1$ & 0.06 & 0.65 & total & 85.7 & 93.2 & $103.3^{1)}$ & ${ }^{1)} 0.02$ \\
\hline & $\mathrm{AUC}_{0-6 \mathrm{~h}}$ & $\mathrm{mmol} /(1 * 6 \mathrm{~h})$ & 0.71 & 0.48 & total & 31.7 & 32.5 & 32.8 & \\
\hline & iAUC $_{0-6 h}$ & $\mathrm{mmol} /(1 * 6 \mathrm{~h})$ & 0.45 & 0.60 & total & 0.05 & -1.59 & -1.1 & \\
\hline \multicolumn{10}{|l|}{ TAG } \\
\hline \multirow{5}{*}{ Leptin } & $\mathrm{t}=0$ & $\mathrm{mmol} / \mathrm{l}$ & 0.40 & 0.11 & total & 1.4 & 1.3 & 1.3 & \\
\hline & $\mathrm{AUC}_{0-6 \mathrm{~h}}$ & $\mathrm{mmol} /\left(1^{*} 6 \mathrm{~h}\right)$ & 0.19 & 0.49 & total & 714 & 690 & 640 & \\
\hline & iAUC $_{0-6 \mathrm{~h}}$ & $\mathrm{mmol} /\left(1^{*} 6 \mathrm{~h}\right)$ & 0.11 & 0.13 & total & 206 & 212 & 173 & \\
\hline & $\mathrm{t}=0$ & $\mathrm{ng} / \mathrm{l}$ & 0.03 & 0.04 & total & 13.6 & $15.6^{1), 2)}$ & 13.5 & $\begin{array}{l}{ }^{1)} 0.04 \\
{ }^{2)} 0.02\end{array}$ \\
\hline & $\mathrm{t}=0$ & $\mathrm{ng} / \mathrm{l}$ & & & women & 19.1 & $22.8^{1), 2)}$ & 18.7 & $\begin{array}{l}{ }^{1)} 0.01 \\
{ }^{2)} 0.01\end{array}$ \\
\hline
\end{tabular}

AUC: Area under the curve; iAUC: incremental AUC; t: treatment, $t * s$ : treatment*sex; EE: energy expenditure; $\triangle \mathrm{RQ}$ : metabolic flexibility; FFA: free fatty acids; $\mathrm{E}+\mathrm{R}$ : epigallocatechin-3-gallate + resveratrol; $\mathrm{E}+\mathrm{R}+\mathrm{S}$ : $\mathrm{E}+\mathrm{R}+$ soy isoflavones; PLA: placebo; 1 ): statistically significant different from PLA; 2: statistically significant difference between polyphenol treatments. 


\section{Discussion}

We hypothesized that a combination of polyphenols may act additively or synergistically to enhance EE and fat oxidation. Indeed, the present study demonstrated for the first time that short-term supplementation ( 3 days) of $\mathrm{E}+\mathrm{R}$ increased fasting and postprandial $\mathrm{EE}$ in humans. This was accompanied by a more pronounced increase in postprandial RQ, metabolic flexibility, in men but not in women. Addition of soy isoflavones partially reversed the beneficial effects of $\mathrm{E}+\mathrm{R}$, except for the increase in postprandial $\mathrm{EE}$.

No effects on resting EE have been previously found during human supplementation studies with either $\mathrm{E}$ or $\mathrm{R}$ alone in the short-term ${ }^{13,15,18}$ or long-term ${ }^{12,25,32-34}$. Potent EEstimulating effects of $\mathrm{E}$ in combination with caffeine have been reported during $12 \mathrm{~h}$ - and 24 h-measurements ${ }^{14,16}$, but this effect could not be confirmed in all studies ${ }^{17}$. Nevertheless, in the former two studies, E was only effective in combination with caffeine and not specified to either fasting or postprandial conditions ${ }^{14,16}$. Indeed, 3 day supplementation with $\mathrm{E}$ alone did not increase resting $\mathrm{EE}$ in overweight volunteers ${ }^{13,20}$, indicating that $\mathrm{R}$ or a synergistic effect of both components may be responsible for the effect on resting EE, which was found in the present study.

The potential of $\mathrm{R}$ to increase $\mathrm{EE}$ has been reported in non-human primates after supplementation for 15 weeks ${ }^{11}$. Also, studies in obese rodents observed that 6 and 10 weeks R supplementation prevented the development of obesity upon an obesogenic diet ${ }^{35,36}$. However, in the latter studies EE or other measures of energy balance such as food intake and energy excretion were not measured. In contrast, we have recently demonstrated that $30 \mathrm{~d}$ supplementation with $\mathrm{R}$ alone decreased $\mathrm{EE}$ in healthy overweight men, mimicking the effects of caloric restriction ${ }^{12}$.

There are several possible mechanisms that may explain the increased EE as a result of short-term E+R supplementation. Rodent studies indicate that E may exert its metabolic effects through an inhibition of the noradrenaline-degrading enzyme catechol-O-methyltransferase (COMT), leading to an increased norepinephrine concentration ${ }^{37,38}$. In the present study norepinephrine concentrations were not affected by $\mathrm{E}+\mathrm{R}$ supplementation, indicating that this cannot explain the observed increase in EE. We cannot exclude the possibility that $\mathrm{R}$ has counteracted $\mathrm{E}$-induced catecholamine signaling, since $\mathrm{R}$ may inhibit 
catecholamine secretion and signaling in rat cardiomyocytes and adrenal medullary cells 39,40 .

The present results indicate that $\mathrm{E}+\mathrm{R}$ supplementation increased fasting leptin concentrations. This might have contributed to the increase in EE, since leptin infusion has been shown to stimulate EE in humans ${ }^{41}$. In line with our findings, it has been shown that 3-days E supplementation increased leptin expression in adipose tissue in overweight men ${ }^{20}$. Since for E supplementation alone no increase in circulating leptin concentrations have been reported in previous short-term studies, it is tempting to postulate that $\mathrm{E}$ and $\mathrm{R}$ act synergistically to enhance leptin concentration. Interestingly, leptin concentrations remained unchanged after addition of soy isoflavone to $\mathrm{E}+\mathrm{R}$ supplementation, suggesting that S may impair leptin secretion. Indeed, Szkudelska et al. ${ }^{42}$ found that genistein attenuated leptin secretion by rodent adipocytes.

Finally, mitochondrial uncoupling in skeletal muscle, liver and (brown) adipose tissue might contribute to the observed increase in $\mathrm{EE}$ following $\mathrm{E}+\mathrm{R}{ }^{43}$. Indeed, studies in rodents reported that $\mathrm{E}$ or $\mathrm{R}$ alone stimulate expression of uncoupling proteins in tissues relevant to $\mathrm{EE}^{11,44}$. In rodent skeletal muscle, $\mathrm{R}$ stimulates PGC-1 $\alpha$, an upstream target of uncoupling genes ${ }^{11}$. Thus, it would be highly interesting to examine the effects of combined polyphenol supplementation on mitochondrial function in future studies. In summary, it remains to be determined whether $\mathrm{R}$ or the synergistic effect of $\mathrm{R}+\mathrm{E}$ is responsible for the observed increase in resting EE in humans.

Metabolic flexibility, reflected by the postprandial increase in RQ, was improved by the combination of $\mathrm{E}+\mathrm{R}$ compared with placebo in men but not women. A recent study performed in our laboratory provided evidence that E supplementation induced a slightly more oxidative phenotype in skeletal muscle of obese men ${ }^{20}$, which may improve metabolic flexibility. Additionally, we recently demonstrated that 30 days of $\mathrm{R}$ supplementation improved muscle mitochondrial respiration and induced a more oxidative phenotype of skeletal muscle in obese men, which was accompanied by improved metabolic flexibility ${ }^{12}$. In line, improved mitochondrial function after R or E treatment was found in rodents ${ }^{10,11,38}$. Thus, further research has to indicate whether R, E and/or additive or synergistic effects between both components explain the short-term improvement in metabolic flexibility in men. 
Interestingly, long-term supplementation of high doses of R $(500 \mathrm{mg} / \mathrm{d}$, 3-fold higher than in the study of Timmers et al. ${ }^{12}$ ) had no significant metabolic effects in young mildly insulin resistant obese subjects ${ }^{25}$ and that $\mathrm{R}(75 \mathrm{mg} / \mathrm{d})$ has no metabolic effects in nonobese women ${ }^{34}$, suggesting that $\mathrm{R}$ is mainly beneficial in metabolically compromised states $45 \mathrm{and} /$ or at lower dosages. Therefore, we cannot exclude the possibility that the fact that we only observed an improved metabolic flexibility in men, may be due to the more pronounced insulin resistance in men compared with women at baseline (HOMA, men: 4.21 \pm 0.44 , women: $2.69 \pm 0.35$ ). Secondly, we cannot exclude that the unaffected metabolic flexibility in women compared with men might be biased by the use of oral contraceptives and/or the phase of the menstrual cycle ${ }^{46}$, which were not taken into account in the present study.

Because metabolic flexibility and mitochondrial function are closely associated with insulin sensitivity ${ }^{1}$, it is tempting to postulate that prolonged combined $\mathrm{E}+\mathrm{R}$ supplementation may improve insulin sensitivity. This is strengthened by long-term studies in rodents, demonstrating insulin-sensitizing properties of both $\mathrm{E}$ and $\mathrm{R}^{47,48}$. Further studies have to address the long-term benefits in both the prevention as well as reversal of obesity-related health complications.

When adding soy isoflavones to the combination of $\mathrm{E}+\mathrm{R}$ the effects on resting $\mathrm{EE}$ and metabolic flexibility was completely reversed. It can be speculated that isoflavones' lipolytic potential, reflected by increased fasting and postprandial FFA concentrations in the present study, may reverse these benefits ${ }^{49}$. More specifically, synergistic amplifications of lipolysis after combination of polyphenols (resveratrol+genistein) have previously been reported ${ }^{26}$. Increased postprandial FFA concentrations may in turn reduce metabolic flexibility in healthy humans ${ }^{50}$.

In conclusion, the present study demonstrated for the first time that short-term (3 days) supplementation of low-to-moderate dosages of $\mathrm{E}+\mathrm{R}$ increased fasting and postprandial $\mathrm{EE}$, which was accompanied by improved metabolic flexibility in men but not women. Soy isoflavones partially reversed the beneficial effects of $\mathrm{E}+\mathrm{R}$, except for increased postprandial EE, possibly due to their higher lipolytic potential.

Our data indicate that the impact of polyphenol supplementation is highly dependent on the type or combination of polyphenols and on gender. Furthermore, for resveratrol supplementation it is postulated ${ }^{51,52}$ that supplementation rather prevents and reverses 
metabolic abnormalities in metabolically high-risk subjects than affecting pathways and phenotypes of originally healthy subjects, which we suggest to account for in future studies. Independent of gender and metabolic profile appears to be the increased energy expenditure. Assuming the increase achieved in this study by supplementing E+R maintains during long-term supplementation without counter regulatory effects, this may result in a $1.4 \mathrm{~kg}$-weight loss over a period of 6 months. According to findings in the US Diabetes Prevention Program, every kilogram of weight loss reduces the risk for developing diabetes by $16 \%{ }^{53}$. Importantly, long-term follow-up studies should further investigate whether these short-term metabolic effects of combined polyphenol supplementation in fact translate into long-term metabolic benefits. This would yield highly important information to further optimize polyphenol supplementation, thereby improving metabolic health and preventing metabolic disease in humans. 


\section{References}

1. Corpeleijn E, Saris WH, Blaak EE. Metabolic flexibility in the development of insulin resistance and type 2 diabetes: effects of lifestyle. Obes Rev 2009;10:178-93.

2. Goossens GH. The role of adipose tissue dysfunction in the pathogenesis of obesityrelated insulin resistance. Physiol Behav 2008;94:206-18.

3. Lara-Castro C, Garvey WT. Intracellular lipid accumulation in liver and muscle and the insulin resistance syndrome. Endocrinol Metab Clin North Am 2008;37:841-56.

4. Mensink M, Blaak EE, van Baak MA, Wagenmakers AJ, Saris WH. Plasma free Fatty Acid uptake and oxidation are already diminished in subjects at high risk for developing type 2 diabetes. Diabetes 2001;50:2548-54.

5. Blaak EE, Hul G, Verdich C, et al. Fat oxidation before and after a high fat load in the obese insulin-resistant state. J Clin Endocrinol Metab 2006;91:1462-9.

6. Chomentowski P, Coen PM, Radikova Z, Goodpaster BH, Toledo FG. Skeletal muscle mitochondria in insulin resistance: differences in intermyofibrillar versus subsarcolemmal subpopulations and relationship to metabolic flexibility. J Clin Endocrinol Metab 2011;96:494-503.

7. van de Weijer T, Sparks LM, Phielix E, et al. Relationships between Mitochondrial Function and Metabolic Flexibility in Type 2 Diabetes Mellitus. PLoS One 2013;8:e51648.

8. Tuomilehto J, Lindstrom J, Eriksson JG, et al. Prevention of type 2 diabetes mellitus by changes in lifestyle among subjects with impaired glucose tolerance. N Engl J Med 2001;344:1343-50.

9. Roumen C, Corpeleijn E, Feskens EJ, Mensink M, Saris WH, Blaak EE. Impact of 3year lifestyle intervention on postprandial glucose metabolism: the SLIM study. Diabet Med 2008;25:597-605.

10. Baur JA, Pearson KJ, Price NL, et al. Resveratrol improves health and survival of mice on a high-calorie diet. Nature 2006;444:337-42.

11. Lagouge $M$, Argmann C, Gerhart-Hines Z, et al. Resveratrol improves mitochondrial function and protects against metabolic disease by activating SIRT1 and PGC-1alpha. Cell 2006;127:1109-22.

12. Timmers S, Konings E, Bilet L, et al. Calorie restriction-like effects of 30 days of resveratrol supplementation on energy metabolism and metabolic profile in obese humans. Cell Metab 2011;14:612-22.

13. Boschmann M, Thielecke F. The effects of epigallocatechin-3-gallate on thermogenesis and fat oxidation in obese men: a pilot study. J Am Coll Nutr 2007;26:389S-95S.

14. Dulloo AG, Duret C, Rohrer D, et al. Efficacy of a green tea extract rich in catechin polyphenols and caffeine in increasing 24-h energy expenditure and fat oxidation in humans. Am J Clin Nutr 1999;70:1040-5.

15. Thielecke F, Rahn G, Bohnke J, et al. Epigallocatechin-3-gallate and postprandial fat oxidation in overweight/obese male volunteers: a pilot study. Eur J Clin Nutr 2010;64:704-13.

16. Berube-Parent S, Pelletier C, Dore J, Tremblay A. Effects of encapsulated green tea and Guarana extracts containing a mixture of epigallocatechin-3-gallate and caffeine on $24 \mathrm{~h}$ energy expenditure and fat oxidation in men. Br J Nutr 2005;94:432-6. 
17. Gregersen NT, Bitz C, Krog-Mikkelsen I, et al. Effect of moderate intakes of different tea catechins and caffeine on acute measures of energy metabolism under sedentary conditions. Br J Nutr 2009;102:1187-94.

18. Lonac MC, Richards JC, Schweder MM, Johnson TK, Bell C. Influence of ShortTerm Consumption of the Caffeine-Free, Epigallocatechin-3-Gallate Supplement, Teavigo, on Resting Metabolism and the Thermic Effect of Feeding. Obesity (Silver Spring) 2010.

19. Venables MC, Hulston CJ, Cox HR, Jeukendrup AE. Green tea extract ingestion, fat oxidation, and glucose tolerance in healthy humans. Am J Clin Nutr 2008;87:778-84.

20. Most J, van Can JGP, van Dijk JW, Goossens GH, Jocken JWE, Hospers JJ, Bendik I, Blaak EE. A 3-day EGCG supplementation reduces interstitial lactate concentration in skeletal muscle in overweight subjects. Scientific Reports 2015: 5, Article number: 17896.

21. Mohamed Salih S, Nallasamy P, Muniyandi P, Periyasami V, Carani Venkatraman A. Genistein improves liver function and attenuates non-alcoholic fatty liver disease in a rat model of insulin resistance. J Diabetes 2009;1:278-87.

22. Cederroth CR, Vinciguerra M, Kuhne F, et al. A phytoestrogen-rich diet increases energy expenditure and decreases adiposity in mice. Environ Health Perspect 2007;115:1467-73.

23. Llaneza P, Gonzalez C, Fernandez-Inarrea J, Alonso A, Diaz F, Perez-Lopez FR. Soy isoflavones improve insulin sensitivity without changing serum leptin among postmenopausal women. Climacteric 2012;15:611-20.

24. Arunkumar E, Anuradha CV. Genistein promotes insulin action through adenosine monophosphate-activated protein kinase activation and p70 ribosomal protein S6 kinase 1 inhibition in the skeletal muscle of mice fed a high energy diet. Nutr Res 2012;32:617-25.

25. Poulsen MM, Vestergaard PF, Clasen BF, et al. High-Dose Resveratrol Supplementation in Obese Men: An Investigator-Initiated, Randomized, PlaceboControlled Clinical Trial of Substrate Metabolism, Insulin Sensitivity, and Body Composition. Diabetes 2012.

26. Rayalam S, Della-Fera MA, Yang JY, Park HJ, Ambati S, Baile CA. Resveratrol potentiates genistein's antiadipogenic and proapoptotic effects in 3T3-L1 adipocytes. J Nutr 2007;137:2668-73.

27. Schoffelen PF, Westerterp KR, Saris WH, Ten Hoor F. A dual-respiration chamber system with automated calibration. J Appl Physiol 1997;83:2064-72.

28. Chen CY, Bakhiet RM, Hart V, Holtzman G. Isoflavones improve plasma homocysteine status and antioxidant defense system in healthy young men at rest but do not ameliorate oxidative stress induced by $80 \%$ VO2pk exercise. Ann Nutr Metab 2005;49:33-41.

29. Ullmann U, Haller J, Bakker GC, Brink EJ, Weber P. Epigallocatechin gallate (EGCG) (TEAVIGO) does not impair nonhaem-iron absorption in man. Phytomedicine 2005;12:410-5.

30. Weir JB. New methods for calculating metabolic rate with special reference to protein metabolism. J Physiol 1949;109:1-9.

31. Frayn KN. Calculation of substrate oxidation rates in vivo from gaseous exchange. $\mathbf{J}$ Appl Physiol 1983;55:628-34. 
32. Cardoso GA, Salgado JM, Cesar Mde C, Donado-Pestana CM. The effects of green tea consumption and resistance training on body composition and resting metabolic rate in overweight or obese women. J Med Food 2012;16:120-7.

33. Diepvens K, Kovacs EM, Nijs IM, Vogels N, Westerterp-Plantenga MS. Effect of green tea on resting energy expenditure and substrate oxidation during weight loss in overweight females. Br J Nutr 2005;94:1026-34.

34. Yoshino J, Conte C, Fontana L, et al. Resveratrol supplementation does not improve metabolic function in nonobese women with normal glucose tolerance. Cell Metab 2012;16:658-64.

35. Arias N, Macarulla MT, Aguirre L, et al. The combination of resveratrol and conjugated linoleic acid is not useful in preventing obesity. J Physiol Biochem 2012;67:471-7.

36. Kim S, Jin Y, Choi Y, Park T. Resveratrol exerts anti-obesity effects via mechanisms involving down-regulation of adipogenic and inflammatory processes in mice. Biochem Pharmacol 2011;81:1343-51.

37. Klaus S, Pultz S, Thone-Reineke C, Wolfram S. Epigallocatechin gallate attenuates diet-induced obesity in mice by decreasing energy absorption and increasing fat oxidation. Int J Obes (Lond) 2005;29:615-23.

38. Murase T, Haramizu S, Shimotoyodome A, Nagasawa A, Tokimitsu I. Green tea extract improves endurance capacity and increases muscle lipid oxidation in mice. Am J Physiol Regul Integr Comp Physiol 2005;288:R708-15.

39. Thandapilly SJ, Wojciechowski P, Behbahani J, et al. Resveratrol prevents the development of pathological cardiac hypertrophy and contractile dysfunction in the SHR without lowering blood pressure. Am J Hypertens 2011;23:192-6.

40. Woo SC, Na GM, Lim DY. Resveratrol inhibits nicotinic stimulation-evoked catecholamine release from the adrenal medulla. Korean J Physiol Pharmacol 2008;12:155-64.

41. Rosenbaum M, Murphy EM, Heymsfield SB, Matthews DE, Leibel RL. Low dose leptin administration reverses effects of sustained weight-reduction on energy expenditure and circulating concentrations of thyroid hormones. J Clin Endocrinol Metab 2002;87:2391-4.

42. Szkudelski T, Nogowski L, Pruszynska-Oszmalek E, Kaczmarek P, Szkudelska K. Genistein restricts leptin secretion from rat adipocytes. J Steroid Biochem Mol Biol 2005;96:301-7.

43. Klaus S, Keipert S, Rossmeisl M, Kopecky J. Augmenting energy expenditure by mitochondrial uncoupling: a role of AMP-activated protein kinase. Genes Nutr 2012;7:369-86.

44. Lee MS, Kim Y. (-)-Epigallocatechin-3-gallate enhances uncoupling protein 2 gene expression in 3T3-L1 adipocytes. Biosci Biotechnol Biochem 2009;73:434-6.

45. Timmers S, Auwerx J, Schrauwen P. The journey of resveratrol from yeast to human. Aging (Albany NY) 2012;4:146-58.

46. Yeung EH, Zhang C, Mumford SL, et al. Longitudinal study of insulin resistance and sex hormones over the menstrual cycle: the BioCycle Study. J Clin Endocrinol Metab 2010;95:5435-42.

47. Kang W, Hong HJ, Guan J, et al. Resveratrol improves insulin signaling in a tissuespecific manner under insulin-resistant conditions only: in vitro and in vivo experiments in rodents. Metabolism 2011;61:424-33. 
48. Zhang J, Chen L, Zheng J, et al. The protective effect of resveratrol on islet insulin secretion and morphology in mice on a high-fat diet. Diabetes Res Clin Pract 2012;97:474-82.

49. Szkudelska K, Nogowski L, Szkudelski T. Genistein affects lipogenesis and lipolysis in isolated rat adipocytes. J Steroid Biochem Mol Biol 2000;75:265-71.

50. Hoeks J, van Herpen NA, Mensink M, et al. Prolonged Fasting Identifies Skeletal Muscle Mitochondrial Dysfunction as Consequence Rather Than Cause of Human Insulin Resistance. Diabetes 2010;59:2117-25.

51. Timmers S, Hesselink MK, Schrauwen P. Therapeutic potential of resveratrol in obesity and type 2 diabetes: new avenues for health benefits? Ann N Y Acad Sci 2013;1290:83-9.

52. Poulsen MM, Jorgensen JO, Jessen N, Richelsen B, Pedersen SB. Resveratrol in metabolic health: an overview of the current evidence and perspectives. Ann N Y Acad Sci 2013;1290:74-82.

53. Hamman RF, Wing RR, Edelstein SL, et al. Effect of weight loss with lifestyle intervention on risk of diabetes. Diabetes Care 2006;29:2102-7. 



\title{
CHAPTER 4
}

\author{
Combined epigallocatechin-3-gallate and \\ resveratrol supplementation for 12 weeks \\ increases mitochondrial capacity and fat \\ oxidation, but not insulin sensitivity in obese \\ humans: a randomized controlled trial
}

Jasper Most, Silvie Timmers, Ines Warnke, Johan WE Jocken, Mark van Boekschoten, Philip de Groot, Igor Bendik, Patrick Schrauwen, Gijs H Goossens, Ellen E Blaak The American Journal of Clinical Nutrition, under revision. 


\section{Abstract}

Background and Objective: The obese, insulin resistant state is characterized by impairments in lipid metabolism. We have previously shown that 3-day supplementation of combined epigallocatechin-3-gallate and resveratrol $(E+R)$ increased energy expenditure, and improved the capacity to switch from fat towards carbohydrate oxidation upon a highfat mixed meal (HFMM)-test in men. The present study aimed to investigate the longerterm effect of $\mathrm{E}+\mathrm{R}$ supplementation on metabolic profile, mitochondrial capacity, fat oxidation, lipolysis and tissue-specific insulin sensitivity.

Design: In this randomized, double-blind study, 38 overweight and obese subjects (18 male, $38 \pm 2$ yrs, body-mass-index $\left.29.7 \pm 0.5 \mathrm{~kg} / \mathrm{m}^{2}\right)$ received either $\mathrm{E}+\mathrm{R}(282$ and $80 \mathrm{mg} / \mathrm{d}$, respectively) or placebo for 12 weeks. Before and after intervention, oxidative capacity and gene expression were assessed in skeletal muscle. Fasting and postprandial (HFMM) lipid metabolism were assessed using indirect calorimetry, blood sampling and microdialysis. Tissue-specific insulin sensitivity was assessed by a hyperinsulinemic-euglycemic clamp with $\left[6,6-{ }^{2} \mathrm{H}_{2}\right]$-glucose infusion.

Results: E+R supplementation did not affect fasting plasma metabolic profile. Although whole-body fat mass was not affected, visceral adipose tissue mass tended to decrease after the intervention compared with placebo $\left(\mathrm{P}_{\text {time*treatment }}=0.09\right)$. E $+\mathrm{R}$ supplementation significantly increased oxidative capacity in permeabilized muscle fibers $\left(\mathrm{P}_{\text {time*treatment }}<0.05\right.$, $\left.\mathrm{P}_{\mathrm{E}+\mathrm{R}}<0.05\right)$. Moreover, $\mathrm{E}+\mathrm{R}$ affected fasting $\left(\mathrm{P}_{\text {time*treatment }}=0.03\right)$ and postprandial respiratory quotient $\left(\mathrm{P}_{\text {time*treatment }}=0.01\right)$ by preserving fat oxidation, which declined after placebo $\left(\mathrm{P}_{\mathrm{PLA}}=0.05\right.$ and $\mathrm{P}_{\mathrm{PLA}}=0.03$, respectively). Energy expenditure was not altered $\left(\mathrm{P}_{\text {time*treatment }}=0.96\right)$. Furthermore, $\mathrm{E}+\mathrm{R}$ supplementation attenuated the increase in plasma triacylglycerol concentration during the HFMM-test that was observed after placebo $\left(\mathrm{P}_{\text {time*treatment }}=0.04, \mathrm{P}_{\mathrm{PLA}}=0.01\right)$. Finally, insulin-stimulated glucose disposal and suppression of endogenous glucose production and lipolysis were not affected by $\mathrm{E}+\mathrm{R}$.

Conclusions: 12 weeks $\mathrm{E}+\mathrm{R}$ supplementation increased mitochondrial capacity and stimulated fat oxidation as compared to placebo, but this did not translate into increased tissue-specific insulin sensitivity in overweight and obese subjects. Further research is required to investigate whether these effects may contribute to reduce cardiometabolic risk. 


\section{Introduction}

The prevalence of obesity and related chronic diseases is continuously increasing ${ }^{1}$. Insulin resistance is a major risk factor for the progression of obesity towards chronic metabolic diseases, including cardiovascular disease and type 2 diabetes mellitus (T2DM) ${ }^{2}$. A reduced lipid storage capacity and impaired endocrine function of adipose tissue ${ }^{3}$, and a decreased mitochondrial capacity and accumulation of lipid-intermediates in skeletal muscle ${ }^{2,4,5}$ are closely associated with insulin resistance.

Current treatment strategies to control the progression of chronic diseases are mainly focused on lifestyle, pharmacological or surgical interventions. However, these interventions show large inter-individual variability in response ${ }^{6}$, which underscores the need for additional strategies to optimize the prevention of obesity-associated metabolic disorders. Polyphenols have been identified as dietary ingredients with antioxidant properties decades ago. More recently, they have also been implicated in the prevention of T2DM and cardiovascular diseases. As such, epigallocatechin-3-gallate (E), most abundant in green tea, and resveratrol (R), which is present in grape skin, red wine and peanuts, have been implicated in the prevention of body weight gain and insulin resistance in rodents on obesogenic diets ${ }^{7-9}$. In animal models of obesity, $\mathrm{E}$ has been shown to reduce the absorption of intestinal lipids and to increase lipid catabolism, possibly by inhibiting catechol-O-methyltransferase ${ }^{10}$ or activating AMP kinase (AMPK) ${ }^{11}$. R has been suggested to stimulate mitochondrial biogenesis by activating sirtuin 1 (SIRT1) and PPAR $\gamma$ coactivator $1-\alpha(\mathrm{PGC} 1 \alpha)^{7,8}$. Human studies have demonstrated that supplementation with both $\mathrm{E}$ (or E-rich products) and $\mathrm{R}$ improved markers of insulin sensitivity (HOMA-IR, E ${ }^{12}$ $\mathrm{R}^{13}$ ), reduced plasma markers of oxidative stress (total antioxidative status) and systemic inflammation (TNF- $\alpha, \mathrm{E}^{12}, \mathrm{R}^{13}$ ), stimulated postprandial fat oxidation $\left(\mathrm{E}^{14}\right)$ and reduced body weight $\left(\mathrm{E}^{15}, \mathrm{R}^{16}\right)$. However, conflicting data in humans have also been reported ${ }^{17-19}$. We have recently postulated that a combination of polyphenols with distinct mechanisms of action may have additional and/or synergistic effects, which may result in physiologically relevant effects on fat oxidation. Indeed, we have shown that supplementation of a specific combination of $\mathrm{E}$ and $\mathrm{R}(\mathrm{E}+\mathrm{R})$ for 3 days significantly increased resting and postprandial energy expenditure (EE), and resulted in a more pronounced increase in respiratory 
quotient (RQ) after a high-fat mixed meal (HFMM) compared to placebo (PLA) in men ${ }^{20}$. Importantly, these effects were not observed after single E supplementation ${ }^{21}$.

Here, we investigated the effects of longer-term combined $\mathrm{E}+\mathrm{R}$ supplementation on metabolic profile, skeletal muscle oxidative capacity, fat oxidation, lipolysis and peripheral, hepatic and adipose tissue insulin sensitivity in overweight and obese subjects.

\section{Subjects and methods}

\section{Subjects}

42 untrained ( $<3 \mathrm{~h}$ organized sports activities per week), weight-stable $(<2 \mathrm{~kg}$ body weight change 3 months prior to inclusion) overweight and obese (BMI $>25 \mathrm{~kg} / \mathrm{m}^{2}$ ), Caucasian men $(\mathrm{n}=21)$ and women $(\mathrm{n}=21)$ between 20 and 50 years with normal glucose tolerance (fasting glucose $<6.1 \mathrm{mmol} / \mathrm{L}, 2$ h-glucose $<7.8 \mathrm{mmol} / \mathrm{L}$ ), normal blood pressure (diastolic, 60-90; systolic, $100-140 \mathrm{mmHg}$ ) were included in this study. Subjects were not allowed to donate blood or use any medication or supplements that might interfere with study outcomes for 3 months before entering the study. Exclusion criteria were pregnancy, menopause, lactation and any reported (history of) chronic inflammatory, cardiovascular, hepatic, pulmonary, renal or gastro-intestinal disease. Intake of caffeine $(<600 \mathrm{mg} / \mathrm{d})$, green tea $(<3 \mathrm{cups} / \mathrm{d})$, alcohol $(<20 \mathrm{~g} / \mathrm{d})$, grapes and peanuts (occasional consumption) had to be limited.

\section{Study design and randomization}

In this randomized, double-blind placebo-controlled, parallel intervention trial, subjects received either a combination of $E$ and $R$ supplements $(E+R ; 282 \mathrm{mg} / \mathrm{d}$ and $80 \mathrm{mg} / \mathrm{d}$, respectively) or PLA (partly hydrolyzed microcrystalline cellulose-filled capsules) for a period of 12 weeks to assess effects of $\mathrm{E}+\mathrm{R}$ supplementation on tissue-specific insulin sensitivity (primary outcome) and metabolic profile, skeletal muscle oxidative capacity, fat oxidation and lipolysis (secondary outcomes). An independent researcher executed a blockwise randomization and packed the supplements according to a computer-generated randomization plan (Microsoft Excel, Mac). The supplementation period started at the day after the last baseline measurement in week 0 and was continued throughout measurements in week 12. Subjects were instructed to maintain their habitual lifestyle pattern throughout the study. In total, subjects were asked to visit the university 10 times: medical screening, 
three clinical investigation days (CIDs) before start of supplementation (within seven days), three control visits during the supplementation period and three CIDs in the last week of supplementation (within seven days). CIDs comprised skeletal muscle biopsies combined with dual energy Xray absorptiometry-scan (CID1), HFMM-test (CID2), and hyperinsulinemic-euglycemic clamp (CID3) and were separated by at least one day. Control visits for compliance, side effects and to provide new capsules were scheduled in week 2, 4, 8 of intervention. In week 0 and 12, subjects were asked to fill in 3-day food records ( 2 weekdays, 1 weekend day) and in week 4 a 1-day food record (1 weekday) in order to monitor and control for changes in dietary habits. An experienced dietitian checked the food records and discussed these with the subjects in case of incomplete or missing information. Energy and nutrient intake were analyzed using the Dutch Food Composition Dataset (NEVO, National Institute for Public Health and the Environment, Ministry of Health, Welfare and Sport, The Netherlands).

\section{Clinical investigation days}

Two days prior to the CIDs, subjects were asked to refrain from intense physical activity and alcohol consumption. Meal intake the evening before each CIDs was standardized per subject by providing the same meal. The first meal was provided ad libitum $(740 \pm 34 \mathrm{kcal}$, $48 \pm 2$ energy $\%$ fat) and subjects were asked to keep the portion size constant at all subsequent CIDs. After an overnight fast, subjects came to the university by car or public transport. Both before and after intervention, a two-step hyperinsulinemic-euglycemic clamp and a HFMM-test were performed, and a skeletal muscle biopsy was collected. All procedures were executed in a resting, half-supine position.

\section{Dual energy Xray absorptiometry and skeletal muscle biopsy (CID1)}

First, body composition was measured by dual energy Xray absorptiometry-scanning using the 3-compartment model (Hologic BCA, VitaK, Maastricht, Netherlands). Next, skeletal muscle ( $m$. vastus lateralis) biopsies were taken under local anesthesia during fasting conditions before and after the 12 weeks intervention period. One portion ( $30 \mathrm{mg})$ was freshly used for high-resolution respirometry ${ }^{22}$, which allows determination of oxidative capacity ex vivo by quantifying the oxygen consumption using the Oxygraph-2k (OROBOROS Instruments, Innsbruck, Austria). The other portion was directly frozen in isopentane and stored at $-80{ }^{\circ} \mathrm{C}$ until further analyses. Protein quantification of 
mitochondrial oxidative phosphorylation (OxPhos) complexes was performed by SDSPAGE followed by western blot analysis using nitrocellulose membranes (Trans-blot ${ }^{\circledR}$ Turbo $^{\text {TM }}$ transfer system, Bio-Rad). Blots were probed with Total OxPhos Antibody Cocktail (Mitoscience/Abcam, Cambridge, UK) and a secondary IRDye680/700 conjugated Donkey anti-Mouse antibody (Licor/Invitrogen, Bleiswijk, NL). Antigen-antibody complexes were visualized using an Odyssey Infrared Imaging System (LICOR Biosciences, Wateringen, the Netherlands).

A detailed description for skeletal muscle microarray analysis and lipid composition has been enclosed in the Supplemental Material. Briefly, for microarray analysis, $100 \mathrm{ng}$ of intact total RNA was extracted from skeletal muscle biopsies using the Trizol method (Qiagen, Venlo, Netherlands) and processed applying the GeneChip ${ }^{\circledR}$ WT PLUS Reagent Kit and Human Transcriptome Array (HTA) 2.0 GeneChips ${ }^{\circledR}$ (Affymetrix, Santa Clara, CA, USA) according to the manufacture's manual. Functional data analysis was based upon false discovery rate q-value $<0.2$ on the filtered data set (interquartile range $>0.2(\log 2)$, intensity $>20,>5$ arrays, $>5$ probes per gen). For determination of lipid composition, total lipids were extracted after lyophilisation of skeletal muscle tissue. Diacylglycerol (DAG) and triacylglycerol (TAG) were separated by thin-layer chromatography and fatty acid profiles were determined on an analytical gas chromatograph, as described previously ${ }^{5}$.

\section{Microdialysis (CID2)}

Four microdialysis probes (CMA 60; CMA Microdialysis, Stockholm, Sweden) were inserted under local anesthesia, two in the medial portion of the gastrocnemius muscle of both legs and two in the subcutaneous adipose tissue $6-8 \mathrm{~cm}$ left and right from the umbilicus in male subjects ( $\mathrm{n}=17$; age: $40.1 \pm 2.0 \mathrm{yrs}$; BMI: $30.0 \pm 0.8 \mathrm{~kg} / \mathrm{m}^{2}$; HOMA-IR: $2.1 \pm 0.4$ ) as described previously ${ }^{23}$. After insertion, $90 \mathrm{~min}$ were allowed for tissue recovery from insertion trauma. Throughout the HFMM-test (CID2), in each tissue, one probe was perfused at $0.3 \mu \mathrm{L} / \mathrm{min}$ with Ringer solution to collect microdialysate for analyses of glycerol, glucose, pyruvate and lactate concentrations by means of CMA enzymatic assay kits on a CMA 600 microdialysis analyzer (CMA Microdialysis, Stockholm, Sweden). The contralateral probe was perfused at $5.0 \mu \mathrm{L} / \mathrm{min}$ with Ringer solution, supplemented with $50 \mathrm{mmol} / \mathrm{L}$ ethanol, to assess ethanol outflow/inflow ratio as an indicator of local blood flow. Ethanol concentrations were measured 
spectrophotometrically at $340 \mathrm{~nm}$ using a standard ethanol assay kit (Boehringer, Mannheim, Germany).

\section{High-fat mixed meal-test (CID2)}

After inserting a cannula into the antecubital vein, substrate oxidation was measured for 30 min under fasting conditions $(\mathrm{t}=0)$ and for $4 \mathrm{~h}$ after the ingestion of a liquid HFMM (625 kcal, 61 energy $\%$ fat, 33 energy $\%$ carbohydrate, 6 energy\% protein), which was consumed within $5 \mathrm{~min}$ at $\mathrm{t}=0$. Blood samples were taken under fasting $(\mathrm{t}=0 \mathrm{~min})$ and postprandial conditions $(\mathrm{t}=30,60,90,120,150,180,210$ and $240 \mathrm{~min})$. Energy expenditure and substrate oxidation were measured by indirect calorimetry, using the open-circuit ventilated hood system (Omnical, Maastricht University, Maastricht, Netherlands) and were calculated according to the formulas of Weir ${ }^{24}$ and Frayn ${ }^{25}$, respectively.

\section{Hyperinsulinemic-euglycemic clamp (CID3)}

A two-step hyperinsulinemic-euglycemic clamp with $\left[6,6-{ }^{2} \mathrm{H}_{2}\right]$-glucose infusion (tracer, Cambridge Isotope Laboratories, Andover, MA, USA) was performed to assess the rate of disappearance (Rd), non-oxidative glucose disposal (NOGD) and endogenous glucose production (EGP) ${ }^{22}$. First, a cannula was inserted into the antecubital vein. A second cannula was inserted into a superficial dorsal hand vein for the sampling of arterialized blood (using a hot-box with air circulating at $\sim 50{ }^{\circ} \mathrm{C}$ ). After the administration of a bolusinjection of $2.4 \mathrm{mg} / \mathrm{kg}\left[6,6-{ }^{2} \mathrm{H}_{2}\right]$-glucose, a continuous $\left[6,6-{ }^{2} \mathrm{H}_{2}\right]$-glucose infusion was started at $0.04 \mathrm{mg} /\left(\mathrm{kg}^{*} \mathrm{~min}\right)$ and continued throughout the measurement. After $2 \mathrm{~h}$, insulin infusion was started at $10 \mathrm{mU} /\left(\mathrm{m}^{2} * \mathrm{~min}\right)$ for $2 \mathrm{~h}$, followed by $40 \mathrm{mU} /\left(\mathrm{m}^{2} * \mathrm{~min}\right)$ insulin for the last $2 \mathrm{~h}$ to suppress lipolysis and EGP. By a variable co-infusion of a $20 \%$-glucose solution, enriched to $1.92 \mathrm{mg} / \mathrm{mL}$ tracer, blood glucose concentrations were maintained at $5.0 \mathrm{mmol} / \mathrm{L}$. During the last $30 \mathrm{~min}$ of each insulin-infusion step $(0,10$ and 40 $\left.\mathrm{mU} /\left(\mathrm{m}^{2} * \mathrm{~min}\right)\right)$ blood samples were collected and substrate oxidation was measured using indirect calorimetry (described under 'High-fat mixed meal-test, CID2') to assess glucose kinetics. Kinetics of Rd and NOGD were calculated during 0 and $40 \mathrm{mU} /\left(\mathrm{m}^{2} * \mathrm{~min}\right)$ insulininfusion, respectively as absolute increase between these steps $(\Delta \mu \mathrm{mol} /(\mathrm{kg} * \mathrm{~min}))$, whereas calculations for insulin-mediated suppression of EGP and free fatty acids (FFA) were performed during 0 and $10 \mathrm{mU} /\left(\mathrm{m}^{2} * \mathrm{~min}\right)$ insulin-infusion, respectively as relative suppression during 10 compared to $0 \mathrm{mU} /\left(\mathrm{m}^{2 *} \mathrm{~min}\right)(\%)$. 


\section{Biochemistry}

Blood was collected into pre-chilled tubes, centrifuged at $1000 \mathrm{~g}$, and plasma was snapfrozen in liquid nitrogen and stored at $-80{ }^{\circ} \mathrm{C}$ until analyses.

To check for treatment compliance, plasma epigallocatechin-3-gallate and resveratrol concentrations were determined, as described before ${ }^{13,26}$. Briefly, for measurement of the $\mathrm{E}$ concentration, plasma $(500 \mu \mathrm{L})$ was first combined with $500 \mu \mathrm{L}$ of a stabilizing E-buffer (containing EDTA, ascorbic acid and sodium acetate) and after addition of an internal standard, samples were analyzed by liquid chromatography-mass spectrometry ${ }^{26}$. Determination of total $\mathrm{R}$ and total dihydro- $\mathrm{R}$ was performed also after internal standard addition on a liquid chromatography-mass spectrometry system ${ }^{13}$.

Isotopic enrichment of plasma glucose was determined by electron ionization gas chromatography-mass spectrometry and expressed as tracer-to-tracee ratio for steady-state calculations of Rd, NOGD and EGP, as performed previously ${ }^{22}$.

Plasma glucose, lactate, FFA, TAG, total cholesterol and HDL-cholesterol (HDL-c) concentrations were determined with an automated spectrophotometer (ABX Pentra 400 autoanalyzer, Horiba ABX, Montpellier, France), using enzymatic colorimetric kits. LDLcholesterol (LDL-c) concentration was calculated by the Friedewald-equation ${ }^{27}$. Plasma glycerol concentrations were measured with an enzymatic assay (Enzytec Glycerol, Roche Biopharm, Basel, Switzerland) automated on a Cobas Fara spectrophotometric autoanalyzer (Roche Diagnostics, Basel, Switzerland). Circulating plasma concentrations of insulin, adiponectin and leptin were analyzed using commercially available radioimmunoassay kits (Human Insulin specific radioimmunoassay, Human Adiponectin radioimmunoassay, Human Leptin radioimmunoassay, Millipore Corporation, Billerica, MA, USA). Plasma concentrations of inflammatory markers (IL-6, IL-8 and TNF- $\alpha$ ) were determined using a multiplex ELISA (Human ProInflammatory II 4-Plex Ultra-Sensitive Kit, Meso Scale Diagnositics, Rockville, MD, USA).

\section{Supplements}

The supplements were commercially available and kindly provided by Pure Encapsulations Inc. (Sudbury, MA, USA). All capsules were manufactured, tested and checked in accordance to standards of EU GMP requirements. 
E capsules contained $94 \%$ epigallocatechin-3-gallate (141 mg per capsule, Lot 3570112) and R capsules $20 \%$ trans-resveratrol (40 mg trans-resveratrol in Polygonum cuspidatum extract per capsule, Lot 1611011). Two lots of placebo capsules (microcrystalline cellulose, Lot 7150712, Lot 7160712) were used for blinding. PLA capsules were encapsulated identically to the active supplements and filled with microcrystalline cellulose and $\tan /$ brown, respectively, pink/red powder to blind both supplements. Capsules were packed into white opaque boxes, labeled per subject without indication of the content. One capsule of each supplement ( $\mathrm{E}$ and $\mathrm{R}$ or both blinded PLA capsules) was ingested during breakfast and dinner. This regimen was maintained until the last measurement. After completion of the study, returned capsules were counted for compliance and stability of polyphenols was assessed by measuring $\mathrm{E}$ and $\mathrm{R}$ via high-performance liquid chromatography in capsules stored for 3 months, according to the manufacture's recommendations. The supplements were considered safe and well-tolerated ${ }^{20}$.

\section{Study approval}

All subjects gave written informed consent for participation in this study, which was reviewed and approved by the local medical ethical committee of Maastricht University Medical Center ${ }^{+}$. All procedures were conducted according to the Declaration of Helsinki.

\section{Statistics}

Sample size $(n=42)$ was calculated to detect a physiological relevant change in insulin sensitivity of $20 \%$ with a power of $80 \%$, assuming a significance level of $\alpha=0.05(n=34)$ and a drop-out of $20 \%(n=8)$. All data are expressed as mean \pm SEM. Data of the HFMMtest are expressed as AUC to define the total measurement period during this test (fasting and postprandial), and as incremental AUC, defining specifically the postprandial response (diet-induced effect as compared to fasting), both calculated by the trapezoid method. Variables were tested for normality using Shapiro-Wilk-test and showed a normal distribution. Differences in subjects' characteristics at baseline were tested by Student's unpaired t-test. Data were analyzed using a two-way repeated measures ANOVA, with time (pre, post) and treatment (PLA, E $+\mathrm{R})$ as factors. A $\mathrm{P}<0.05$ was considered as statistically significant and a $\mathrm{P}<0.10$ as a trend. In case of a significant time*treatment interaction ( $\left.\mathrm{P}_{\text {time*treatment }}\right)$, post-hoc analyses with Bonferroni correction were applied to identify significant within-group effects $\left(\mathrm{P}_{\mathrm{E}+\mathrm{R}}, \mathrm{P}_{\mathrm{PLA}}\right)$. In case of significant baseline differences 
between treatment groups (for state 3 respiration and protein expression of OxPhos complexes III and V), the baseline value was included as covariate in an univariate ANOVA with the change over time as dependent variable and treatment as between-subject factor. In the ANOVA model no interactions between gender and primary and secondary outcomes were observed. Statistics was done using SPSS 19.0 (IBM Corporation, Armonk, NY, USA) for Macintosh.

\section{Results}

\section{Subjects' characteristics and plasma biochemistry}

42 overweight and obese men and women volunteered to participate in this study (August 2012 - December 2013). In total, 4 subjects (3 men, 1 women) did not complete the study due to traveling abroad $(n=1)$, re-employment $(n=1)$ or non-compliance with respect to supplementation or changing lifestyle $(n=2)$. Characteristics of the 38 subjects (18 men, 20 women) who completed the study are summarized in Table 4.1.

Table 4.1. Subjects' characteristics

\begin{tabular}{lccc}
\hline & PLA, $\mathrm{n}=20$ & $\mathrm{E}+\mathrm{R}, \mathrm{n}=18$ & $\mathrm{P}$ \\
Age, years & $38.7 \pm 2.2$ & $36.1 \pm 2.2$ & 0.43 \\
Body-mass-index, $\mathrm{kg} / \mathrm{m}^{2}$ & $29.5 \pm 0.7$ & $29.9 \pm 0.6$ & 0.67 \\
Waist-hip-ratio & $0.87 \pm 0.02$ & $0.87 \pm 0.02$ & 0.78 \\
Systolic blood pressure, $\mathrm{mmHg}$ & $114 \pm 2$ & $117 \pm 2$ & 0.27 \\
Diastolic blood pressure, $\mathrm{mmHg}$ & $76 \pm 2$ & $76 \pm 2$ & 0.86 \\
Fasting plasma glucose, $\mathrm{mmol} / \mathrm{L}$ & $5.10 \pm 0.08$ & $5.19 \pm 0.09$ & 0.44 \\
2 h plasma glucose, mmol/L & $5.38 \pm 0.21$ & $5.34 \pm 0.24$ & 0.92 \\
HbAlc, \% & $5.15 \pm 0.06$ & $5.12 \pm 0.06$ & 0.76 \\
Hemoglobin, mmol/L & $8.9 \pm 0.1$ & $8.6 \pm 0.2$ & 0.22 \\
Hematocrit, L/L & $0.43 \pm 0.01$ & $0.39 \pm 0.02$ & 0.18 \\
Creatinine, $\mu$ mol/L & $79.5 \pm 3.7$ & $74.2 \pm 2.7$ & 0.29 \\
Alanine-aminotransferase, U/L & $27.9 \pm 4.4$ & $26.9 \pm 2.2$ & 0.86 \\
\hline \hline
\end{tabular}

Values are given as means \pm SEM. Data were analyzed using a Student's unpaired t-test. A $\mathrm{P}<0.05$ was considered statistically significant for the difference between PLA and E+R group. $2 \mathrm{~h}$ plasma glucose, plasma glucose concentration $2 \mathrm{~h}$ after oral glucose ingestion ( $75 \mathrm{~g}$ in $200 \mathrm{~mL}$ water).

There were no significant differences between the $\mathrm{E}+\mathrm{R}(\mathrm{n}=18,8$ men) and PLA ( $\mathrm{n}=20,10$ men) group with respect to baseline characteristics. Compliance was confirmed by counting returned supplements $(<3 \%$ of supplements were returned). Supplements were well 
tolerated and no adverse events were reported. Importantly, plasma concentrations of $\mathrm{E}, \mathrm{R}$ and dihydro-R were significantly increased in all subjects who had received E+R (Table 4.2 ), indicating compliance to the supplementation regimen. No significant changes in fasting plasma concentrations of glucose, insulin, lactate, glycerol, FFA and TAG were observed (Table 4.2 and/or Figures 4.1A-F). Likewise, fasting plasma concentrations of leptin, adiponectin, and the inflammatory markers IL-6, IL-8 and TNF- $\alpha$ were not significantly affected by the intervention (Table 4.2). Furthermore, fasting plasma concentrations of total cholesterol, HDL-c and LDL-c were not significantly changed after 12 weeks E+R-supplementation versus PLA. However, the ratio of total cholesterol/HDL-c, a marker for myocardial infarction risk ${ }^{28}$, tended to decrease after $\mathrm{E}+\mathrm{R}$ supplementation but not after PLA ( $\mathrm{P}_{\text {time*treatment }}=0.03, \mathrm{P}_{\mathrm{E}+\mathrm{R}}=0.09, \mathrm{P}_{\mathrm{PLA}}=0.13$, Table 4.2).

Table 4.2. Fasting plasma biochemistry before and after intervention

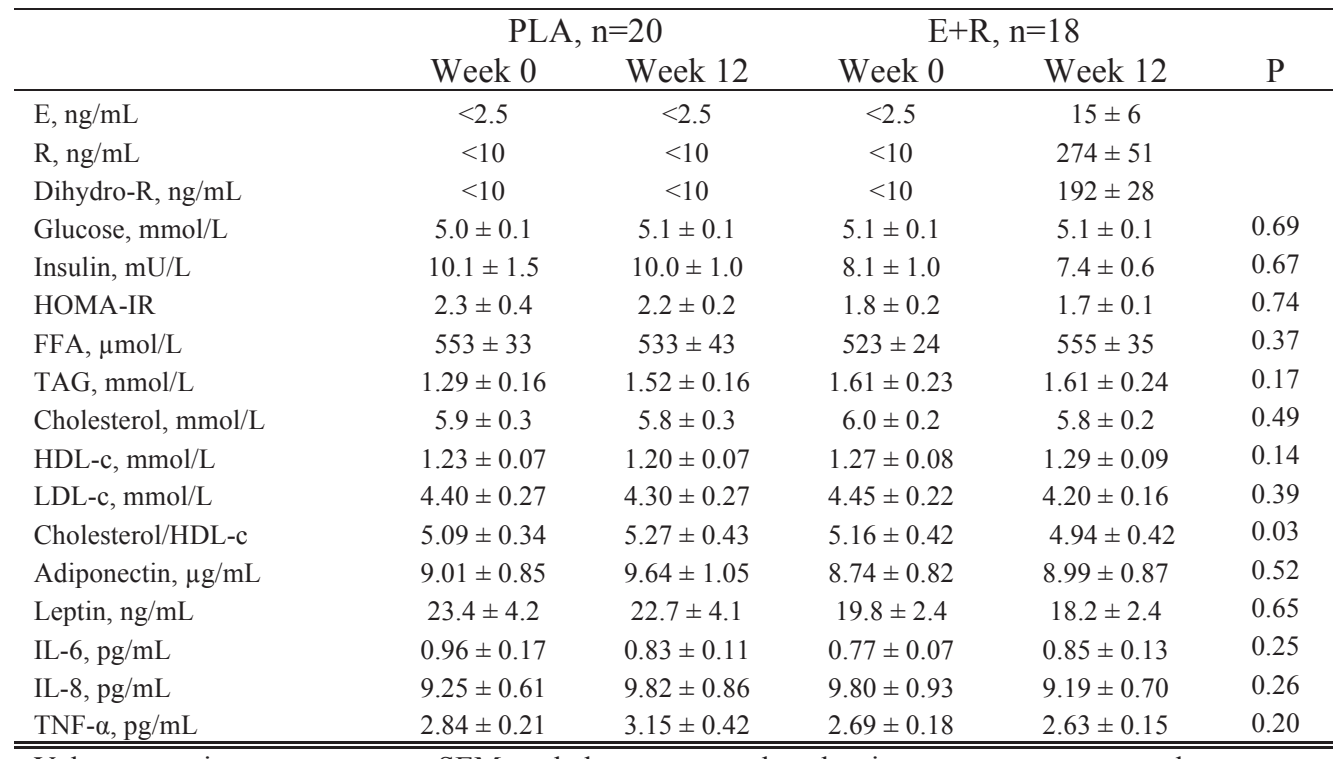

Values are given as means \pm SEM and data were analyzed using a two-way repeated measures ANOVA, with time (pre, post) and treatment (PLA, E+R) as factors. A $\mathrm{P}<0.05$ was considered as statistically significant. No baseline differences were observed (Student's t-test). In case of a significant time*treatment interaction $(\mathrm{P}<0.05)$, post-hoc analyses with Bonferroni correction were applied to identify significant within-group effects. E, free plasma epigallocatechin-3-gallate; FFA, free fatty acids; HDL-c, HDL-cholesterol; HOMA-IR, homeostatic model assessment of insulin resistance; LDL-c, LDL-cholesterol; R, total plasma resveratrol; TAG, plasma triacylglycerol. 


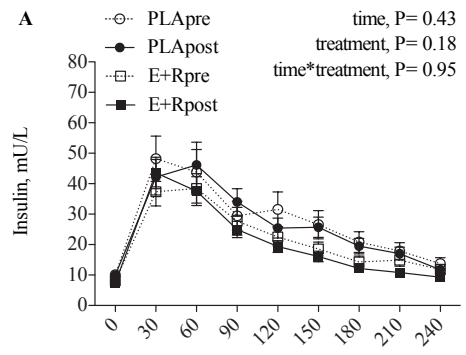

time, $\min$

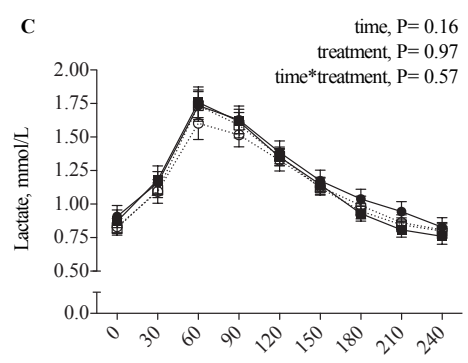

time, $\min$

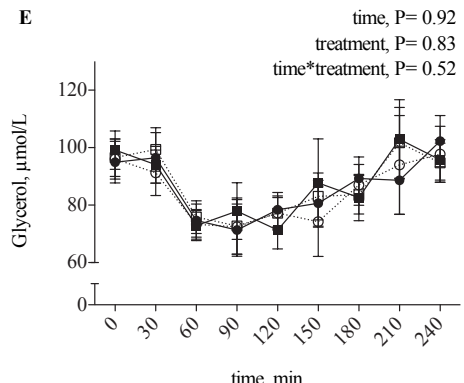

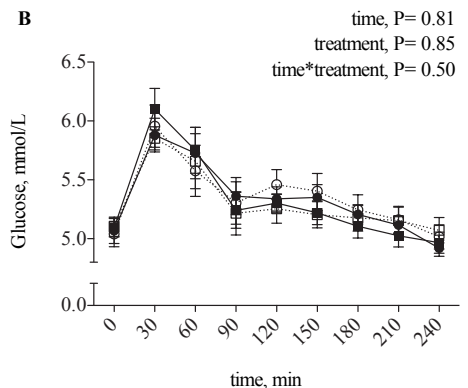

D

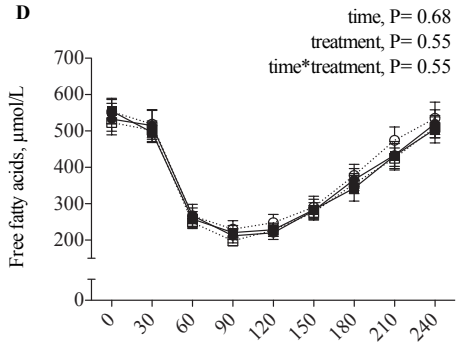

time, $\min$

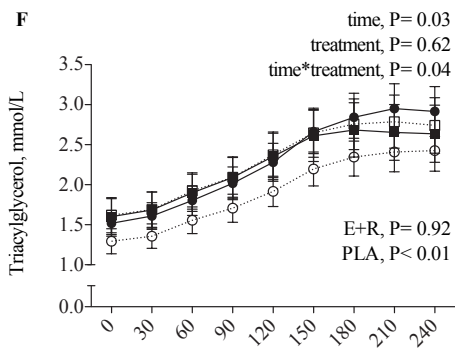

time, $\min$

Figure 4.1. Fasting and postprandial insulin and metabolite concentrations before and after intervention

Values are given as means \pm SEM ( $\mathrm{n}=38)$. Fasting plasma insulin (A) and metabolite (B-F) concentrations, AUCs during the HFMM-test and the incremental AUCs were analyzed using a twoway repeated measures ANOVA, with time $\left(\mathrm{P}_{\text {time }}\right.$, pre, post) and treatment $\left(\mathrm{P}_{\text {treatment }}, \mathrm{PLA}, \mathrm{E}+\mathrm{R}\right)$ as factors. A $\mathrm{P}<0.05$ was considered as statistically significant. No time*treatment interactions were observed on fasting concentrations and incremental AUCs. Reported P-values refer to the respective AUCs. In case of a significant time*treatment interaction $\left(\mathrm{P}_{\text {time }}{ }^{*}\right.$ treatment $)$, post-hoc analyses with Bonferroni correction were applied to identify significant within-group effects. Dashed line, open circles: PLA pre; solid line, filled circles: PLA post; Dashed line, open squares: E+R pre; solid line, filled squares: $\mathrm{E}+\mathrm{R}$ post. 


\section{E+R did not alter food intake and body composition}

Food intake, assessed using self-reported 3-day food records, was not changed after supplementation in either group (E+R: $2092 \pm 200 \mathrm{kcal} / \mathrm{d}, 45 \pm 1$ energy\% carbohydrate, $39 \pm 1$ energy $\%$ fat, $15 \pm 1$ energy\% protein, PLA: $1982 \mathrm{kcal} / \mathrm{d}, 45 \pm 2,38 \pm 2,16 \pm 1$ energy $\%)$. Body weight, body fat percentage and body fat distribution (upper and lower body fat mass) were not significantly altered by $E+R$ supplementation (Table 4.3). Interestingly, however there was a tendency towards a differential effect on visceral adipose tissue mass, with a tendency towards a decrease after $\mathrm{E}+\mathrm{R}$ as compared to PLA $\left(\mathrm{P}_{\text {time*treatment }}=0.09\right)$.

Table 4.3. Body composition before and after intervention

\begin{tabular}{lccccc}
\hline & \multicolumn{2}{c}{ PLA, $\mathrm{n}=20$} & \multicolumn{2}{c}{ E+R, n=18 } & \\
& Week 0 & Week 12 & Week 0 & Week 12 & P \\
\hline Body weight, $\mathrm{kg}$ & $88.3 \pm 2.8$ & $88.6 \pm 2.9$ & $92.4 \pm 3.6$ & $92.0 \pm 3.8$ & 0.41 \\
Body fat, $\mathrm{kg}$ & $26.7 \pm 1.9$ & $26.5 \pm 1.9$ & $29.4 \pm 1.4$ & $29.1 \pm 1.6$ & 0.85 \\
Body fat, \% & $30.1 \pm 1.9$ & $29.9 \pm 1.8$ & $31.9 \pm 1.4$ & $31.5 \pm 1.4$ & 0.84 \\
Lean mass, $\mathrm{kg}$ & $59.5 \pm 2.5$ & $59.6 \pm 2.5$ & $61.2 \pm 3.0$ & $61.1 \pm 3.2$ & 0.73 \\
Upper body fat, $\mathrm{kg}$ & $13.1 \pm 1.0$ & $12.9 \pm 1.0$ & $14.0 \pm 0.7$ & $13.8 \pm 0.7$ & 0.93 \\
Lower body fat, $\mathrm{kg}$ & $9.4 \pm 0.9$ & $9.4 \pm 0.9$ & $11.0 \pm 0.8$ & $10.8 \pm 0.9$ & 0.51 \\
Visceral fat, kg & $0.48 \pm 0.04$ & $0.50 \pm 0.05$ & $0.44 \pm 0.05$ & $0.41 \pm 0.04$ & 0.09 \\
\hline \hline
\end{tabular}

Values are given as means \pm SEM and data were analyzed using a two-way repeated measures ANOVA, with time (pre, post) and treatment (PLA, E+R) as factors. A $\mathrm{P}<0.05$ was considered as statistically significant. No baseline differences were observed (Student's t-test). In case of a significant time*treatment interaction, post-hoc analyses with Bonferroni correction were applied to identify significant within-group effects.

\section{$\mathbf{E}+\mathbf{R}$ increased skeletal muscle oxidative capacity}

Next, we investigated whether skeletal muscle oxidative capacity was increased after 12 weeks $\mathrm{E}+\mathrm{R}$ supplementation, since we have previously shown that $\mathrm{R}$ supplementation for 30 days improved mitochondrial capacity ${ }^{13}$. Therefore, ex vivo mitochondrial respiration using different substrate combinations was determined in human, isolated, permeabilized skeletal muscle fibers ${ }^{22}$.

ADP-stimulated complex I-linked respiration upon addition of malate + glutamate was not affected by $\mathrm{E}+\mathrm{R}$ supplementation (data not shown). Also, respiration on a fatty acid substrate, assessed by input of malate + octanoyl-carnitine, was not significantly affected by $\mathrm{E}+\mathrm{R} \quad\left(\mathrm{P}_{\text {time* }}\right.$ treatment $=0.19$, Figure $\left.4.2 \mathrm{~A}\right)$. Interestingly, however, we found that mitochondrial respiration upon electron input of both complexes I and II (state 3, complex I 
\& II), assessed by addition of succinate after malate + glutamate or after malate + octanoylcarnitine + glutamate, was increased in the E+R group versus PLA after 12 weeks supplementation (state 3 respiration (MGS): $\mathrm{P}_{\text {time*treatment }}=0.01, \mathrm{P}_{\mathrm{E}+\mathrm{R}}=0.01, \mathrm{P}_{\mathrm{PLA}}=0.26$; state 3 respiration (MOGS): $\mathrm{P}_{\text {time }}$ treatment $=0.05, \mathrm{P}_{\mathrm{E}+\mathrm{R}}<0.01, \mathrm{P}_{\mathrm{PLA}}=0.45$, Figure 4.2B-C).

Furthermore, maximal mitochondrial respiration, as determined by titration of the chemical uncoupler Carbonyl Cyanide p-Trifluoromethoxyphenylhydrazone (FCCP), was increased after $\mathrm{E}+\mathrm{R}$ compared with PLA ( $\mathrm{P}_{\text {time*treatment }}=0.01 ; \mathrm{P}_{\mathrm{E}+\mathrm{R}}=0.01, \mathrm{P}_{\mathrm{PLA}}=0.31$, Figure 4.2D). Mitochondrial proton leak, which was assessed by the addition of the ATP synthase inhibitor oligomycin, was not significantly affected by the intervention (state 40 , $\mathrm{P}_{\text {time*treatment }}=0.10$, Figure 4.2E). Despite randomization, there was a significant difference in state 3 mitochondrial respiration before intervention between treatment groups $\left(\mathrm{P}_{\text {pre }}=0.01\right)$, which was negatively related to the change over time $(\mathrm{r}=-0.57, \mathrm{P}<0.01)$.

\section{$\mathrm{E}+\mathrm{R}$ increased oxidative metabolism pathways at the transcriptional and translational level}

To identify pathways that may underlie the $\mathrm{E}+\mathrm{R}$-induced improvement of mitochondrial capacity, we next determined whether protein expression of OxPhos complexes in skeletal muscle was altered by $\mathrm{E}+\mathrm{R}$. We found an $\mathrm{E}+\mathrm{R}$-induced increase in complexes III

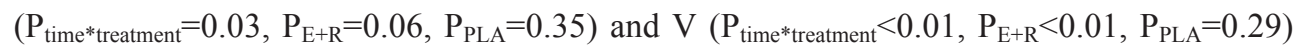
compared to PLA (Figure 4.2G-H). Based on these findings, we performed microarray analysis on skeletal muscle biopsies ( $m$. vastus lateralis), collected before and after 12 weeks E+R or PLA treatment. Indeed, gene set enrichment analysis indicated that the most upregulated pathways after $\mathrm{E}+\mathrm{R}$ supplementation were related to the citric acid cycle and respiratory electron transport chain, while pathways related to carbohydrate metabolism were upregulated in the PLA group (Figure 4.3). Taken together, these data indicate that the increased mitochondrial capacity following $\mathrm{E}+\mathrm{R}$ is accompanied by changes at the transcriptional and translational level. 

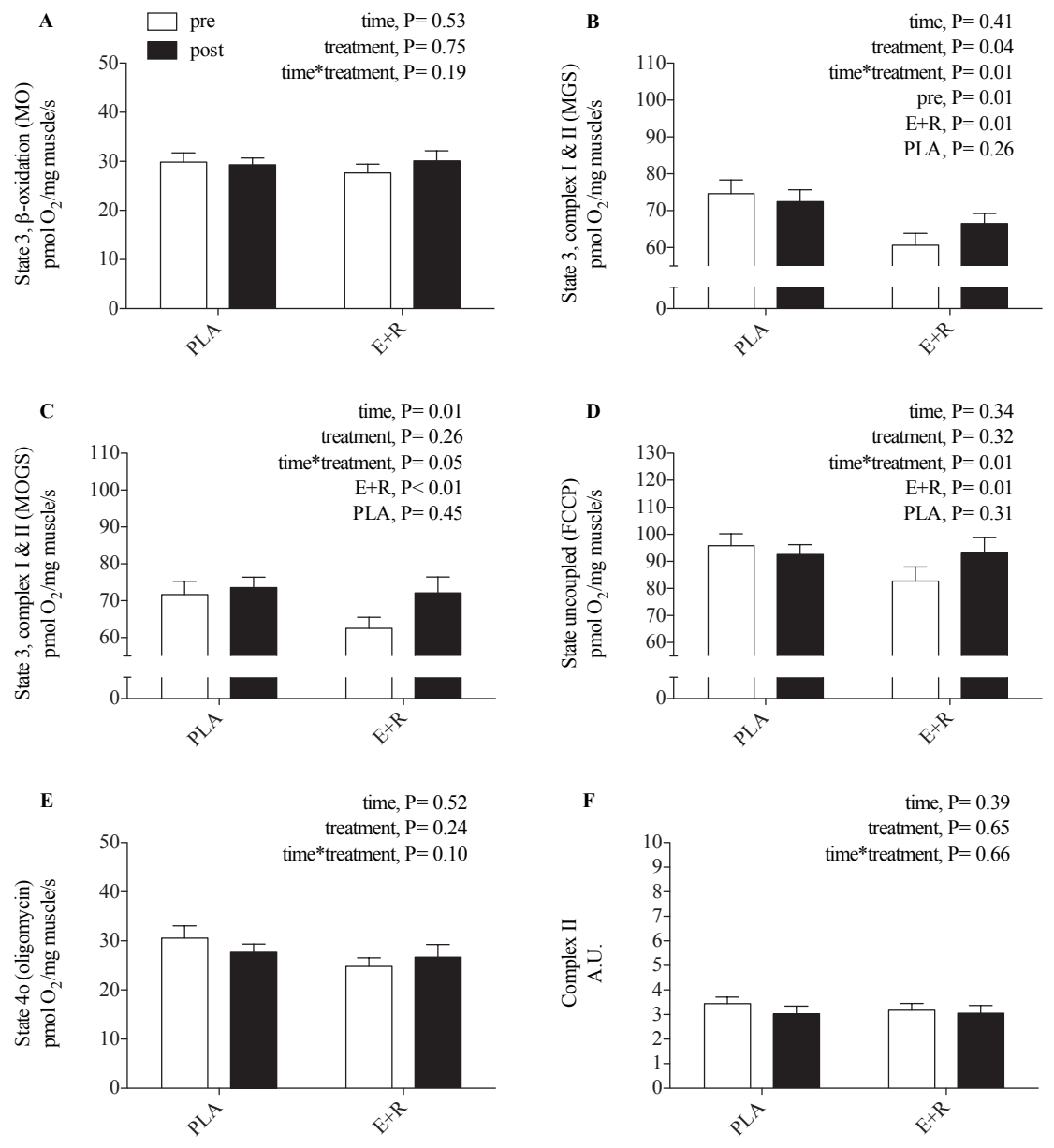

G

time, $\mathrm{P}=0.45$
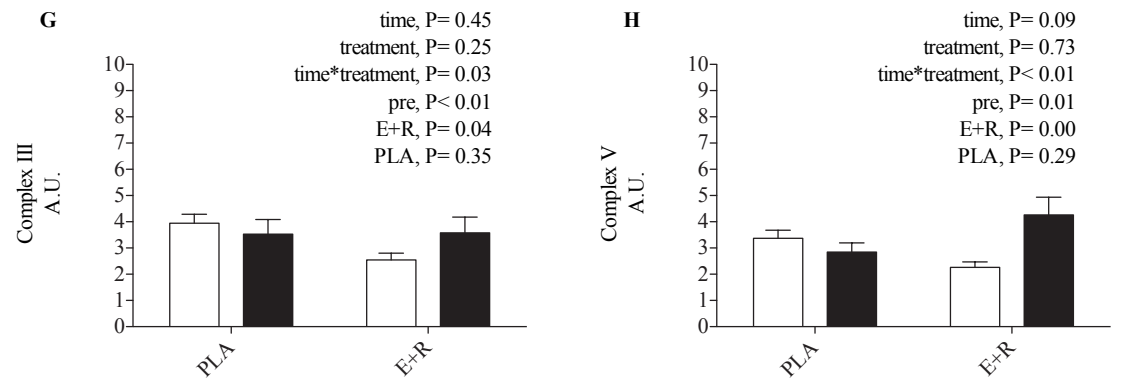
Figure 4.2. Skeletal muscle oxidative capacity and OxPhos protein content before and after intervention

Values are given as means \pm SEM $(\mathrm{n}=29)$. Oxidative capacity (A-E) was assessed by means of ex vivo respirometry on skeletal muscle ( $m$. vastus lateralis), isolated after an overnight fast. In aliquots, protein contents of OxPhos complexes were analyzed by western blots $(\mathrm{F}-\mathrm{H})$. Basal respiration

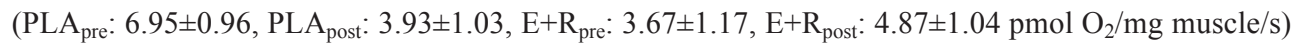
was increased by about 10 -fold by addition of ADP (state 3 respiration). Variables were analyzed using a two-way repeated measures ANOVA, with time $\left(\mathrm{P}_{\text {time, }}\right.$, pre, post $)$ and treatment $\left(\mathrm{P}_{\text {treatment }}\right.$, PLA, E $+R$ ) as factors. A $\mathrm{P}<0.05$ was considered as statistically significant. Significant baseline differences were identified by Student's unpaired t-test $\left(\mathrm{P}_{\text {pre }}\right)$ and in case of a significant time*treatment interaction $\left(\mathrm{P}_{\text {time }}{ }^{*}\right.$ treatment $)$, post-hoc analyses with Bonferroni correction were applied to identify significant within-group effects.

White bars: pre; black bars: post; AU: arbitrary units; FCCP: Carbonyl Cyanide pTrifluoromethoxyphenylhydrazone; G: glutamate; M: malate; O: octanoyl-carnitine; S: succinate.

\section{$\mathbf{E}+\mathbf{R}$ preserves fat oxidation without changes in energy expenditure}

Next, we investigated whether the improved skeletal muscle oxidative capacity after 12 weeks of $\mathrm{E}+\mathrm{R}$ supplementation may translate into whole-body effects on fasting substrate oxidation. Indeed, E+R supplementation significantly affected fasting substrate oxidation, as reflected by a non-significant decrease in fasting RQ after E+R and a significant increase in the PLA group $\left(E+R_{\text {pre }}: 0.803 \pm 0.009, E+R_{\text {post }}: 0.785 \pm 0.016, P_{L A}\right.$ pre: 0.784 \pm 0.009 , PLA $_{\text {post }}: 0.821 \pm 0.015, \mathrm{P}_{\text {time*treatment }}=0.03, \mathrm{P}_{\mathrm{E}+\mathrm{R}}=0.31, \mathrm{P}_{\mathrm{PLA}}=0.04$, Figure $4.4 \mathrm{~A}$ ), without effects on EE (Figure 4.4B). More specific, a concomitant significant increase in fasting carbohydrate oxidation was observed after PLA, but not after $\mathrm{E}+\mathrm{R}\left(\mathrm{P}_{\text {time*treatment }}=0.05\right.$, $\left.\mathrm{P}_{\mathrm{E}+\mathrm{R}}=0.44, \mathrm{P}_{\mathrm{PLA}}=0.04\right)$. Vice versa, $\mathrm{E}+\mathrm{R}$ supplementation preserved fasting fat oxidation, whilst there was a significant decrease in the PLA group $\left(\mathrm{P}_{\text {time*tratment }}=0.06, \mathrm{P}_{\mathrm{E}+\mathrm{R}}=0.46\right.$, $\mathrm{P}_{\mathrm{PLA}}=0.05$, Figures $4.4 \mathrm{C}$ and D). 


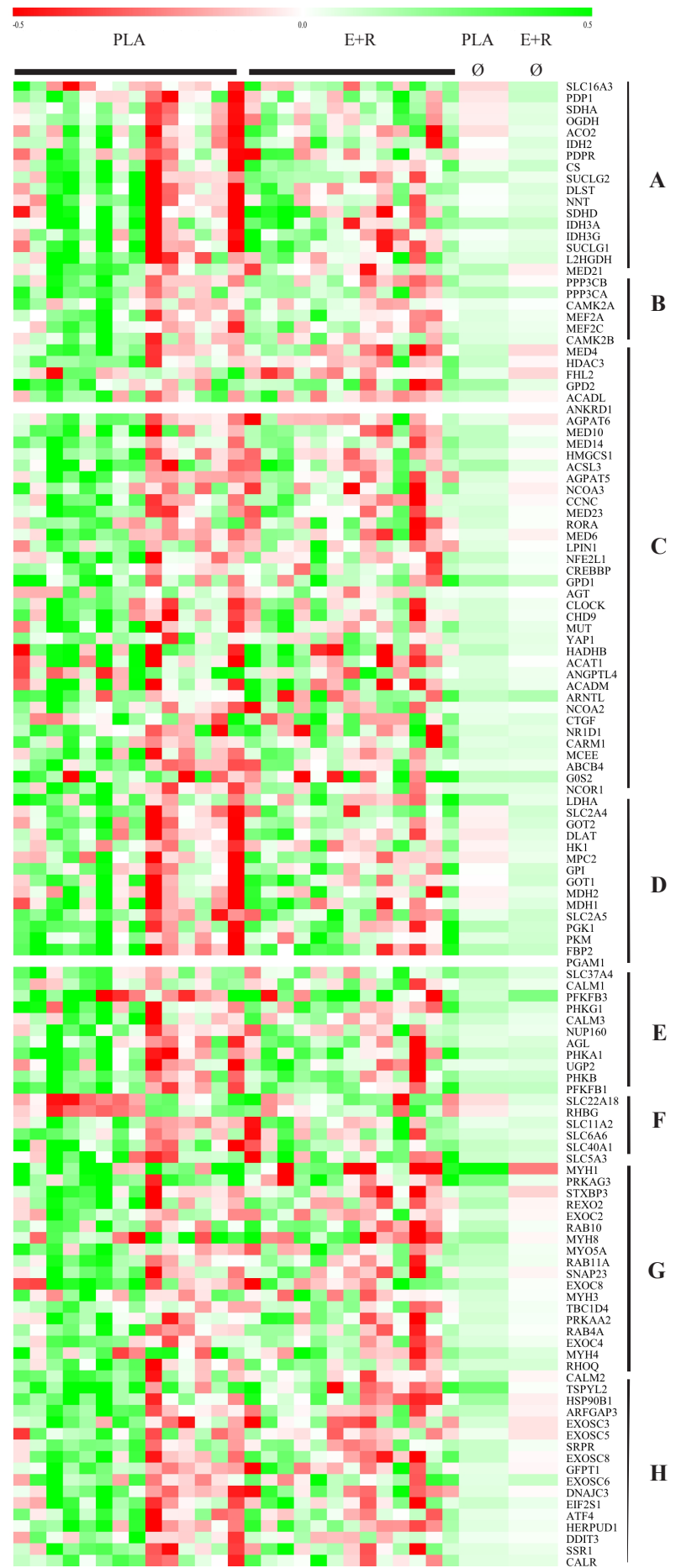

Figure 4.3. Skeletal muscle gene set enrichment analyses before and after intervention

A Heatmap of pathways related to metabolic function from gene set enrichment analyses on skeletal muscle ( $m$. vastus lateralis) $(n=27)$. Signal log-ratio's are presented per subject and as mean per group. Genes in the heatmap represent significantly contributing genes to most affected pathways by $\mathrm{E}+\mathrm{R}$ or PLA supplementation (false discovery rate, q-value $<0.2$ ). Color in the heat-maps reflects the signal log-ratio's per subject and group (Ø) with red being down-and green upregulated comparing post versus premeasurement.

A: WP2766, the citric acid TCA cycle and respiratory electron transport;

B: BIOC, PGC1A pathway;

C: fatty acid triacylglycerol and ketone body metabolism; D: WP534, glycolysis and gluconeogenesis;

E: WP1848, metabolism of carbohydrates;

F: WP1935, transport of glucose and other sugars, bile salts, organic acids, metal ions and amine compounds;

G: translocation of GLUT4 to the plasma membrane;

$\mathbf{H}$ : unfolded protein response UPR. 

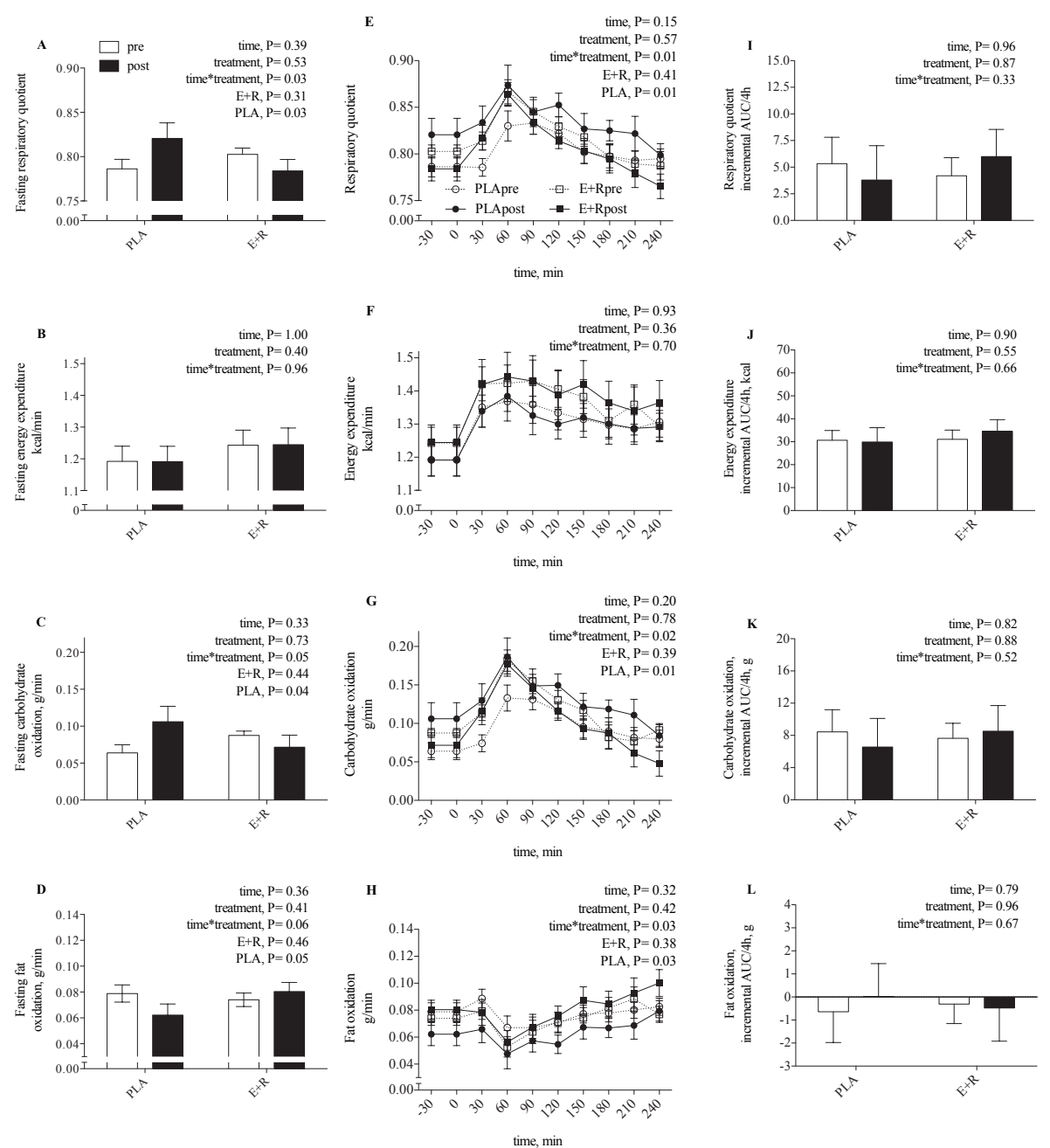

Figure 4.4. Fasting and postprandial whole-body substrate oxidation and energy expenditure before and after intervention

Values are given as means \pm SEM $(n=31)$. Indirect calorimetry was performed during fasting conditions and for $4 \mathrm{~h}$ after intake of a liquid HFMM. Mean $\mathrm{O}_{2}$-consumption and $\mathrm{CO}_{2}$-production over 20 min were used for calculations. Fasting substrate oxidation (A, C-D) and energy expenditure (B), AUCs during the HFMM-test (E-H) and the incremental AUCs (I-L) were analyzed using a twoway repeated measures ANOVA, with time $\left(\mathrm{P}_{\text {time }}\right.$, pre, post $)$ and treatment $\left(\mathrm{P}_{\text {treatment }}, \mathrm{PLA}, \mathrm{E}+\mathrm{R}\right)$ as factors. A $\mathrm{P}<0.05$ was considered as statistically significant. In case of a significant time*treatment interaction $\left(\mathrm{P}_{\text {time*treatment }}\right)$, post-hoc analyses with Bonferroni correction were applied to identify significant within-group effects. Figures A-D and I-L: White bars: pre; black bars: post; Figures E-H: Dashed line, open circles: PLA pre; solid line, filled circles: PLA post; Dashed line, open squares: $\mathrm{E}+\mathrm{R}$ pre; solid line, filled squares: $\mathrm{E}+\mathrm{R}$ post. 


\section{$E+R$ affects triacylglycerol concentrations but did not change postprandial responses of substrate oxidation and local lipolysis}

To examine E+R-induced effects on postprandial substrate utilization and energy expenditure, we performed a HFMM-test (625 kcal, 61 energy\% fat). More specific, we determined whole-body, adipose tissue and skeletal muscle substrate metabolism in the postprandial state combining plasma blood sampling, indirect calorimetry and microdialysis.

The preserved fat oxidation with $\mathrm{E}+\mathrm{R}$ as compared to in the fasting state was maintained throughout the postprandial period (AUC fat oxidation, $\mathrm{P}_{\text {time*treatment }}=0.03, \mathrm{P}_{\mathrm{E}+\mathrm{R}}=0.38$, $\mathrm{P}_{\mathrm{PLA}}=0.03$, Figure 4.4E-H). The postprandial responses (incremental AUC) of RQ, EE, carbohydrate and fat oxidation as well as the postprandial responses of plasma metabolites and insulin were not significantly affected by the intervention (Figure 4.4I-L and Figure 4.1A-F, respectively).

Importantly, however, E+R supplementation significantly attenuated the increase in plasma TAG concentrations during the HFMM-test, that was observed in the PLA group $\left(\mathrm{E}+\mathrm{R}_{\text {pre }}\right.$ : $\mathrm{AUC}=527 \pm 59, \mathrm{E}+\mathrm{R}_{\text {post }}: \mathrm{AUC}=530 \pm 66, \quad \mathrm{PLA}_{\text {pre }}: \mathrm{AUC}=440 \pm 56, \quad \mathrm{PLA}_{\text {post }}: \mathrm{AUC}=531 \pm 62$ $\mathrm{mmol} /(\mathrm{L} * 4 \mathrm{~h}), \mathrm{P}_{\text {time*treatment }}=0.04, \mathrm{P}_{\mathrm{E}+\mathrm{R}}=0.92, \mathrm{P}_{\mathrm{PLA}}<0.01$, Figure $\left.4.1 \mathrm{~F}\right)$.

Skeletal muscle and abdominal subcutaneous adipose tissue substrate metabolism and blood flow were investigated in men using microdialysis. Adipose tissue and skeletal muscle ethanol outflow/inflow ratios, which indicate local blood flow, were not significantly affected by the intervention (Supplemental Figure 4.S1). Interstitial glycerol concentrations, reflecting local lipolysis, were also not affected by E+R (Supplemental Figure 4.S2). Furthermore, no effects of $\mathrm{E}+\mathrm{R}$ were observed on interstitial glucose, pyruvate and lactate concentrations.

\section{E $+\mathbf{R}$ did not affect intramuscular lipid content and composition}

A preserved fat oxidation may contribute to reduced intramyocellular lipid metabolites and consequently insulin sensitivity ${ }^{2}$. E+R supplementation for 12 weeks did not alter total lipid content (TAG and DAG) or saturation of the TAG and DAG fraction (Supplemental Table 4.4.). 
Chapter 4

Table 4.4. Skeletal muscle lipid fractions and proteins before and after intervention

\begin{tabular}{lccccc}
\hline & \multicolumn{2}{c}{ PLA, $\mathrm{n}=17$} & \multicolumn{2}{c}{ E+R, n=12 } & \\
& Week 0 & Week 12 & Week 0 & Week 12 & P \\
\hline DAG & & & & & \\
Total, $\mu \mathrm{mol} / \mathrm{g}$ & $13.6 \pm 1.6$ & $11.7 \pm 1.9$ & $20.4 \pm 6.9$ & $14.9 \pm 2.8$ & 0.52 \\
SFA, \% & $35.4 \pm 2.0$ & $36.9 \pm 2.6$ & $37.4 \pm 2.6$ & $37.0 \pm 2.4$ & 0.59 \\
MUFA, \% & $52.8 \pm 1.7$ & $51.0 \pm 2.4$ & $49.8 \pm 3.4$ & $49.7 \pm 3.5$ & 0.70 \\
PUFA, \% & $11.8 \pm 0.5$ & $12.1 \pm 0.8$ & $12.8 \pm 1.2$ & $13.3 \pm 1.3$ & 0.92 \\
\hline TAG & & & & & \\
Total, $\mu \mathrm{mol} / \mathrm{g}$ & $308 \pm 103$ & $285 \pm 98$ & $392 \pm 137$ & $154 \pm 31$ & 0.27 \\
SFA, \% & $38.9 \pm 2.1$ & $40.1 \pm 2.2$ & $43.9 \pm 3.9$ & $42.9 \pm 3.8$ & 0.62 \\
MUFA, \% & $51.1 \pm 1.6$ & $50.0 \pm 1.8$ & $44.7 \pm 4.4$ & $46.8 \pm 4.0$ & 0.55 \\
PUFA, \% & $10.1 \pm 0.6$ & $9.9 \pm 0.6$ & $11.4 \pm 1.3$ & $10.4 \pm 1.3$ & 0.52 \\
\hline \hline
\end{tabular}

Values are given as means \pm SEM and data were analyzed using a two-way repeated measures ANOVA, with time (pre, post) and treatment (PLA, E+R) as factors. A $\mathrm{P}<0.05$ was considered as statistically significant. DAG, diacylglycerol; MUFA, mono-unsaturated fatty acids; PUFA, polyunsaturated fatty acids; SFA, saturated fatty acids; TAG, triacylglycerol.

\section{E+R did not affect tissue-specific insulin sensitivity}

Finally, we investigated whether the improved mitochondrial capacity and whole-body fat oxidation resulted in improved insulin sensitivity following $\mathrm{E}+\mathrm{R}$ supplementation. We found no changes in peripheral, hepatic or adipose tissue insulin sensitivity after $E+R$ compared to PLA supplementation (Table 4.5), which is in agreement with unchanged fasting and postprandial plasma glucose and insulin concentrations. More specific, the $\mathrm{Rd}$ and EGP under fasting and insulin-stimulated conditions were not significantly affected following 12 weeks of E+R supplementation (Table 4.5). Similar results were found when values were expressed as changes relative to fasting conditions (Table 4.5). Interestingly, $\mathrm{E}+\mathrm{R}$ increased fasting NOGD $\left(\mathrm{P}_{\text {time*treatment }}=0.10, \mathrm{P}_{\mathrm{E}+\mathrm{R}}=0.01, \mathrm{P}_{\mathrm{PLA}}=0.91\right)$. Furthermore, $\mathrm{E}+\mathrm{R}$ did not improve insulin-mediated suppression of plasma FFA, indicating that adipose tissue

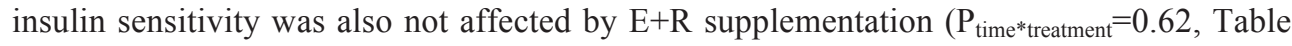
4.5). 
Table 4.5. Whole-body substrate kinetics before and after intervention

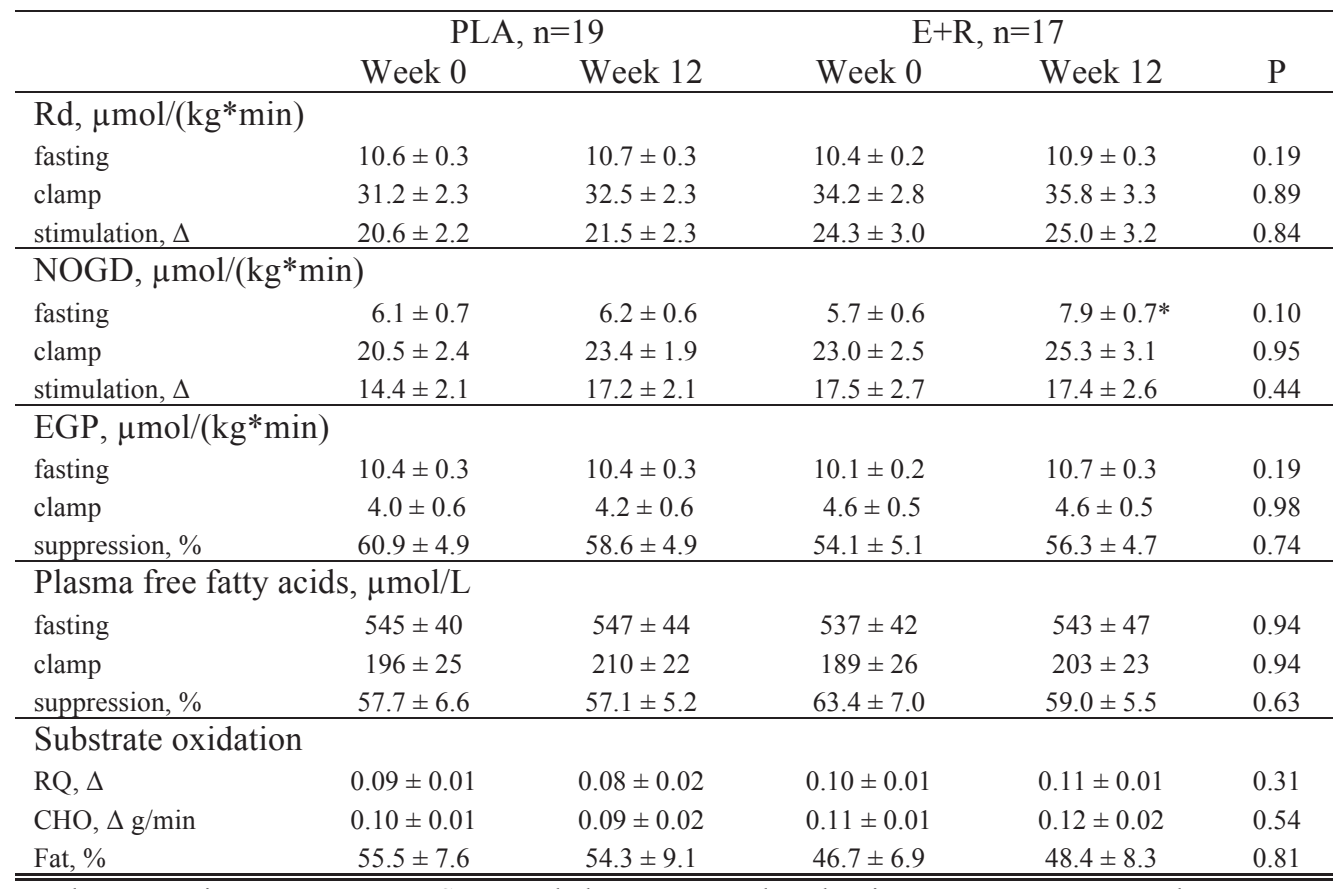

Values are given as means \pm SEM and data were analyzed using a two-way repeated measures ANOVA, with time ( $\mathrm{P}_{\text {time, }}$, pre, post) and treatment $\left(\mathrm{P}_{\text {treatment }}, \mathrm{PLA}, \mathrm{E}+\mathrm{R}\right)$ as factors. A $\mathrm{P}<0.05$ was considered as statistically significant. No baseline differences were observed (Student's t-test). In case of a significant time*treatment interaction, post-hoc analyses with Bonferroni correction were applied to identify significant within-group effects, which are indicated by asterisk (*). $\mathrm{CHO}$, carbohydrate oxidation; EGP, endogenous glucose production; NOGD, non-oxidative glucose disposal; Rd, rate of disappearance; RQ, respiratory quotient.

\section{Discussion}

Combining polyphenols with distinct mechanisms of action may lead to additional and/or synergistic beneficial metabolic effects compared to single-polyphenol supplementation ${ }^{20,21}$. Here, we show that after 12 weeks, combined $\mathrm{E}+\mathrm{R}$ supplementation has preserved fasting and postprandial fat oxidation as compared to the PLA group. This coincided with an increased skeletal muscle oxidative capacity in the $\mathrm{E}+\mathrm{R}$ group. In addition, $\mathrm{E}+\mathrm{R}$ attenuated the increase in TAG concentrations compared to PLA, and the reduction in visceral adipose tissue mass tended to be higher with $\mathrm{E}+\mathrm{R}$ as compared to PLA. These 
beneficial metabolic effects, however, did not translate into improved peripheral, hepatic and adipose tissue insulin sensitivity in overweight men and women.

We have previously shown that 3 days of $E+R$ supplementation increased energy expenditure ${ }^{20}$. The present study demonstrated that this increase is not maintained following 12 weeks supplementation. Furthermore, consistent with unchanged food intake, we found that body weight and body composition were not affected by longer-term $E+R$ supplementation. These findings are in line with most ${ }^{13,14,17,18,29,30}$ but not all ${ }^{15}$ previous studies in humans. Although no significant effects on total fat mass were apparent, we found that $\mathrm{E}+\mathrm{R}$ tended to decrease visceral adipose tissue mass by approximately $11 \%$ as compared to PLA. Likewise, $\mathrm{E}$ and $\mathrm{R}$ have reduced visceral adipose tissue in animals ${ }^{31,32}$. As visceral adipose tissue is known to be detrimental with respect to metabolic health ${ }^{33}$, its reduction may be of physiological importance in the long-term.

Interestingly, we demonstrated that combined $\mathrm{E}+\mathrm{R}$ supplementation significantly affected fasting substrate oxidation as compared to PLA (Figure 4.4). E+R supplementation preserved fat oxidation, whereas it significantly declined in the PLA group. This effect was maintained during postprandial conditions. In agreement with our findings, previous studies in rodents have shown that polyphenols may stimulate fat oxidation under fasting conditions ${ }^{9,31,34}$. The compensatory increase in carbohydrate oxidation that we found in the PLA group was not accompanied by alterations in whole-body glucose disposal. Rather, we found that $\mathrm{E}+\mathrm{R}$ may diminish glycolysis and increase glycogen storage ${ }^{35}$, as indicated by the increased fasting NOGD $\left(\sim 40 \%, \mathrm{P}_{\mathrm{E}+\mathrm{R}}=0.01\right)$. Importantly, the differentially affected fat oxidation in the present study is neither driven by an increased lipid supply towards skeletal muscle nor by a significant reduction in muscle lipid stores (TAG and DAG content). Indeed, it has previously been shown that a shift in fasting fat oxidation can occur independently of changes in intramuscular lipid content, energy expenditure, adiposity or insulin sensitivity ${ }^{36,37}$. Alternatively, a higher oxidative capacity of skeletal muscle mitochondria was found predictive for a lower fasting respiratory exchange ratio or, in other words, a greater relative reliance on lipids instead of carbohydrate as a fuel source during fasting conditions ${ }^{37-39}$. Interestingly, we indeed found that 12 weeks $\mathrm{E}+\mathrm{R}$ supplementation increased skeletal muscle oxidative capacity in permeabilized muscle fibers. This was accompanied by an increased muscle protein content of OxPhos complexes and an upregulation of mitochondrial pathways (citric acid cycle and respiratory electron 
transport chain, Figures 4.2 and 4.3). In line, others and we have previously shown that $\mathrm{R}$ increased mitochondrial capacity by activating the AMPK-SIRT-PGC1 $\alpha$-pathway ${ }^{7,8,13}$. Additionally, since the R supplement is composed of Polygonum cuspidatum extract, we cannot exclude minor metabolic effects of other components (piceid and emodin ${ }^{40}$ ). It has been suggested that $\mathrm{E}$ increases $\beta$-adrenergic stimulation by norepinephrine due to catechol-O-methyltransferase inhibition ${ }^{10,41}$. However, in our previous study we did not observe altered norepinephrine concentrations after $\mathrm{E}+\mathrm{R}$ supplementation ${ }^{20}$. Finally, reduced oxidative stress, indicated by a reduced unfolded protein response pathway ${ }^{42}$, might have contributed to the observed improvement of skeletal muscle oxidative capacity ${ }^{43-45}$ or vice versa ${ }^{46}$.

An increased mitochondrial capacity might reflect an improved metabolic risk profile, since increased mitochondrial capacity has been associated with higher insulin sensitivity in several cross-sectional studies in men ${ }^{37-39,47}$. Therefore, we hypothesized that the improvements in lipid metabolism may lead to increased insulin sensitivity following 12 weeks of E+R supplementation. However, we did not find a significant change in peripheral, hepatic or adipose tissue insulin sensitivity. To date, only three human clinical trials with $\mathrm{R}$, but not a single study with $\mathrm{E}$, have examined the effects of polyphenol supplementation on peripheral and hepatic insulin sensitivity using the gold standard hyperinsulinemic-euglycemic clamp. In accordance with our findings, these studies did not observe significant changes in peripheral ${ }^{17,18,29}$ and hepatic ${ }^{18}$ insulin sensitivity in lean ${ }^{18}$, obese ${ }^{17}$ and patients with non-alcoholic fatty-liver disease ${ }^{29}$ after supplementation with $\mathrm{R}$ for 4,8 or 12 weeks, respectively. Importantly, in these studies, mitochondrial capacity was not assessed ${ }^{29}$ or not improved ${ }^{17,18}$, based on gene expression and protein abundance of related enzymes. Therefore, the present study is the first to demonstrate that combined $\mathrm{E}+\mathrm{R}$ supplementation has beneficial effects on skeletal muscle oxidative capacity, although this was not accompanied by increased peripheral, hepatic or adipose tissue insulin sensitivity in overweight and obese men and women.

In line, the insulin-mediated stimulation of carbohydrate oxidation and suppression of lipid oxidation was not affected by $\mathrm{E}+\mathrm{R}$ supplementation after meal ingestion or during the hyperinsulinemic-euglycemic clamp. Previously, we have shown that single supplementation of R for 4 weeks and combined $\mathrm{E}+\mathrm{R}$ supplementation for 3 days improved metabolic flexibility in humans ${ }^{13,20}$, as shown by a more pronounced suppression of 
postprandial fat oxidation. The apparent discrepancy between the present and earlier studies may be explained by the duration of supplementation. E+R supplementation had no effect on postprandial glucose, insulin and FFA concentrations or local interstitial glucose and glycerol concentrations. This is in agreement with other placebo-controlled trials in Caucasians ${ }^{13,19}$, whereas gender-specific analyses may reveal metabolic effects ${ }^{14}$.

Strikingly, we found that E+R supplementation for 12 weeks attenuated the increase in plasma TAG during the HFMM-test that was seen in the PLA group. Previous studies in humans ${ }^{13,14}$ and rodents have also shown reduced plasma TAG after $\mathrm{E}$ or $\mathrm{R}$ supplementation ${ }^{9,31,48}$. This might, at least partly, be explained by a reduced intestinal lipid uptake, an improved buffering capacity of dietary TAGs in adipose tissue or increased peripheral (e.g. muscle and liver) TAG extraction. In accordance, a reduced intestinal lipid uptake after E supplementation in rodents has been suggested ${ }^{9}$, although this could not be confirmed in humans ${ }^{30}$. Additionally, E and R supplementation may have affected hepatic lipid clearance, storage and oxidation, as indicated by several animal studies ${ }^{48-50}$.

In conclusion, the present study demonstrated that 12 weeks of $\mathrm{E}+\mathrm{R}$ supplementation improved skeletal muscle oxidative capacity, preserved fasting and postprandial fat oxidation and prevented an increase in TAG concentrations compared to PLA. These putative beneficial metabolic effects did not translate into improved peripheral, hepatic or adipose tissue insulin sensitivity after 12 weeks. Importantly, the improved mitochondrial capacity and fat oxidation may increase physical condition ${ }^{51}$ and prevent the progression of obesity ${ }^{52}$ and insulin resistance ${ }^{4}$ in the long term. 


\section{References}

1. Ng M, Fleming $\mathrm{T}$, Robinson $\mathrm{M}$, et al. Global, regional, and national prevalence of overweight and obesity in children and adults during 1980-2013: a systematic analysis for the Global Burden of Disease Study 2013. Lancet 2014;384:766-81.

2. Shulman GI. Ectopic Fat in Insulin Resistance, Dyslipidemia, and Cardiometabolic Disease. The New England journal of medicine 2014;371:1131-41.

3. Goossens GH. The role of adipose tissue dysfunction in the pathogenesis of obesityrelated insulin resistance. Physiology \& behavior 2008;94:206-18.

4. Szendroedi J, Phielix E, Roden M. The role of mitochondria in insulin resistance and type 2 diabetes mellitus. Nature reviews Endocrinology 2012;8:92-103.

5. van Hees AM, Jans A, Hul GB, Roche HM, Saris WH, Blaak EE. Skeletal muscle fatty acid handling in insulin resistant men. Obesity 2011;19:1350-9.

6. Roumen C, Corpeleijn E, Feskens EJ, Mensink M, Saris WH, Blaak EE. Impact of 3year lifestyle intervention on postprandial glucose metabolism: the SLIM study. Diabetic medicine : a journal of the British Diabetic Association 2008;25:597-605.

7. Baur JA, Pearson KJ, Price NL, et al. Resveratrol improves health and survival of mice on a high-calorie diet. Nature 2006;444:337-42.

8. Lagouge M, Argmann C, Gerhart-Hines Z, et al. Resveratrol improves mitochondrial function and protects against metabolic disease by activating SIRT1 and PGC-1alpha. Cell 2006;127:1109-22.

9. Klaus S, Pultz S, Thone-Reineke C, Wolfram S. Epigallocatechin gallate attenuates diet-induced obesity in mice by decreasing energy absorption and increasing fat oxidation. International journal of obesity 2005;29:615-23.

10. Lu H, Meng X, Yang CS. Enzymology of methylation of tea catechins and inhibition of catechol-O-methyltransferase by (-)-epigallocatechin gallate. Drug metabolism and disposition: the biological fate of chemicals 2003;31:572-9.

11. Collins QF, Liu HY, Pi J, Liu Z, Quon MJ, Cao W. Epigallocatechin-3-gallate (EGCG), a green tea polyphenol, suppresses hepatic gluconeogenesis through 5'AMP-activated protein kinase. The Journal of biological chemistry 2007;282:30143-9.

12. Bogdanski P, Suliburska J, Szulinska M, Stepien M, Pupek-Musialik D, Jablecka A. Green tea extract reduces blood pressure, inflammatory biomarkers, and oxidative stress and improves parameters associated with insulin resistance in obese, hypertensive patients. Nutrition research 2012;32:421-7.

13. Timmers S, Konings E, Bilet L, et al. Calorie restriction-like effects of 30 days of resveratrol supplementation on energy metabolism and metabolic profile in obese humans. Cell metabolism 2011;14:612-22.

14. Mahler A, Steiniger J, Bock M, et al. Metabolic response to epigallocatechin-3-gallate in relapsing-remitting multiple sclerosis: a randomized clinical trial. The American journal of clinical nutrition 2015;101:487-95.

15. Brown AL, Lane J, Holyoak C, Nicol B, Mayes AE, Dadd T. Health effects of green tea catechins in overweight and obese men: a randomised controlled cross-over trial. Br J Nutr 2011;106:1880-9.

16. Mendez-Del Villar M, Gonzalez-Ortiz M, Martinez-Abundis E, Perez-Rubio KG, Lizarraga-Valdez R. Effect of Resveratrol Administration on Metabolic Syndrome, 
Insulin Sensitivity, and Insulin Secretion. Metabolic syndrome and related disorders 2014.

17. Poulsen MM, Vestergaard PF, Clasen BF, et al. High-dose resveratrol supplementation in obese men: an investigator-initiated, randomized, placebocontrolled clinical trial of substrate metabolism, insulin sensitivity, and body composition. Diabetes 2013;62:1186-95.

18. Yoshino J, Conte C, Fontana L, et al. Resveratrol supplementation does not improve metabolic function in nonobese women with normal glucose tolerance. Cell metabolism 2012;16:658-64.

19. Brown AL, Lane J, Coverly J, et al. Effects of dietary supplementation with the green tea polyphenol epigallocatechin-3-gallate on insulin resistance and associated metabolic risk factors: randomized controlled trial. The British journal of nutrition 2009;101:886-94.

20. Most J, Goossens GH, Jocken JW, Blaak EE. Short-term supplementation with a specific combination of dietary polyphenols increases energy expenditure and alters substrate metabolism in overweight subjects. International journal of obesity 2014;38:698-706.

21. Most J, van Can JGP, van Dijk JW, Goossens GH, Jocken JWE, Hospers JJ, Bendik I, Blaak EE. A 3-day EGCG supplementation reduces interstitial lactate concentration in skeletal muscle in overweight subjects. Scientific Reports 2015: 5, Article number: 17896.

22. Phielix E, Schrauwen-Hinderling VB, Mensink M, et al. Lower intrinsic ADPstimulated mitochondrial respiration underlies in vivo mitochondrial dysfunction in muscle of male type 2 diabetic patients. Diabetes 2008;57:2943-9.

23. Goossens GH, Blaak EE, Saris WH, van Baak MA. Angiotensin II-induced effects on adipose and skeletal muscle tissue blood flow and lipolysis in normal-weight and obese subjects. The Journal of clinical endocrinology and metabolism 2004;89:26906.

24. Weir JB. New methods for calculating metabolic rate with special reference to protein metabolism. The Journal of physiology 1949;109:1-9.

25. Frayn KN. Calculation of substrate oxidation rates in vivo from gaseous exchange. Journal of applied physiology: respiratory, environmental and exercise physiology 1983;55:628-34.

26. Ullmann U, Haller J, Decourt JD, Girault J, Spitzer V, Weber P. Plasma-kinetic characteristics of purified and isolated green tea catechin epigallocatechin gallate (EGCG) after 10 days repeated dosing in healthy volunteers. Int J Vitam Nutr Res 2004;74:269-78.

27. Friedewald WT, Levy RI, Fredrickson DS. Estimation of the concentration of lowdensity lipoprotein cholesterol in plasma, without use of the preparative ultracentrifuge. Clinical chemistry 1972;18:499-502.

28. Stampfer MJ, Sacks FM, Salvini S, Willett WC, Hennekens CH. A prospective study of cholesterol, apolipoproteins, and the risk of myocardial infarction. The New England journal of medicine 1991;325:373-81.

29. Chachay VS, Macdonald GA, Martin JH, et al. Resveratrol Does Not Benefit Patients With Nonalcoholic Fatty Liver Disease. Clinical gastroenterology and hepatology : the official clinical practice journal of the American Gastroenterological Association 2014. 
30. Janssens PL, Hursel R, Westerterp-Plantenga MS. Long-term green tea extract supplementation does not affect fat absorption, resting energy expenditure, and body composition in adults. The Journal of nutrition 2015;145:864-70.

31. Friedrich M, Petzke KJ, Raederstorff D, Wolfram S, Klaus S. Acute effects of epigallocatechin gallate from green tea on oxidation and tissue incorporation of dietary lipids in mice fed a high-fat diet. International journal of obesity 2012;36:73543.

32. Jimenez-Gomez Y, Mattison JA, Pearson KJ, et al. Resveratrol improves adipose insulin signaling and reduces the inflammatory response in adipose tissue of rhesus monkeys on high-fat, high-sugar diet. Cell metabolism 2013;18:533-45.

33. Tchernof A, Despres JP. Pathophysiology of human visceral obesity: an update. Physiological reviews 2013;93:359-404.

34. Park SJ, Ahmad F, Philp A, et al. Resveratrol ameliorates aging-related metabolic phenotypes by inhibiting cAMP phosphodiesterases. Cell 2012;148:421-33.

35. Bouskila M, Hunter RW, Ibrahim AF, et al. Allosteric regulation of glycogen synthase controls glycogen synthesis in muscle. Cell metabolism 2010;12:456-66.

36. Hoehn KL, Turner N, Swarbrick MM, et al. Acute or chronic upregulation of mitochondrial fatty acid oxidation has no net effect on whole-body energy expenditure or adiposity. Cell metabolism 2010;11:70-6.

37. van de Weijer T, Sparks LM, Phielix E, et al. Relationships between mitochondrial function and metabolic flexibility in type 2 diabetes mellitus. PloS one 2013;8:e51648.

38. Phielix E, Meex R, Ouwens DM, et al. High oxidative capacity due to chronic exercise training attenuates lipid-induced insulin resistance. Diabetes 2012;61:2472-8.

39. Corpeleijn E, Mensink M, Kooi ME, Roekaerts PM, Saris WH, Blaak EE. Impaired skeletal muscle substrate oxidation in glucose-intolerant men improves after weight loss. Obesity 2008;16:1025-32.

40. Kuo $\mathrm{CH}$, Chen BY, Liu YC, et al. Optimized Ultrasound-Assisted Extraction of Phenolic Compounds from Polygonum cuspidatum. Molecules 2014;19:67-77.

41. Hursel R, Janssens PL, Bouwman FG, Mariman EC, Westerterp-Plantenga MS. The role of catechol-O-methyl transferase Val(108/158)Met polymorphism (rs4680) in the effect of green tea on resting energy expenditure and fat oxidation: a pilot study. PloS one 2014;9:e106220.

42. Zhang K, Kaufman RJ. From endoplasmic-reticulum stress to the inflammatory response. Nature 2008;454:455-62.

43. Jackson JR, Ryan MJ, Alway SE. Long-term supplementation with resveratrol alleviates oxidative stress but does not attenuate sarcopenia in aged mice. The journals of gerontology Series A, Biological sciences and medical sciences 2011;66:751-64.

44. Serrano JC, Gonzalo-Benito H, Jove M, et al. Dietary intake of green tea polyphenols regulates insulin sensitivity with an increase in AMP-activated protein kinase alpha content and changes in mitochondrial respiratory complexes. Molecular nutrition \& food research 2013;57:459-70.

45. Boudina S, Sena S, Sloan C, et al. Early mitochondrial adaptations in skeletal muscle to diet-induced obesity are strain dependent and determine oxidative stress and energy expenditure but not insulin sensitivity. Endocrinology 2012;153:2677-88.

46. Liesa M, Shirihai OS. Mitochondrial dynamics in the regulation of nutrient utilization and energy expenditure. Cell metabolism 2013;17:491-506. 
47. Ukropcova B, McNeil M, Sereda O, et al. Dynamic changes in fat oxidation in human primary myocytes mirror metabolic characteristics of the donor. The Journal of clinical investigation 2005;115:1934-41.

48. Cho SJ, Jung UJ, Choi MS. Differential effects of low-dose resveratrol on adiposity and hepatic steatosis in diet-induced obese mice. The British journal of nutrition 2012;108:2166-75.

49. Zhou J, Farah BL, Sinha RA, et al. Epigallocatechin-3-gallate (EGCG), a green tea polyphenol, stimulates hepatic autophagy and lipid clearance. PloS one 2014;9:e87161.

50. Murase T, Nagasawa A, Suzuki J, Hase T, Tokimitsu I. Beneficial effects of tea catechins on diet-induced obesity: stimulation of lipid catabolism in the liver. International journal of obesity and related metabolic disorders : journal of the International Association for the Study of Obesity 2002;26:1459-64.

51. Overmyer KA, Evans CR, Qi NR, et al. Maximal oxidative capacity during exercise is associated with skeletal muscle fuel selection and dynamic changes in mitochondrial protein acetylation. Cell metabolism 2015;21:468-78.

52. Flatt JP, Ravussin E, Acheson KJ, Jequier E. Effects of dietary fat on postprandial substrate oxidation and on carbohydrate and fat balances. The Journal of clinical investigation 1985;76:1019-24. 


\section{Supplemental Material}




\title{
Supplemental Methods
}

\author{
Dual energy Xray absorptiometry \\ Dual energy Xray absorptiometry measurements have been evaluated against computed \\ tomography ${ }^{1}$.
}

\section{Microarray analysis}

For microarray analysis, total RNA was extracted from skeletal muscle biopsies using the Trizol method (Qiagen, Venlo, Netherlands). $100 \mathrm{ng}$ of intact total RNA was processed applying the GeneChip ${ }^{\circledR}$ WT PLUS Reagent Kit (Affymetrix, Santa Clara, CA, USA) according to the manufacture's manual. Fragmented and labelled single strand (ss)-cDNA (quantity and quality verified via Nanodrop-8000 and Agilent 2100 Bioanalyzer) of each sample was hybridized onto a Human Transcriptome Array (HTA) 2.0 GeneChip ${ }^{\circledR}$ (Affymetrix). Hybridization, washing and scanning of the GeneChips was performed using the Affymetrix GeneChip ${ }^{\circledR}$ Hybridization oven 640, Fluidics Station 450/250 and Scanner 3000 , according to the manufacture's user guides. Quality control of the scanned HTA 2.0 GeneChips was performed using the Expression Console application (Affymetrix Launcher software). Gene chip data were analyzed using the MADMAX database and analysis pipeline ${ }^{2}$. Probe sets were defined according to Dail et al. ${ }^{3}$. Ranked gene lists based on the intensity based moderated t-statistics ${ }^{4}$ were used as input for Gene Set Enrichment Analysis, which was run with 1000 permutations ${ }^{5,6}$. Functional data analysis was based upon FDR q-value $<0.2$ on the filtered data set (IQR $>0.2(\log 2)$, intensity $>20,>5$ arrays, $>5$ probes per gen). The data discussed in this publication have been deposited in NCBI's Gene Expression Omnibus ${ }^{7}$ and are accessible through GEO Series accession number GSE71614 (http://www.ncbi.nlm.nih.gov/geo/query/acc.cgi?acc=GSE71614).

\section{Skeletal muscle lipid composition}

For determination of lipid composition, skeletal muscle biopsies were dissected free from extramyocellular adipose, blood and connective tissue before lyophilisation. Total lipids were extracted after addition of internal standards by the chloroform-methanol $(2: 1 \mathrm{vol} / \mathrm{vol})$ method. After evaporation under nitrogen at $37{ }^{\circ} \mathrm{C}$, lipids were separated into diacylglycerol (DAG) and triacylglycerol (TAG) by thin-layer chromatography and transferred into tubes for methylation with $1 \mathrm{~mL}$ of toluene-methanol BF3-methanol (14\%, 
20-55-25\%). Incubation in capped tubes for 30 minutes at $100{ }^{\circ} \mathrm{C}$ was followed by addition of $2 \mathrm{~mL}$ pentane to the samples and after vortexing and centrifugation (1000 g, $5 \mathrm{~min}, 20$ ${ }^{\circ} \mathrm{C}$ ) pentane extracts were isolated and evaporated (nitrogen, $30^{\circ} \mathrm{C}$ ) before fatty acid profiles were determined on an analytical gas chromatograph, as described previously ${ }^{8}$.

\section{High-fat mixed meal composition}

Ingredients:

$125 \mathrm{~g}$ whole milk

$15 \mathrm{~g}$ sucrose

$50 \mathrm{~g}$ whipped crème

$150 \mathrm{~g}$ whipped crème ice

Macronutrient composition:

Energy content, $625 \mathrm{kcal}$

protein, 6.3 energy $\%$

carbohydrate, 32.6 energy $\%$

fat, 61.2 energy $\%$

saturated fatty acids, 35.5 energy\%

mono-unsaturated fatty acids, 18.8 energy $\%$

poly-unsaturated fatty acids, 1.7 energy $\%$ 


\section{Supplemental Results}
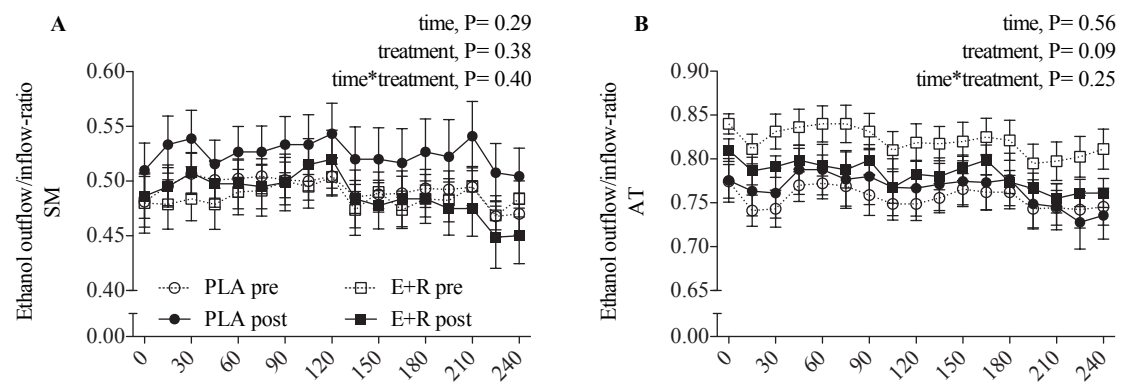

Supplemental Figure 4.S1. Local fasting and postprandial interstitial blood flow before and after intervention

Values are given as means \pm SEM ( $n=17)$. Fasting and postprandial interstitial local blood flow (ethanol outflow/inflow-ratio) were measured by means of microdialysis in skeletal muscle $(\mathrm{m}$. gastrocnemius; A) and abdominal subcutaneous adipose tissue (B) of male subjects. Fasting values, AUCs during the HFMM-test and the incremental AUCs were analyzed using a two-way repeated measures ANOVA, with time $\left(\mathrm{P}_{\text {time }}\right.$, pre, post) and treatment $\left(\mathrm{P}_{\text {treatment }}\right.$, PLA, E+R) as factors. A $\mathrm{P}<0.05$ was considered as statistically significant. Reported $\mathrm{P}$-values refer to the AUCs of the respective metabolite concentrations. AT, adipose tissue; SM, skeletal muscle. Dashed line, open circles: PLA pre; solid line, filled circles: PLA post; Dashed line, open squares: E+R pre; solid line, filled squares: $E+R$ post. 

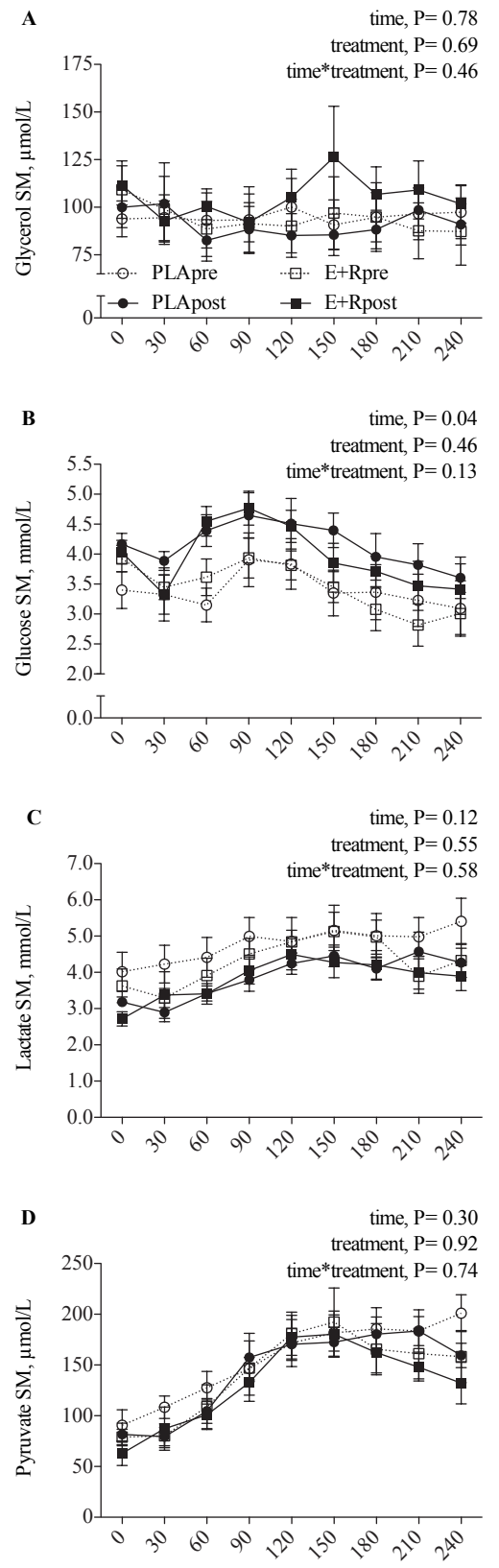
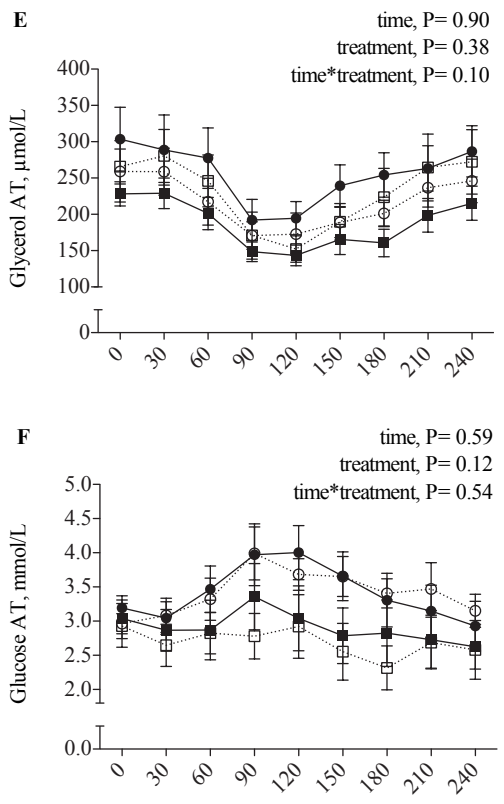

G

time, $\mathrm{P}=0.14$
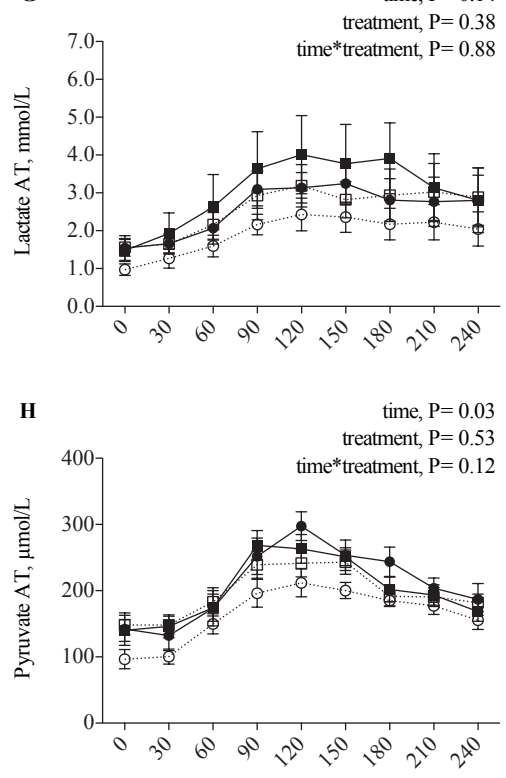


\section{Chapter 4}

Supplemental Figure 4.S2. Local fasting and postprandial interstitial metabolite concentrations before and after intervention

Values are given as means \pm SEM $(\mathrm{n}=17)$. Fasting and postprandial interstitial metabolite concentrations (glycerol, glucose, lactate and pyruvate) were measured by means of microdialysis in skeletal muscle (m. gastrocnemius; A-D) and abdominal subcutaneous adipose tissue (E-H) of male subjects. Fasting values, AUCs during the HFMM-test and the incremental AUCs were analyzed using a two-way repeated measures ANOVA, with time $\left(\mathrm{P}_{\text {time }}\right.$, pre, post $)$ and treatment $\left(\mathrm{P}_{\text {treatment }}\right.$, PLA, E $+\mathrm{R}$ ) as factors. A $\mathrm{P}<0.05$ was considered as statistically significant. Reported $\mathrm{P}$-values refer to the AUCs of the respective metabolite concentrations. AT, adipose tissue; SM, skeletal muscle. Dashed line, open circles: PLA pre; solid line, filled circles: PLA post; Dashed line, open squares: $\mathrm{E}+\mathrm{R}$ pre; solid line, filled squares: $\mathrm{E}+\mathrm{R}$ post. 


\section{Supplemental References}

1. Micklesfield LK, Goedecke JH, Punyanitya M, Wilson KE, Kelly TL. Dual-energy Xray performs as well as clinical computed tomography for the measurement of visceral fat. Obesity 2012;20:1109-14.

2. Lin K, Kools H, de Groot PJ, et al. MADMAX - Management and analysis database for multiple $\sim$ omics experiments. Journal of integrative bioinformatics 2011;8:160.

3. Dai MH, Wang PL, Boyd AD, et al. Evolving gene/transcript definitions significantly alter the interpretation of GeneChip data. Nucleic Acids Res 2005;33.

4. Sartor MA, Tomlinson CR, Wesselkamper SC, Sivaganesan S, Leikauf GD, Medvedovic M. Intensity-based hierarchical Bayes method improves testing for differentially expressed genes in microarray experiments. Bmc Bioinformatics 2006;7.

5. Subramanian A, Tamayo P, Mootha VK, et al. Gene set enrichment analysis: A knowledge-based approach for interpreting genome-wide expression profiles. P Natl Acad Sci USA 2005;102:15545-50.

6. Mootha VK, Lindgren CM, Eriksson KF, et al. PGC-1 alpha-responsive genes involved in oxidative phosphorylation are coordinately downregulated in human diabetes. Nat Genet 2003;34:267-73.

7. Edgar R, Domrachev M, Lash AE. Gene Expression Omnibus: NCBI gene expression and hybridization array data repository. Nucleic Acids Res 2002;30:207-10.

8. van Hees AM, Jans A, Hul GB, Roche HM, Saris WH, Blaak EE. Skeletal muscle fatty acid handling in insulin resistant men. Obesity 2011;19:1350-9. 


\section{CHAPTER 5}

\section{The effects of polyphenol supplementation on adipose tissue morphology and gene expression in overweight and obese humans}

Jasper Most, Ines Warnke, Mark van Boekschoten, Johan WE Jocken, Philip de Groot, Angelika Friedel, Igor Bendik, Gijs H Goossens, Ellen E Blaak International Journal of Obesity, to be submitted. 


\section{Abstract}

Objective: Alterations in adipose tissue (AT) morphology and function are associated with obesity-related chronic diseases. Dietary polyphenols may have beneficial effects on AT mass and function in rodents, but human studies are scarce.

Methods: In a randomized, placebo-controlled study, 25 (15 men) overweight and obese humans received a combination of epigallocatechin-3-gallate and resveratrol $(282 \mathrm{mg} / \mathrm{d}, 80$ $\mathrm{mg} / \mathrm{d}$, respectively, E+R) or placebo (PLA) supplementation for 12 weeks. Before and after intervention, AT biopsies were collected for assessment of adipocyte morphology and microarray analysis.

Results: E+R supplementation had no significant effects on mean adipocyte size and distribution compared with PLA. However, pathways contributing to adipogenesis, cell cycle and apoptosis were significantly downregulated in AT by $E+R$ versus PLA. Furthermore, E $+\mathrm{R}$ significantly decreased the expression of genes involved in pathways related to substrate and energy metabolism, oxidative stress, inflammation and immune defense as compared with PLA.

Conclusion: In conclusion, the AT gene expression profile indicates a reduced cell turnover after 12-week E+R supplementation in overweight and obese subjects. It remains to be elucidated whether these alterations translate into metabolic effects in the longer term. 


\section{Introduction}

Enlargement of abdominal subcutaneous adipocytes is an independent marker of insulin resistance ${ }^{1}$, and predicts the development of type 2 diabetes ${ }^{2}$. This suggests that the morphology and function of adipose tissue (AT), rather than AT mass per se, determine the risk of developing chronic metabolic conditions accompanying the obese phenotype.

Epigallocatechin-3-gallate (E) and resveratrol (R) are dietary polyphenols, abundantly available in green tea and in grapes, respectively. Both have been shown to prevent the development of fat mass accretion and insulin resistance in rodents on obesogenic diets via inhibition of adipogenesis and inflammation, and increased lipolysis and energy expenditure ${ }^{3-6}$. However, most human studies have not found significant effects on AT mass (body composition) and whole-body metabolic profile after supplementation with either $\mathrm{E}$ or $\mathrm{R}^{7,8}$, Nevertheless, $\mathrm{R}$ supplementation for 4 weeks induced a reduction in adipocyte size in obese men ${ }^{9}$, which was accompanied by an AT gene expression profile indicative of increased adipogenesis, autophagy and inflammation. We have recently postulated that combining different polyphenols may lead to additional and/or synergistic and, therefore, more pronounced metabolic effects compared with single supplementation. Indeed, combined $\mathrm{E}$ and $\mathrm{R}(\mathrm{E}+\mathrm{R})$ supplementation for 3 days increased fasting and postprandial energy expenditure and plasma leptin concentrations in overweight subjects ${ }^{10}$. More recently, we have shown that combined E+R supplementation for 12 weeks increased whole-body fat oxidation and mitochondrial capacity in skeletal muscle, but did not significantly alter whole-body lipolysis, AT and skeletal muscle lipolysis and tissuespecific insulin sensitivity. Here, we investigated whether E+R supplementation for 12 weeks induced alterations in abdominal subcutaneous AT morphology and gene expression profiles in overweight and obese men and women compared with placebo (PLA).

\section{Subjects and methods}

\section{Study design}

The current study was conducted as part of a randomized, double-blind placebo-controlled intervention trial. The effects of 12 weeks E+R supplementation $(282 \mathrm{mg} / \mathrm{d}$ and $80 \mathrm{mg} / \mathrm{d}$, 
respectively) on insulin sensitivity and lipid metabolism were investigated in 38 overweight and obese men and women. Before and after intervention, an abdominal subcutaneous AT biopsy was collected after an overnight fast. All subjects gave written informed consent for participation in the original study, which was approved by the Medical Ethical Committee of Maastricht University Medical Center ${ }^{+}$. All procedures were conducted according to the Declaration of Helsinki.

\section{Abdominal subcutaneous adipocyte size}

The AT biopsy ( $\sim 1 \mathrm{~g})$ was taken under local anesthesia using a needle biopsy technique ${ }^{11}$ and snap-frozen at $-80^{\circ} \mathrm{C}$ until further analyses. One portion of the biopsy was embedded in paraffin, of which sections were cut for staining, digital imaging and computerized measurement of 400 individual adipocytes to determine adipocyte morphology ${ }^{11}$.

\section{Adipose tissue gene and protein expression}

For microarray analysis, total RNA was extracted from frozen AT aliquots ( $300 \mathrm{mg})$ using the Trizol method (Qiagen, Venlo, Netherlands). Fragmented and labeled ss-cDNA of each sample was hybridized onto a Human Transcriptome Array (HTA) 2.0 GeneChip $^{\circledR}$ (Affymetrix) ${ }^{12}$. Functional data analysis was based upon FDR q-value $<0.05$ for the interaction ( $\mathrm{E}+\mathrm{R}$ versus $\mathrm{PLA}$ ) with gene set enrichment analysis which was run with 1000 permutations. An upstream analysis was performed on the differentially expressed genes $(\mathrm{P}<0.05)$ with Ingenuity Pathway Analysis (June 2015, QIAGEN Silicon Valley, Redwood City, CA, USA). After protein extraction, protein quantification of oxidative phosphorylation (OxPhos)-complexes was performed by Image Lab ${ }^{\mathrm{TM}}$ Software (V5.2.1. Build 11, BioRad, Venendaal, the Netherlands).

\section{Statistics}

Data are expressed as mean \pm SEM. Variables were normally distributed. Baseline differences between the E+R and PLA group were tested by Student's unpaired t-test. The effects of $\mathrm{E}+\mathrm{R}$ supplementation compared with PLA were analyzed using repeatedmeasures ANOVA (time*treatment interaction). Statistics was done using SPSS 19.0 (IBM Corporation, Armonk, NY, USA) for Macintosh. $\mathrm{P}<0.05$ was considered as statistically significant. 


\section{Results}

\section{Subjects characteristics}

Twenty-five subjects (15 men) were included in the present sub-study, since AT biopsies were not available for all individuals that completed the main trial $(n=38)$. At baseline, subject characteristics were not significantly different between groups in the total study population ${ }^{12}$, and were comparable in the present sub-study (Table 5.1).

Table 5.1. Subjects' characteristics and plasma biochemistry

\begin{tabular}{|c|c|c|c|c|c|}
\hline & \multicolumn{2}{|c|}{ PLA, $n=14$} & \multicolumn{2}{|c|}{$\mathrm{E}+\mathrm{R}, \mathrm{n}=11$} & \multirow[b]{2}{*}{$\mathrm{P}$} \\
\hline & Week 0 & Week 12 & Week 0 & Week 12 & \\
\hline Age, years & $40 \pm 3$ & - & $36 \pm 3$ & - & \\
\hline Body-mass-index, $\mathrm{kg} / \mathrm{m} 2$ & $29.7 \pm 1.1$ & - & $30.5 \pm 0.7$ & - & \\
\hline Waist-hip-ratio & $0.88 \pm 0.03$ & - & $0.88 \pm 0.03$ & - & \\
\hline Diastolic blood pressure, $\mathrm{mmHg}$ & $111 \pm 3$ & - & $119 \pm 2$ & - & \\
\hline Systolic blood pressure, $\mathrm{mmHg}$ & $74 \pm 2$ & - & $76 \pm 2$ & - & \\
\hline $\mathrm{HbA} 1 \mathrm{c}, \%$ & $5.15 \pm 0.08$ & - & $5.05 \pm 0.06$ & - & \\
\hline Glucose, mmol/1 & $5.11 \pm 0.11$ & $5.12 \pm 0.12$ & $5.13 \pm 0.13$ & $5.08 \pm 0.14$ & 0.50 \\
\hline $2 \mathrm{~h}$ glucose, $\mathrm{mmol} / \mathrm{l}$ & $5.29 \pm 0.29$ & - & $5.19 \pm 0.30$ & - & \\
\hline Insulin, $\mathrm{mU} / 1$ & $8.97 \pm 1.19$ & $10.55 \pm 1.06$ & $8.70 \pm 1.34$ & $7.84 \pm 1.20$ & 0.03 \\
\hline HOMA-IR & $2.03 \pm 0.26$ & $2.39 \pm 0.24$ & $1.97 \pm 0.29$ & $1.77 \pm 0.27$ & 0.03 \\
\hline Free fatty acids, $\mu \mathrm{mol} / 1$ & $532 \pm 32$ & $491 \pm 18$ & $497 \pm 55$ & $532 \pm 53$ & 0.33 \\
\hline Triacylglycerol, mmol/1 & $1.06 \pm 0.22$ & $1.31 \pm 0.24$ & $1.75 \pm 0.25$ & $1.93 \pm 0.27$ & 0.65 \\
\hline Adiponectin, $\mu \mathrm{g} / \mathrm{ml}$ & $8.27 \pm 1.00$ & $8.57 \pm 1.00$ & $6.98 \pm 1.12$ & $7.13 \pm 1.13$ & 0.77 \\
\hline Leptin, ng/ml & $23.1 \pm 4.5$ & $24.3 \pm 4.5$ & $17.8 \pm 5.1$ & $16.1 \pm 5.1$ & 0.16 \\
\hline Interleukin-6, pg/ml & $1.00 \pm 0.17$ & $0.91 \pm 0.13$ & $0.69 \pm 0.19$ & $0.77 \pm 0.14$ & 0.46 \\
\hline Interleukin-8, pg/ml & $9.28 \pm 0.94$ & $10.32 \pm 1.06$ & $9.79 \pm 1.07$ & $9.79 \pm 1.20$ & 0.43 \\
\hline $\mathrm{TNF}-\alpha, \mathrm{pg} / \mathrm{ml}$ & $2.86 \pm 0.24$ & $3.30 \pm 0.46$ & $2.87 \pm 0.27$ & $2.81 \pm 0.52$ & 0.26 \\
\hline $\mathrm{E}, \mathrm{ng} / \mathrm{ml}$ & $<2.5$ & $<2.5$ & $<2.5$ & $15 \pm 10$ & 0.00 \\
\hline $\mathrm{R}, \mathrm{ng} / \mathrm{ml}$ & $<10$ & $<10$ & $<10$ & $233 \pm 55$ & 0.00 \\
\hline Dihydro-R, ng/ml & $<10$ & $<10$ & $<10$ & $177 \pm 35$ & 0.00 \\
\hline
\end{tabular}

WHR, waist-to-hip-ratio; HbA1c, glycated hemoglobin A 1c; 2h-glucose, plasma glucose after oral glucose-tolerance test; HOMA-IR, Homeostatic Model Assessment of insulin resistance; TNF- $\alpha$, tumor necrosis factor alpha; E, epigallocatechin-3-gallate; $\mathrm{R}$, resveratrol. Values given as mean \pm SEM. P, P-value for statistical significance of time*treatment interaction.

\section{Adipocyte size}

$\mathrm{E}+\mathrm{R}$ supplementation had no significant effect on mean adipocyte size or surface area in abdominal subcutaneous AT (Figure 5.1A-B). In line, adipocyte size distribution was unchanged after $\mathrm{E}+\mathrm{R}$ supplementation (Figure 5.1C), indicating that $\mathrm{E}+\mathrm{R}$ did not induce a shift from large to small adipocytes or vice versa. 


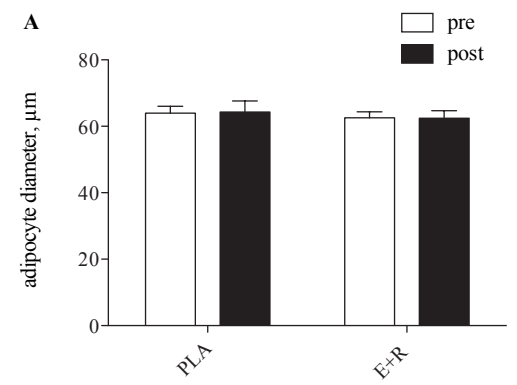

C $\quad<50 \mu \mathrm{m}$

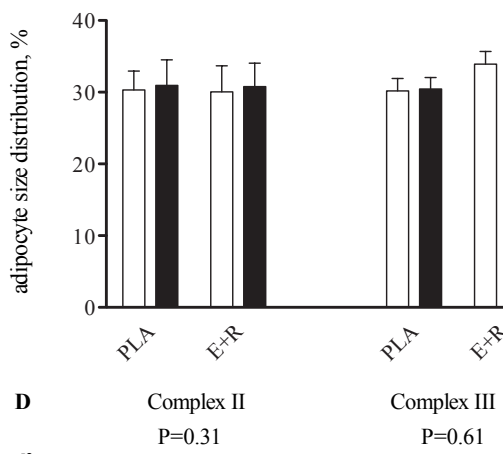

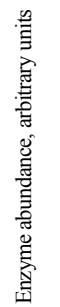

$50-69 \mu \mathrm{m}$

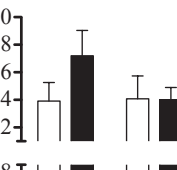

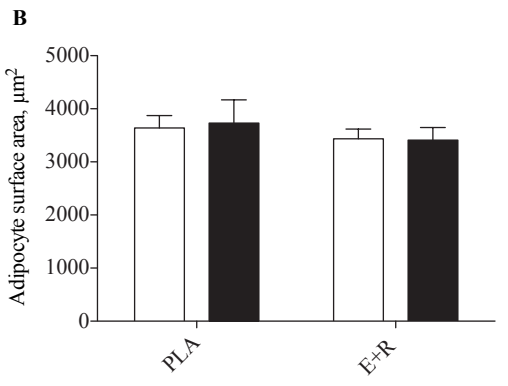

$70-89 \mu \mathrm{m}$

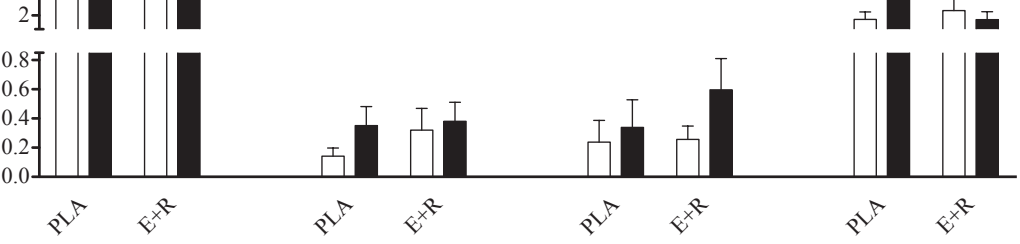

Figure 5.1. Abdominal subcutaneous adipocyte morphology and OxPhos protein expression before and after intervention.

A) Mean adipocyte diameter, B) surface area and C) adipocyte size distribution, and D) mitochondrial protein content of complexes I-V were not affected by E+R supplementation compared with PLA. Open bars: week 0; solid bars: week 12. Statistical significance of time*supplementation interaction indicated as *, when $\mathrm{P}<0.05$. Values are given as means \pm SEM. 


\section{Adipose tissue OxPhos protein expression}

Protein expression of mitochondrial complex $\mathrm{V}$ tended to be decreased by $\mathrm{E}+\mathrm{R}$ supplementation compared with PLA ( $\mathrm{P}=0.11$, Figure 5.1D). Furthermore, complexes II, III and $\mathrm{I}+\mathrm{IV}$ were not significantly affected by $\mathrm{E}+\mathrm{R}(\mathrm{P}=0.31, \mathrm{P}=0.61, \mathrm{P}=0.55$, respectively $)$.

\section{Adipose tissue gene expression profile}

Of the 26876 genes on the array, 10987 were analyzed after filtering (IQR $>0.2(\log 2)$, intensity $>20,>5$ arrays, $>5$ probes per gene). 763 genes were differentially expressed after $\mathrm{E}+\mathrm{R}$ supplementation as compared to PLA $(\mathrm{P}<0.05)$, of which 424 genes were significantly upregulated.

\section{Gene set enrichment analyses}

$\mathrm{E}+\mathrm{R}$ supplementation induced a downregulation of 332 pathways (Databases Kyoto Encyclopedia of Genes and Genomes, Wikipathways, Biocarta) compared with PLA, whereas no pathways were significantly upregulated. More specific, gene sets related to cell turnover (circadian rhythm, cytoskeleton and autophagy) and transcription and translaton were suppressed (Figure 5.2). Furthermore, E+R decreased the expression of pathways related to energy and substrate metabolism, oxidative stress, immune defense (Figure 5.2) and various diseases, including Alzheimer's, types of cancer, and infectious, immune and inflammatory diseases.

\section{Ingenuity analyses}

Upstream analyses of significantly altered genes $(n=763)$ revealed that possible regulators of adipogenesis ( $\beta$-estradiol, Prolactin), oxidative stress (Genistein, nuclear factor and erythroid 2-like 2) and inflammation $(\mathrm{TNF}-\alpha)$ were significantly decreased after $\mathrm{E}+\mathrm{R}$ versus PLA supplementation (Table 5.2.). In line, pathways regulated by anti-carcinogenic and immune-suppressant drugs were activated and implicate an inhibited proliferation capacity (5-Flourouracil, Trichostatin A, Gentamicin, CD 437 and sirolimus). 


\section{Chapter 5}

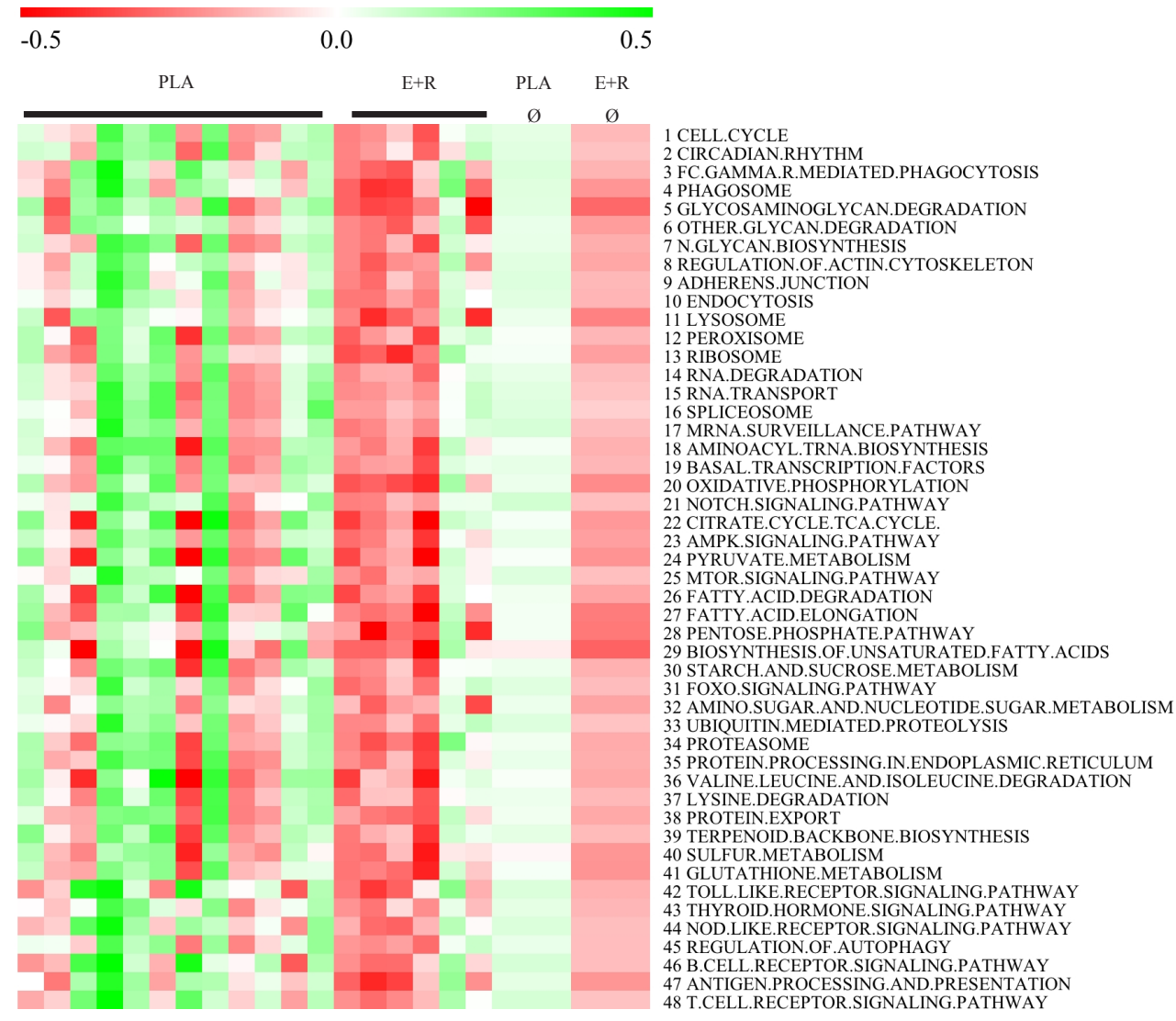

Figure 5.2. Adipose tissue gene expression changes by intervention.

Gene set enrichment analysis of adipose tissue microarray data revealed that gene sets (Kyoto Encyclopedia of Genes and Genomes database) related to cell turnover (1-19), energy and substrate metabolism (20-40), inflammation and the immune system (41-48) were significantly downregulated following $E+R$ supplementation (PLA, $n=12 ; E+R, n=6$ ). Red color indicates downregulated pathways, whereas green color indicates upregulated pathways after $\mathrm{E}+\mathrm{R}$ versus PLA. 
Table 5.2. Ingenuity upstream analysis including related genes

\begin{tabular}{|c|c|c|c|c|c|}
\hline & $\begin{array}{l}\text { Upstream } \\
\text { regulator }\end{array}$ & $\begin{array}{l}\text { Downstream } \\
\text { targets/pathways }\end{array}$ & & genes & $\mathrm{P}$ \\
\hline \multicolumn{6}{|c|}{ Adipogenesis } \\
\hline Inhibited & $\beta$-Estradiol & adipogenesis & $\begin{array}{l}\text { chemical - } \\
\text { endogenous } \\
\text { mammalian }\end{array}$ & 49 & 0.040 \\
\hline Inhibited & Prolactin & early in adipogenesis & cytokine & 30 & 0.000 \\
\hline Activated & $\operatorname{miR}-124-3 p$ & adipogenic & $\begin{array}{l}\text { mature } \\
\text { microRNA }\end{array}$ & 24 & 0.001 \\
\hline \multicolumn{6}{|c|}{ Oxidative stress } \\
\hline Inhibited & Genistein & PPARs, NRF, autophagy & $\begin{array}{l}\text { chemical } \\
\text { drug }\end{array}$ & 34 & 0.000 \\
\hline Inhibited & NFE2L $2,=$ NRF2 & antioxidant defense & $\begin{array}{l}\text { transcription } \\
\text { regulator }\end{array}$ & 31 & 0.001 \\
\hline \multicolumn{6}{|c|}{ Inflammation and Immune defense } \\
\hline Inhibited & $\mathrm{TNF}-\alpha$ & inflammation & cytokine & 49 & 0.023 \\
\hline Activated & $\begin{array}{l}\text { Sirolimus } \\
\text { (=Rapamycin) }\end{array}$ & $\begin{array}{l}\text { impairs T- \& B-cell proliferation and } \\
\text { activation }\end{array}$ & $\begin{array}{l}\text { chemical } \\
\text { drug }\end{array}$ & 29 & 0.007 \\
\hline \multicolumn{6}{|c|}{ Anti-carcinogenic } \\
\hline Inhibited & Trichostatin A & $\begin{array}{l}\text { antibiotic, inhibits histone } \\
\text { deacetylase }\end{array}$ & $\begin{array}{l}\text { chemical } \\
\text { drug }\end{array}$ & 30 & 0.040 \\
\hline Inhibited & Gentamicin & antibiotic, binds bacterial ribosome & $\begin{array}{l}\text { chemical } \\
\text { drug }\end{array}$ & 24 & 0.002 \\
\hline Activated & 5-Fluorouracil & cytostaticum & $\begin{array}{l}\text { chemical } \\
\text { drug }\end{array}$ & 26 & 0.000 \\
\hline Activated & CD 437 & $\begin{array}{l}\text { adipogenesis, anti-carcinogenic (by } \\
\text { ER-stress) }\end{array}$ & $\begin{array}{l}\text { chemical } \\
\text { drug }\end{array}$ & 25 & 0.000 \\
\hline
\end{tabular}

PPAR- $\alpha$, Peroxisome proliferator-activated receptor $\alpha$; NFE2L2, Nuclear factor (erythroid-derived 2)-like 2 (=NRF2); TNF- $\alpha$, tumor necrosis factor $\alpha$. P, statistical significance of activation/inhibition of upstream regulator for post versus pre-enrichment.

\section{Discussion}

Numerous rodent studies have demonstrated that dietary polyphenols, including $\mathrm{E}$ and R, modulate AT biology ${ }^{3,5}$. Here, we demonstrate that supplementation of E+R for 12 weeks downregulated pathways related to adipocyte turnover, energy metabolism, inflammation and the immune defense. Strikingly, however, E+R did not induce alterations in adipocyte morphology or OxPhos protein expression in overweight and obese subjects. 


\section{Chapter 5}

Interestingly, the present study demonstrated that $\mathrm{E}+\mathrm{R}$ supplementation decreased the expression of gene sets related to adipogenesis and apoptosis, which is indicative of a reduced adipocyte turnover. This, in turn, may have caused the reduction in the expression of pathways related to substrate metabolism and mitochondrial function, because of lower energy requirements of AT. Importantly, a low turnover rate of adipocytes may reflect a less flexible metabolic phenotype. Indeed, decreased adipocyte and lipid turnover has been related to hypertrophic, dysfunctional AT ${ }^{13}$, obesity ${ }^{14}$ and familial combined hyperlipidemia ${ }^{15}$. Nevertheless, the observed inactivation of pathways corresponding to adipocyte turnover did not translate into a change in adipocyte size or AT mass in the present study. Moreover, we have previously found that $\mathrm{E}+\mathrm{R}$ supplementation had no significant effects on AT lipolysis and insulin sensitivity, assessed during a high-fat mixedmeal test ( $625 \mathrm{kcal}, 61$ energy\% fat) by means of microdialysis and expressed as insulinmediated suppression of plasma FFA, respectively ${ }^{12}$.

At first glance, the present data seem in contrast to a previous study of our group, demonstrating that adipocyte size was significantly reduced, whereas fat mass was unchanged, after 30 days of R supplementation $(150 \mathrm{mg} / \mathrm{d})$ in obese men ${ }^{9}$. In that study, gene expression and pathway analysis indicated that $\mathrm{R}$ increased adipogenesis and enhanced lysosomal and phagosomal lipid breakdown, which may have contributed to the observed reduction in adipocyte size 9 . Importantly, however, the duration of supplementation (12 vs. 4 weeks), the lower dose of $\mathrm{R}$ and the addition of $\mathrm{E}$ as supplement in the present study might explain these opposing findings.

Intriguingly, the present data demonstrate that pathways related to oxidative stress, inflammation and the immune response were downregulated in AT after E+R intake compared with PLA. These findings are consistent with previous studies showing antioxidant and anti-proliferative effects of $\mathrm{E}$ and $\mathrm{R}$, which led to the administration of polyphenols in chemoprevention and cancer therapy (reviewed in ${ }^{16,17}$ ). However, due to the importance of oxidative stress and autophagy in cell and tissue homeostasis, cancer development and cardiometabolic complications ${ }^{18,19}$, the (patho)physiological relevance of the present findings over a longer period of time remains to be investigated. Contrary to our observations, Konings et al. ${ }^{9}$ reported an elevated gene expression for pathways related to immune response. This was interpreted as subsequent effect induced by an increased lysosomal lipid breakdown, and by the decrease in adipocyte size causing traction forces 
between the fat cells and their embedding extracellular matrix. As indicated above, both duration of supplementation and the addition of E supplementation may have played a role in these differential findings.

In conclusion, the present study illustrated that $\mathrm{E}+\mathrm{R}$ supplementation for 12 weeks induced significant suppression of gene sets related to adipocyte turnover, inflammation and the immune system in AT in overweight and obese men and women. Although E+R did not induce any significant effects on body composition, AT morphology and insulin sensitivity ${ }^{12}$, it remains to be determined how the alterations in the AT gene expression pattern may translate into changes in metabolic health in the longer term. 


\section{References}

1. Lundgren M, Svensson M, Lindmark S, Renstrom F, Ruge T, Eriksson JW. Fat cell enlargement is an independent marker of insulin resistance and 'hyperleptinaemia'. Diabetologia 2007;50:625-33.

2. Heinonen S, Saarinen L, Naukkarinen J, et al. Adipocyte morphology and implications for metabolic derangements in acquired obesity. International journal of obesity 2014;38:1423-31.

3. Kim S, Jin Y, Choi Y, Park T. Resveratrol exerts anti-obesity effects via mechanisms involving down-regulation of adipogenic and inflammatory processes in mice. Biochemical pharmacology 2011;81:1343-51.

4. Lagouge M, Argmann C, Gerhart-Hines Z, et al. Resveratrol improves mitochondrial function and protects against metabolic disease by activating SIRT1 and PGC-1alpha. Cell 2006;127:1109-22.

5. Lee MS, Kim CT, Kim Y. Green tea (-)-epigallocatechin-3-gallate reduces body weight with regulation of multiple genes expression in adipose tissue of diet-induced obese mice. Annals of nutrition \& metabolism 2009;54:151-7.

6. Wolfram S, Raederstorff D, Wang Y, Teixeira SR, Elste V, Weber P. TEAVIGO (epigallocatechin gallate) supplementation prevents obesity in rodents by reducing adipose tissue mass. Annals of nutrition \& metabolism 2005;49:54-63.

7. Yoshino J, Conte C, Fontana L, et al. Resveratrol supplementation does not improve metabolic function in nonobese women with normal glucose tolerance. Cell metabolism 2012;16:658-64.

8. Mielgo-Ayuso J, Barrenechea L, Alcorta P, Larrarte E, Margareto J, Labayen I. Effects of dietary supplementation with epigallocatechin-3-gallate on weight loss, energy homeostasis, cardiometabolic risk factors and liver function in obese women: randomised, double-blind, placebo-controlled clinical trial. The British journal of nutrition 2014;111:1263-71.

9. Konings E, Timmers S, Boekschoten MV, et al. The effects of 30 days resveratrol supplementation on adipose tissue morphology and gene expression patterns in obese men. International journal of obesity 2014;38:470-3.

10. Most J, Goossens GH, Jocken JW, Blaak EE. Short-term supplementation with a specific combination of dietary polyphenols increases energy expenditure and alters substrate metabolism in overweight subjects. International journal of obesity 2014;38:698-706.

11. Goossens GH, Bizzarri A, Venteclef N, et al. Increased adipose tissue oxygen tension in obese compared with lean men is accompanied by insulin resistance, impaired adipose tissue capillarization, and inflammation. Circulation 2011;124:67-76.

12. Most J, Timmers S, Warnke I, Jocken JWE, van Boekschoten M, de Groot P, Bendik I, Schrauwen P, Goossens GH, Blaak EE. Combined epigallocatechin-3-gallate and resveratrol supplementation for 12 weeks increases mitochondrial capacity and fat oxidation, but not insulin sensitivity in obese humans: a randomized controlled trial. The American Journal of Clinical Nutrition, under revision.

13. Arner E, Westermark PO, Spalding KL, et al. Adipocyte turnover: relevance to human adipose tissue morphology. Diabetes 2010;59:105-9. 
14. Ryden M, Andersson DP, Bernard S, Spalding K, Arner P. Adipocyte triglyceride turnover and lipolysis in lean and overweight subjects. Journal of lipid research 2013;54:2909-13.

15. Arner P, Bernard S, Salehpour M, et al. Dynamics of human adipose lipid turnover in health and metabolic disease. Nature 2011;478:110-3.

16. Goswami SK, Das DK. Resveratrol and chemoprevention. Cancer letters 2009;284:16.

17. Yang CS, Wang X, Lu G, Picinich SC. Cancer prevention by tea: animal studies, molecular mechanisms and human relevance. Nature reviews Cancer 2009;9:429-39.

18. Kim KH, Lee MS. Autophagy--a key player in cellular and body metabolism. Nature reviews Endocrinology 2014;10:322-37.

19. Gorrini C, Harris IS, Mak TW. Modulation of oxidative stress as an anticancer strategy. Nature reviews Drug discovery 2013;12:931-47. 



\section{CHAPTER 6}

\section{Gut microbiota composition strongly correlates to peripheral insulin sensitivity in obese men but not in women}




\begin{abstract}
Aims: Gut microbiota composition may play an important role in the development of obesity-related comorbidities. However, only few studies have investigated genderdifferences in microbiota composition and gender-specific associations with insulin sensitivity.
\end{abstract}

Methods: Insulin sensitivity (hyperinsulinemic-euglycemic clamp), body composition (Dual Energy X-ray Absorptiometry), substrate oxidation (indirect calorimetry), systemic inflammatory markers and microbiota composition (PCR) were determined in male $(\mathrm{n}=15)$ and female $(\mathrm{n}=14)$ overweight and obese subjects.

Results: Bacteroidetes/Firmicutes-ratio was higher in men than in women $(\mathrm{P}=0.001)$. Bacteroidetes/Firmicutes-ratio was inversely related to peripheral insulin sensitivity only in men (men: $\mathrm{P}=0.003$, women: $\mathrm{P}=0.882$ ). This association between Bacteroidetes/Firmicutesratio and peripheral insulin sensitivity did not change after adjustment for dietary fiber and saturated fat intake, body composition, fat oxidation and markers of inflammation. Bacteroidetes/Firmicutes-ratio was not associated with hepatic insulin sensitivity.

Conclusion: Men and women differ in microbiota composition and its impact on insulin sensitivity, implying that women might be less sensitive to gut microbiota-induced metabolic aberrations than men. 


\section{Introduction}

Gut microbiota dysbiosis has been associated with metabolic impairments, such as dyslipidemia and insulin resistance in obese, non-diabetic subjects ${ }^{1}$. However, gender differences have been widely ignored in most studies. Here, we analyzed cross-sectional data of overweight and obese, non-diabetic Caucasian men $(n=15)$ and women $(n=14)$ on microbiota composition, and gender-specifically investigated the relationship between bacterial abundances and the host metabolic phenotype, determined by gold-standard techniques for insulin sensitivity, substrate oxidation and body composition.

\section{Methods}

Analyzed data were baseline measurements from subjects that were recruited for a 12-wk polyphenol-supplementation study, in which effects on insulin sensitivity (primary outcome), substrate oxidation and microbiota composition (secondary outcomes) were assessed. Participants completed a detailed medical and lifestyle questionnaire, were sedentary $(<3 \mathrm{~h} / \mathrm{wk}$ in sports activities) and had no cardiometabolic or gastrointestinal complications or disease. Subjects had been weight-stable and had not taken antibiotics or medication that may interfere with study outcomes for at least 3 months prior to enrollment. We assessed insulin sensitivity by combining a two-step hyperinsulinemic-euglycemic clamp with stable-isotope $\left[6,6-{ }^{2} \mathrm{H}_{2}\right]$-glucose tracer-infusion (Cambridge Isotope Laboratories, Andover, MA, USA) ${ }^{2}$. This enabled determination of peripheral and hepatic insulin sensitivity, expressed as insulin-stimulated rate of disappearance ( $\mathrm{Rd}$, $\mu \mathrm{mol} /(\mathrm{kg} * \min ))$ at an infusion-rate of $40 \mathrm{mU} /\left(\mathrm{m}^{2} * \mathrm{~min}\right)$ and suppression of endogenous glucose production (suppression EGP, \%) at $10 \mathrm{mU}\left(\mathrm{m}^{2} * \mathrm{~min}\right)$, respectively.

Fecal samples were collected and immediately frozen at $-80{ }^{\circ} \mathrm{C}$ until further analysis. For enumeration of selected bacterial groups, metagenomic DNA was extracted and subjected to PCR assays targeting the major bacterial phyla (Applied Biosystems, Waltham, USA). For $\gamma$-Proteobacteria, Actinobacteria, Akkermansia muciniphila (phylum Verrucomicrobia) and Bacteroidetes, detection of PCR-products was conducted with SYBR Green I (Bio-rad Laboratories Inc, Hercules, Canada) ${ }^{3,4}$. For Firmicutes, the 5'-nuclease technique was used (ABgene, Hamburg, Germany) ${ }^{5}$. Dietary intake of saturated fat (expressed as percentage of 
energy intake, \%EI) and fiber (g/MJ) were calculated from 3-day food records using the Dutch food table (NEVO). Body fat percentage was determined by a Dual Energy X-ray Absorptiometry (DXA, Hologic BCA, VitaK, Maastricht, Netherlands) and waist and hip circumferences were measured using a non-expandable measuring tape midway between the lower rib margin and the iliac crest ("waist"), respectively, at largest circumference between the waist and the thighs ("hip"). Energy expenditure (EE) and fat oxidation (expressed as percentage of EE, \%EE) was determined by means of indirect calorimetry (Omnical, Maastricht University, Maastricht, Netherlands) in a half-supine position during fasting conditions and for 4 hours postprandially $(2.6 \mathrm{MJ}, 61 \text { energy } \% \text { fat })^{6}$. Fasting blood samples were taken for measurements of tumor necrosis factor- $\alpha$ (TNF- $\alpha$ ) and interleukin- 6 (IL-6) using a multiplex ELISA (Human ProInflammatory II 4-Plex Ultra-Sensitive Kit, Meso Scale Diagnositics, Rockville, MD, USA).

Gender differences were analyzed by Students' unpaired $t$-test. All variables were tested for outliers and normal distribution (Shapiro-Wilk). We performed regression analyses genderspecifically with insulin sensitivity as dependent and bacterial groups as independent variables, corrected for age (Model 1). Statistically significant relations were then subsequently adjusted for putative relevant covariates. Independent variables were included for food intake (FI, dietary saturated fat and fiber, Model 1+FI), body composition (BC, body fat percentage and distribution, Model $1+\mathrm{BC}$ ), fat oxidation (FO, fasting and postprandial, Model 1+FO) and systemic inflammatory markers (SIM, TNF- $\alpha$ and IL-6, Model 1+SIM). TNF- $\alpha$ was $1 n$-transformed, because it was not normally distributed. Independent variables showed no inter-correlations (defined as $r>0.80$ ).

All subjects gave written informed consent before participation in this study, which was reviewed and approved by the local Medical Ethical Committee of Maastricht University Medical Centre ${ }^{+}$. All procedures were performed according to the declaration of Helsinki.

\section{Results}

We found higher abundances of $\gamma$-Proteobacteria and Bacteroidetes in men than women, while presence of other phyla were not different between gender (Table 6.1). Furthermore, the $\mathrm{B} / \mathrm{F}$-ratio was significantly higher in men as compared to women $(\mathrm{P}<0.001$, Table 6.1). 
Table 6.1. Subjects' characteristics

\begin{tabular}{|c|c|c|c|c|}
\hline & & Men, $n=15$ & Women, $\mathrm{n}=14$ & $\mathrm{P}$ \\
\hline \multirow[t]{2}{*}{ Subjects characteristics } & Age, yrs & $39.2 \pm 2.4$ & $35.1 \pm 3.0$ & 0.29 \\
\hline & Body-mass-index, $\mathrm{kg} / \mathrm{m}^{2}$ & $29.4 \pm 0.7$ & $29.4 \pm 0.7$ & 0.99 \\
\hline \multirow[t]{2}{*}{ Insulin sensitivity } & $\mathrm{Rd}, \mu \mathrm{mol} / \mathrm{kg} / \mathrm{min}$ & $29.6 \pm 2.4$ & $35.6 \pm 3.2$ & 0.14 \\
\hline & EGP suppression, $\%$ & $46.5 \pm 5.4$ & $68.4 \pm 3.3$ & 0.00 \\
\hline \multirow[t]{2}{*}{ Food intake } & Fiber, g/MJ & $1.8 \pm 0.1$ & $1.9 \pm 0.2$ & 0.74 \\
\hline & Saturated fatty acids, $\%$ EI & $17.9 \pm 0.9$ & $16.8 \pm 0.8$ & 0.37 \\
\hline \multirow[t]{3}{*}{ Body composition } & Body fat, $\%$ & $23.4 \pm 0.8$ & $37.0 \pm 1.0$ & 0.00 \\
\hline & Waist-hip-ratio & $0.92 \pm 0.02$ & $0.79 \pm 0.01$ & 0.00 \\
\hline & Visceral fat, $\mathrm{g}$ & $500 \pm 45$ & $387 \pm 42$ & 0.08 \\
\hline \multirow[t]{2}{*}{ Fat oxidation } & Fasting, $\% \mathrm{EE}$ & $56.1 \pm 2.8$ & $54.7 \pm 3.8$ & 0.77 \\
\hline & Postprandial, \%EE & $52.5 \pm 2.7$ & $45.3 \pm 2.5$ & 0.06 \\
\hline \multirow[t]{2}{*}{ Systemic inflammation } & $\mathrm{TNF}-\alpha, \mathrm{pg} / \mathrm{ml}$ & $3.49 \pm 0.22$ & $2.28 \pm 0.09$ & 0.00 \\
\hline & IL-6, pg/ml & $0.73 \pm 0.14$ & $0.93 \pm 0.17$ & 0.37 \\
\hline \multirow[t]{6}{*}{ Bacterial composition } & $\gamma$-Proteobacteria, $\log$ & $11.3 \pm 0.1$ & $10.9 \pm 0.1$ & 0.03 \\
\hline & Actinobacteria, log & $11.5 \pm 0.1$ & $11.7 \pm 0.1$ & 0.35 \\
\hline & Akkermansia, log & $8.7 \pm 0.5$ & $9.6 \pm 0.4$ & 0.19 \\
\hline & Firmicutes, log & $12.3 \pm 0.1$ & $12.4 \pm 0.1$ & 0.40 \\
\hline & Bacteroidetes, log & $13.2 \pm 0.1$ & $12.8 \pm 0.1$ & 0.00 \\
\hline & $\mathrm{B} / \mathrm{F}$-ratio & $10.13 \pm 1.66$ & $3.15 \pm 0.48$ & 0.00 \\
\hline
\end{tabular}

Rd, insulin-stimulated glucose rate of disappearance; EGP, insulin-mediated suppression of endogenous glucose production; EI, total daily energy intake; EE, energy expenditure; TNF- $\alpha$, tumor necrosis factor-alpha; IL-6, Interleukin 6; B/F-ratio, fecal Bacteroidetes/Firmicutes-ratio; P, statistical significance of difference between men and women by Student's unpaired t-test.

Interestingly, a significant inverse linear association was found between the B/F-ratio and peripheral insulin sensitivity in men $(\mathrm{P}=0.003$, Figure $6.1 \mathrm{~A})$ but not in women $(\mathrm{P}=0.882$, Figure 6.1B). No significant correlations were found between B/F-ratio and hepatic insulin sensitivity for both gender (Figure 6.1C-D). Specific phyla abundances ( $\gamma$-Proteobacteria, Actinobacteria, Akkermansia muciniphila, Bacteroidetes and Firmicutes) were not significantly correlated with any measure of insulin sensitivity in men or women (data not shown). 

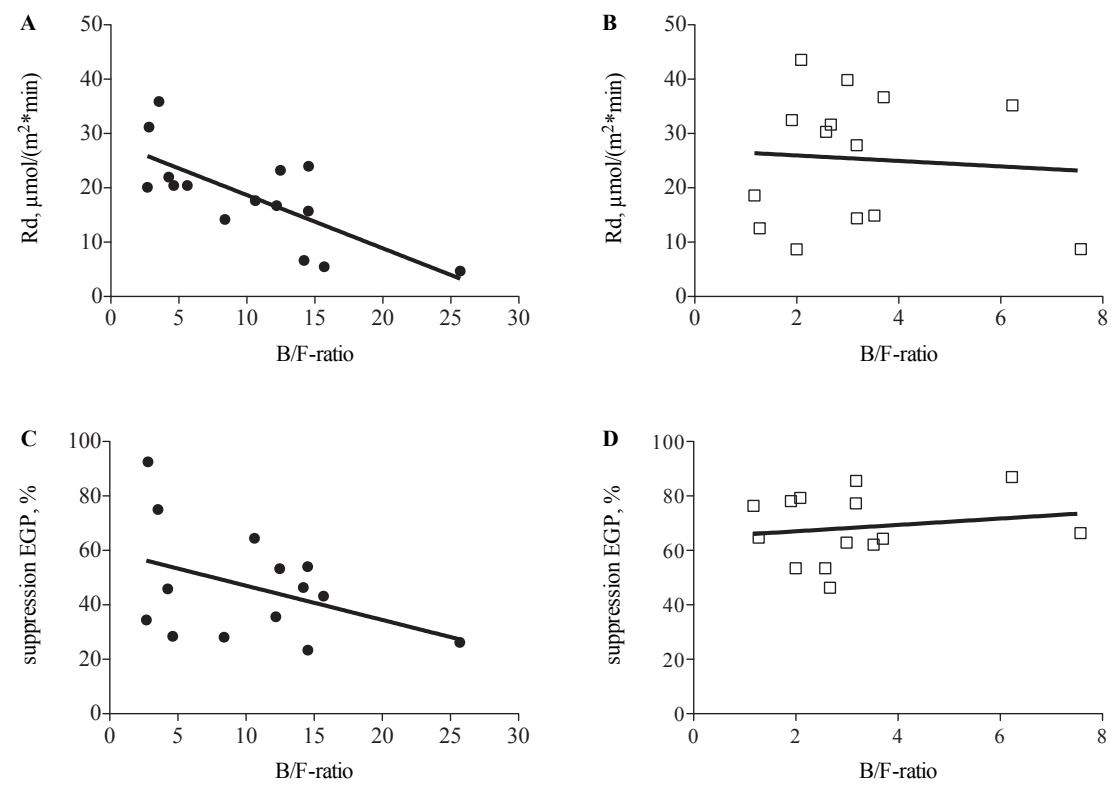

Figure 6.1. Relations between Bacteroidetes/Firmicutes-ratio and insulin sensitivity by gender

Bacteroidetes/Firmicutes-ratio (B/F-ratio) plotted against peripheral (A-B) and hepatic (C-D) insulin sensitivity of men (filled circles) and women (open squares), Rd: insulin-stimulated glucose rate of disappearance, suppression EGP: insulin-mediated suppression of endogenous glucose production.

Dietary fiber and saturated fat intake (relative to energy intake) were comparable for men and women, while body fat percentage and distribution were different, as expected (Table 6.1). While fasting fat oxidation ( $\% \mathrm{EE})$ and IL-6 were comparable between gender, postprandial fat oxidation (\%EE) and TNF- $\alpha$ were higher in men versus women (Table 6.1). Further adjustment for dietary fiber and saturated fat intake (Model 1+FI), body fat percentage and distribution (Model 1+BC), fasting and postprandial fat oxidation (Model $1+\mathrm{FO}$ ) and plasma inflammatory markers, TNF- $\alpha$ and IL-6 (Model 1+SIM) did not change the relation between B/F-ratio and peripheral insulin sensitivity in men, as indicated by similar standardized beta-coefficients for the B/F-ratio in the models (Model 1: Std. $\beta(\mathrm{B} / \mathrm{F}-$ ratio $=-0.71, \mathrm{P}=0.005$; Model 1+FI: $-0.70,0.011$, Model 1+BC: $-0.79,0.004$, Model 1+FO: -0.65, 0.013, Model 1+SIM: -0.75, 0.005). 


\section{Discussion}

The Bacteroidetes-content and the B/F-ratio were significantly higher in men as compared to women, which is in line with previous findings ${ }^{7}$. Importantly, differences in ethnicity (Caucasian), age (20-50 years), BMI (27-40 kg/m2) and regular exercise $(<3 \mathrm{~h} / \mathrm{wk})$ cannot explain these discrepancies, because groups were well-matched for these parameters in the present study. However, early life acquisition (delivery mode, breastfeeding status, use of antibiotics), lifestyle (local environment, eating and defecation pattern, exercise) and the hormonal environment may underlie the gender-specific microbiota composition.

Interestingly, we found an inverse association between the B/F-ratio and peripheral insulin sensitivity, assessed using the gold-standard hyperinsulinemic-euglycemic clamp, in men but not in women. Thus, the impact of microbiota on tissue-specific insulin sensitivity seems to differ between gender. Indeed, there is evidence for an increased gender-specific susceptibility to obesity and related co-morbidities after induction of microbial dysbiosis ${ }^{8,9}$. While no such information is available for adult humans yet, childhood obesity was significantly more associated to early life antibiotic exposure in boys than girls (5-8 years) after adjustment for several cofactors ${ }^{8}$. Likewise, the combination of antibiotic-treatment and high-fat diet, independently and synergistically, evoked alterations in microbial composition, increased obesity and hepatic steatosis, with all these effects being more pronounced in male than female mice ${ }^{9}$. Of note, this detrimental phenotype was also observed after transfer of cecal microbiota from antibiotic-treated animals to germ-free mice, eliminating direct effects of antibiotic treatment itself. Finally also gender-specific effects of diet on vertebrate's microbiota have been previously reported ${ }^{10}$. Therefore, it is tempting to speculate that our gut microbiota may be involved as a determinant in differential gender-related metabolic responses to dietary interventions.

The inverse relationship between B/F-ratio and peripheral insulin sensitivity in men is consistent with a relative higher abundance of Bacteroidetes and deteriorated metabolic profile in non-diabetic subjects ${ }^{1}$. Likewise, a reduction in Firmicutes and decreased peripheral insulin sensitivity was observed after antibiotic-treatment in obese men with the metabolic syndrome ${ }^{11}$. Interestingly, in accordance with our findings, induced alterations in gut microbiota composition were paralleled by a reduction in peripheral, but not hepatic insulin sensitivity ${ }^{11}$. 
Several lifestyle and metabolic factors may mediate the relationship between B/F-ratio and insulin sensitivity ${ }^{12}$. Dietary fiber intake has been associated with beneficial effects on glucose metabolism, while high-fat diets were associated with insulin resistance. A reduced bacterial diversity and altered microbial composition, induced by high-fat, low-fiber diets, may contribute to disturbances in substrate oxidation and insulin sensitivity by modulation of short-chain fatty acid and bile acid concentrations in the gut and circulation. Additionally, our microbiome may affect insulin sensitivity through induction of inflammatory and hormonal signals (lipopolysaccharides, respectively glucagon-likepeptide 1). Taken together, there appears to be a strong interaction between dietary factors, the microbial composition and insulin resistance. Therefore, we investigated whether the relationship between the B/F-ratio and insulin sensitivity in men can, at least partly, be explained by lifestyle factors such as dietary fiber and saturated fat intake, or metabolic factors such as fat oxidation and low-grade inflammation. Strikingly, adjustment for the above-mentioned factors did not change the strong association between the B/F-ratio and peripheral insulin sensitivity in men, suggesting involvement of other factors.

It is beyond the scope of this study, which is associative in nature, to draw any conclusions on putative mechanisms responsible for the strong association between B/F-ratio and peripheral insulin sensitivity. However, our data clearly indicate that microbiome-host interactions should be taken into account in controlled intervention studies.

In conclusion, the present study demonstrated a significant difference in microbiota composition between men and women. Furthermore, we found a strong relationship between intestinal microbiota composition and peripheral, but not hepatic, insulin sensitivity in men but not in women, which remained unchanged after adjustment of dietary saturated fat and fiber intake, body composition, fat oxidation and systemic inflammation. Our findings are preliminary in nature and require confirmation in larger populations using state-of-the-art next generation sequencing. Understanding the etiology of microbial dysbiosis, and elucidating how the microbiota impacts host metabolism in a gender-specific manner may open new avenues for the treatment of obesity-related cardiometabolic disorders. 


\section{References}

1. Le Chatelier E, Nielsen T, Qin J, et al. Richness of human gut microbiome correlates with metabolic markers. Nature 2013;500:541-6.

2. Phielix E, Schrauwen-Hinderling VB, Mensink M, et al. Lower intrinsic ADPstimulated mitochondrial respiration underlies in vivo mitochondrial dysfunction in muscle of male type 2 diabetic patients. Diabetes 2008;57:2943-9.

3. Bacchetti De Gregoris T, Aldred N, Clare AS, Burgess JG. Improvement of phylumand class-specific primers for real-time PCR quantification of bacterial taxa. Journal of microbiological methods 2011;86:351-6.

4. Collado MC, Derrien M, Isolauri E, de Vos WM, Salminen S. Intestinal integrity and Akkermansia muciniphila, a mucin-degrading member of the intestinal microbiota present in infants, adults, and the elderly. Applied and environmental microbiology 2007;73:7767-70.

5. Armougom F, Henry M, Vialettes B, Raccah D, Raoult D. Monitoring bacterial community of human gut microbiota reveals an increase in Lactobacillus in obese patients and Methanogens in anorexic patients. PloS one 2009;4:e7125.

6. Most J, Goossens GH, Jocken JW, Blaak EE. Short-term supplementation with a specific combination of dietary polyphenols increases energy expenditure and alters substrate metabolism in overweight subjects. International journal of obesity 2014;38:698-706.

7. Dominianni C, Sinha R, Goedert JJ, et al. Sex, body mass index, and dietary fiber intake influence the human gut microbiome. PloS one 2015;10:e124599.

8. Murphy R, Stewart AW, Braithwaite I, et al. Antibiotic treatment during infancy and increased body mass index in boys: an international cross-sectional study. International journal of obesity 2014;38:1115-9.

9. Cox LM, Yamanishi S, Sohn J, et al. Altering the intestinal microbiota during a critical developmental window has lasting metabolic consequences. Cell 2014;158:705-21.

10. Bolnick DI, Snowberg LK, Hirsch PE, et al. Individual diet has sex-dependent effects on vertebrate gut microbiota. Nature communications 2014;5:4500.

11. Vrieze A, Out C, Fuentes $\mathrm{S}$, et al. Impact of oral vancomycin on gut microbiota, bile acid metabolism, and insulin sensitivity. Journal of hepatology 2014;60:824-31.

12. Khan MT, Nieuwdorp M, Backhed F. Microbial modulation of insulin sensitivity. Cell metabolism 2014;20:753-60. 



\section{CHAPTER 7}

Gut microbiota composition in relation to the metabolic response to 12 weeks combined polyphenol supplementation in overweight men and women 


\section{Abstract}

Background: The intestinal microbiota may have a profound impact on host metabolism. Since evidence suggests that polyphenols affect substrate utilization, the present study aimed to investigate the effects of polyphenol supplementation on intestinal microbiota composition in humans. Furthermore, we examined whether (changes in) gut microbiota composition may determine the metabolic response to polyphenol supplementation.

Methods: In this randomized, double-blind, placebo-controlled trial, 37 overweight and obese men and women (18M/19F, $37.8 \pm 1.6$ years, BMI: $\left.29.6 \pm 0.5 \mathrm{~kg} / \mathrm{m}^{2}\right)$ received either epigallocatechin-3-gallate and resveratrol $(\mathrm{E}+\mathrm{R}, 282$ and $80 \mathrm{mg} / \mathrm{d}$, respectively) or placebo for 12 weeks. Before and after intervention, feces samples were collected to determine microbiota composition. Fat oxidation was assessed by indirect calorimetry during a highfat mixed meal-test (2.6 MJ, 61 energy\% fat), and skeletal muscle mitochondrial oxidative capacity by means of ex vivo respirometry on isolated skeletal muscle fibers. Body composition was measured by Dual Energy X-ray absorptiometry.

Results: Fecal abundance of Bacteroidetes was higher in men as compared to women, whereas other assessed bacterial taxa were comparable. E+R supplementation significantly decreased Bacteroidetes and tended to reduce Faecalibacterium prausnitzii in men $(\mathrm{P}=0.05$ and $\mathrm{P}=0.10$, respectively), but not in women $(\mathrm{P}=0.15$ and $\mathrm{P}=0.77$, respectively). Strikingly, baseline Bacteroidetes abundance was predictive for the $\mathrm{E}+\mathrm{R}$-induced increase in fat oxidation in men but not women. Other bacterial genera and species were not affected by $\mathrm{E}+\mathrm{R}$ supplementation.

Conclusion: We demonstrated that 12-wk E+R supplementation affected the gut microbiota composition in men but not women. Baseline microbiota composition determined the increase in fat oxidation after $\mathrm{E}+\mathrm{R}$ supplementation in men. 


\section{Introduction}

The human intestinal microbiota consists of $10^{12}$ to $10^{14}$ bacteria and may significantly impact health status ${ }^{1}$. Microbiota richness, diversity and composition seem to be associated with the inflammatory and metabolic phenotype of the host ${ }^{1-4}$. Although antibiotic or fecal transplantation studies provide important proof-of-principle evidence for the impact of the microbiota on host metabolism ${ }^{5,6}$, dietary interventions may offer a more feasible approach to manipulate gut microbiota ${ }^{7}$.

Changes in macronutrient composition have been shown to affect the intestinal microbiota $^{8,9}$ and improve insulin sensitivity in patients with type 2 diabetes ${ }^{10}$. Interestingly, polyphenols may induce beneficial metabolic effects ${ }^{11-13}$, which may, at least partly, be mediated by alterations of the gut microbiota composition. For example, polyphenol-enriched products induced alterations in microbial composition and had beneficial effects on insulin sensitivity ${ }^{14-17}$, ectopic fat storage ${ }^{14-16}$ and inflammation ${ }^{15-19}$ in rodents. In line, supplementation of the polyphenols epigallocatechin-3-gallate (E) and resveratrol $(\mathrm{R})$ has been shown to improve markers of insulin sensitivity, inflammation and fat oxidation in humans ${ }^{11,13,20,21}$. These effects have largely been attributed to direct effects on peripheral organs ${ }^{22-24}$. Importantly, however, our gut microbes may play an important role in the conversion of polyphenols to bioactive compounds ${ }^{25,26}$. Furthermore, polyphenols may modify the gut microbial composition, thereby acting as prebiotics ${ }^{27}$. Until now, studies that have examined the effects of polyphenols on gut microbiota composition, and assessed the involvement of the intestinal microbiota in effects on peripheral metabolism are scarce ${ }^{28}$.

Here, we aimed to investigate the effects of combined $\mathrm{E}$ and $\mathrm{R}$ supplementation for 12 weeks on gut microbiota composition in humans. Therefore, we measured fecal abundances of key microbial phyla and functional groups before and after 12-wk supplementation with either $\mathrm{E}+\mathrm{R}$ or placebo (PLA) in overweight and obese men and women. Secondly, we examined whether (changes in) microbiota composition may underlie the E+R-induced improvement in lipid oxidation and mitochondrial oxidative capacity in humans that we have previously found ${ }^{29}$. 


\section{Methods}

\section{Study design}

In this randomized, double-blind, placebo-controlled study, which was a sub-study of a larger study designed to investigate the effects of polyphenol supplementation on insulin sensitivity, fat oxidation and skeletal muscle oxidative capacity ${ }^{29}$, subjects received a combination of $\mathrm{E}$ and $\mathrm{R}$ supplements $(\mathrm{E}+\mathrm{R} ; 282 \mathrm{mg} / \mathrm{d}$ and $80 \mathrm{mg} / \mathrm{d}$, respectively) or placebo (PLA; partly hydrolyzed microcrystalline cellulose-filled supplements) for a period of 12 weeks. Body composition was determined by Dual Energy Xray Absorptiometry (DXA, VitaK, Maastricht, Netherlands).

Abundances of fecal microbiota were measured using stool samples. Sample collection and clinical measurements were performed before and in the last week of supplementation. Subjects were instructed to maintain their habitual lifestyle pattern throughout the study. Control visits were scheduled at week 2, 4, 8 of intervention. In week 0, 4 and 12, subjects were asked to fill in a $3-\mathrm{d}$ food intake record in order to assess dietary intake.

\section{Subjects}

42 untrained ( $<3 \mathrm{~h}$ organized sports activities per week), weight-stable $(<2 \mathrm{~kg}$ body weight change 3 months prior to inclusion), overweight/obese (BMI $>25 \mathrm{~kg} / \mathrm{m}^{2}$ ), but otherwise healthy Caucasian men and women (1:1) between 20 and 50 years with normal glucose tolerance, normal blood pressure were included in this study. Subjects were not allowed to use any antibiotics or medication/supplements that might interfere with insulin sensitivity and substrate metabolism for 3 months before entering the study. Daily intake of caffeine $(<600 \mathrm{mg})$, green tea $(<3 \mathrm{cups})$ and alcohol $(<20 \mathrm{~g})$ had to be limited. Detailed in- and exclusion criteria for study participants were published earlier ${ }^{29}$. All subjects gave written informed consent for participation in this study, which was reviewed and approved by the local Medical Ethical Committee of Maastricht University Medical Centre ${ }^{+}$. All procedures were according to the declaration of Helsinki.

\section{Gut microbiota composition}

DNA-isolation

Metagenomic DNA was isolated as described previously ${ }^{30}$. Briefly, approximately $200 \mathrm{mg}$ of feces was added to a $2-\mathrm{mL}$ vial containing $0.5 \mathrm{~g}$ zirconia beads $(0.1 \mathrm{~mm})$ and 4 glass 
beads (3 mm) (BioSpec, Bartlesville, USA) and $1.2 \mathrm{~mL}$ of PSP lysis buffer (Stractec biomedical, Berlin, Germany). Samples were treated in a Magna Lyser at 5,5 ms in 3 cycli of $1 \mathrm{~min}$ and cooled on ice in between cycli. Subsequently, the DNA isolation was continued using the PSP SPIN Stool DNA plus kit as per the manufacturer's instructions and finally eluted in $200 \mu \mathrm{L}$.

Microbial analysis using real-time PCR assays

DNA from all fecal samples was subjected to real-time PCR assays for the enumeration of the bacterial phyla $\gamma$-Proteobacteria, Actinobacteria, Firmicutes, Bacteroidetes, as well as for the quantification of Akkermansia muciniphila, Faecalibacterium prausnitizii, sulphatereducing bacteria, acetogenic bacteria, and the archeon Methanobrevibacter smithii.

For the enumeration of $\gamma$-Proteobacteria, Actinobacteria, Bacteroidetes, A. muciniphila, $F$. prausnitzii, sulphate-reducing bacteria and acetogens real-time detection of PCR products was conducted with SYBR Green I. The PCRs were conducted in a total volume of $25 \mu \mathrm{L}$, containing $1 \mathrm{x} \mathrm{iQ}^{\mathrm{TM}}$ SYBR ${ }^{\circledR}$ Green Supermix (Bio-rad Laboratories Inc, Hercules, Canada), $400 \mathrm{nM}$ of both primers ${ }^{31-35}$, and $2 \mu \mathrm{L}$ of purified and tenfold diluted target DNA. Amplification, melting curve analysis and detection were conducted with the MiQ-SingleColor real-time PCR Detection System (Bio-rad).

The 5'-nuclease technique was used for the detection of Firmicutes and M. smithii as described previously ${ }^{36}$. PCRs were conducted in a total volume of $25 \mu \mathrm{L}$, containing $1 \mathrm{x}$ ABsolute qPCR Mix (ABgene, Hamburg, Germany), $200 \mathrm{nM}$ of both primers and $200 \mathrm{nM}$ TaqMan probe, and $2 \mu \mathrm{L}$ of purified and tenfold diluted target DNA. The amplification and detection were conducted with an Applied Biosystems Prism 7900 sequence detection system (Applied Biosystems, Waltham, USA). Serial dilutions of plasmid constructs containing the target sequences were used to create calibration curves for quantification.

\section{Fat oxidation and ex vivo mitochondrial oxidative capacity}

As described elsewhere ${ }^{29}$, a high-fat mixed meal-test (HFMM, 2.6 MJ, 61.2 energy\% fat) was performed to assess whole-body energy expenditure and fat oxidation before $(\mathrm{t}=0 \mathrm{~min})$ and for 4 hours after ingestion of the HFMM by means of indirect calorimetry, using an open-circuit ventilated hood system (Omnical, Maastricht University, Maastricht, Netherlands). Mitochondrial oxidative capacity was measured by ex vivo high-resolution respirometry (Oroboros Instruments, Innsbruck, Austria) on permeabilized skeletal muscle 
fibers that were isolated from biopsies ( $m$. vastus lateralis), which were collected under fasting conditions under local anesthesia ${ }^{37}$.

\section{Supplements}

The supplements were commercially available and kindly provided by Pure Encapsulations Inc. (Sudbury, MA, USA). All capsules were manufactured, tested and checked in accordance to standards of EU GMP requirements.

E capsules contained $94 \%$ epigallocatechin-3-gallate (141 mg per capsule) and R capsules $20 \%$ trans-resveratrol (40 mg per capsule). Two kinds of placebo capsules (Microcrystalline cellulose) were used for blinding. Capsules were packed into white opaque boxes, labeled per subject without indication of the content. After completion of the study, returned capsules were counted for compliance.

\section{Statistics}

All data are expressed as mean \pm SEM. Log10 DNA copies for a given microbial group/species per gram of wet weight feces were calculated for each stool sample from the $\mathrm{Ct}$-values using the constructed calibration curves.

Analyses were performed by gender because of differences in bacterial composition. Differences between supplementation groups were analyzed using repeated-measures ANOVA with time and supplementation as factors. Regression analysis was performed to assess relations between baseline abundances or intervention-induced changes $\left(\Delta_{\text {Week12- }}\right.$ Week 0 ) in the abundance of microbial taxa and changes in fat oxidation and muscle mitochondrial oxidative capacity in the $\mathrm{E}+\mathrm{R}$ group (men, $\mathrm{n}=7$; women, $\mathrm{n}=7$ ). Microbial abundances and E+R-induced changes in microbial abundances were used as independent variable and changes in fat oxidation and mitochondrial oxidative capacity as dependent variables. Variables were normally distributed and the mean of the dependent variable ([week $0+$ week 12]/2) was included in the model to correct for regression to the mean. Statistics was done using SPSS 19.0 (IBM Corporation, Armonk, NY, USA) for Macintosh. $\mathrm{P}<0.05$ of the interaction term (time*supplementation) and for the standardized $\beta$ within a regression term was considered as statistically significant. 


\section{Results}

\section{Subjects characteristics}

42 overweight and obese but otherwise healthy men and women volunteered to participate in this study, of which 4 subjects ( 3 men, 1 women) dropped out ( 1 went traveling abroad, 1 was re-employed at full-time job, 1 did not comply with supplementation and 1 substantially changed diet and/or physical activity pattern). In addition, 1 female subject was excluded from analyses because of reported diarrhea. Characteristics of the thirtyseven subjects who completed the study are summarized in Table 7.1. There were no significant differences between the $\mathrm{E}+\mathrm{R}$ and PLA group with respect to baseline characteristics. Men had higher fasting plasma glucose and inflammatory cytokine levels (Table 7.1) but leptin and adiponectin concentrations were, as expected, significantly lower. Compliance was confirmed by counting returned supplements and increased plasma concentrations of $\mathrm{E}, \mathrm{R}$ and dihydro- $\mathrm{R}$ after the intervention in the $\mathrm{E}+\mathrm{R}$-group as reported earlier ${ }^{29}$. Energy intake and macronutrient composition were not significantly changed in the $\mathrm{E}+\mathrm{R}$ and PLA group over time.

Table 7.1. Baseline subjects' characteristics

\begin{tabular}{|c|c|c|c|c|c|c|}
\hline & men & women & PLA & $\mathrm{E}+\mathrm{R}$ & $P_{\text {gender }}$ & $P_{\text {group }}$ \\
\hline Age, years & $40.2 \pm 2.1$ & $35.6 \pm 2.4$ & $39.5 \pm 2.3$ & $36.1 \pm 2.3$ & 0.17 & 0.30 \\
\hline Weight, kg & $96.3 \pm 3.5$ & $83.2 \pm 2.2$ & $87.1 \pm 2.9$ & $92.2 \pm 3.5$ & 0.00 & 0.28 \\
\hline BMI, $\mathrm{kg} / \mathrm{m}^{2}$ & $30.0 \pm 0.8$ & $29.2 \pm 0.6$ & $29.3 \pm 0.8$ & $29.9 \pm 0.6$ & 0.46 & 0.50 \\
\hline Body fat, $\%$ & $24.4 \pm 0.9$ & $36.6 \pm 0.9$ & $29.7 \pm 1.9$ & $31.6 \pm 1.4$ & 0.00 & 0.45 \\
\hline Waist-Hip-Ratio & $0.94 \pm 0.02$ & $0.81 \pm 0.02$ & $0.88 \pm 0.02$ & $0.87 \pm 0.02$ & 0.00 & 0.66 \\
\hline Diastolic BP, mmHg & $118 \pm 2$ & $113 \pm 2$ & $114 \pm 3$ & $117 \pm 2$ & 0.15 & 0.30 \\
\hline Systolic BP, mmHg & $77 \pm 2$ & $75 \pm 2$ & $77 \pm 2$ & $76 \pm 2$ & 0.59 & 0.83 \\
\hline Fasting glucose, mmol/1 & $5.29 \pm 0.05$ & $5.02 \pm 0.10$ & $5.11 \pm 0.08$ & $5.19 \pm 0.09$ & 0.03 & 0.52 \\
\hline 2h-glucose, $\mathrm{mmol} / \mathrm{l}$ & $5.27 \pm 0.24$ & $5.48 \pm 0.25$ & $5.41 \pm 0.23$ & $5.34 \pm 0.25$ & 0.55 & 0.84 \\
\hline $\mathrm{HbA} 1 \mathrm{c}, \%$ & $5.16 \pm 0.07$ & $5.14 \pm 0.06$ & $5.17 \pm 0.06$ & $5.12 \pm 0.06$ & 0.79 & 0.57 \\
\hline Adiponectin, mg/ml & $6.4 \pm 0.5$ & $11.0 \pm 0.8$ & $8.8 \pm 0.9$ & $8.7 \pm 0.8$ & 0.00 & 0.93 \\
\hline Leptin, ng/ml & $10.8 \pm 1.5$ & $30.3 \pm 3.0$ & $21.7 \pm 4.1$ & $19.8 \pm 2.4$ & 0.00 & 0.68 \\
\hline Interleukin-6, pg/ml & $0.79 \pm 0.14$ & $0.88 \pm 0.14$ & $0.89 \pm 0.17$ & $0.77 \pm 0.07$ & 0.63 & 0.52 \\
\hline Interleukin-8, pg/ml & $10.9 \pm 0.7$ & $8.1 \pm 0.7$ & $9.1 \pm 0.6$ & $9.8 \pm 0.9$ & 0.01 & 0.55 \\
\hline $\mathrm{TNF}-\alpha, \mathrm{pg} / \mathrm{ml}$ & $3.30 \pm 0.22$ & $2.30 \pm 0.08$ & $2.88 \pm 0.22$ & $2.69 \pm 0.18$ & 0.00 & 0.49 \\
\hline
\end{tabular}

BMI, body mass index; BP, blood pressure; 2h-glucose, plasma glucose concentration $2 \mathrm{~h}$ after oral glucose ingestion; HbA1c, glycated hemoglobin A1c; TNF- $\alpha$, tumor necrosis factor- $\alpha$; P, P-value for statistical difference between men $(\mathrm{n}=18)$ and women $(\mathrm{n}=19)$ and PLA $(\mathrm{n}=19)$ versus $\mathrm{E}+\mathrm{R}(\mathrm{n}=18)$, respectively. Values are given as mean \pm SEM. 


\section{Gender differences in microbiota composition}

Fecal abundances of microbial groups were different between men and women (Table 7.2). Absolute abundances of $\gamma$-Proteobacteria $(\mathrm{P}=0.05)$ and Bacteroidetes $(\mathrm{P}<0.01)$ were higher in men as compared to women, while other phyla and species were comparable. The relative abundance of Bacteroidetes, expressed as percentage of the five dominant phyla, was higher in men than women $(\mathrm{P}<0.01)$, while Firmicutes $(\mathrm{P}<0.01)$ and Actinobacteria $(\mathrm{P}=0.04)$ abundance was relatively lower in men (Table 7.2).

Table 7.2. Baseline abundances of bacterial phyla and species

\begin{tabular}{|c|c|c|c|}
\hline & men, $\mathrm{n}=18$ & women, $n=19$ & $\mathrm{P}$ \\
\hline \multicolumn{4}{|l|}{$\log 10$} \\
\hline$\gamma$-Proteobacteria & $11.29 \pm 0.11$ & $10.93 \pm 0.14$ & 0.05 \\
\hline Actinobacteria & $11.50 \pm 0.08$ & $11.55 \pm 0.12$ & 0.77 \\
\hline A. muciniphila & $8.77 \pm 0.45$ & $9.71 \pm 0.36$ & 0.11 \\
\hline Firmicutes & $12.33 \pm 0.06$ & $12.34 \pm 0.06$ & 0.83 \\
\hline Bacteroidetes & $13.21 \pm 0.07$ & $12.88 \pm 0.06$ & 0.00 \\
\hline M. smithii & $9.38 \pm 0.33$ & $8.95 \pm 0.36$ & 0.40 \\
\hline F.prausnitzii & $12.03 \pm 0.09$ & $11.98 \pm 0.10$ & 0.71 \\
\hline Sulphate-reducing b. & $10.54 \pm 0.27$ & $10.15 \pm 0.41$ & 0.43 \\
\hline Acetogen $b$ & $10.83 \pm 0.06$ & $10.88 \pm 0.06$ & 0.58 \\
\hline B/F-ratio & $9.4 \pm 1.4$ & $3.8 \pm 0.5$ & 0.00 \\
\hline \multicolumn{4}{|l|}{$\%$} \\
\hline$\gamma$-Proteobacteria & $1.4 \pm 0.3$ & $1.3 \pm 0.2$ & 0.61 \\
\hline Actinobacteria & $2.5 \pm 0.6$ & $6.0 \pm 1.6$ & 0.05 \\
\hline A. muciniphila & $0.2 \pm 0.1$ & $0.7 \pm 0.4$ & 0.17 \\
\hline Firmicutes & $12.5 \pm 1.6$ & $22.7 \pm 2.0$ & 0.00 \\
\hline Bacteroidetes & $83.3 \pm 2.0$ & $69.3 \pm 2.9$ & 0.00 \\
\hline
\end{tabular}

Absolute ( $\log 10)$ and relative (\%) abundances of bacterial phyla and species in $1 \mathrm{~g}$ wet weight of fecal samples. A, Akkermansia; B, bacteria; B/F-ratio, Bacteroidetes/Firmicutes-ratio; F, feacalibacterium; M, methanobrevibacter. P-value for statistical difference between gender. Values are given as means \pm SEM.

\section{$E+R$ supplementation decreased Bacteroidetes abundance in men but not women}

In men, E+R supplementation significantly reduced the abundance of Bacteroidetes $(\mathrm{P}=0.05)$ and tended to decrease $F$. prausnitizii-abundance as compared to PLA ( $\mathrm{P}=0.10$, Table 7.3). However, these changes were not observed in women (Table 7.4). The abundance of Firmicutes, Actinobacteria, $\gamma$-Proteobacteria and A. muciniphila (phylum Verrucomicrobiae), sulphate-reducing bacteria, acetogenic bacteria, and the archeon $M$. 
smithii were not significantly affected by the intervention, neither in men (Table 7.3) not in women (Table 7.4).

Table 7.3. The abundance of bacterial phyla and species before and after intervention in men

\begin{tabular}{|c|c|c|c|c|c|}
\hline & \multicolumn{2}{|c|}{ PLA, $n=10$} & \multicolumn{2}{|c|}{$E+R, n=8$} & \multirow[b]{2}{*}{$\mathrm{P}$} \\
\hline & Week 0 & Week 12 & Week 0 & Week 12 & \\
\hline \multicolumn{6}{|l|}{$\log 10$} \\
\hline$\gamma$-Proteobacteria & $11.31 \pm 0.16$ & $11.20 \pm 0.09$ & $11.26 \pm 0.13$ & $10.95 \pm 0.23$ & 0.49 \\
\hline Actinobacteria & $11.51 \pm 0.10$ & $11.44 \pm 0.07$ & $11.50 \pm 0.13$ & $11.32 \pm 0.20$ & 0.59 \\
\hline A. muciniphila & $9.38 \pm 0.56$ & $8.17 \pm 0.61$ & $8.01 \pm 0.65$ & $7.29 \pm 0.51$ & 0.59 \\
\hline Firmicutes & $12.31 \pm 0.09$ & $12.33 \pm 0.07$ & $12.35 \pm 0.07$ & $12.17 \pm 0.15$ & 0.28 \\
\hline Bacteroidetes & $13.18 \pm 0.09$ & $13.19 \pm 0.07$ & $13.25 \pm 0.11$ & $12.94 \pm 0.14$ & 0.05 \\
\hline M. smithii & $9.31 \pm 0.44$ & $8.80 \pm 0.42$ & $9.56 \pm 0.58$ & $8.57 \pm 0.72$ & 0.75 \\
\hline F. prausnitzii & $11.99 \pm 0.13$ & $12.02 \pm 0.13$ & $12.08 \pm 0.12$ & $11.64 \pm 0.30$ & 0.10 \\
\hline Sulphate-reducing b. & $10.70 \pm 0.24$ & $10.57 \pm 0.25$ & $10.34 \pm 0.54$ & $9.38 \pm 0.88$ & 0.14 \\
\hline Acetogen $b$. & $10.76 \pm 0.10$ & $10.77 \pm 0.06$ & $10.92 \pm 0.06$ & $10.82 \pm 0.16$ & 0.47 \\
\hline $\mathrm{B} / \mathrm{F}$-ratio & $8.8 \pm 1.6$ & $8.9 \pm 1.5$ & $10.1 \pm 2.7$ & $6.4 \pm 0.9$ & 0.22 \\
\hline \multicolumn{6}{|l|}{$\%$} \\
\hline$\gamma$-Proteobacteria & $1.7 \pm 0.4$ & $1.1 \pm 0.2$ & $1.1 \pm 0.3$ & $1.2 \pm 0.4$ & 0.30 \\
\hline Actinobacteria & $2.8 \pm 1.0$ & $1.7 \pm 0.3$ & $2.0 \pm 0.5$ & $2.8 \pm 0.7$ & 0.19 \\
\hline A. muciniphila & $0.4 \pm 0.2$ & $0.1 \pm 0.1$ & $0.0 \pm 0.0$ & $0.0 \pm 0.0$ & 0.37 \\
\hline Firmicutes & $12.6 \pm 2.1$ & $13.5 \pm 2.9$ & $12.5 \pm 2.7$ & $14.5 \pm 1.8$ & 0.79 \\
\hline Bacteroidetes & $82.5 \pm 2.9$ & $83.6 \pm 3.2$ & $84.3 \pm 2.9$ & $81.5 \pm 1.8$ & 0.38 \\
\hline
\end{tabular}

Absolute ( $\log 10)$ and relative (\%) abundances of bacterial phyla and species in $1 \mathrm{~g}$ wet weight of fecal samples. A, Akkermansia; B, bacteria; B/F-ratio, Bacteroidetes/Firmicutes-ratio; F, feacalibacterium; $\mathrm{M}$, methanobrevibacter. P-value for statistical significance for time*treatment interactions. Values are given as means $\pm \mathrm{SEM}$.

\section{Fat oxidation and mitochondrial oxidative capacity}

The effects of $\mathrm{E}+\mathrm{R}$ supplementation on fat oxidation and mitochondrial oxidative capacity have been reported previously for the total group of participants ${ }^{29}$. Briefly, fat oxidation, expressed as percentage of energy expenditure, was increased in the $E+R$ group as compared to PLA during fasting $(\mathrm{P}=0.03)$ and postprandial conditions after consumption of a high-fat mixed meal (2.6 MJ, 61 energy\% fat, $\mathrm{P}=0.02)$. In line, skeletal muscle mitochondrial oxidative capacity, assessed using ex vivo high-resolution respirometry, was increased after $\mathrm{E}+\mathrm{R}$ supplementation versus PLA $(\mathrm{P}=0.01)$. 
Chapter 7

Table 7.4. The abundance of bacterial phyla and species before and after intervention in women

\begin{tabular}{lccccc}
\hline & \multicolumn{2}{c}{ PLA, $\mathrm{n}=9$} & \multicolumn{2}{c}{ E+R, $\mathrm{n}=10$} \\
& Week 0 & Week 12 & Week 0 & Week 12 & P \\
\hline $\log 10$ & & & & & \\
$\gamma$-Proteobacteria & $11.09 \pm 0.08$ & $11.17 \pm 0.08$ & $10.78 \pm 0.26$ & $10.99 \pm 0.16$ & 0.71 \\
Actinobacteria & $11.61 \pm 0.22$ & $11.42 \pm 0.14$ & $11.48 \pm 0.13$ & $11.39 \pm 0.12$ & 0.70 \\
A. muciniphila & $9.36 \pm 0.63$ & $9.20 \pm 0.54$ & $10.02 \pm 0.39$ & $9.94 \pm 0.36$ & 0.91 \\
Firmicutes & $12.43 \pm 0.07$ & $12.32 \pm 0.10$ & $12.27 \pm 0.10$ & $12.22 \pm 0.06$ & 0.66 \\
Bacteroidetes & $12.82 \pm 0.08$ & $12.96 \pm 0.07$ & $12.95 \pm 0.10$ & $12.87 \pm 0.05$ & 0.15 \\
M. smithii & $9.81 \pm 0.11$ & $9.70 \pm 0.11$ & $8.66 \pm 0.41$ & $8.25 \pm 0.79$ & 0.93 \\
F. prausnitzii & $11.92 \pm 0.17$ & $11.84 \pm 0.19$ & $12.03 \pm 0.13$ & $11.91 \pm 0.09$ & 0.77 \\
Sulphate-reducing b. & $10.76 \pm 0.10$ & $10.76 \pm 0.08$ & $9.60 \pm 0.74$ & $10.07 \pm 0.52$ & 0.38 \\
Acetogen b. & $10.91 \pm 0.10$ & $10.85 \pm 0.08$ & $10.86 \pm 0.09$ & $10.78 \pm 0.07$ & 0.71 \\
B/F-ratio & $2.7 \pm 0.5$ & $4.7 \pm 0.7$ & $4.8 \pm 0.8$ & $4.9 \pm 0.6$ & 0.70 \\
\% & & & & & \\
$\gamma$-Proteobacteria & $1.3 \pm 0.2$ & $1.3 \pm 0.1$ & $1.2 \pm 0.4$ & $1.2 \pm 0.3$ & 0.91 \\
Actinobacteria & $7.6 \pm 2.8$ & $3.3 \pm 1.2$ & $4.3 \pm 1.2$ & $4.0 \pm 1.7$ & 0.66 \\
A. muciniphila & $0.5 \pm 0.3$ & $0.2 \pm 0.1$ & $1.0 \pm 0.6$ & $0.6 \pm 0.4$ & 0.15 \\
Firmicutes & $26.9 \pm 2.7$ & $18.6 \pm 2.2$ & $18.6 \pm 2.4$ & $17.7 \pm 2.0$ & 0.93 \\
Bacteroidetes & $63.7 \pm 4.4$ & $76.6 \pm 2.5$ & $74.9 \pm 2.8$ & $76.5 \pm 2.2$ & 0.77 \\
\hline \hline Absiute (log10)
\end{tabular}

Absolute $(\log 10)$ and relative (\%) abundances of bacterial phyla and species in $1 \mathrm{~g}$ wet weight of fecal samples. A, Akkermansia; B, bacteria; B/F-ratio, Bacteroidetes/Firmicutes-ratio; F, feacalibacterium; M, methanobrevibacter. P-value for statistical significance for time*treatment interactions. Values are given as means \pm SEM.

\section{Relation between (changes in) microbiota composition and fat oxidation following E $+\mathbf{R}$ supplementation}

Strikingly, baseline Bacteroidetes abundance was significantly correlated with the E+Rinduced increase in postprandial fat oxidation (AUC) $(\mathrm{r}=0.855, \mathrm{P}=0.01$, Figure $7.1 \mathrm{~A})$ in men. This correlation remained significant after adjustment for mean fat oxidation

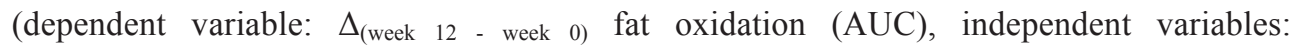

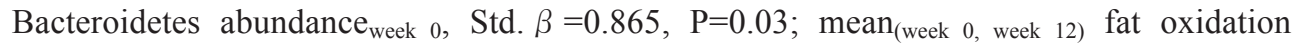
(AUC), Std. $\beta=-0.057, \quad \mathrm{P}=0.84$ ). Moreover, the Bacteroidetes/Firmicutes ratio was significantly correlated with postprandial fat oxidation $(\mathrm{r}=0.813, \mathrm{P}=0.03)$. The abundance of Firmicutes was not related to changes in fat oxidation $(\mathrm{r}=-0.191, \mathrm{P}=0.68)$. Other bacterial groups showed no significant association with fat oxidation (data not shown). The E+Rinduced reduction in the abundance of Bacteroidetes and F. prausnitzii in men was, 
however, not related to the observed changes in fat oxidation und oxidative capacity following $\mathrm{E}+\mathrm{R}$ supplementation as compared to PLA. Likewise, no significant relationship was found between (changes in) gut microbiota composition and skeletal muscle mitochondrial oxidative capacity.

In women, no significant associations were observed between (changes in) gut microbiota composition and $\mathrm{E}+\mathrm{R}$-induced effects on fasting and postprandial fat oxidation (Figure 7.1B for baseline Bacteroidetes and postprandial fat oxidation).
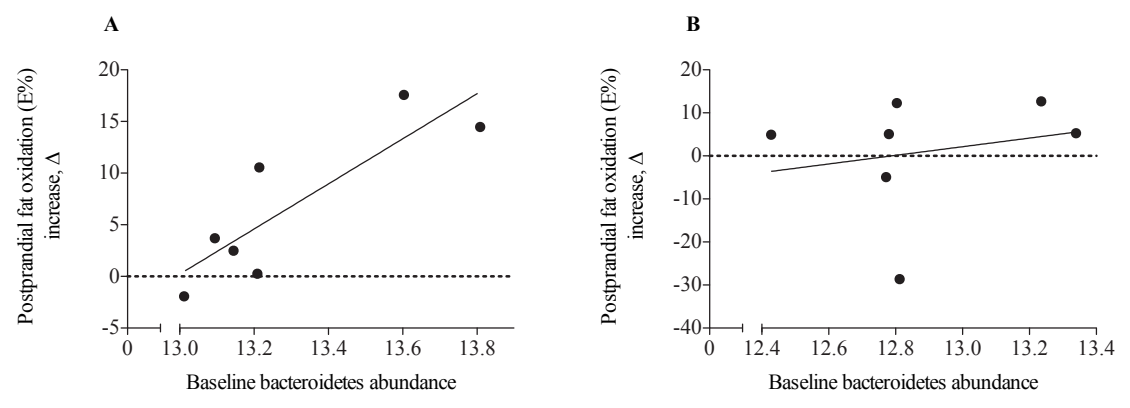

Figure 7.1. Correlation between baseline Bacteroidetes abundance and the E+R-induced increase in postprandial fat oxidation

Baseline Bacteroidetes abundance significantly correlated with A) the increase in postprandial fat oxidation in men $(n=7, P=0.03)$ but $B)$ not in women $(n=7, P=0.68)$. The increase in fat oxidation is expressed as $\Delta_{\text {Week12-Week0 }}$, calculated from the relative contribution of fat oxidation to total energy expenditure (\%).

\section{Discussion}

Dietary polyphenols have been associated with a variety of health benefits related to chronic metabolic and inflammatory diseases such as obesity, diabetes and cardiovascular diseases 11,13,20,21. Accumulating evidence indicates that the gut microbiome influences metabolic health ${ }^{5,6}$, but very few studies have examined the effects of dietary interventions on the gut microbiota. Interestingly, polyphenol supplementation may affect gut microbiota composition and, consequently, metabolic health ${ }^{28,38}$. Here, we report that men show a pronounced higher abundance of Bacteroidetes as compared to women. Furthermore, 12 weeks of $\mathrm{E}+\mathrm{R}$-supplementation decreased the fecal abundance of Bacteroidetes and tended 
to reduce $F$. prausnitzii in men, whereas no alterations were found in women. Interestingly, our data indicate that baseline Bacteroidetes abundance seems to be involved in the E+Rinduced increase in fat oxidation in men, but not in women.

Previous studies have demonstrated gender differences in gut microbiota composition in humans ${ }^{7,39}$, which may at least partly be explained by differences in sex hormones ${ }^{40,41}$. Alternatively, early life acquisition (use of antibiotics) ${ }^{42}$ and lifestyle (local environment, eating and defecation pattern) ${ }^{43,44}$ may underlie inter-individual variation, and may also contribute to gender-specific microbiota composition. The present study, therefore, examined the effects of prolonged polyphenol supplementation on gut microbiota composition in a gender-specific manner. Interestingly, we found that $\mathrm{E}+\mathrm{R}$ supplementation reduced the abundance of Bacteroidetes but not Firmicutes in men, which resulted in a decreased Bacteroidetes/Firmicutes ratio following 12-wk E+R supplementation. In line with our findings, polyphenols seem to have anti-microbial characteristics ${ }^{45}$, most likely because of their chelating properties on iron, which is an important oligo-element for hemeutilizing bacteria ${ }^{46}$. In contrast to most previous studies (reviewed in ${ }^{27,38}$ ), we did not observe any polyphenol-induced prebiotic effects on Firmicutes abundance in overweight and obese humans.

Next, we investigated whether microbial species and phyla relate to host metabolism, as has previously been suggested 2,7,28,39,43. Intriguingly, we found that a high abundance of Bacteroidetes at baseline was correlated with a more pronounced $\mathrm{E}+\mathrm{R}$-induced increase in postprandial fat oxidation in men.

Only $5-10 \%$ of the ingested polyphenols are absorbed in the small intestine ${ }^{47}$, and the majority is transferred to the colon where they are subjected to microbial metabolism ${ }^{48}$. Interestingly, the produced polyphenolic metabolites show a high inter-individual variability, which may be dependent on the gut microbiota ${ }^{49}$. These metabolites seem to have distinct and/or synergistic effects on peripheral tissues ${ }^{50,51}$. Bacteroidetes contain more glycan-degrading enzymes ${ }^{52}$, and may therefore facilitate diffusion of polyphenols and/or related metabolites through the intestinal barrier, thereby enhancing bioavailability. Although our data should be interpreted with caution, it is tempting to postulate that a high baseline abundance of Bacteroidetes might allow a more pronounced improvement in fat oxidation following polyphenol supplementation. In fact, it has been proposed earlier that metabolic health status might determine the effect of $\mathrm{R}$ supplementation on host 
metabolism ${ }^{53}$. Bacteroidetes abundance appears to be related to markers of impaired metabolic health ${ }^{54}$. Moreover, Bacteroidetes abundance was related to low fecal shortchain fatty acid concentrations ${ }^{55}$, which may stimulate fat oxidation in overweight humans 56,57 . Noteworthy, in the present study, a higher abundance of Bacteroidetes in men was paralleled by a more unhealthy metabolic profile (increased fasting glucose and inflammatory markers) as compared to women, which might support this notion.

Changes in microbial composition after pharmacological interventions have been related to changes in host physiology ${ }^{5,6}$. In line, polyphenol supplementation in rodents reduced adipose tissue mass and ectopic fat accumulation, insulin resistance and inflammation, and these improvements were related to changes in microbiota composition ${ }^{14-16,18,19,58}$. In the present study, however, we did not find significant correlations between the changes in gut microbiota composition and other metabolic parameters beside fat oxidation after $\mathrm{E}+\mathrm{R}$ supplementation. Queipo-Ortuño et al. ${ }^{28}$ have reported previously that effects of red wine polyphenol supplementation on blood pressure, plasma triacylglycerol, cholesterol and CRP concentrations were linked to changes in microbial composition. Thus, the ability of microbiota to mediate effects on physiological parameters clearly warrants further investigation ${ }^{59-61}$.

The present findings in women should be interpreted with some caution, since we did not obtain information on the phase of the menstrual cycle. Moreover, the use of oral contraceptives (11 out of 19 female participants) may have influenced substrate metabolism 62 and intestinal microbiota composition, as has already been reported for vaginal microbiota ${ }^{63}$. Lastly, although determination of phyla-abundances has been used as valuable indicator of the impact of microbiota on substrate metabolism ${ }^{2}$, a detailed microbial phenotyping using state-of-the-art next generation sequencing may provide additional insight into relevant bacterial species in future studies ${ }^{64}$. Importantly, within the phyla Bacteroidetes, different genera, Bacteroides and Prevotella, do have different metabolic traits and define a host's enterotype ${ }^{9,65}$.

In conclusion, we demonstrated that overweight and obese men and women differ in their intestinal microbiota and in their susceptibility to intervention-effects. Whereas $\mathrm{E}+\mathrm{R}$ supplementation for 12 weeks reduced abundance of Bacteroidetes in men, no effects were observed in women. Furthermore, Bacteroidetes abundance at baseline was a significant predictor for the $\mathrm{E}+\mathrm{R}$-induced increase in fat oxidation in men. Future studies are warranted 


\section{Chapter 7}

to further explore gender differences in gut microbiota composition and its relationship with metabolic outcome after interventions. Furthermore, state-of-the-art sequencing techniques to determine microbiota composition should be combined with metabolomics approaches to assess polyphenol metabolite profiles to obtain better insight into interindividual variability in the response to polyphenol supplementation on metabolic health in humans. 


\section{References}

1. Clemente JC, Ursell LK, Parfrey LW, Knight R. The impact of the gut microbiota on human health: an integrative view. Cell 2012;148:1258-70.

2. Ley RE, Turnbaugh PJ, Klein S, Gordon JI. Microbial ecology: human gut microbes associated with obesity. Nature 2006;444:1022-3.

3. Diamant M, Blaak EE, de Vos WM. Do nutrient-gut-microbiota interactions play a role in human obesity, insulin resistance and type 2 diabetes? Obesity reviews : an official journal of the International Association for the Study of Obesity 2011;12:27281.

4. Sommer F, Backhed F. The gut microbiota--masters of host development and physiology. Nat Rev Microbiol 2013;11:227-38.

5. Vrieze A, Out C, Fuentes S, et al. Impact of oral vancomycin on gut microbiota, bile acid metabolism, and insulin sensitivity. Journal of hepatology 2014;60:824-31.

6. Vrieze A, Van Nood E, Holleman F, et al. Transfer of intestinal microbiota from lean donors increases insulin sensitivity in individuals with metabolic syndrome. Gastroenterology 2012;143:913-6 e7.

7. Bolnick DI, Snowberg LK, Hirsch PE, et al. Individual diet has sex-dependent effects on vertebrate gut microbiota. Nature communications 2014;5:4500.

8. David LA, Maurice CF, Carmody RN, et al. Diet rapidly and reproducibly alters the human gut microbiome. Nature 2014;505:559-63.

9. Wu GD, Chen J, Hoffmann $\mathrm{C}$, et al. Linking long-term dietary patterns with gut microbial enterotypes. Science 2011;334:105-8.

10. Chandalia M, Garg A, Lutjohann D, von Bergmann K, Grundy SM, Brinkley LJ. Beneficial effects of high dietary fiber intake in patients with type 2 diabetes mellitus. The New England journal of medicine 2000;342:1392-8.

11. Bogdanski P, Suliburska J, Szulinska M, Stepien M, Pupek-Musialik D, Jablecka A. Green tea extract reduces blood pressure, inflammatory biomarkers, and oxidative stress and improves parameters associated with insulin resistance in obese, hypertensive patients. Nutrition research 2012;32:421-7.

12. Most J, Goossens GH, Jocken JW, Blaak EE. Short-term supplementation with a specific combination of dietary polyphenols increases energy expenditure and alters substrate metabolism in overweight subjects. International journal of obesity 2014;38:698-706.

13. Timmers S, Konings E, Bilet L, et al. Calorie restriction-like effects of 30 days of resveratrol supplementation on energy metabolism and metabolic profile in obese humans. Cell metabolism 2011;14:612-22.

14. Qiao Y, Sun J, Xia S, Tang X, Shi Y, Le G. Effects of resveratrol on gut microbiota and fat storage in a mouse model with high-fat-induced obesity. Food \& function 2014;5:1241-9.

15. Anhe FF, Roy D, Pilon G, et al. A polyphenol-rich cranberry extract protects from diet-induced obesity, insulin resistance and intestinal inflammation in association with increased Akkermansia spp. population in the gut microbiota of mice. Gut 2015;64:872-83. 
16. Roopchand DE, Carmody RN, Kuhn P, et al. Dietary polyphenols promote growth of the gut bacterium Akkermansia muciniphila and attenuate high fat diet-induced metabolic syndrome. Diabetes 2015.

17. Dao TM, Waget A, Klopp P, et al. Resveratrol increases glucose induced GLP-1 secretion in mice: a mechanism which contributes to the glycemic control. PloS one 2011;6:e20700.

18. Espley RV, Butts CA, Laing WA, et al. Dietary flavonoids from modified apple reduce inflammation markers and modulate gut microbiota in mice. The Journal of nutrition 2014;144:146-54.

19. Neyrinck AM, Van Hee VF, Bindels LB, De Backer F, Cani PD, Delzenne NM. Polyphenol-rich extract of pomegranate peel alleviates tissue inflammation and hypercholesterolaemia in high-fat diet-induced obese mice: potential implication of the gut microbiota. The British journal of nutrition 2013;109:802-9.

20. Brown AL, Lane J, Holyoak C, Nicol B, Mayes AE, Dadd T. Health effects of green tea catechins in overweight and obese men: a randomised controlled cross-over trial. The British journal of nutrition 2011;106:1880-9.

21. Mendez-del Villar M, Gonzalez-Ortiz M, Martinez-Abundis E, Perez-Rubio KG, Lizarraga-Valdez R. Effect of resveratrol administration on metabolic syndrome, insulin sensitivity, and insulin secretion. Metabolic syndrome and related disorders 2014; 12:497-501.

22. Park SJ, Ahmad F, Philp A, et al. Resveratrol ameliorates aging-related metabolic phenotypes by inhibiting cAMP phosphodiesterases. Cell 2012;148:421-33.

23. Price NL, Gomes AP, Ling AJ, et al. SIRT1 is required for AMPK activation and the beneficial effects of resveratrol on mitochondrial function. Cell metabolism 2012;15:675-90.

24. Li Y, Zhao S, Zhang W, et al. Epigallocatechin-3-O-gallate (EGCG) attenuates FFAsinduced peripheral insulin resistance through AMPK pathway and insulin signaling pathway in vivo. Diabetes research and clinical practice 2011;93:205-14.

25. Chiou YS, Wu JC, Huang QR, et al. Metabolic and colonic microbiota transformation may enhance the bioactivities of dietary polyphenols. J Funct Foods 2014;7:3-25.

26. Chen HD, Sang SM. Biotransformation of tea polyphenols by gut microbiota. J Funct Foods 2014;7:26-42.

27. Duenas M, Munoz-Gonzalez I, Cueva C, et al. A survey of modulation of gut microbiota by dietary polyphenols. BioMed research international 2015;2015:850902.

28. Queipo-Ortuno MI, Boto-Ordonez M, Murri M, et al. Influence of red wine polyphenols and ethanol on the gut microbiota ecology and biochemical biomarkers. The American journal of clinical nutrition 2012;95:1323-34.

29. Most J, Timmers S, Warnke I, Jocken JWE, van Boekschoten M, de Groot P, Bendik I, Schrauwen P, Goossens GH, Blaak EE. Combined epigallocatechin-3-gallate and resveratrol supplementation for 12 weeks increases mitochondrial capacity and fat oxidation, but not insulin sensitivity in obese humans: a randomized controlled trial. The American Journal of Clinical Nutrition, under revision.

30. Tedjo DI, Jonkers DM, Savelkoul PH, et al. The effect of sampling and storage on the fecal microbiota composition in healthy and diseased subjects. PloS one 2015;10:e0126685.

31. Bacchetti De Gregoris T, Aldred N, Clare AS, Burgess JG. Improvement of phylumand class-specific primers for real-time PCR quantification of bacterial taxa. Journal of microbiological methods 2011;86:351-6. 
32. Rinttila T, Kassinen A, Malinen E, Krogius L, Palva A. Development of an extensive set of $16 \mathrm{~S}$ rDNA-targeted primers for quantification of pathogenic and indigenous bacteria in faecal samples by real-time PCR. Journal of applied microbiology 2004;97:1166-77.

33. Gagen EJ, Denman SE, Padmanabha J, et al. Functional gene analysis suggests different acetogen populations in the bovine rumen and tammar wallaby forestomach. Applied and environmental microbiology 2010;76:7785-95.

34. Wang RF, Cao WW, Cerniglia CE. PCR detection and quantitation of predominant anaerobic bacteria in human and animal fecal samples. Applied and environmental microbiology 1996;62:1242-7.

35. Collado MC, Derrien M, Isolauri E, de Vos WM, Salminen S. Intestinal integrity and Akkermansia muciniphila, a mucin-degrading member of the intestinal microbiota present in infants, adults, and the elderly. Applied and environmental microbiology 2007;73:7767-70.

36. Armougom F, Henry M, Vialettes B, Raccah D, Raoult D. Monitoring bacterial community of human gut microbiota reveals an increase in Lactobacillus in obese patients and Methanogens in anorexic patients. PloS one 2009;4:e7125.

37. Phielix E, Schrauwen-Hinderling VB, Mensink M, et al. Lower intrinsic ADPstimulated mitochondrial respiration underlies in vivo mitochondrial dysfunction in muscle of male type 2 diabetic patients. Diabetes 2008;57:2943-9.

38. Cardona F, Andres-Lacueva C, Tulipani S, Tinahones FJ, Queipo-Ortuno MI. Benefits of polyphenols on gut microbiota and implications in human health. The Journal of nutritional biochemistry 2013;24:1415-22.

39. Dominianni C, Sinha R, Goedert JJ, et al. Sex, body mass index, and dietary fiber intake influence the human gut microbiome. PloS one 2015;10:e 0124599.

40. Flores R, Shi J, Fuhrman B, et al. Fecal microbial determinants of fecal and systemic estrogens and estrogen metabolites: a cross-sectional study. Journal of translational medicine 2012;10:253.

41. Markle JG, Frank DN, Mortin-Toth S, et al. Sex differences in the gut microbiome drive hormone-dependent regulation of autoimmunity. Science 2013;339:1084-8.

42. Cho I, Blaser MJ. The human microbiome: at the interface of health and disease. Nature reviews Genetics 2012;13:260-70.

43. Tyakht AV, Kostryukova ES, Popenko AS, et al. Human gut microbiota community structures in urban and rural populations in Russia. Nature communications 2013;4:2469.

44. Zarrinpar A, Chaix A, Yooseph S, Panda S. Diet and feeding pattern affect the diurnal dynamics of the gut microbiome. Cell metabolism 2014;20:1006-17.

45. Marin L, Miguelez EM, Villar CJ, Lombo F. Bioavailability of dietary polyphenols and gut microbiota metabolism: antimicrobial properties. BioMed research international 2015;2015:905215.

46. Monagas M, Urpi-Sarda M, Sanchez-Patan F, et al. Insights into the metabolism and microbial biotransformation of dietary flavan-3-ols and the bioactivity of their metabolites. Food \& function 2010;1:233-53.

47. Manach C, Williamson G, Morand C, Scalbert A, Remesy C. Bioavailability and bioefficacy of polyphenols in humans. I. Review of 97 bioavailability studies. The American journal of clinical nutrition 2005;81:230S-42S. 
48. Dall'Asta M, Calani L, Tedeschi M, Jechiu L, Brighenti F, Del Rio D. Identification of microbial metabolites derived from in vitro fecal fermentation of different polyphenolic food sources. Nutrition 2012;28:197-203.

49. Bode LM, Bunzel D, Huch M, et al. In vivo and in vitro metabolism of transresveratrol by human gut microbiota. The American journal of clinical nutrition 2013;97:295-309.

50. Calamini B, Ratia K, Malkowski MG, et al. Pleiotropic mechanisms facilitated by resveratrol and its metabolites. The Biochemical journal 2010;429:273-82.

51. Lambert JD, Sang S, Yang CS. Biotransformation of green tea polyphenols and the biological activities of those metabolites. Molecular pharmaceutics 2007;4:819-25.

52. Mahowald MA, Rey FE, Seedorf $\mathrm{H}$, et al. Characterizing a model human gut microbiota composed of members of its two dominant bacterial phyla. Proceedings of the National Academy of Sciences of the United States of America 2009;106:5859-64.

53. Timmers S, Hesselink MK, Schrauwen P. Therapeutic potential of resveratrol in obesity and type 2 diabetes: new avenues for health benefits? Annals of the New York Academy of Sciences 2013;1290:83-9.

54. Larsen N, Vogensen FK, van den Berg FW, et al. Gut microbiota in human adults with type 2 diabetes differs from non-diabetic adults. PloS one 2010;5:e9085.

55. Fernandes J, Su W, Rahat-Rozenbloom S, Wolever TM, Comelli EM. Adiposity, gut microbiota and faecal short chain fatty acids are linked in adult humans. Nutrition \& diabetes 2014;4:e121.

56. Canfora EE, van der Beek CM, Goossens GH, et al. Colonic short-chain fatty acids infusions promote fat oxidation and improve metabolic parameters in overweight males. Obes Facts 2015;8.

57. Canfora EE, van der Beek CM, Lenaerts K, et al. Colonic Acetate Infusions Promote Fat Oxidation and Improve Metabolic Parameters in Overweight Males. Diabetes 2014;63.

58. Unno T, Sakuma M, Mitsuhashi S. Effect of dietary supplementation of (-)epigallocatechin gallate on gut microbiota and biomarkers of colonic fermentation in rats. Journal of nutritional science and vitaminology 2014;60:213-9.

59. Sharon G, Garg N, Debelius J, Knight R, Dorrestein PC, Mazmanian SK. Specialized metabolites from the microbiome in health and disease. Cell metabolism 2014;20:71930 .

60. Belkaid Y, Hand TW. Role of the microbiota in immunity and inflammation. Cell 2014;157:121-41.

61. Tremaroli V, Backhed F. Functional interactions between the gut microbiota and host metabolism. Nature 2012;489:242-9.

62. Perseghin G, Scifo P, Pagliato E, et al. Gender factors affect fatty acids-induced insulin resistance in nonobese humans: effects of oral steroidal contraception. The Journal of clinical endocrinology and metabolism 2001;86:3188-96.

63. van de Wijgert JH, Verwijs MC, Turner AN, Morrison CS. Hormonal contraception decreases bacterial vaginosis but oral contraception may increase candidiasis: implications for HIV transmission. Aids 2013;27:2141-53.

64. Karlsson F, Tremaroli V, Nielsen J, Backhed F. Assessing the human gut microbiota in metabolic diseases. Diabetes 2013;62:3341-9.

65. Arumugam M, Raes J, Pelletier E, et al. Enterotypes of the human gut microbiome. Nature 2011;473:174-80. 


\section{CHAPTER 8}

General discussion 

Over the past decades, obesity has evolved as one of the major health concerns of Western society. The excessive amount of fat mass does not only impair physical performance, but has significant impact on physiological and psychological function and health ${ }^{1-5}$. Impaired metabolic flexibility, defined as the capacity of skeletal muscle to increase fat oxidation upon high availability and to suppress fat oxidation during insulin-stimulated conditions, may favor fat storage above oxidation ${ }^{6}$. Indeed, this capacity to regulate fat oxidation has been suggested to be impaired in the obese insulin resistant state, and may contribute to ectopic lipid accumulation interfering with insulin signaling ${ }^{7-9}$.

Strategies to improve fat oxidation may be helpful to increase metabolic flexibility and prevent or improve insulin resistance and related cardiometabolic diseases. Lifestyle interventions aiming at weight loss and increasing physical fitness should be implemented as first treatment option. However, $\sim 30 \%$ of subjects enrolled in lifestyle interventions did not achieve any intervention goal or discontinued participation ${ }^{10,11}$. Strikingly, metabolic parameters at baseline were poorer and metabolic improvements (glucose tolerance) were less pronounced in drop-outs than in completers in one study ${ }^{11}$, and insulin sensitivity improved to a greater extent in metabolically unhealthy subjects than in 'healthier' subjects after weight-loss intervention ${ }^{12}$. These findings indicate that people who most urgently need intervention and benefit most from intervention have an increased tendency to dropout. Thus, additional treatment strategies are required because incidence rates of obesityrelated cardiometabolic diseases are still increasing at an alarming rate.

Therefore, in this thesis, we investigated the potential of dietary polyphenols to modulate substrate and energy metabolism, which may contribute to the prevention of insulin resistance and related metabolic diseases in the long term.

\section{Short-term effects of polyphenol supplementation}

Green tea polyphenols, specifically epigallocatechin-3-gallate (EGCG), have been suggested to reduce body weight and insulin resistance ${ }^{13}$, possibly through effects on fat oxidation and energy expenditure ${ }^{14}$.

Therefore, we investigated in Chapter 2 whether 3 days supplementation with EGCG increases postprandial fat oxidation in overweight subjects, and whether an increased skeletal muscle lipolysis may be involved. We found that EGCG supplementation did neither affect postprandial fat oxidation nor skeletal muscle lipolysis. Previously performed 
studies including overweight subjects and using an identical macronutrient composition of the meal (35 energy\% fat), have found that EGCG stimulated postprandial fat oxidation ${ }^{15,16}$. This discrepancy may have been caused by an extra dose of $135 \mathrm{mg}$ EGCG $1 \mathrm{~h}$ prior to the test-meal ${ }^{15}$. Notably, in contrast to previous studies, we have included women $(15 / 24)$ in our study, who appear generally less susceptible to dietary interventions ${ }^{17-19}$.

Although EGCG-mediated effects on postprandial fat oxidation were not significant in our study, we found that EGCG supplementation reduced skeletal muscle interstitial lactate concentrations as compared to placebo, whilst skeletal muscle blood flow and interstitial glucose concentration were unchanged. This may be indicative of a reduced glycolytic flux, hence a more oxidative metabolism, which has also been reported by others using EGCGrich supplements ${ }^{20}$. Higher doses might increase the benefit of EGCG supplementation on postprandial fat oxidation ${ }^{14,15}$. However, Berube-Parent et al. ${ }^{21}$ showed that increasing the EGCG dose yielded no additional benefit on 24-h energy expenditure or substrate oxidation, suggesting that other factors are more likely to explain the variation between studies. In fact, higher doses of antioxidants may induce other or opposite effects as compared to lower doses ${ }^{22}$.

High doses of dietary antioxidative supplements may induce large changes in oxidative stress that may impair cellular function, whereas small and confined changes confer positive benefits, for example mitochondrial biogenesis, as stated in the hypothesis of a hormetic response ${ }^{23}$. In that respect, high doses of resveratrol $(1500 \mathrm{mg} / \mathrm{d})$ were found not effective with respect to improving mitochondrial capacity and insulin sensitivity ${ }^{24}$ as compared to others supplementing $10(150 \mathrm{mg} / \mathrm{d}){ }^{25}$ or 20 times $(80 \mathrm{mg} / \mathrm{d}){ }^{26}$ less. Additionally, Price and colleagues ${ }^{27}$ found higher variability in outcome measures in highdose, as compared to low-dose supplementation in rodents.

Based on these studies, we postulated that greater effects on oxidative metabolism might be achieved by combining "low dose" polyphenols with distinct and synergistic mechanisms of action as compared to single high-dose supplementation.

\section{Combining EGCG and resveratrol - Are two better than one?}

In diet-induced obese rodents, resveratrol prevented insulin resistance, ectopic fat accumulation and inflammation, which were accompanied by increased mitochondrial oxidative pathways, induced by activation of the AMPK-SIRT1-PGC1 $\alpha$ pathway ${ }^{28,29}$. 
Therefore, we investigated in Chapter 3 whether the combination of polyphenols with distinct mechanisms of action had beneficial effects on lipolysis and fat oxidation. We performed a placebo-controlled randomized crossover study with 18 men and women, who received supplementation with EGCG and resveratrol for 3 days $(\mathrm{E}+\mathrm{R}, 270 \mathrm{mg} / \mathrm{d}$ and 200 $\mathrm{mg} / \mathrm{d})$ or $\mathrm{E}+\mathrm{R}$ plus additional soy isoflavones $(\mathrm{E}+\mathrm{R}+\mathrm{S}, 80 \mathrm{mg} / \mathrm{d}, \sim 65 \%$ genistein, $\sim 30 \%$ daidzein). At day 3 of the supplementation protocol, we performed a high-fat mixed mealtest (61 energy\% fat) and measured substrate oxidation and plasma metabolite concentrations using indirect calorimetry and blood sampling, respectively. Interestingly, $\mathrm{E}+\mathrm{R}$ increased resting energy expenditure after an overnight fast and during the midpostprandial period (2-4 h) as compared to placebo. Furthermore, metabolic flexibility, measured as the increase in RQ from fasting to postprandial conditions, increased in men after $\mathrm{E}+\mathrm{R}$ supplementation, but not in women.

Under healthy conditions, resting energy expenditure is determined by mitochondrial respiration through two mechanisms. First, mitochondrial respiration increases upon increased energy supply, which activates mitochondrial complexes, pumping protons across the inner mitochondrial membrane and thereby increasing the proton gradient across the mitochondrial membrane (membrane potential).

However, no changes in plasma metabolite, insulin or norepinephrine concentrations were observed; hence the hypothesized mechanism of a prolonged $\beta$-adrenergic stimulation through inhibition of norepinephrine breakdown by EGCG ${ }^{14}$ does not seem to explain our findings. Alternatively, both EGCG and resveratrol may have activated AMPK, as previously reported ${ }^{25,28-30}$, which would lead to an increased substrate supply of intracellular stored energy and oxidation ${ }^{31}$. Intriguingly, resveratrol had no effect on mitochondrial respiratory enzymes upon acute exposure or during insulin-stimulated conditions or on ex vivo mitochondrial respiration in isolated human skeletal muscle fibers directly exposed to resveratrol ${ }^{32}$.

When membrane potential increases, more energy is required to pump additional protons against the gradient. This limits respiration induced by an increased supply. Thus, secondly, respiration is facilitated by uncoupling or ATP synthesis relieving the protein-motive force by proton transport back into the mitochondrial matrix ${ }^{33}$.

A stimulation of uncoupling has been reported after supplementation with EGCG and resveratrol in rodents ${ }^{29,34}$, but not in obese humans ${ }^{25}$. Lastly, resveratrol might have 
increased adenine nucleotide translocase 2 (ANT2) protein content and therefore facilitated ADP influx into mitochondria and increased ADP stimulated respiration ${ }^{35}$.

Importantly, fat is known to have the lowest thermogenic properties ${ }^{36,37}$, and obese subjects have been characterized by an impaired postprandial thermogenesis as compared to lean subjects ${ }^{38}$. The stimulating effect of $\mathrm{E}+\mathrm{R}$ on postprandial energy expenditure should be studied for other macronutrient compositions as well, since relative carbohydrate intake increases over a lifespan ${ }^{39}$.

\section{Adding soy isoflavones - Are three better than two?}

In the study described in Chapter 3, we investigated whether additional soy isoflavones $(\mathrm{E}+\mathrm{R}+\mathrm{S})$ alters the effects of $\mathrm{E}+\mathrm{R}$ supplementation. Surprisingly, addition of soy isoflavones reversed the effects of $\mathrm{E}+\mathrm{R}$ on resting energy expenditure and metabolic flexibility. It can be speculated that soy isoflavones diminished AMPK activity independently ${ }^{40}$ or dependent on scavenging of reactive oxygen species (ROS) ${ }^{41}$. As mentioned, overdosing of antioxidants may act detrimental ${ }^{23}$.

Strikingly, $\mathrm{E}+\mathrm{R}+\mathrm{S}$ increased fasting lipolysis, as indicated by increased plasma free fatty acids and glycerol concentrations. The synergistic effect of genistein and resveratrol on lipolysis has been demonstrated in vitro in adipocytes ${ }^{42}$. Increasing lipolysis may reduce lipid accumulation in adipose tissue, but may lead to ectopic lipid storage after long-term soy isoflavones supplementation, because no compensatory increase in lipid oxidation was observed. Therefore, we concluded that soy isoflavones may not provide additional benefit to $\mathrm{E}+\mathrm{R}$ supplementation under the investigated conditions.

\section{Translation to long-term potential}

The studies described in Chapters 2 and 3 assessed the effects of short-term polyphenol supplementation. These data show that $\mathrm{E}+\mathrm{R}$ increases energy expenditure in both males and females, possibly mediated by an increased mitochondrial respiration, and that $\mathrm{E}+\mathrm{R}$ may improve substrate regulation in men but not women; effects that we did not observe after EGCG supplementation alone. The increased energy expenditure after high-fat meals may be a valuable strategy to contribute to improved body weight control through effects on energy balance. To draw conclusions concerning the impact of these findings on the risk of developing chronic metabolic diseases, it is highly important to also examine more longterm effects of this intervention. Without compensatory mechanisms, the increased energy 
expenditure we found with $\mathrm{E}+\mathrm{R}$ supplementation would translate into a weight loss of $\sim 0.7$ $\mathrm{kg}$ after 12 weeks. According to findings in the US Diabetes Prevention Program, this amount of weight loss reduced the risk for diabetes by $11 \%$ (16\% per kilogram) ${ }^{43}$. Moreover, the improvement of metabolic flexibility, as we observed in males, may contribute to insulin sensitivity as seen after body weight loss of $\sim 15 \%$ in obese insulinresistant subjects ${ }^{44}$.

Therefore, in Chapter 4, we performed a study to investigate whether the increase in energy expenditure induced by 3 days $\mathrm{E}+\mathrm{R}$ supplementation would translate into increased insulin sensitivity after long-term $\mathrm{E}+\mathrm{R}$ supplementation in overweight and obese men and women. To this end, 42 subjects received $E+R(n=20)$ or placebo $(n=22)$ for 12 weeks in a randomized, double-blind parallel study ( 38 completed the study, $n=18$ and $n=20$, respectively). Before and after intervention, peripheral, hepatic and adipose tissue insulin sensitivity was assessed by means of a hyperinsulinemic-euglycemic clamp with primed co-infusion of a $\left[6,6-{ }^{2} \mathrm{H}_{2}\right]$-glucose-tracer. To investigate mechanisms underlying a potential improvement in insulin sensitivity, we measured body composition, performed a high-fat mixed meal-test and collected skeletal muscle and adipose tissue biopsies.

\section{Adipose tissue cell turnover}

As mentioned in Chapter 5, we report that 12 weeks E+R supplementation did not affect adipocyte size as compared to placebo in overweight/obese subjects. Surprisingly, the adipose tissue microarray data indicated that adipogenic gene expression was reduced by $\mathrm{E}+\mathrm{R}$ supplementation. Interestingly, we observed a concomitant reduction in gene expression of autophagy and apoptosis markers, suggesting that adipocyte turnover was reduced after $\mathrm{E}+\mathrm{R}$ supplementation. This might be interpreted in two manners.

First, a low turnover rate of adipocytes may reflect a less flexible adipose tissue metabolic phenotype. Despite reduced expression of genes involved in adipocyte turnover, we did not observe changes in adipocyte size. In contrast, previous studies found that low adipocyte turnover was related to hypertrophic, dysfunctional AT ${ }^{45}$. Moreover reduced TAG turnover, indicated by reduced expression of lipid metabolic pathways, were related to obesity ${ }^{46}$ and familial combined hyperlipidemia ${ }^{47}$. Thus, although in conditions of energy balance, as in the present study, lower cell turnover may not impair metabolic function, reduced adipocyte generation may lead to adipocyte hypertrophy and, consequently, insulin 
resistance in the long term ${ }^{48}$, especially in situations where weight gain occurs (e.g. during aging) ${ }^{49}$.

Second, we found a down regulation of inflammatory signaling pathways. Importantly, immune cells can make up to for $50 \%$ of cells in adipose tissue. Thus, the 'adipose tissue' gene expression pattern is the result of combined cell-specific gene expression within the tissue ${ }^{50}$. The observed downregulation of inflammatory signaling pathways following $\mathrm{E}+\mathrm{R}$ supplementation may indicate that adipose tissue inflammation is at least partly reversed, which might preserve tissue function and ameliorate the progression of chronic inflammatory diseases ${ }^{51,52}$.

Interestingly, the expression profile of genes and proteins related to mitochondrial biogenesis and oxidative phosphorylation were downregulated in adipose tissue following $\mathrm{E}+\mathrm{R}$ supplementation. This might be a consequence of reduced energy requirements of cellular processes that are involved in cell turnover. These expression patterns are opposite to those observed in skeletal muscle, suggesting a tissue-specific effect of combined polyphenol supplementation on gene expression.

\section{Skeletal muscle mitochondrial capacity}

In line with the findings in the short-term study, E+R supplementation significantly increased oxidative metabolism after 12 weeks. Resveratrol and EGCG have been shown to activate AMPK and its downstream target PGC-1 ${ }^{25,28-30}$, the master activator of mitochondrial biogenesis ${ }^{53}$, which likely contributes to the increased mitochondrial capacity in the present study. Transient increases in reactive oxygen species (ROS) may induce mitochondrial biogenesis in skeletal muscle after high-fat diet- or exercise-induced ROS production ${ }^{54,55}$. ROS-induced $\mathrm{Ca}^{2+}$-release stimulates $\mathrm{Ca}^{2+} /$ calmodulin-dependent protein kinase II (CAMKII), an activator of AMPK-mediated mitochondrial biogenesis ${ }^{56}$. This pathway is however unlikely to account for increases of mitochondrial capacity in our study because the antioxidant capacity of polyphenols would rather cause ROS scavenging 57,58 .

Skeletal muscle oxidative capacity was increased by $9 \%$ (14\% on a lipid substrate) in the present study, which was accompanied by increased expression of proteins involved in oxidative phosphorylation. Interestingly, we did not observe a specific increase in mitochondrial mass (ratio NADH dehydrogenase/lipoprotein lipase) or the oxidative 
capacity per mitochondrion, pointing towards inter-individual variability in response regarding increases in mass and function. It has previously been shown that resveratrol supplementation $(150 \mathrm{mg} / \mathrm{d})$ induced a comparable increase $(\sim 10 \%)$ in respiratory capacity after 4 weeks ${ }^{25}$. It may well be that this increase has also occurred in our study in the early phase of the intervention. In line, gene expression of mitochondrial biogenesis pathways was not increased after 12 weeks, thus we do not expect a further increase in mitochondrial oxidative capacity when supplementation had been continued for a longer period of time.

\section{Mitochondrial function and oxidative stress}

Persistent high ROS production, as seen in skeletal muscle and adipose tissue of obese insulin resistant subjects ${ }^{59,60}$, impairs protein function, induces DNA damage and activates inflammatory pathways via c-Jun NH2-terminal kinase (JNK) and nuclear transcription

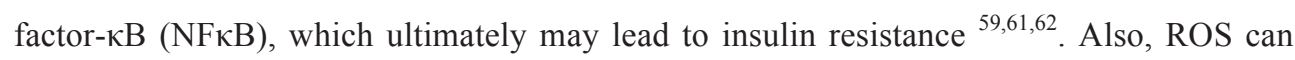
impair mitochondrial enzymes through downregulation of mitochondrial biogenesis and activity ${ }^{63}$. Interestingly, antioxidants acting in the cytosol (catalase, tetrakis-(benzoic acid)porphyrin (MnTBAP)) reduced age- or diet-induced ROS production and rescued mitochondrial function ${ }^{64,65}$, whereas antioxidants targeting mitochondrial complex I and III did not improve mitochondrial function ${ }^{66}$. Thus, a reduced ROS emission may be an alternative mechanism that has contributed to the increased mitochondrial function observed in our study, besides the earlier suggested AMPK activation (Chapter 4).

\section{Mitochondrial capacity and substrate oxidation}

In line with a higher mitochondrial capacity in skeletal muscle (9-14 \%), we observed an increased fat oxidation during fasting and postprandial conditions of $30 \%$ in $\mathrm{E}+\mathrm{R} v s$. placebo. This was accompanied by a reduced absolute and relative (to EE) carbohydrate oxidation, whereas energy expenditure remained unchanged. Since the increased fat oxidation was not observed after 30-day resveratrol supplementation ${ }^{25}$, the present findings may be explained by the addition of EGCG. Indeed, it has previously been shown that EGCG can induce a more oxidative phenotype in the short term, as we reported in Chapter 2 , and exert a stimulatory effect on fat oxidation after a longer supplementation period ${ }^{67,68}$. Alternatively, or additionally, this effect might be due to the increased mitochondrial capacity. A greater reliance on fat oxidation with increased mitochondrial capacity has been suggested by many investigators, although surprisingly little evidence is available. 
In insulin resistance, increased lipid-intermediates have been shown to inhibit ANT ${ }^{69,70}$. Moreover, a reduced ability of ADP to stimulate mitochondrial respiration (ADP sensitivity) has been reported in subjects with a reduced respiratory capacity ${ }^{71,72}$. A lower ADP availability and sensitivity leads to increased cytosolic ADP concentrations, signaling low energy status. Consequently, cytosolic ADP stimulates the glycolytic flux through activation of glycogen phosphorylase and pyruvate dehydrogenase ${ }^{73,74}$, whereas the ratelimiting enzyme of fat oxidation, CPT-1, is not stimulated by ADP ${ }^{75,76}$. Consequently, glycolytic energy production quickly overrules fat oxidation upon increased ADP concentrations. Interestingly, resveratrol has been shown to increase ADP stimulated respiration in ZDF rats by increasing ANT2 expression ${ }^{35}$, thereby facilitating oxidative ATP production. Moreover, resveratrol increased acyl-CoA stimulated respiration in the rodent model, pointing towards a preference towards fat oxidation ${ }^{57}$. With an increased mitochondrial capacity, as shown after E+R supplementation, skeletal muscle can produce the same amount of ATP at lower ADP concentrations ${ }^{71}$. Therefore, less glycolytic energy is required and glycogen breakdown is limited ${ }^{72}$.

\section{Mitochondrial function and insulin sensitivity}

There is substantial debate with respect to the (causal) relationship between mitochondrial dysfunction and insulin resistance ${ }^{77-79}$. Mitochondrial abnormalities, including reduced oxidative capacity, can accelerate progression of insulin resistance and subsequent organ dysfunction via increased ROS production ${ }^{79}$ and accumulation of lipid-intermediates ${ }^{80}$. On the other hand, insulin resistance may contribute to mitochondrial dysfunction ${ }^{81}$. Contrary to the model, in which both deteriorate, defects in either insulin resistance or mitochondrial function might induce a compensatory increase in each other. In order to maintain energy provision, reduced mitochondrial oxidative ATP production may be compensated by an increased AMPK activity, leading to enhanced glucose uptake and glycolysis, and vice versa ${ }^{77}$. However, this compensation hypothesis derives from either pathological conditions or genetically modified animal models with severe mitochondrial deficiency. As discussed, transient increases in mitochondrial capacity, despite insulin resistance, after overeating ${ }^{54}$ need to be distinguished from those in obese and diabetic conditions, caused by a sedentary lifestyle and overeating, in which both mitochondrial function and insulin sensitivity are reduced ${ }^{53,82-84}$. 


\section{Insulin sensitivity}

We hypothesized that improvements in fat oxidation and mitochondrial oxidative capacity, as we indeed observed after 12 weeks E+R supplementation, would translate into increased peripheral insulin sensitivity by reducing the accumulation of TAG and lipid metabolites. In Chapter 4, we report that peripheral, hepatic and adipose tissue insulin sensitivity were not affected by 12 weeks supplementation with E+R. In line with unchanged insulin sensitivity, gene expression profiles in adipose tissue and skeletal muscle were not significantly altered with respect to insulin signaling pathways, lipid accumulation in skeletal muscle was unchanged and markers of systemic inflammation were not affected by the intervention. An unchanged insulin sensitivity is in line with previous studies that assessed insulin sensitivity by means of a hyperinsulinemic-euglycemic clamp in subjects with comparable insulin sensitivity at baseline of resveratrol supplementation studies ${ }^{18,24,85}$. Importantly, however, we are the first to report that $\mathrm{E}+\mathrm{R}$ improved skeletal muscle mitochondrial capacity, TAG concentrations and tended to reduce visceral adipose tissue (AT) mass, but these effects did not translate into improved peripheral, hepatic or adipose tissue insulin sensitivity.

The cross-sectional associations between impaired mitochondrial capacity and insulin resistance include diabetic patients and non-diabetic controls ${ }^{53,82-84}$, thus a significantly broader range as in the present study. Interestingly, in line with our findings, it has been suggested that these associations were not strong enough within a defined group of obese or diabetic patients ${ }^{86}$. Moreover, the impact of the $10-15 \%$ improvement of mitochondrial capacity may be too small to impact insulin sensitivity after 12 weeks. Nevertheless, the stimulation of fat oxidation by $30 \%$ may prevent mitochondrial overload and dysfunction and therefore accumulation of detrimental lipid intermediates and ROS production. Moreover, the relatively small increase in skeletal muscle mitochondrial capacity might, in the long term, prevent insulin resistance by delaying deteriorations associated with an impaired mitochondrial function.

Insulin sensitizing effects of EGCG and resveratrol have been proposed earlier. This was mainly based on effects on fasting glucose and insulin concentrations (e.g. HOMA-IR). The proposed insulin sensitizing effects were more pronounced in diabetic subjects (resveratrol) ${ }^{87}$ and in studies with high-quality $(\mathrm{EGCG}){ }^{88}$, assessed by the Jadad-scale, which scores clinical trials based on reported blinding, randomization and drop-outs ${ }^{89}$. A reduction of 
fasting glucose, insulin and HOMA-IR may, however, rather reflect hepatic insulin sensitivity. This would be in line with reduced liver fat in obese subjects after 30 days of resveratrol supplementation ${ }^{25}$, although no effect of resveratrol on hepatic insulin sensitivity, lipid content or steatosis was observed in NAFLD patients ${ }^{85}$. In the latter studies, fasting plasma glucose and insulin concentrations were not affected. In our study, subjects were classified as normoglycemic (fasting concentrations and OGTT), and insulin resistance was less progressed than in other obese populations based on a hyperinsulinemiceuglycemic clamp ${ }^{90}$. Therefore, we cannot exclude the possibility that $\mathrm{E}+\mathrm{R}$ supplementation might have beneficial effects on insulin sensitivity through effects on lipid metabolism in a more insulin resistant population.

\section{Body weight maintenance}

The data after 12 weeks combined polyphenol supplementation of unchanged body weight and composition suggest that the increase in energy expenditure that we observed after 3 days of $\mathrm{E}+\mathrm{R}$ supplementation was transient. It is possible that the previously suggested effect of EGCG, namely stimulation of thermogenesis ${ }^{14}$, may have counteracted the caloric restriction-like effects of resveratrol ${ }^{25}$. Although energy balance was not affected by 12 weeks $\mathrm{E}+\mathrm{R}$ supplementation, fat oxidation was significantly increased. Flatt ${ }^{36,91}$ hypothesized that insufficient fat oxidation causes glycogen depletion, which promotes food intake ${ }^{92}$. Although pronounced effects on adiposity appear only possible with changes in energy expenditure, excretion or intake, which we did not observe after 12 weeks supplementation ${ }^{93}$, the increased fat oxidation in the present study may drive a negative fat balance and spare glycogen stores and may therefore have beneficial effects on body weight regulation on longer terms ${ }^{94}$.

\section{Ectopic fat accumulation}

Thus, combined $\mathrm{E}+\mathrm{R}$ supplementation has the potential to reduce ectopic lipid accumulation and therefore may prevent or reverse insulin resistance.

Whereas subcutaneous AT mass and morphology were unchanged after 12 weeks E+R supplementation, visceral AT mass tended to be decreased. This may reduce the risk of developing cardiometabolic diseases, since visceral AT mass is related to cardiovascular and metabolic risk ${ }^{95-97}$. 
While the reduction of visceral AT in our study may have caused a transient increased FFA flux towards the liver ${ }^{98}$, this increased lipid availability might have contributed to increase hepatic fat oxidation. Of note, since substrate oxidation was assessed by indirect calorimetry, we cannot specify the contribution of the liver to the observed increase in whole body fat oxidation. In rodents, EGCG and resveratrol supplementation have both been shown to reduce visceral AT $^{99,100}$ and to increase hepatic fat oxidation ${ }^{101,102}$. This increase may have contributed to reduce hepatic lipid accumulation in obese humans after resveratrol supplementation ${ }^{25}$.

There are two likely explanations for the visceral AT reduction. First, visceral AT is more sensitive to lipolytic stimuli, which may explain the depot-specific effect. As the contribution of visceral lipolysis to plasma FFA is minimal ${ }^{103}$, this may explain the unchanged circulating FFA concentrations in our study. Second, the present data of improved postprandial plasma triacylglycerol concentration and unchanged intramyocellular lipid content suggests a preferential uptake and oxidation of extracellular lipids, which is in line with previous findings ${ }^{104}$. The increased fat oxidation may reduce lipid availability to visceral AT and may furthermore compensate for an increased skeletal muscle lipid uptake that is frequently observed in obese, insulin resistant subjects ${ }^{105}$. In line, intramyocellular lipid stores are unchanged after intervention, as discussed in Chapter 4.

\section{Polyphenol-gut microbiota interaction}

The role of the gut microbiota in host metabolism has been highlighted by many recent publications, as reviewed ${ }^{106-112}$. In Chapter 6, we were able to contribute to these findings by showing that the microbiota composition (Bacteriodetes/Firmicutes-(B/F-)ratio) was negatively related to peripheral insulin sensitivity, assessed by the gold-standard technique hyperinsulinemic-euglycemic clamp with glucose tracer-infusion in men but not women. The relationship between B/F-ratio and peripheral insulin sensitivity in men remained significant after adjustment for parameters that have been related to insulin sensitivity, including body composition, fiber and saturated fat intake, fat oxidation and markers of systemic inflammation. Thus, other factors related to the intestine may underlie the association between gut microbiota composition and peripheral insulin sensitivity. These may, amongst others, include short-chain fatty acids (SCFA) ${ }^{113}$ and glucagon-like peptide 
1 (GLP-1) ${ }^{114}$. Intervention studies in humans showed that microbial transplantation from healthy donors to metabolic syndrome patients increased peripheral insulin sensitivity ${ }^{115}$, whereas decreased peripheral insulin sensitivity has been reported after antibiotic treatment in obese subjects ${ }^{116}$. Moreover, microbiota composition is affected by diet ${ }^{117}$. Interestingly, as described in Chapter 7, we found that dietary polyphenol supplementation alters microbial composition in a gender-specific manner. In men, but not in women, an antimicrobial effect of polyphenol supplementation was shown. Due to the impact of the microbiota on host metabolism and the property of polyphenols to affect microbial composition, we speculated that $\mathrm{E}+\mathrm{R}$-induced effects on fat oxidation might be mediated by changes in gut microbiota composition and function. Indeed, we demonstrated that the baseline Bacteroidetes abundance was predictive for the stimulatory effect of $\mathrm{E}+\mathrm{R}$ on fat oxidation in men. This suggests that the characterization of the microbiota composition might add valuable information to explain variability of dietary interventions on host metabolism that has been frequently observed in previous studies. Gender should be generally taken into account as modulatory factor, considering the differences in physiology ${ }^{118,119}$ and microbiota composition ${ }^{120-122}$, and the altered susceptibility to intervention-effects on physiology ${ }^{17,26}$ and microbiota composition $\left({ }^{117}\right.$, present thesis). 


\section{Implications and future directions}

In this thesis, we describe the effects of polyphenol supplementation on substrate and energy metabolism in overweight and obese men and women. The short-term effects of combined $\mathrm{E}+\mathrm{R}$ supplementation of an increased energy expenditure and metabolic flexibility (in men but not women) did translate into an increased mitochondrial capacity and increased fat oxidation after 12 weeks, whereas body composition and tissue-specific insulin sensitivity were not affected. Several important issues need to be addressed in future studies to improve our understanding of the potential benefits of polyphenol supplementation.

1. Generally, gender should be put more forward as modulatory factor in metabolic research, considering the pronounced differences in metabolism ${ }^{123}$. Wherever feasible, in basic and applied research, the factor gender should be included in study designs, data analyses or interpretation in order to allow qualitative and quantitative conclusion for both gender. Importantly, measurements in women should be performed in the same stage of the menstrual cycle before and after intervention, if possible.

2. Based on the short-term studies described in this thesis, it can be concluded that polyphenols do not necessarily induce additive or synergistic effects $(E+R)$, but can also exert opposing effects $(\mathrm{E}+\mathrm{R}+\mathrm{S})$.

3. Due to the heterogeneity in the response to polyphenol supplementation between subjects, a more detailed characterization of subjects by means of -omics technologies may help to specify subgroups that are more responsive to polyphenol intervention than others. These methodologies may additionally help to identify biomarkers that predict the intervention success. It has been hypothesized that metabolically compromised subjects may benefit more from polyphenol supplementation, but this has not yet been addressed directly.

4. The benefit of polyphenol supplementation on metabolic health parameters and exercise performance ${ }^{68,124,125}$ has been shown in overweight and obese subjects. It remains to be investigated, whether these improvements may increase the effectiveness of lifestyle intervention studies. Importantly, additional effects seem more likely in programs aimed at increasing daily physical activities rather than on exercise interventions for 2 reasons. First, the magnitude of polyphenol interventions on e.g. mitochondrial function (9-14\%) seems 
to be limited as compared to exercise induced increases of $30 \%$ (combined training ${ }^{126}$ ) up to $60 \%$ (resistance training ${ }^{127}$ ). Secondly, antioxidant supplementation may even attenuate benefits of exercise by blunting the adaptive oxidative response ${ }^{128-132}$.

5. So far, very little human studies addressed the preventive effect of polyphenols on body weight, mitochondrial function and insulin sensitivity during 'challenged' conditions such as fructose-induced insulin resistance or weight maintenance, during which weight gain is more likely, although the first ones were promising ${ }^{133,134}$. This preventive effect might also be applied to clinical conditions during which physical activity is limited such as immobilization during injury and bed rest during illness.

6. An increased relative fat oxidation has been frequently associated with a reduced likelihood to gain weight over many years, not weeks ${ }^{135}$. It remains yet speculative whether glycogen stores are spared by the shift towards fat oxidation. A more detailed investigation of acute hunger and satiety feelings and food intake patterns after polyphenol supplementation may offer potential insight. Indices of hepatic glycogen stores and lipid accumulation ( ${ }^{1} \mathrm{H}$-magnetic resonance spectroscopy, MRS) and lipid fluxes (tracer for endogenous and dietary fat) may offer clarification.

7. To increase insight in the interplay between the metabolic pathways, the mitochondrial dynamics and kinetics of lipids, ADP and ROS should be studied in more detail, also in the context of polyphenol supplementation.

8. We and others showed that the gut microbiota is related to its host metabolism and may be predictive for intervention effects in men. State-of-the-art techniques to determine microbiota composition, microbial metabolomics (of polyphenols) and plasma metabolomics may certainly advance our understanding of the interaction between diet, supplements, the microbiota and peripheral metabolism ${ }^{136,137}$.

9. A complete new view on the effects of polyphenol supplementation was brought by a recent study in rodents, which suggested that the effects of resveratrol on mitochondrial function and insulin sensitivity were dependent on the activity of resveratrol in intestinal cells ${ }^{138}$. It remains to be established, whether polyphenols' effects in humans are dependent on duodenal sensing as well or whether effects are induced directly at peripheral tissues, as it has been suggested. Interestingly, a recent study found no direct effects of resveratrol on mitochondrial respiration ex vivo in isolated human skeletal muscle fibers ${ }^{32}$. 


\section{References}

1. Bhaskaran K, Douglas I, Forbes H, dos-Santos-Silva I, Leon DA, Smeeth L. Bodymass index and risk of 22 specific cancers: a population-based cohort study of 5.24 million UK adults. Lancet 2014;384:755-65.

2. Emerging Risk Factors C, Wormser D, Kaptoge S, et al. Separate and combined associations of body-mass index and abdominal adiposity with cardiovascular disease: collaborative analysis of 58 prospective studies. Lancet 2011;377:1085-95.

3. Forhan M, Gill SV. Obesity, functional mobility and quality of life. Best practice \& research Clinical endocrinology \& metabolism 2013;27:129-37.

4. Kahn SE, Hull RL, Utzschneider KM. Mechanisms linking obesity to insulin resistance and type 2 diabetes. Nature 2006;444:840-6.

5. Preiss K, Brennan L, Clarke D. A systematic review of variables associated with the relationship between obesity and depression. Obesity reviews : an official journal of the International Association for the Study of Obesity 2013;14:906-18.

6. Hulver MW, Berggren JR, Carper MJ, et al. Elevated stearoyl-CoA desaturase-1 expression in skeletal muscle contributes to abnormal fatty acid partitioning in obese humans. Cell metabolism 2005;2:251-61.

7. Corpeleijn E, Saris WH, Blaak EE. Metabolic flexibility in the development of insulin resistance and type 2 diabetes: effects of lifestyle. Obesity reviews : an official journal of the International Association for the Study of Obesity 2009;10:178-93.

8. Kelley DE. Skeletal muscle fat oxidation: timing and flexibility are everything. The Journal of clinical investigation 2005;115:1699-702.

9. Muoio DM. Metabolic inflexibility: when mitochondrial indecision leads to metabolic gridlock. Cell 2014;159:1253-62.

10. Tuomilehto J, Lindstrom J, Eriksson JG, et al. Prevention of type 2 diabetes mellitus by changes in lifestyle among subjects with impaired glucose tolerance. The New England journal of medicine 2001;344:1343-50.

11. Roumen C, Corpeleijn E, Feskens EJ, Mensink M, Saris WH, Blaak EE. Impact of 3year lifestyle intervention on postprandial glucose metabolism: the SLIM study. Diabet Med 2008;25:597-605.

12. Janiszewski PM, Ross R. Effects of weight loss among metabolically healthy obese men and women. Diabetes care 2010;33:1957-9.

13. Wolfram S, Wang Y, Thielecke F. Anti-obesity effects of green tea: from bedside to bench. Mol Nutr Food Res 2006;50:176-87.

14. Dulloo AG, Duret C, Rohrer D, et al. Efficacy of a green tea extract rich in catechin polyphenols and caffeine in increasing 24-h energy expenditure and fat oxidation in humans. The American journal of clinical nutrition 1999;70:1040-5.

15. Thielecke F, Rahn G, Bohnke J, et al. Epigallocatechin-3-gallate and postprandial fat oxidation in overweight/obese male volunteers: a pilot study. European journal of clinical nutrition 2010;64:704-13.

16. Boschmann M, Thielecke F. The effects of epigallocatechin-3-gallate on thermogenesis and fat oxidation in obese men: a pilot study. J Am Coll Nutr 2007;26:389S-95S.

17. Tierney AC, McMonagle J, Shaw DI, et al. Effects of dietary fat modification on insulin sensitivity and on other risk factors of the metabolic syndrome--LIPGENE: a 
European randomized dietary intervention study. International journal of obesity 2011;35:800-9.

18. Yoshino J, Conte C, Fontana L, et al. Resveratrol supplementation does not improve metabolic function in nonobese women with normal glucose tolerance. Cell metabolism 2012;16:658-64.

19. Leblanc V, Begin C, Hudon AM, et al. Gender differences in the long-term effects of a nutritional intervention program promoting the Mediterranean diet: changes in dietary intakes, eating behaviors, anthropometric and metabolic variables. Nutr $\mathrm{J}$ 2014;13:107.

20. Van Dorsten FA, Daykin CA, Mulder TP, Van Duynhoven JP. Metabonomics approach to determine metabolic differences between green tea and black tea consumption. Journal of agricultural and food chemistry 2006;54:6929-38.

21. Berube-Parent S, Pelletier C, Dore J, Tremblay A. Effects of encapsulated green tea and Guarana extracts containing a mixture of epigallocatechin-3-gallate and caffeine on 24 h energy expenditure and fat oxidation in men. Br J Nutr 2005;94:432-6.

22. Skrobuk P, von Kraemer S, Semenova MM, Zitting A, Koistinen HA. Acute exposure to resveratrol inhibits AMPK activity in human skeletal muscle cells. Diabetologia 2012;55:3051-60.

23. Surh YJ. Xenohormesis mechanisms underlying chemopreventive effects of some dietary phytochemicals. Ann N Y Acad Sci 2011;1229:1-6.

24. Poulsen MM, Vestergaard PF, Clasen BF, et al. High-dose resveratrol supplementation in obese men: an investigator-initiated, randomized, placebocontrolled clinical trial of substrate metabolism, insulin sensitivity, and body composition. Diabetes 2013;62:1186-95.

25. Timmers S, Konings E, Bilet L, et al. Calorie restriction-like effects of 30 days of resveratrol supplementation on energy metabolism and metabolic profile in obese humans. Cell metabolism 2011;14:612-22.

26. Most J, Goossens GH, Jocken JW, Blaak EE. Short-term supplementation with a specific combination of dietary polyphenols increases energy expenditure and alters substrate metabolism in overweight subjects. International journal of obesity 2014;38:698-706.

27. Price NL, Gomes AP, Ling AJ, et al. SIRT1 is required for AMPK activation and the beneficial effects of resveratrol on mitochondrial function. Cell metabolism 2012;15:675-90.

28. Baur JA, Pearson KJ, Price NL, et al. Resveratrol improves health and survival of mice on a high-calorie diet. Nature 2006;444:337-42.

29. Lagouge M, Argmann C, Gerhart-Hines Z, et al. Resveratrol improves mitochondrial function and protects against metabolic disease by activating SIRT1 and PGC-1alpha. Cell 2006;127:1109-22.

30. Li Y, Zhao S, Zhang W, et al. Epigallocatechin-3-O-gallate (EGCG) attenuates FFAsinduced peripheral insulin resistance through AMPK pathway and insulin signaling pathway in vivo. Diabetes research and clinical practice 2011;93:205-14.

31. Canto C, Gerhart-Hines Z, Feige JN, et al. AMPK regulates energy expenditure by modulating NAD+ metabolism and SIRT1 activity. Nature 2009;458:1056-60.

32. Williams $\mathrm{CB}$, Hughes $\mathrm{MC}$, Edgett BA, et al. An examination of resveratrol's mechanisms of action in human tissue: impact of a single dose in vivo and dose responses in skeletal muscle ex vivo. PloS one 2014;9:e102406. 
33. Jadad AR, Moore RA, Carroll D, et al. Assessing the quality of reports of randomized clinical trials: is blinding necessary? Control Clin Trials 1996;17:1-12.

34. Chen N, Bezzina R, Hinch E, et al. Green tea, black tea, and epigallocatechin modify body composition, improve glucose tolerance, and differentially alter metabolic gene expression in rats fed a high-fat diet. Nutrition research 2009;29:784-93.

35. Smith BK, Perry CG, Herbst EA, et al. Submaximal ADP-stimulated respiration is impaired in ZDF rats and recovered by resveratrol. The Journal of physiology 2013;591:6089-101.

36. Flatt JP, Ravussin E, Acheson KJ, Jequier E. Effects of dietary fat on postprandial substrate oxidation and on carbohydrate and fat balances. The Journal of clinical investigation 1985;76:1019-24.

37. Martinez JA, Navas-Carretero S, Saris WH, Astrup A. Personalized weight loss strategies-the role of macronutrient distribution. Nature reviews Endocrinology 2014;10:749-60.

38. Blaak EE, Hul G, Verdich $\mathrm{C}$, et al. Impaired fat-induced thermogenesis in obese subjects: the NUGENOB study. Obesity 2007;15:653-63.

39. Yancy WS, Jr., Wang CC, Maciejewski ML. Trends in energy and macronutrient intakes by weight status over four decades. Public health nutrition 2014;17:256-65.

40. Stallings MT, Cardon BR, Hardman JM, et al. A high isoflavone diet decreases 5' adenosine monophosphate-activated protein kinase activation and does not correct selenium-induced elevations in fasting blood glucose in mice. Nutr Res 2014;34:30817.

41. Chen CY, Bakhiet RM, Hart V, Holtzman G. Isoflavones improve plasma homocysteine status and antioxidant defense system in healthy young men at rest but do not ameliorate oxidative stress induced by $80 \%$ VO2pk exercise. Annals of nutrition \& metabolism 2005;49:33-41.

42. Rayalam S, Della-Fera MA, Yang JY, Park HJ, Ambati S, Baile CA. Resveratrol potentiates genistein's antiadipogenic and proapoptotic effects in 3T3-L1 adipocytes. The Journal of nutrition 2007;137:2668-73.

43. Hamman RF, Wing RR, Edelstein SL, et al. Effect of weight loss with lifestyle intervention on risk of diabetes. Diabetes care 2006;29:2102-7.

44. Corpeleijn E, Mensink M, Kooi ME, Roekaerts PM, Saris WH, Blaak EE. Impaired skeletal muscle substrate oxidation in glucose-intolerant men improves after weight loss. Obesity 2008;16:1025-32.

45. Arner E, Westermark PO, Spalding KL, et al. Adipocyte turnover: relevance to human adipose tissue morphology. Diabetes 2010;59:105-9.

46. Ryden M, Andersson DP, Bernard S, Spalding K, Arner P. Adipocyte triglyceride turnover and lipolysis in lean and overweight subjects. Journal of lipid research 2013;54:2909-13.

47. Arner P, Bernard S, Salehpour M, et al. Dynamics of human adipose lipid turnover in health and metabolic disease. Nature 2011;478:110-3.

48. Kim SM, Lun M, Wang M, et al. Loss of white adipose hyperplastic potential is associated with enhanced susceptibility to insulin resistance. Cell metabolism 2014;20:1049-58.

49. Kyle UG, Genton L, Slosman DO, Pichard C. Fat-free and fat mass percentiles in 5225 healthy subjects aged 15 to 98 years. Nutrition 2001;17:534-41. 
50. Weisberg SP, McCann D, Desai M, Rosenbaum M, Leibel RL, Ferrante AW, Jr. Obesity is associated with macrophage accumulation in adipose tissue. The Journal of clinical investigation 2003;112:1796-808.

51. Zhang K, Kaufman RJ. From endoplasmic-reticulum stress to the inflammatory response. Nature 2008;454:455-62.

52. Hotamisligil GS. Endoplasmic reticulum stress and the inflammatory basis of metabolic disease. Cell 2010;140:900-17.

53. Mootha VK, Lindgren CM, Eriksson KF, et al. PGC-1alpha-responsive genes involved in oxidative phosphorylation are coordinately downregulated in human diabetes. Nature genetics 2003;34:267-73.

54. Jain SS, Paglialunga S, Vigna C, et al. High-fat diet-induced mitochondrial biogenesis is regulated by mitochondrial-derived reactive oxygen species activation of CaMKII. Diabetes 2014;63:1907-13.

55. Egan B, Zierath JR. Exercise metabolism and the molecular regulation of skeletal muscle adaptation. Cell Metab 2013;17:162-84.

56. $\mathrm{Wu} \mathrm{H}$, Kanatous SB, Thurmond FA, et al. Regulation of mitochondrial biogenesis in skeletal muscle by CaMK. Science 2002;296:349-52.

57. Beaudoin MS, Perry CG, Arkell AM, et al. Impairments in mitochondrial palmitoylCoA respiratory kinetics that precede development of diabetic cardiomyopathy are prevented by resveratrol in ZDF rats. The Journal of physiology 2014;592:2519-33.

58. Casanova E, Baselga-Escudero L, Ribas-Latre A, et al. Epigallocatechin gallate counteracts oxidative stress in docosahexaenoxic acid-treated myocytes. Biochimica et biophysica acta 2014;1837:783-91.

59. Anderson EJ, Lustig ME, Boyle KE, et al. Mitochondrial $\mathrm{H} 2 \mathrm{O} 2$ emission and cellular redox state link excess fat intake to insulin resistance in both rodents and humans. The Journal of clinical investigation 2009;119:573-81.

60. Chattopadhyay M, Khemka VK, Chatterjee G, Ganguly A, Mukhopadhyay S, Chakrabarti S. Enhanced ROS production and oxidative damage in subcutaneous white adipose tissue mitochondria in obese and type 2 diabetes subjects. Mol Cell Biochem 2015;399:95-103.

61. Furukawa S, Fujita T, Shimabukuro M, et al. Increased oxidative stress in obesity and its impact on metabolic syndrome. The Journal of clinical investigation 2004;114:1752-61.

62. Houstis N, Rosen ED, Lander ES. Reactive oxygen species have a causal role in multiple forms of insulin resistance. Nature 2006;440:944-8.

63. Bonnard C, Durand A, Peyrol S, et al. Mitochondrial dysfunction results from oxidative stress in the skeletal muscle of diet-induced insulin-resistant mice. The Journal of clinical investigation 2008;118:789-800.

64. Boudina S, Sena S, Sloan C, et al. Early mitochondrial adaptations in skeletal muscle to diet-induced obesity are strain dependent and determine oxidative stress and energy expenditure but not insulin sensitivity. Endocrinology 2012;153:2677-88.

65. Lee HY, Choi CS, Birkenfeld AL, et al. Targeted expression of catalase to mitochondria prevents age-associated reductions in mitochondrial function and insulin resistance. Cell Metab 2010;12:668-74.

66. Paglialunga S, van Bree B, Bosma M, et al. Targeting of mitochondrial reactive oxygen species production does not avert lipid-induced insulin resistance in muscle tissue from mice. Diabetologia 2012;55:2759-68. 
67. Mahler A, Steiniger J, Bock M, et al. Metabolic response to epigallocatechin-3-gallate in relapsing-remitting multiple sclerosis: a randomized clinical trial. The American journal of clinical nutrition 2015;101:487-95.

68. Roberts JD, Roberts MG, Tarpey MD, Weekes JC, Thomas CH. The effect of a decaffeinated green tea extract formula on fat oxidation, body composition and exercise performance. Journal of the International Society of Sports Nutrition 2015;12:1.

69. Ellis BA, Poynten A, Lowy AJ, et al. Long-chain acyl-CoA esters as indicators of lipid metabolism and insulin sensitivity in rat and human muscle. American journal of physiology Endocrinology and metabolism 2000;279:E554-60.

70. Ludzki A, Paglialunga S, Smith BK, et al. Rapid Repression of ADP Transport by Palmitoyl-CoA Is Attenuated by Exercise Training in Humans: A Potential Mechanism to Decrease Oxidative Stress and Improve Skeletal Muscle Insulin Signaling. Diabetes 2015;64:2769-79.

71. Holloszy JO, Coyle EF. Adaptations of skeletal muscle to endurance exercise and their metabolic consequences. Journal of applied physiology: respiratory, environmental and exercise physiology 1984;56:831-8.

72. Zoll J, Sanchez H, N'Guessan B, et al. Physical activity changes the regulation of mitochondrial respiration in human skeletal muscle. The Journal of physiology 2002;543:191-200.

73. Rush JW, Spriet LL. Skeletal muscle glycogen phosphorylase a kinetics: effects of adenine nucleotides and caffeine. J Appl Physiol (1985) 2001;91:2071-8.

74. Pratt ML, Roche TE. Mechanism of pyruvate inhibition of kidney pyruvate dehydrogenasea kinase and synergistic inhibition by pyruvate and ADP. J Biol Chem 1979;254:7191-6.

75. Starritt EC, Howlett RA, Heigenhauser GJ, Spriet LL. Sensitivity of CPT I to malonyl-CoA in trained and untrained human skeletal muscle. American journal of physiology Endocrinology and metabolism 2000;278:E462-8.

76. Bezaire V, Heigenhauser GJ, Spriet LL. Regulation of CPT I activity in intermyofibrillar and subsarcolemmal mitochondria from human and rat skeletal muscle. American journal of physiology Endocrinology and metabolism 2004;286:E85-91.

77. Goodpaster BH. Mitochondrial deficiency is associated with insulin resistance. Diabetes 2013;62:1032-5.

78. Holloszy JO. "Deficiency" of mitochondria in muscle does not cause insulin resistance. Diabetes 2013;62:1036-40.

79. Szendroedi J, Phielix E, Roden M. The role of mitochondria in insulin resistance and type 2 diabetes mellitus. Nature reviews Endocrinology 2012;8:92-103.

80. Koves TR, Ussher JR, Noland RC, et al. Mitochondrial overload and incomplete fatty acid oxidation contribute to skeletal muscle insulin resistance. Cell metabolism 2008;7:45-56.

81. Stump CS, Short KR, Bigelow ML, Schimke JM, Nair KS. Effect of insulin on human skeletal muscle mitochondrial ATP production, protein synthesis, and mRNA transcripts. Proceedings of the National Academy of Sciences of the United States of America 2003;100:7996-8001.

82. Phielix E, Schrauwen-Hinderling VB, Mensink M, et al. Lower intrinsic ADPstimulated mitochondrial respiration underlies in vivo mitochondrial dysfunction in muscle of male type 2 diabetic patients. Diabetes 2008;57:2943-9. 
83. Schrauwen-Hinderling VB, Kooi ME, Hesselink MK, et al. Impaired in vivo mitochondrial function but similar intramyocellular lipid content in patients with type 2 diabetes mellitus and BMI-matched control subjects. Diabetologia 2007;50:113-20.

84. Lowell BB, Shulman GI. Mitochondrial dysfunction and type 2 diabetes. Science 2005;307:384-7.

85. Chachay VS, Macdonald GA, Martin JH, et al. Resveratrol does not benefit patients with nonalcoholic fatty liver disease. Clinical gastroenterology and hepatology : the official clinical practice journal of the American Gastroenterological Association 2014;12:2092-103 e1-6.

86. Phielix E, Jelenik T, Nowotny P, Szendroedi J, Roden M. Reduction of non-esterified fatty acids improves insulin sensitivity and lowers oxidative stress, but fails to restore oxidative capacity in type 2 diabetes: a randomised clinical trial. Diabetologia 2014;57:572-81.

87. Liu K, Zhou R, Wang B, Mi MT. Effect of resveratrol on glucose control and insulin sensitivity: a meta-analysis of 11 randomized controlled trials. The American journal of clinical nutrition 2014;99:1510-9.

88. Liu K, Zhou R, Wang B, et al. Effect of green tea on glucose control and insulin sensitivity: a meta-analysis of 17 randomized controlled trials. The American journal of clinical nutrition 2013;98:340-8.

89. Hoeks J, Schrauwen P. Muscle mitochondria and insulin resistance: a human perspective. Trends Endocrinol Metab 2012;23:444-50.

90. DeFronzo RA, Tripathy D. Skeletal muscle insulin resistance is the primary defect in type 2 diabetes. Diabetes care 2009;32 Suppl 2:S157-63.

91. Flatt JP. The difference in the storage capacities for carbohydrate and for fat, and its implications in the regulation of body weight. Ann N Y Acad Sci 1987;499:104-23.

92. Lopez-Soldado I, Zafra D, Duran J, Adrover A, Calbo J, Guinovart JJ. Liver glycogen reduces food intake and attenuates obesity in a high-fat diet-fed mouse model. Diabetes 2015;64:796-807.

93. Hoehn KL, Turner N, Swarbrick MM, et al. Acute or chronic upregulation of mitochondrial fatty acid oxidation has no net effect on whole-body energy expenditure or adiposity. Cell Metab 2010;11:70-6.

94. Munsters MJ, Saris WH. Body weight regulation and obesity: dietary strategies to improve the metabolic profile. Annu Rev Food Sci Technol 2014;5:39-51.

95. Fox CS, Massaro JM, Hoffmann U, et al. Abdominal visceral and subcutaneous adipose tissue compartments: association with metabolic risk factors in the Framingham Heart Study. Circulation 2007;116:39-48.

96. Mundi MS, Karpyak MV, Koutsari C, Votruba SB, O'Brien PC, Jensen MD. Body fat distribution, adipocyte size, and metabolic characteristics of nondiabetic adults. J Clin Endocrinol Metab 2010;95:67-73.

97. Marinou K, Hodson L, Vasan SK, et al. Structural and functional properties of deep abdominal subcutaneous adipose tissue explain its association with insulin resistance and cardiovascular risk in men. Diabetes care 2014;37:821-9.

98. Jensen MD. Is visceral fat involved in the pathogenesis of the metabolic syndrome? Human model. Obesity 2006;14 Suppl 1:20S-4S.

99. Bose M, Lambert JD, Ju J, Reuhl KR, Shapses SA, Yang CS. The major green tea polyphenol, (-)-epigallocatechin-3-gallate, inhibits obesity, metabolic syndrome, and fatty liver disease in high-fat-fed mice. The Journal of nutrition 2008;138:1677-83. 
100. Jimenez-Gomez Y, Mattison JA, Pearson KJ, et al. Resveratrol improves adipose insulin signaling and reduces the inflammatory response in adipose tissue of rhesus monkeys on high-fat, high-sugar diet. Cell Metab 2013;18:533-45.

101. Friedrich M, Petzke KJ, Raederstorff D, Wolfram S, Klaus S. Acute effects of epigallocatechin gallate from green tea on oxidation and tissue incorporation of dietary lipids in mice fed a high-fat diet. International journal of obesity 2012;36:73543.

102. Poulsen MM, Larsen JO, Hamilton-Dutoit S, et al. Resveratrol up-regulates hepatic uncoupling protein 2 and prevents development of nonalcoholic fatty liver disease in rats fed a high-fat diet. Nutr Res 2012;32:701-8.

103. Jensen MD. Gender differences in regional fatty acid metabolism before and after meal ingestion. The Journal of clinical investigation 1995;96:2297-303.

104. Corpeleijn E, Hessvik NP, Bakke SS, et al. Oxidation of intramyocellular lipids is dependent on mitochondrial function and the availability of extracellular fatty acids. American journal of physiology Endocrinology and metabolism 2010;299:E14-22.

105. Moors CC, van der Zijl NJ, Diamant M, Blaak EE, Goossens GH. Impaired insulin sensitivity is accompanied by disturbances in skeletal muscle fatty acid handling in subjects with impaired glucose metabolism. Int J Obes (Lond) 2012;36:709-17.

106. Khan MT, Nieuwdorp M, Backhed F. Microbial modulation of insulin sensitivity. Cell metabolism 2014;20:753-60.

107. Tilg H, Moschen AR. Microbiota and diabetes: an evolving relationship. Gut 2014;63:1513-21.

108. Nieuwdorp M, Gilijamse PW, Pai N, Kaplan LM. Role of the microbiome in energy regulation and metabolism. Gastroenterology 2014;146:1525-33.

109. Sharon G, Garg N, Debelius J, Knight R, Dorrestein PC, Mazmanian SK. Specialized metabolites from the microbiome in health and disease. Cell metabolism 2014;20:71930 .

110. Belkaid Y, Hand TW. Role of the microbiota in immunity and inflammation. Cell 2014;157:121-41.

111. Garrett WS. Cancer and the microbiota. Science 2015;348:80-6.

112. Ridaura V, Belkaid Y. Gut microbiota: the link to your second brain. Cell 2015;161:193-4.

113. Canfora EE, Jocken JW, Blaak EE. Short-chain fatty acids in control of body weight and insulin sensitivity. Nature reviews Endocrinology 2015.

114. Sjoberg KA, Rattigan S, Jeppesen JF, Lundsgaard AM, Holst JJ, Kiens B. Differential effects of glucagon-like peptide-1 on microvascular recruitment and glucose metabolism in short- and long-term insulin resistance. The Journal of physiology 2015;593:2185-98.

115. Vrieze A, Van Nood E, Holleman F, et al. Transfer of intestinal microbiota from lean donors increases insulin sensitivity in individuals with metabolic syndrome. Gastroenterology 2012;143:913-6 e7.

116. Vrieze A, Out C, Fuentes S, et al. Impact of oral vancomycin on gut microbiota, bile acid metabolism, and insulin sensitivity. Journal of hepatology 2014;60:824-31.

117. Bolnick DI, Snowberg LK, Hirsch PE, et al. Individual diet has sex-dependent effects on vertebrate gut microbiota. Nature communications 2014;5:4500.

118. Blaak E. Sex differences in the control of glucose homeostasis. Current opinion in clinical nutrition and metabolic care 2008;11:500-4. 
119. Wenz M, Berend JZ, Lynch NA, Chappell S, Hackney AC. Substrate oxidation at rest and during exercise: effects of menstrual cycle phase and diet composition. Journal of physiology and pharmacology : an official journal of the Polish Physiological Society 1997;48:851-60.

120. Dominianni C, Sinha R, Goedert JJ, et al. Sex, body mass index, and dietary fiber intake influence the human gut microbiome. PloS one 2015;10:e0124599.

121. Flores R, Shi J, Fuhrman B, et al. Fecal microbial determinants of fecal and systemic estrogens and estrogen metabolites: a cross-sectional study. Journal of translational medicine 2012;10:253.

122. Markle JG, Frank DN, Mortin-Toth S, et al. Sex differences in the gut microbiome drive hormone-dependent regulation of autoimmunity. Science 2013;339:1084-8.

123. Society D-GfRSa. FINAL REPORT OF THE STUDY ON THE INTEGRATION OF SCIENCE AND SOCIETY ISSUES IN THE SIXTH FRAMEWORK PROGRAMME: European Commission; 2007.

124. Dean S, Braakhuis A, Paton C. The effects of EGCG on fat oxidation and endurance performance in male cyclists. Int J Sport Nutr Exerc Metab 2009;19:624-44.

125. Richards JC, Lonac MC, Johnson TK, Schweder MM, Bell C. Epigallocatechin-3gallate increases maximal oxygen uptake in adult humans. Med Sci Sports Exerc 2010;42:739-44.

126. Phielix E, Meex R, Moonen-Kornips E, Hesselink MK, Schrauwen P. Exercise training increases mitochondrial content and ex vivo mitochondrial function similarly in patients with type 2 diabetes and in control individuals. Diabetologia 2010;53:1714-21.

127. Porter C, Reidy PT, Bhattarai N, Sidossis LS, Rasmussen BB. Resistance Exercise Training Alters Mitochondrial Function in Human Skeletal Muscle. Med Sci Sports Exerc 2015;47:1922-31.

128. Petersen AC, McKenna MJ, Medved I, et al. Infusion with the antioxidant Nacetylcysteine attenuates early adaptive responses to exercise in human skeletal muscle. Acta physiologica 2012;204:382-92.

129. Gliemann L, Schmidt JF, Olesen J, et al. Resveratrol blunts the positive effects of exercise training on cardiovascular health in aged men. The Journal of physiology 2013;591:5047-59.

130. Ristow M, Zarse K, Oberbach A, et al. Antioxidants prevent health-promoting effects of physical exercise in humans. Proceedings of the National Academy of Sciences of the United States of America 2009;106:8665-70.

131. Gomez-Cabrera MC, Domenech E, Romagnoli M, et al. Oral administration of vitamin $\mathrm{C}$ decreases muscle mitochondrial biogenesis and hampers training-induced adaptations in endurance performance. The American journal of clinical nutrition 2008;87:142-9.

132. Strobel NA, Peake JM, Matsumoto A, Marsh SA, Coombes JS, Wadley GD. Antioxidant supplementation reduces skeletal muscle mitochondrial biogenesis. Med Sci Sports Exerc 2011;43:1017-24.

133. Westerterp-Plantenga MS, Lejeune MP, Kovacs EM. Body weight loss and weight maintenance in relation to habitual caffeine intake and green tea supplementation. Obesity research 2005;13:1195-204.

134. Hokayem M, Blond E, Vidal H, et al. Grape polyphenols prevent fructose-induced oxidative stress and insulin resistance in first-degree relatives of type 2 diabetic patients. Diabetes care 2013;36:1454-61. 
135. Seidell JC, Muller DC, Sorkin JD, Andres R. Fasting respiratory exchange ratio and resting metabolic rate as predictors of weight gain: the Baltimore Longitudinal Study on Aging. Int J Obes Relat Metab Disord 1992;16:667-74.

136. Franzosa EA, Hsu T, Sirota-Madi A, et al. Sequencing and beyond: integrating molecular 'omics' for microbial community profiling. Nat Rev Microbiol 2015;13:360-72.

137. Guo L, Milburn MV, Ryals JA, et al. Plasma metabolomic profiles enhance precision medicine for volunteers of normal health. Proceedings of the National Academy of Sciences of the United States of America 2015.

138. Cote CD, Rasmussen BA, Duca FA, et al. Resveratrol activates duodenal Sirt1 to reverse insulin resistance in rats through a neuronal network. Nature medicine 2015;21:498-505. 



\section{APPENDICES}

Summary 

The obese insulin resistant state is characterized by an impaired regulation of substrate metabolism, which seems to be associated with adipose tissue dysfunction, an impaired skeletal muscle fat oxidation, ectopic lipid accumulation and systemic low-grade inflammation (Chapter 1). These disturbances contribute to the increased risk of developing type 2 diabetes mellitus, cardiovascular diseases, and certain types of cancers and mental diseases.

Since about $30 \%$ of the subjects that participate in lifestyle interventions are not successful in achieving the intervention goals, additional strategies are required to reduce the growing prevalence of obesity and its associated cardiometabolic complications. There is increasing evidence that polyphenols such as epigallocatechin-3-gallate, resveratrol and soy isoflavones, which are well known for their anti-oxidant action, may also exert beneficial effects on energy and substrate metabolism.

\section{Short-term polyphenol supplementation}

In the first randomized, double-blind placebo-controlled cross-over study (Chapter 2), we showed that $282 \mathrm{mg} / \mathrm{d}$ epigallocatechin-3-gallate (EGCG) supplementation for 3 days had no effect on fat oxidation or energy expenditure in 24 overweight men and women $(9 \mathrm{M} / 15 \mathrm{~F})$. Despite no effects on fat oxidation, EGCG reduced fasting and postprandial skeletal muscle lactate concentrations despite comparable muscle blood flow as compared to placebo, which may indicate a switch towards a more oxidative phenotype of skeletal muscle.

We postulated the hypothesis that a combination of polyphenols with distinct mechanisms of action might induce additive and/or synergistic effects on fat oxidation, thereby reducing ectopic lipid accumulation. To investigate this hypothesis, in Chapter $\mathbf{3}$, the effects of the combinations of EGCG and resveratrol (E+R, 282 and $200 \mathrm{mg} / \mathrm{d})$ and $\mathrm{E}+\mathrm{R}$ plus soy isoflavones $(\mathrm{E}+\mathrm{R}+\mathrm{S}, 282,200$ and $80 \mathrm{mg} / \mathrm{d})$ on fasting and postprandial fat oxidation were examined in 18 overweight subjects $(9 \mathrm{M} / 9 \mathrm{~F})$ in a randomized, double-blind placebocontrolled cross-over study. On day 3 of supplementation, energy expenditure, substrate oxidation and plasma metabolite concentrations were measured before and after consumption of a high-fat mixed meal (2.6 MJ, 61 energy\% fat). We demonstrated that $\mathrm{E}+\mathrm{R}$ increased resting and postprandial energy expenditure. Interestingly, metabolic flexibility, defined as the shift from fat to carbohydrate oxidation after consumption of a 
Appendices

high-fat mixed meal, was improved by $\mathrm{E}+\mathrm{R}$ in men but not in women. Addition of soy isoflavones $(\mathrm{E}+\mathrm{R}+\mathrm{S})$ abrogated the latter effects, but increased fasting free fatty acid concentrations, indicating a stimulation of lipolysis by soy isoflavones.

\section{Long-term polyphenol supplementation}

Next, we questioned whether the short-term effects of the most promising combination of polyphenols, E+R, would translate into long-term benefits on tissue-specific insulin sensitivity (Chapter 4). We performed a randomized, placebo-controlled double-blind study to assess the effects of 12 weeks combined E+R supplementation on peripheral, hepatic and adipose tissue insulin sensitivity, skeletal muscle oxidative capacity, fat oxidation, lipolysis and circulating metabolites in 42 overweight and obese, non-diabetic subjects $(21 \mathrm{M} / 21)$.

\section{Fat oxidation, mitochondrial capacity and insulin sensitivity}

$\mathrm{E}+\mathrm{R}$ supplementation increased skeletal muscle oxidative capacity, as evidenced by ex vivo respiration measurements using isolated permeabilized skeletal muscle fibers and increased in vivo whole-body fat oxidation during fasting and postprandial conditions. These findings were supported by an increased expression of genes and proteins involved in mitochondrial respiration. Energy expenditure, however, was not significantly altered by 12 weeks E+R supplementation. Furthermore, E+R supplementation prevented an increase in plasma triacylglycerol concentration during fasting conditions and after intake of a high-fat mixed meal as compared to the placebo group. Moreover, visceral adipose tissue mass tended to be reduced after $\mathrm{E}+\mathrm{R}$ supplementation versus placebo. Nevertheless, these beneficial metabolic effects did not translate into improved peripheral, hepatic or adipose tissue insulin sensitivity assessed during a hyperinsulinemic-euglycemic clamp with $\left[6,6-{ }^{2} \mathrm{H}_{2}\right]-$ glucose infusion.

\section{Adipose tissue morphology and gene expression}

Adipose tissue biopsies were collected to determine adipose cell morphology and gene expression profiles, as described in chapter 5. Interestingly, microarray analyses of adipose tissue revealed that gene expression related to adipose tissue cell turnover was reduced by $\mathrm{E}+\mathrm{R}$ supplementation compared to placebo. No significant effects of $\mathrm{E}+\mathrm{R}$ supplementation 
were found on adipocyte morphology and local adipose tissue lipolysis that was assessed in vivo before and after a high-fat mixed meal and during the hyperinsulinemic-euglycemic clamp. The long-term effect of the E+R-induced downregulation of pathways related to adipose tissue cell turnover requires further investigation, since low adipocyte turnover has been associated with adipose tissue hypertrophy, dyslipidemia and insulin resistance. On the other hand, gene expression of pathways related to oxidative stress, inflammation and the immune response were downregulated, which may be indicative of reduced adipose tissue inflammation.

\section{Gut microbiota, gender and insulin sensitivity}

Accumulating evidence suggests that the gut microbiota may contribute to impairments in metabolic health. Therefore, we determined the microbiota composition in feces samples that were collected from subjects participating in the long-term E+R supplementation study. First, we found significant differences in the microbiota composition between men and women, with a higher abundance of Bacteroidetes and $\gamma$-Proteobacteria in men than women (Chapter 6 and 7).

\section{Microbiota composition and insulin sensitivity}

Next, the relationship between gut microbiota composition and insulin sensitivity was assessed. We demonstrated a strong inverse correlation between peripheral insulin sensitivity and the ratio of the two dominant phyla in the gut microbiota, Bacteroidetes and Firmicutes in men but not in women. Strikingly, this relation in men remained significant after correction for food intake (saturated fat and dietary fiber), body composition (\% body fat), fat oxidation and markers of inflammation.

\section{Microbiota composition and polyphenol-induced metabolic effects}

Finally, we investigated whether E+R-induced alterations in the gut microbiota composition may have contributed to the improvement in skeletal muscle oxidative capacity after $\mathrm{E}+\mathrm{R}$ supplementation. E+R-supplementation reduced the abundance of the Bacteroidetes-phyla and tended to reduce Faecalibacteria prausnitzii in men but not in women. The abundance of the phylum Bacteroidetes at baseline was a significant predictor for the $\mathrm{E}+\mathrm{R}$-induced increase in postprandial fat oxidation in men (Chapter 7), suggesting 
that the gut microbiota composition may at least partly determine the effects of $E+R$ supplementation on fat oxidation.

\section{Conclusion}

The studies described in this thesis have shown that short-term supplementation of epigallocatechin-3-gallate and resveratrol $(E+R)$ increased fasting and postprandial energy expenditure. Long-term supplementation (12 weeks) of $\mathrm{E}+\mathrm{R}$ in overweight and obese men and women increased skeletal muscle oxidative capacity as compared to placebo, but did not translate into significant effects on tissue-specific insulin sensitivity. Furthermore, the intestinal microbiota composition is different between men and women, and is related to peripheral insulin sensitivity in men, but not in women. Interestingly, the abundance of the phylum Bacteroidetes appears to modulate the effect of $E+R$ supplementation on postprandial fat oxidation. Although 12 weeks E+R supplementation did not significantly alter peripheral, hepatic and adipose tissue insulin sensitivity and body composition, the increase in skeletal muscle oxidative capacity and whole-body fat oxidation may prevent the progression of insulin resistance and contribute to a reduced risk of developing obesityrelated cardiovascular disease and type 2 diabetes mellitus in the long term. 
Samenvatting 

Obese personen die insulineresistent zijn worden vaak gekenmerkt door een verstoorde regulatie van het substraatgebruik, een minder goede werking van het vetweefsel, een verlaagde vetverbranding in de spieren, vetopslag in organen zoals de spieren en de lever en een verhoogde hoeveelheid ontstekingsfactoren in het bloed (Hoofdstuk 1). Deze verstoringen kunnen bijdragen aan een verhoogd risico op het ontwikkelen van type 2 diabetes mellitus, hart- en vaatziekten en verschillende vormen van kanker en psychische aandoeningen.

Aangezien $30 \%$ van de mensen die proberen hun leefstijl te veranderen de gestelde doelen niet bereiken zijn alternatieve strategieën essentieel. Wetenschappelijke studies hebben aangetoond dat polyfenolen, zoals epigallocatechin-3-gallate, resveratrol en soja isoflavonen, naast hun bekende werking als antioxidant ook positieve effecten op de energie- en substraathuishouding kunnen hebben.

\section{Korte-termijn polyphenol supplementatie}

In de eerste gerandomiseerde, dubbel-blinde, placebo-gecontroleerde cross-over studie (Hoofdstuk 2) hebben wij laten zien dat supplementatie van $282 \mathrm{mg} / \mathrm{d}$ epigallocatechin-3gallate (EGCG) gedurende 3 dagen geen effect op de vetverbranding of het energieverbruik had in een groep van 24 mannen en vrouwen ( 9 mannen,15 vrouwen) met overgewicht. Echter, EGCG verlaagde wel de lactaatconcentratie in de spieren voor en na inname van een maaltijd vergeleken met placebo, wat kan duiden op een verhoogde oxidatieve stofwisseling.

Onze hypothese was dat combinaties van polyfenolen met verschillende werkingsmechanisme aanvullende en/of synergistische effecten op de vetverbranding zouden hebben, en daardoor ectopische vetstapeling zouden verlagen. Om deze hypothese te onderzoeken hebben wij het effect van combinaties van EGCG en resveratrol (E+R, 282 en $200 \mathrm{mg} / \mathrm{d})$ en $\mathrm{E}+\mathrm{R}$ met daarnaast soja isoflavonen (E+R+S, 282, 200 en $80 \mathrm{mg} / \mathrm{d})$ op de nuchtere en postprandiale vetverbranding bij 18 proefpersonen met overgewicht ( 9 mannen, 9 vrouwen) onderzocht in een gerandomiseerde, dubbel-blinde, placebo-gecontroleerde cross-over studie (Hoofdstuk 3). Op dag 3 van de supplementatie werden het energiegebruik, vetverbranding en plasma metabolieten voor en na inname van een maaltijd met een hoge hoeveelheid vet (2.6 MJ, 61 energie\% vet) gemeten. De combinatie van E+R verhoogde het nuchtere en postprandiale energiegebruik ten opzichte van placebo. De 
flexibiliteit van het metabolisme, gedefinieerd als het omschakelen van vet- naar koolhydraatverbranding na inname van een maaltijd, verbeterde door $\mathrm{E}+\mathrm{R}$ supplementatie bij mannen, terwijl dit bij vrouwen niet het geval was. Het toevoegen van soja isoflavonen aan deze combinatie $(\mathrm{E}+\mathrm{R}+\mathrm{S})$ deed dit effect verdwijnen. Echter, $\mathrm{E}+\mathrm{R}+\mathrm{S}$ resulteerde in hogere concentraties van vrije vetzuren en glycerol tijdens gevaste omstandigheden, wat duidt op een hogere vetafbraak (lipolyse).

\section{Lange-termijn polyphenol supplementatie}

Gebaseerd op bovenstaande bevindingen hebben wij onderzocht of het positieve korte termijn effect van de meest belovende combinatie, $\mathrm{E}+\mathrm{R}$, zich vertaalde in lange-termijn verbeteringen van de insulinegevoeligheid. Hiervoor hebben wij een gerandomiseerd, placebo-gecontroleerd, dubbel-blind onderzoek uitgevoerd, waarin de effecten van E+R supplementatie gedurende 12 weken op perifere-, hepatische- en vetweefselinsulinegevoeligheid, de oxidatieve capaciteit van de spier, de vetverbranding, de lipolyse en plasma metabolieten werden bekeken bij 42 mannen en vrouwen (21 mannen, 21 vrouwen) met overgewicht.

\section{Vetverbranding, mitochondriële capaciteit en insulinegevoeligheid}

$\mathrm{E}+\mathrm{R}$ supplementatie verbeterde de oxidatieve capaciteit van de spier en verhoogde de vetverbranding tijdens gevaste (nuchtere) omstandigheden en na inname van een hoog-vet maaltijd (2.6 MJ, 61 energy\% vet) in vergelijking met de placebo-groep. Dit ging gepaard met een verhoogde expressie van genen en eiwitten die een belangrijk rol spelen in het oxidatieve metabolisme in de mitochondriën en de vetverbranding. Terwijl in de placebogroep de concentratie triacylglycerol na inname van de hoog-vet maaltijd hoger waren na 12 weken supplementatie, was deze toename niet aanwezig in de $\mathrm{E}+\mathrm{R}$ groep. De hoeveelheid visceraal vet nam af na $\mathrm{E}+\mathrm{R}$ supplementatie versus placebo. Deze positieve metabole effecten hebben niet geleid tot veranderingen in de perifere-, hepatische- of vetweefsel-insulinegevoeligheid.

\section{Vetcelgrootte en genexpressie in het vetweefsel}

Biopten van het onderhuids buikvet werden voor en na de 12 weken supplementatie afgenomen om de vetcelgrootte en genexpressie te bepalen (Hoofdstuk 5). Genen, die een 
rol spelen bij de adipogenese kwamen na $\mathrm{E}+\mathrm{R}$ supplementatie minder sterk tot expressie in vergelijking met de placebo groep. De morfologie en de vetafbraak (in vivo lipolyse) van het vetweefsel waren na $\mathrm{E}+\mathrm{R}$ supplementatie onveranderd. De langere-termijn effect van de E+R-geïnduceerde verlaging van de expressie van genen betrokken bij de adipogenese dient nader onderzocht te worden, omdat dit in eerder onderzoek in verband is gebracht met vergroting van vetcellen (hypertrofie), verstoringen in het lipidenprofiel in het bloed (dyslipidemie) en insulineresistentie. Een andere interessant bevinding is dat $\mathrm{E}+\mathrm{R}$ de expressie van genen die betrokken zijn bij oxidatieve stress en het immuun systeem verlaagde, hetgeen kan duiden op minder ontsteking van het vetweefsel.

\section{Darmflora, geslacht en insulinegevoeligheid}

Er komt steeds meer bewijs dat de darmbacterieën (microbiota) een belangrijke rol spelen bij verstoringen in de stofwisseling en de algehele gezondheid. Daarom hebben wij de microbiota in de ontlasting van de deelnemers aan de lange-termijn $\mathrm{E}+\mathrm{R}$ supplementatie studie bepaald. Ten eerste vonden wij significante hogere hoeveelheden van het fylum (stam) Bacteroidetes en van de klasse $\gamma$-Proteobacteriën in mannen ten opzichte van vrouwen (Hoofdstukken 6 en 7).

\section{Samenstelling van de microbiota en insulinegevoeligheid}

Vervolgens werd de relatie tussen de microbiota en de insulinegevoeligheid bekeken. Er was een negatieve relatie tussen de perifere insulinegevoeligheid en de verhouding tussen de twee meest voorkomende fyla (stammen) in de darm - Bacteroidetes en Firmicutes - in mannen, maar niet in vrouwen (Hoofdstuk 6). Opmerkelijk was dat deze associatie niet beïnvloedt werd door voedingsinname (verzadigd vet en voedingsvezels), lichaamssamenstelling $(\%$ lichaamsvet $)$ vetverbranding en systemische ontstekingsfactoren, zo bleek uit een regressie-analyse.

\section{Microbiota en polyfenol-gë̈nduceerde metabole effecten}

Tenslotte hebben wij onderzocht of de veranderingen in de microbiota samenstelling na 12 weken $E+R$ supplementatie aan de verbeteringen van oxidatieve capaciteit van de spier hebben bijgedragen. E+R supplementatie reduceerde de hoeveelheid van het Bacteroidetesfylum bij mannen, maar niet bij vrouwen. Verder liet $\mathrm{E}+\mathrm{R}$ supplementatie een tendens tot 
reductie van het fylum Faecalibacteria prausnitzii zien. Opvallend was dat de hoeveelheid van het fylum Bacteroidetes voor de start van $\mathrm{E}+\mathrm{R}$ supplementatie significant gerelateerd was aan de toename van de postprandiale vetverbranding na $E+R$ supplementatie in vergelijking met placebo-supplementatie (Hoofdstuk 7). Dit suggereert dat de microbiota samenstelling bij kan dragen aan het effect van $\mathrm{E}+\mathrm{R}$ supplementatie op de vetverbranding.

\section{Conclusie}

De onderzoeken die beschreven zijn in dit proefschrift hebben aangetoond dat korte-termijn supplementatie met epigallocatechin-3-gallate en resveratrol $(\mathrm{E}+\mathrm{R})$ het gevaste (nuchtere) en postprandiale energiegebruik significant verhoogt. Lange-termijn supplementatie (12 weken) van $\mathrm{E}+\mathrm{R}$ verbeterde de oxidatieve capaciteit van de spier en verhoogde de vetverbranding tijdens gevaste (nuchtere) omstandigheden en na inname van een hoog-vet maaltijd in vergelijking met de placebo-groep in mannen en vrouwen, maar had geen effect op de insulinegevoeligheid.

Verder is er een duidelijk verschil in de samenstelling van de darmflora (microbiota) tussen mannen en vrouwen. Deze samenstelling was gerelateerd aan de perifere insulinegevoeligheid in mannen, maar niet in vrouwen. Bovendien bleek dat de microbiota samenstelling bij kan dragen aan het effect van $E+R$ supplementatie op de vetverbranding. Hoewel E+R supplementatie gedurende 12 weken geen significant effect had op de insulinegevoeligheid en de lichaamssamenstelling, zouden de verhoogde mitochondriële capaciteit van de spier en de toegenomen vetverbranding het ontstaan van insulineresistentie kunnen voorkomen. Toekomstig onderzoek zal uit moeten wijzen of $\mathrm{E}+\mathrm{R}$ supplementatie gedurende een langere periode dan 12 weken, of supplementatie bij mensen met een duidelijke verstoring in het substraat- en/of energiegebruik en de insulinegevoeligheid, het risico op het ontwikkelen van overgewicht en gerelateerde aandoeningen zoals type 2 diabetes mellitus en hart- en vaatziektes kan verlagen. 


\section{Zusammenfassung}



Bei übergewichtigen, insulinresistenten Menschen ist eine gestörte Regulierung des Fett und Energie-Metabolismus' festzustellen. Charakteristika dieses Zustandes sind unter anderem eine verminderte Funktion des Fettgewebes, eine verringerte Fettverbrennung, Fettablagerungen in Geweben wie dem Muskel und der Leber und eine systemische Entzündung (Kapitel 1). Diese Verstörungen könnten zu einem erhöhten Risiko für die Entwicklung von Typ 2 Diabetes Mellitus, Herz-Kreislauf-Erkrankungen, aber auch verschiedene Arten von Krebs oder psychische Krankheiten beitragen.

Weil etwa $30 \%$ der Probanden die Teilnahme an Lebensstil-Interventionen die gesteckten Ziele nicht erreichen, sind alternative Maßnahmen daher zwingend notwendig um die stetig steigende Prävalenz von Übergewicht und den damit verbundenen Krankheiten zu reduzieren. Wissenschaftliche Studien haben gezeigt, dass Polyfenole wie Epigallocatechin-3-gallat, Resveratrol und Soja Isoflavone über die bekannte antioxidative Wirkung hinaus auch positive Effekte auf Stoffwechselabläufe des Energie- und Substrathaushaltes ausüben können.

\section{Kurzzeit-Studien mit Polyfenol-Supplementierung}

In der ersten randomisierten, doppel-blinden, Placebo-kontrollierten crossover Studie (Kapitel 2), zeigten wir, dass täglicher Konsum von $282 \mathrm{mg}$ Epigallocatechin-3-gallat (EGCG) über eine Dauer von 3 Tagen keinen Effekt auf die Fettverbrennung oder den Energieverbrauch von 24 übergewichtigen Männern und Frauen (9M, 15F) hatte. Dennoch hat Epigallocatechin-3-gallate, verglichen mit dem Placebo, die Konzentration von Laktat im Muskel trotz unveränderter Durchblutung des Muskels sowohl vor als auch nach einer Mahlzeit verringert, was auf einen oxidativeren Stoffwechsel deutet.

Wir haben die Hypothese aufgestellt, dass eine Kombination von Polyfenolen mit unterschiedlichen Wirkungsmechanismen additive und/oder synergistische Effekte auf die Fettverbrennung haben könnte und dadurch ektopische Fettablagerungen vermindern könnte. Um diese Hypothese zu untersuchen, wurden Kombinationen von Epigallocatechin-3-gallat und Resveratrol (E+R, $282 \mathrm{mg} / \mathrm{d}$ und $200 \mathrm{mg} / \mathrm{d})$ oder $\mathrm{E}+\mathrm{R}$ und Soja Isoflavonen $(\mathrm{E}+\mathrm{R}+\mathrm{S}, 282,200$ und $80 \mathrm{mg} / \mathrm{d})$ auf ihren Effekt auf die Fettverbrennung in 18 übergewichtigen Probanden (9M, 9F) in einer randomisierten, doppel-blinden Placebo-kontrollierten Studie untersucht (Kapitel 3). Am 3. Tag der Supplementierung wurden Energieverbrauch, Fettverbrennung und das Plasma-Metabolit-Profil vor und nach 
Appendices

einer Mahlzeit mit hohem Fettgehalt (2.6 MJ, 61 Energie\% Fett) gemessen. Die Kombination E+R hat den Energieverbrauch vor und nach der Mahlzeit signifikant erhöht. Des Weiteren hat sich die Flexibilität des Stoffwechsels, also das Umschalten von Fett- zu Kohlenhydratverbrennung nach einer Mahlzeit, bei Männern durch E+R-Supplementierung verbessert, aber nicht bei Frauen. Die zusätzliche Gabe von Soja Isoflavonen $(E+R+S)$ hat diese Effekte aufgehoben und Konzentrationen freier Fettsäuren und Glyzerol im NüchternZustand erhöht, welches ein Indiz für einen erhöhten Fettabbau im Fettgewebe ist.

\section{Langzeit-Studie mit Polyfenol-Supplementierung}

Basierend auf diesen Ergebnissen haben wir als Nächstes untersucht, ob die nach 3 Tagen auftretenden Effekte der vielversprechendsten Kombination, E+R, sich auch in LangzeitVerbesserungen der Insulinsensitivität widerspiegeln. Dafür haben wir eine randomisierte, Placebo-kontrollierte, doppel-blinde Interventionsstudie ausgeführt, in der wir die Effekte einer 12-wöchigen E+R-Supplementierung auf die gewebsspezifische Insulinsensitivität, die oxidative Kapazität des Muskels, die Fettverbrennung, die Lipolyse und auf das Blutbild von 42 übergewichtigen Männer und Frauen (21M, 21F) untersucht haben.

\section{Fettverbrennung, mitochondrielle Kapazität und Insulinsensitivität}

E+R-Supplementierung verbesserte die oxidative Kapazität des Muskels und erhöhte die Fettverbrennung in vivo vor und nach der Mahlzeit. Diese Ergebnisse wurden durch eine erhöhte Expression von Genen und Proteinen, die im oxidativen Stoffwechsel der Mitochondrien und bei der Fettverbrennung eine Rolle spielen, bestätigt. Der Energieverbrauch wurde durch $\mathrm{E}+\mathrm{R}$ Supplementierung nicht beeinflusst. $\mathrm{E}+\mathrm{R}$ verhinderte den Anstieg der Triazylglyzerol-Konzentrationen vor und nach einer Mahlzeit, reich an Fett, den wir in der Placebo-Gruppe festgestellt haben. Des Weiteren hat sich die viszerale Fettmasse nach E+R- im Vergleich $\mathrm{zu}$ Placebo-Supplementierung verkleinert. Nichtsdestotrotz, haben diese positiven metabolen Effekte nicht zu einer Veränderung der peripheren, hepatischen oder Fettgewebs-Insulinsensitivität geführt.

\section{Fettzell-Größe und Genexpression im Fettgewebe}

In Biopsien aus dem Fettgewebe unter dem Bauchfett haben wir die Fettzell-Größe und das Genexpressionsprofil vor und nach der Intervention analysiert (Kapitel 5). In den 
Microarray-Analysen zeigte sich, dass Gene der Fettzellerneuerung nach E+RSupplementierung weniger stark exprimiert wurden verglichen mit der Placebo-Gruppe. Die Morphologie und Fettabbau im Fettgewebe (in vivo Lipolyse) blieben unverändert. Die E+R-induzierte Herunterregulierung der Fettzellerneuerung bedarf weiterer Untersuchungen, da dies in anderen Studien mit einer Vergrößerung der Fettzellen, einem ungünstigeren Lipid-Profil im Blut (Dyslipidemie) und Insulinresistenz in Verbindung gebracht worden ist. Interessanterweise, hat $\mathrm{E}+\mathrm{R}$ in unserer Studie die Expression von Genen, die bei oxidativem Stress, Entzündung und im Immunsystem eine Rolle spielen, verringert. Dies spricht für einen verminderte Entzündung des Fettgewebes.

\section{Darmbakterien (Mikrobiota), Geschlecht und Insulinsensitivität}

Zunehmende wissenschaftliche Erkenntnisse deuten darauf hin, dass die Mikrobiota im Darm den Stoffwechsel des Menschen beeinflussen kann. Darum haben wir auch von den Probanden der Langzeit-Studie die Mikrobiota in Stuhlproben analysiert. Zuerst fanden wir signifikant größere Anzahlen des Stammes (Phylums) Bacteroidetes und der Klasse $\gamma$ Proteobacterien in Männern verglichen mit Frauen (Kapitel 6 und 7).

\section{Mikrobiota-Zusammensetzung und Insulinsensitivität}

Als Nächstes haben wir die Beziehung zwischen der Mikrobiota im Darm und der Insulinsensitivität untersucht. Wir haben bei Männern, aber nicht bei Frauen, eine starke negative Assoziation zwischen der peripheren Insulinsensitivität und dem Verhältnis der beiden dominanten Phyla im menschlichen Darm - Bacteroidetes und Firmicutes gefunden (Kapitel 6). Bemerkenswert war, dass diese Assoziation in einer Regressionsanalyse nicht durch Ernährung (gesättigte Fettsäuren und Ballaststoffe), Körperzusammensetzung (\% Körperfett), Fettverbrennung und systemische Entzündungsfaktoren verändert wurde.

\section{Mikrobiota und Polyfenol-induzierte metabole Effekte}

Zuletzt haben wir untersucht, ob Veränderungen der Mikrobiota des Darms zu den Verbesserungen der oxidativen Kapazität des Muskels durch E+R-Supplementierung beigetragen haben. Polyfenol-Supplementierung reduzierte bei Männern, nicht bei Frauen, die Anzahl des Bacteroidetes-Phylums und zeigte einen Trend zu einer reduzierten Anzahl 
von Faecalibacteria Prausnitzii. Des Weiteren konnten wir zeigen, dass die Anzahl des Bacteroidetes-Phylums vor Eingang in die Studie signifikant assoziiert war mit dem Anstieg der Fettverbrennung durch E+R-Supplementierung (Kapitel 7). Dies suggeriert, dass die Mikrobiota den Effekt von Polyfenol-Supplementierung moduliert.

\section{Schlussfolgerung}

Die Studien, die in dieser Arbeit beschrieben sind, zeigten, dass Epigallocatechin-3-gallat und Resveratrol Supplementierung den nüchternen und postprandialen Energieverbrauch nach 3 Tagen signifikant erhöhte. Lang-Zeit Supplementierung (12 Wochen) mit E+R hat die oxidativen Kapazität des Muskels und die Fettverbrennung in übergewichtigen Männern und Frauen stimuliert, aber nicht die gewebsspezifische Insulinsensitivität.

Die Mikrobiota im Darm unterscheidet sich deutlich zwischen Männern und Frauen. Bei Männern, aber nicht bei Frauen, ist diese mit der peripheren Insulinsensitivität assoziiert. Die Anzahl des Phylums Bacteroidetes scheint den Effekt von Polyfenolen auf die postprandiale Fettverbrennung zu modulieren.

Obwohl 12 Wochen E+R-Supplementierung die gewebsspezifische Insulinsensitivität und die Körperzusammensetzung nicht signifikant verändert hat, könnten die erhöhte mitochondrielle Kapazität und die stimulierte Fettverbrennung der Entwicklung von Insulinresistenz entgegenwirken. Über einen längeren Zeitraum oder bei Patienten, deren Stoffwechsel schon beeinträchtigt ist, könnte das Risiko für das Entwickeln von Übergewicht und assoziierten Krankheiten wie Typ 2 Diabetes Mellitus und HerzKreislauf-Beschwerden so verringert werden. 
Valorization 

Dutch universities are obliged by law to ensure that their research findings impact society. The following chapter is dedicated to the valorization of the findings in the present thesis, which is defined as 'process of creating value from knowledge, by making knowledge suitable and/or available for social (and/or economic) use and by making knowledge suitable for translation into competitive products, services, processes and new commercial activities'. In other words, this chapter covers (a) the social and economic relevance of the investigated problem, (b) the possible implementations for target groups and further research, and (c) possible applications with respect to industrial development and marketing of the combined polyphenol-approach, as investigated in this thesis, and to dietary intervention studies in general.

\section{Social and economic relevance}

The prevalence of obesity has reached an epidemic dimension and is continuously increasing all over the world. Overweight and obesity have been defined by the World Health Organization as 'abnormal or excessive fat accumulation that may impair health', indicating that obesity relates and predisposes to a variety of diseases such as type 2 diabetes mellitus, cardiovascular diseases, certain types of cancer and depression. Consequently, obesity reduces the quality of life and causes around 2.8 million deaths each year worldwide ${ }^{1}$.

The European Commission estimated that obesity costs represented $7 \%$ of its total health care spending in 2006, which equates to around $€ 81$ billion per year in $2012^{2}$. Another 10 $\%$ of healthcare expenditures were spent on type 2 diabetes mellitus, estimated by the London School of Economics ${ }^{3}$. Taking into account absenteeism, early retirement and social benefits, the costs of obesity- and diabetes-related health impairments in the European Union added up to around $€ 400$ billion in $2010^{4}$.

Approximately $30-40 \%$ of the European population is using dietary supplements, of which half are non-vitamins ${ }^{5}$. The retail value in 2009 was already $€ 4$ billion in Europe and increasing, creating 500.000 jobs. However, the scientific evidence for health benefits of such supplements is poor as compared to their marketing claims. This is indicated by the great inconsistency in scientific studies and the lack of approved health claims for polyphenolic supplements on energy and substrate metabolism by the European Food Safety Association. Thus, it remains to be investigated how effective this money is spent. 
Appendics

\section{Target groups}

The aim is to make all results described in this thesis available for the scientific community through publication in international peer-reviewed journals. Beyond academia and academic journals, newspaper articles have been published on our research, which has enabled a broader audience to take notice of our findings.

By performing randomized, clinical trials with human subjects, scientific evidence can be acquired on specific supplements and their effects in different groups of subjects. These studies are inevitable in order to organize, control and align the overwhelming amount of information on nutrition, diets and supplements that is presented by the media every day. Evaluation of such studies by independent institutions, non-profit organization or others (e.g. European Food Safety Authority, Netherlands Nutrition and Health Council) may help to generate a synergistic database. In that manner, dietary recommendations can be evidence-based and communicated to target groups. As an example for the necessity of the mentioned institutions, that communicate science to the media and the public, the beneficial effects of $\mathrm{E}+\mathrm{R}$ that we describe in this thesis might be taken. Our findings of 'increased fat oxidation after E+R supplementation as compared to placebo' might be misinterpreted by the media or cause false hope for consumers (e.g. the idea that it may lead to weight loss). However, neither energy expenditure nor body composition or food intake were changed after long-term E+R supplementation, as described in this thesis, to scientifically support such hopes. It is highly relevant that results are critically reviewed and communicated into the right context.

\section{Activities and products}

In the present thesis, it is described that polyphenol supplementation improved risk factors for the development of chronic metabolic diseases (e.g. oxidative capacity, fat oxidation, plasma lipids), which led us to conclude that polyphenol supplementation may prevent or delay the development of cardiometabolic diseases. Importantly, studies that assess the possible benefit of polyphenol supplementation over years need to confirm such claims. The diversity in the effects that we have demonstrated in the present thesis (e.g. genderspecific effects, microbiota-related effects or tissue-specific effects on gene and protein expression) indicates that $\mathrm{E}+\mathrm{R}$ may not be evenly effective in all consumers, or may not exclusively exert beneficial effects at all organs. 
The results of the present studies have provided additional insight in the potential of polyphenol supplementation to stimulate whole-body fat oxidation and skeletal muscle oxidative capacity. However, we have found that the average effect size is limited due to variation in effect between subjects. A valuable approach to increase the beneficial impact of polyphenols might be the identification of biomarkers that can predict the susceptibility to supplementation. Possible biomarkers may be identified in the human and microbial genotype, phenotype and metabolome. Moreover, metabolites of polyphenols may offer additional biomarkers due to the possibly extensive metabolism of polyphenols in the gastrointestinal system and the liver and their diverse effects.

With respect to the investigated supplements, it has been suggested that people with metabolic impairments or under metabolic challenges may benefit the most from polyphenol supplementation. For example, polyphenol-supplementation for 8 weeks had no effect on hepatic insulin sensitivity in humans, whereas it prevented fructose-induced hepatic insulin resistance, which was observed in the placebo-group after another week ${ }^{6}$. This preventive effect may be applied to conditions of metabolic impairment and/or in situations in which metabolic health deteriorates rapidly.

In the present thesis, we performed microbiota analysis in a dietary intervention study, designed to investigate effects on energy and substrate metabolism. Since we and others have shown that the microbiota may have a profound modulatory impact on dietary polyphenol interventions, it is highly important to consider the impact of alterations in the gut microbiota on energy and substrate metabolism in future dietary intervention studies.

The benefit of this combined approach is supported by the results of the present thesis and may generate broad applicability and perspective for the food supplement industry. The combined polyphenol-approach may translate into indefinite market opportunities by developing new indication-specific combinations of supplements, or treatment regimens in general.

In general terms, it might be considered to produce polyphenol-enriched foods (e.g. resveratrol-enriched rice has been developed ${ }^{7}$ ), rather than distributing encapsulated supplements. In this manner, aversions against taking pills can be circumvented. 
Appendics

\section{Innovation}

Although various multi-ingredient supplements have been developed and promoted, the claims on these supplements are almost exclusively based on their antioxidant potential. To specifically determine the effects of combined polyphenols on energy and substrate metabolism is however novel. By using state-of-the-art methodologies for both in vivo measurements and laboratory analyses, we were able to investigate effects on whole-body, organ-specific and cellular level. Moreover, the inclusion of the gut microbiota analysis allowed to account for a new dimension to the field of nutritional and health sciences, which is described in Chapters 6 and 7 of this thesis.

The work described in this thesis is the result of several (inter)national collaborations with both academic and industrial partners. Without the contributions of these partners, it would not have been possible to achieve the results described in this thesis, and as such it would not have been possible to achieve the scientific advancement that has been made.

\section{Implementation}

The increased fat oxidative capacity as result of chronic $\mathrm{E}+\mathrm{R}$ supplementation may be of importance in the prevention of chronic metabolic diseases, often characterized by impairments in oxidative capacity. This remains to be determined in future studies. As discussed above, dietary polyphenol supplementation may be rather applicable as a subgroup-based approach as compared to a population-wide approach since intervention response may depend on initial metabolic status, gender and possibly other, yet unknown factors. In general, prevention is known to be less intensive and less expensive than treatment. However, to prevent a disease that develops over decades would require decades of supplementation. Obviously, this is not feasible. To prevent unnecessary and unsuccessful supplementation regimens, the identification of biomarkers may offer an extremely valuable approach to be able to predict effectiveness to polyphenol supplementation. By that means, subjects can be characterized by their disease risk profile and by their susceptibility to an intervention. We have shown in the present thesis that polyphenol supplementation may have the potential to reverse disturbances in lipid metabolism, thereby contributing to a reduced risk of developing type 2 diabetes mellitus and cardiovascular diseases. The analysis of the gut microbiota may further add to improve a more targeted intervention approach. 


\section{References}

1. World Health Organisation. Fact sheet N³11 - Obesity and overweight 2015.

2. European Commission. Fact sheet - Nutrition and obesity prevention 2006.

3. Kanavos P, Aardweg Svd, Schurer W. Diabetes expenditure, burden of disease and management in 5 EU countries: LSE Health, London School of Economics; 2012.

4. Health and Environment Alliance. Health costs in theEuropean UnionJune 2014.

5. Brookes G. Economic Impact Assessment of the European Union (EU)'s Nutrition \& Health Claims Regulation on the EU food supplement sector and market: European Health Claims Alliance (EHCA); 2010.

6. Hokayem M, Blond E, Vidal H, et al. Grape polyphenols prevent fructose-induced oxidative stress and insulin resistance in first-degree relatives of type 2 diabetic patients. Diabetes care 2013;36:1454-61.

7. Baek SH, Shin WC, Ryu HS, et al. Creation of resveratrol-enriched rice for the treatment of metabolic syndrome and related diseases. PloS one 2013;8:e57930. 

Acknowledgements, Dankwoord,

Danksagungen 

Het is tijd om te danken!!!!!!!!!!!!!!!!!!!!!!!

Beginnen wil ik natuurlijk met jou, Ellen. Je hebt me vanaf dag 1 geleerd, dat de wetenschap niet zo makkelijk en snel te overzien is, hoe ik het me altijd weer bedacht had. Dit begon al ermee, dat ik voor mijn review bedacht had, dat het 'ontstaan overgewicht'deel slechts een pagina hoefde te zijn, maar er nu een inleiding van 46 pagina's in dit 'boekje' is. Dit is vanuit mijn zicht ook een leuk voorbeeld, hoe de samenwerking tussen ons werkte. Je hebt me er altijd toe geleid nog meer aspecten uit te zoeken, die ik nog overzien had. Ook ging de focus soms wat ver, heeft dit toch altijd ertoe geleid, dat ik mijn horizont kon verbreden en nieuwe dingen geleerd heb, wat me niet alleen tijdens mijn verdediging tegemoet zou komen, maar ook in mijn verdere carrière. Jouw wetenschappelijk inzicht en je oordeelsvermogen hebben veel indruk gemaakt op mij! Dat soms aan een artikel in versie 9 nog eens een andere draai gegeven moest worden, was voor mij niet altijd makkelijk te verteren, maar elk artikel is toch in elke versie weer beter geworden en het is vooral aan jou te danken, dat dit proefschrift tot stand gekomen is en ik daadwerkelijk achter de resultaten durf te staan, die wij hier opgeschreven hebben. Ik denk, dat het niet vanzelfsprekend is, dat je zo veel tijd voor je AiO's neemt en hun toch nooit het gevoel geeft, dat ze je lastig vallen;).

Gijs, mijn co-promotor officieel pas vanaf jaar 3. Je was vanaf begin aan altijd het perfecte combinatie tussen professor en AiO. Ik kon zo vaak hoe nodig binnen vallen, kreeg altijd (meer dan genoeg; ;) ) antwoord en kon weer verder. Ik ben tot de laatste dag nog onder de indruk, hoe veel tijd je in het werk van mij gestoken hebt, ook al heeft mij dat dan wederom meer werk opgeleverd. Ook hiervan zijn de artikelen zeker niet slechter geworden. Je hebt altijd veel waarde eraan gehecht me gemotiveerd en positief te houden, wat niet altijd makkelijk was. Je maakte mij altijd duidelijk, dat we altijd ondanks een of andere omweg op de goeie weg waren, en vooral op weg naar een super leuk resultaat! Dat je een erg leuke, gezellige mens bent, met die ik erg veel plezier kon hebben, heeft gelukkig wat buffer gegevens voor als ik weer een artikel in het rood terug kreeg;). Dat je soms ook nog wat met de AiOs mee kon feesten, heeft aan onze goeie relatie ook een stuk bijgedragen;). Dank je, Gijs, voor al het wetenschappelijke, maar ook het psychologische werk, wat je in deze thesis hebt gestoken. 
Next, I would like to thank the members of the thesis assessment committee, Prof. Aalt Bast, Dr. Joerg Hager, Prof. Matthijs Hesselink, Prof. Martine Laville en Dr. Koen Venema, as well as the members of the corona at my thesis defence, Prof. Wim Saris and Prof. Wouter van Marken-Lichtenbelt, for your time and effort that you put into this thesis.

Ik wil me bij alle officiële en inofficiële co-auteurs bedanken, die aan deze thesis hebben bijgedragen.

Johan, begonnen ermee, dat jij dit protocol voor mij hebt geschreven, stond je altijd paraat als ik eens weer probeerde te begrijpen, hoe en hoe niet de lipolyse werkt en hoe dit van invloed is op de stofwisseling.

Silvie, het was me een groot plezier met je samen te werken en van jou te leren. Ik heb je erg zeker veel tijd gekost, soms ook zenuwen neem ik aan ;), en ik ben heel erg dankbaar, dat je, ook al was het vroeg in de ochtend, altijd professioneel en vrolijk was en oplette, dat ik alles bij elkaar had. Volgens mij is het me in 84 testdagen maar enkele keren gelukt, dat je niet meer moest ingrijpen ;).

Over de spier gesproken, volgt natuurlijk ook jouw inzet, Kirsten. Ik heb met zekerheid niet alle tijd terug goed kunnen maken, die jij aan mij kwijt was. Dank je voor je werk, je flexibiliteit en je prettige manier om mee te samen te werken!

Mark en John, jullie hebben een aanzienlijk bijdrage aan dit proefschrift geleverd. Ik kon veel van jullie kennis profiteren en jullie hebben mij bij tot stand komen van dit proefschrift in een begrijpelijke en aangename manier geholpen, waar ik zeker nog veel aan zal hebben. Ines, danke für deine detaillierten Reviews der Arbeit und all die Tippfehler und Inkonsistenzen du noch gefunden hast, die Ellen, Gijs und ich nicht mehr gesehen haben.

Patrick, je hebt in mijn ogen een heel belangrijke draai aan het core-paper weten te geven, dank je! Esther, Joris, bedankt voor jullie hulp en geduld om de belangrijkste metingen van dit onderzoek aan mij uit te leggen!

Loek en Paul, jullie werken hard eraan, om de methodische en technische mogelijkheden te bieden, die deze afdeling zo uniek maakt. Een groot compliment en dank!

Graham, you have been my roommate for only a few months, but your knowledge, insight and critics have been invaluable for my discussion and my confidence towards my thesis defense! I greatly appreciate the time you took to teach me how to interpret my data, to find the flaws and to understand the bigger picture of human energy and substrate metabolism. 
Al het klinische werk op de mens zou natuurlijk niet mogelijk geweest zijn zonder de 60 vrijwilligers, die mij toestonden, hun bloed, vet, spier en zelfs ontlasting te verzamelen. Jullie hebben dit werk pas mogelijk gemaakt. Bij deze wil ik ook mijn stagiaires bedanken, die mij geholpen hebben, deze studies uit te voeren.

De belangrijkste mannen, die niet direct bij mijn studies betrokken waren:

Manu, ich war und bin immer noch schwer beeindruckt von der Art und Weise, wie du deine Arbeit machst. An einem Tag hast du gleichzeitig Testtag, schreibst an deinen Reviews und hast immer noch genug Zeit mit jedem, der Lust hat, über Fussball und deine Urlaube zu quatschen. Als Zimmerkollege warst du mal still und konzentriert und mal unterhaltsam und die perfekte Ablenkung, aber nie anstrengend. Nicht erst seit deinem Nature-Review war mir bewusst, dass du auch wissenschaftlich einiges auf dem Kasten hast, was sich vielleicht ja irgendwann mal in meinem CV gut macht, dass du mein Sitznachbar warst und ich dir den Job vermittelt habe ;). Am meisten zu schätzen weiß ich aber, dass du immer helfen wolltest und konntest, wenn es nötig war.

Bram, ik vind het echt zo super jammer, dat je niet bij mijn verdediging en feest aanwezig kan zijn. Maar ja, who am I to jugde, dat je je thuis verlaat ;) In de afgelopen 5 jaar ben je voor mij de perfecte vriend-wetenschaper geweest. Met je wetenschappelijke manier van denken, je kennis, nieuwsgierigheid, en vooral ook je passie en enthousiasme (zelfs voor HSV) ben jij voor mij tijdens het werk een super collega geweest, en een super vriend tijdens ongetelde geweldige avonden bij Jon in de Walkabout!

Guy, over jou kan ik hetzelfde zeggen, maar toch op een heel andere manier. Je hebt mij laten zien, hoe zo een wetenschappers-leven over 10 jaar kan uitzien, en mij tot de conclusie geleid, dat dit iets voor mij kan zijn! Dat we elkaar in sommige manier wel lijken, heeft me plezier en steun geboden, als ik het kon gebruiken!

Jos, je weet zelf erg goed, wat je voor deze afdeling betekend. Misschien zegt het genoeg, dat ik een/de hoofdprofiteur van jouw onverwoestbare inzet was ;). Ik heb heel erg genoten van jouw borrels en jouw muziekvoorkeur. Als een van de tientallen voorbeelden bied zich wel de avond aan, waar we met ons tweeën het Helene-Fischer-concert bekeken hebben en het all-inclusive bier-drinken voor 2 euro schandalig goedkoop werd.

In deze lijst wil ik dan ook Freek en Antoine bedanken. Het was ontzettend gezellig met jullie, niet alleen maar tijdens jullie geweldige carnavalsfeesten, maar ook de vele avonden 
op de uni. Ook dankzij jullie voelde ik me ook altijd weer terecht een idioot zo lang nodig gehad te hebben, te snappen wat ik aan Dorien zou hebben.

Stefan, ook jou wil ik in de lijst niet vergeten van mannen, die mijn AiO-periode tot een erg leuke tijd gemaakt hebben. Je was er altijd, als ik de avond 's wat langer wilde maken, ook al was het een donderdag;).

De groep mannen, die er helaas niet meer zijn (of minder, Boris) en in mijn ogen erg in de afdeling gemist zijn, zijn Maarten, Boris, Erik, Simon en Guy. Mannen, jullie hebben in de eerste jaren voor stemming gezorgd en de congressen, op die we samen waren, in Istanboel en Lyon, ook tot super leuke vakanties gemaakt!

Ik moet eerlijk zeggen, tot een jaar geleden, werd me niet zo bewust, hoe veel ik aan jullie te danken zou hebben, maar nu weet ik het wel: Desiree, Claudia, Cleo en Yolanda, de administratoren van de afdelingen, die me vooral in de laatste maanden de rust gegeven hebben, dat alle benodigde documenten daar zijn, waar ze moeten zijn en ik me hier niet druk over moest maken, als er niks in mijn inbox zat.

Dan zijn er natuurlijk een aantal collega's, die me op de een of andere manier met mijn werk geholpen hebben of de afdeling zo gezellig gemaakt hoe die was. Gabby, dank aan jou voor al het werk met de pilletjes en de ongetelde opgeloste spoedgevallen!!! Yvonne, Nicole, Wendy, Hasibe, ik ben erg blij, dat jullie met zo een goeie zin zo goed werk uitgevoerd hebben. Heel erg bedankt ervoor, dat jullie dit werk van mij overgenomen hebben! Rudi, Birgitta, Pilou, Roel, Rick, Hannah, Marlies, Jan, Mathijs, Dirk, Sophie, Cyril, Dorien P, Sabine, Giulio, Charlotte, Max, Mattea, jullie hebben een echt leuke groep collega's om me heen creëert!

$\mathrm{Zu}$ diesem sozialen Umfeld darf natürlich auch der Handball nicht fehlen. Stellvertretend für MSHV Manos allen voran Helmar, Topper, Fabi, David, Lena, Marnie, Jana, Kerstin, ..., und stellvertretend für den Stolberger SV Ekki, Bömmel, Schumi, Danny und Max!

Dorien, jij was een aardige collega en een gezellige kamergenoot.

Jackie, Tineke, Hub, ik wil jullie ook bij dit dankwoord betrekken, omdat jullie een super leuke en gezellige familie zijn, waarin me ik me altijd welkom voel! En Jackie, natuurlijk dank aan jou voor je werk met het design van het boek. 
Papa, angefangen bei den Medizinergenen, hast du mir wohl bewusst oder unterbewusst mitgegeben, was mich zu dieser Promotion geführt hat. Ich habe dir vor 1.5 Jahren einmal versucht zu beschreiben, wie viel Respekt ich für dich und deinen Lebenslauf habe: Ohne mit der Wimper zu zucken, hast du uns Kindern im Laufe der letzten 35 Jahre alles ermöglicht, das es zu ermöglichen gab, und tust es immer noch. Du hast dir jeden Tag Urlaub verdient, den du jetzt genießt! Du bist mein Vorbild!

Mamma, jij bent op dezelfde en op een heel andere manier de reden geweest, waarom ik dit boek uiteindelijk kon schrijven. We waren er niet altijd over alles eens, maar het meest belangrijke was altijd duidelijk: je wilde het beste voor mij. Het maakte niet uit, wat ik me in mijn hoofd gezet had, of ik nou naar München of naar Nederland ging. De reden, waarom ik deze beslissingen zo makkelijk kon nemen, is dat ik altijd wist, dat ik op jouw steun van thuis kon rekenen en dat jouw vertrouwen me aangemoedigd heeft. Ik had zeker niet al die ervaringen kunnen maken en de gelukkige mens kunnen zijn, die dit boek geschreven heeft, als ik jouw psychologische support had moeten missen.

Dorien, boven het feit dat je een aardige collega en gezellige kamergenoot was, ben jij natuurlijk de reden, dat ik op een zo onvergetelijke tijd terug kan blikken en elke dag graag weer op de uni was; zelfs, misschien vooral, voor dat de rest er was. Ik heb jou het leven zeker niet altijd makkelijk gemaakt; omgekeerd jij mij wel! Ik was erg blij, dat ik naast Manu, die ik al kende, zo een leuke collega's erbij kreeg ;). Ik was onder de indruk, hoe snel je alles aan het begin al geregeld kreeg en toch meestal de trein om 5 uur haalde. Jouw manier van werken, was niet altijd de mijne, maar juist daarom konden we misschien zo goed samenwerken. We wisten altijd, wat de andere aan het doen was, vergeten was of nodig had, ook al was het maar koffie, lunch of Stracciatella-kwark. Ik denk dat we over de jaren wel het beste team gebouwd hebben, dat de afdeling gezien heeft, zonder officieel bij elkaars projecten betrokken te zijn ;). Intussen mag ik me nog gelukkiger schatten, dat wij dit nou 24/7 kunnen zijn. Als het niet altijd zo duidelijk is, je bent van onschatbare waarde, om mij gemotiveerd, vrolijk, redelijk uitgeslapen, minder gestrest en zelfs gezond te houden. Ik kan bij jou zijn wie ik ben, klagen hoeveel ik wil, zo veel flauwe grapjes maken hoe mijn hoofd kan verzinnen, je bent de meest tolerante mens ooit (mag wel soms wat minder for your own good ;)) en je zorgt voor mijn welzijn en gezondheid.

Schat, jij bent de reden, dat ik mijn werk en mijn leven zo kan genieten en geniet! 



\section{Publications}



Most J, van Can JGP, van Dijk JW, Goossens GH, Jocken JWE, Hospers JJ, Bendik I, Blaak EE. A 3-day EGCG supplementation reduces interstitial lactate concentration in skeletal muscle in overweight subjects. Scientific Reports 2015: 5, Article number: 17896.

Most J, Goossens GH, Jocken JWE, Blaak EE. Dietary Polyphenols and lipid oxidation in humans, Obesity Facts 2012;5(Suppl.1): 178-234, accepted poster 743.

Most J, Goossens GH, Jocken JWE, Blaak EE. Short-term supplementation with a specific combination of dietary polyphenols increases energy expenditure and alters substrate metabolism in overweight subjects. International Journal of Obesity. 2014;38(5):698-706.

Most J, Timmers S, Warnke I, Jocken JWE, van Boekschoten M, de Groot P, Bendik I, Schrauwen P, Goossens GH, Blaak EE. Combined epigallocatechin-3-gallate and resveratrol supplementation for 12 weeks increases mitochondrial capacity and fat oxidation, but not insulin sensitivity in obese humans: a randomized controlled trial. The American Journal of Clinical Nutrition, under revision.

Most J, Warnke I, van Boekschoten M, Jocken JWE, de Groot P, Friedel A, Bendik I, Goossens GH, Blaak EE. The effects of polyphenol supplementation on adipose tissue morphology and gene expression in overweight and obese humans. International Journal of Obesity, to be submitted.

Most J, Goossens GH, Reijnders D, Canfora E, Penders J, Blaak EE. Gut microbiota composition strongly correlates to peripheral insulin sensitivity in obese men but not in women, Diabetologia, to be submitted.

Most J, Penders J, Lucchesi M, Goossens GH, Blaak EE. Gut microbiota composition in relation to the metabolic response to 12 weeks combined polyphenol supplementation in overweight men and women. To be submitted. 

Curriculum vitae 

Jasper Most was born on September $28^{\text {th }} 1986$ in Flensburg, Germany. After completing secondary school at Auguste-Viktoria-Schule, Flensburg, Germany, he worked as an intern at Malteser Hospital St. Franziskus, Flensburg (2005), and at the Department of Biotechnology and Process Engineering at Flensburg University of Applied Sciences (2006). Thereafter, he completed a Spanish language course at the University of Granada, Spain, during a two-month stay. He started the Bachelor Science of Nutrition at 'Technische Universität München', Germany, where he graduated in 2009. In 2010, he obtained a Master's degree in Physical Activity and Health, with specialization in Metabolism and Nutrition, at Maastricht University, The Netherlands. In September 2010, he started his PhD research at the Department of Human Biology (NUTRIM School of Nutrition and Translational Research in Metabolism) at Maastricht University under supervision of Prof. dr. Ellen Blaak and Dr. Gijs Goossens. The research performed during this project is described in this thesis, entitled 'Dietary polyphenols: Modulators of energy and substrate metabolism in obese humans'. Jasper has presented these results at several national and international conferences. 
